HYPOLAYR, a Computer Program for Determining Hypocenters of Local Earthquakes in an Earth Consisting of Uniform Flat Layers over a Half Space

by

J. P. Eaton

National Center for Earthquake Research

U.S. Geological Survey, Menlo Park, Callfornia

$69-85$

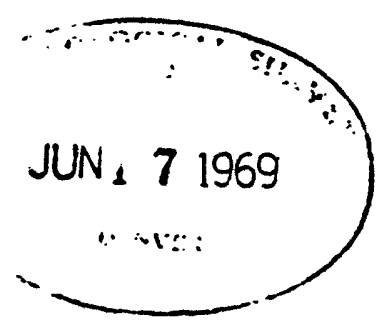

ס. 5. Geological Survor OPER BIIS BEPOBT Ae roport is prellminars and has net beon odited or sevioved for creorilts vith Goolosioal Surver

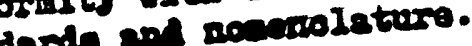


introduction

Geiger least-squares adjustment of the hypocenter (M/Prog)

Solution of the normal equations (HYCOR)

12

Miscellaneous computational routines

Epicentral distances (M/Prog)

Cartesian coordinate system

Selection of special stations

Calculation of preliminary hypocenter (PREHY)

Calculation of traveltimes, derivatives, and angles of

incicence at the focus (TRVDRV.)

Plane-wave "substitute" solution (VELAZ)

Calculation of Magnitude (MAGNTD)

Statistical computations (M/Prog)

Restrictions and termination conditions (M/Prog)

List of variables

Appencix: 73

Description of output

Appendix 289

Description of input

Appendix 3100

Block diagrams

Appendix $4 \quad 109$

Listing

Appendix $5 \quad 117$ 
HYPOLAYR, a Computer Program for Determining Hypocenters of Local Earthquakes in an Earth Consisting of Uniform Flat Layers over a Half Space

by

\author{
J. P. Eaton \\ National Center for Earthquake Research \\ U.S. Goological Survey, Menlo Park, California
}

\begin{abstract}
INTRODUCTION
HYPOLAYR was designed to determine hypocenters of local earthquakes recorced at siose range on a cense cluster of seismographs, primarily on the basis of first P-wave arrivals. A first estimate of the hypocenter (from subroutine PREHY) is adjusted by Geiger's metnod so as to minimize the sum of the squares of the resiouals of observed arrival times with respect to those computed from an earth model consisting of flat-lying constant velocity layers (from subroutine TRVDRV). Adjustment (by subroutine HYCOR) is continued until a set of adequacy criteria are met, or until an iteration iimit is exceeded. Individual arrivals are weighted in this adjustment according to two factors: quality or clarity of the P-wave arrival, and epicentrai distance of the station (for later adjustments). If amplitude, perioc, and calibration data are available, the program computes two magnitudes for the earthquake, one from the P-phase and the other fron the maximum, $X$, phase (oy subroutine MAGNTD).
\end{abstract}


The program is set up for batch processing of earthquakes. Station parameters (location, elevation, delay, model), model parameters (depths to boundaries and layer velocities), and control parameters are first read in, and some preliminary calculationsaare carried out. Data for the first earthquake (arrival times, amplitudes, periods, calibrations) are then read in, and its hypocenter and magnitude are computed and. the results printed out. Additional earthquakes are located one at a time until the batch is completed. A variety (or combination) of solution modes (free solution, depth restricted, origin time restricted) can be called by an instruction card that is required to initiate execution of each hypocenter determination. An optional statistical summary of arrival time and magnitude residuals at individual stations can be caileo by a controi parameter. HYPOLAYR contains a number of special features that should be noted:

1. The traveltime and derivatives of the direct refracted wave are computed without recourse to interpolation between tabulated precalculated reference curves; so the earth model can be changed without difficulty. Thus, any earth model consisting of not more than 24 ilat-lying constant velocity layers, velocity increasing from layar to layer downward, can be used--it simply is read in along with the station locations, etc., at the time of execution.

2. For the specific circumstance in which a group of earthquakes occurs along a known boundary between differing crustal structure provinces (e.g., aftershocks along the San Andreas fault), two earth models can be read in and individual stations can be assigned to the 
model approprlate for the side of the fault on which they lie. Lateral refraction induced by the juxtaposition of the two structures is neglected. This option should be used with caution.

3. The program is designed to permit locations to be calculated for events recorded on any number of stations from 3 to 98 . If only three stations record the event, the depth or origin time must be specified (depth assigned or origin time computed from S-P data) so that the number of variables does not exceed the number of equations.

4. Several solution modes (free, depth restricted, origin time fixed by S-P) can be called by the variable INST on the "execution" card at the end of an event "phase" deck.

5. The usual condition uncer which solutions cannot be obtained (other than due to gross errors) is that in which the epicenter lies far outsice of the cluster of seismographs. In this case, the next best estimate of the earthquake's point or origin is calculated: the azimuth to the source and the apparent velocity of the P-wave across the cluster.

HYPOLAYR makes only limited use of S-phase data. Under the "origin-time-restrained" option, the origin time is set equal to that computed from available S-P data. S-wave arrival times are not used along with P-wave data in adjusting the hypocenter.

In this write-up of HYPOLAYR, the mathematical bases of the principal sections of the program will be outlined. Also included are several appendices that will be helpful to anyone wishing to use the program:

1. annotated IIsting of HYPOLAYR and subroutines. 
2. block diagrams (simplified flow charts) of HYPOLAYR and subroutines.

3. list and definition of variables used in HYPOLAYR and subroutines.

4. annotated list and explanation of input parameters and the role they play in the control and use of the program.

5. description of the output options, together with a listing of the output "blocks" and an explanation of the variables printed. 
Least-Squares Adjustment of an Initial Approximate

Hypocenter by Geiger's Method

Definitions:

$X_{0}, y_{0}, z_{0}$ are the cartesian grid coordinates of the hypocenter,

$t_{0}$ is the origin time of the event

$X_{i}, y_{i}, z_{i}$ are grld coordinates of station $i$

$T_{i}$ is the observed first P-wave arrival time at station $i$

$T_{i}$ is the computed traveltime of the first P-wave

- arrival to station

$t_{i}$ is the computed P-wave arrival time at station $i$

$t_{i}=t_{0}+T_{i}$

$F_{i}=\tau_{i}-\tau_{i}$ is the arrival time anomaiy at station $i$.

$t_{i}$ is a function of the hypocentral parameters

$X_{0}, 4_{0}, \Sigma_{0}, t t_{0}$ and we can express the change

in $t_{i}$ due to small changes in these parameters

by a Taylor's expansion

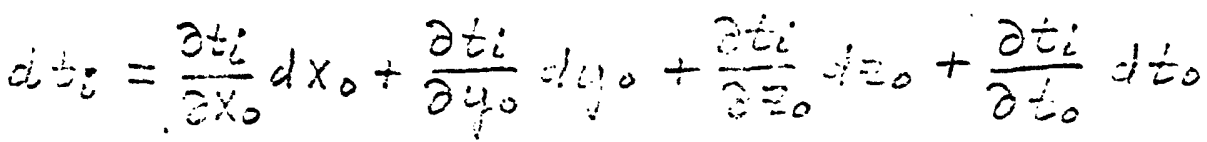

If we had only four stations, we could set $F_{i}+d F_{i}=0$

(or $\left.F_{i}-d t_{i}=0\right)$ at each station and calculate $d x_{0}, d j_{0}, d z_{0}$. and $2 t_{0}$ which would result in zero anomalies at all stations. With more than four stations such a solution cannot, in general, be found. Rather any adjustment of $x_{0}, y_{0}, z_{0}$, and $t_{0}$ designed to reduce the arrival-time anomalies results in "residuals" at at least some stations. 
Thus, we can write for station $i, F_{i}+d F_{i}-E_{i}$, or

$$
F_{i}-d t_{i}=\Xi_{i}
$$

where $F_{i}$ is the arrival time anomaly we wish to eliminate, di ti is the change in calculated arrival time resulting from adjustment $d x_{0}$, f yo. $d \Xi_{0}$, and $d t_{0}$, and $E_{i}$ is the residual arrival-time anomaly after the adjustment. From (3) and (4), we have

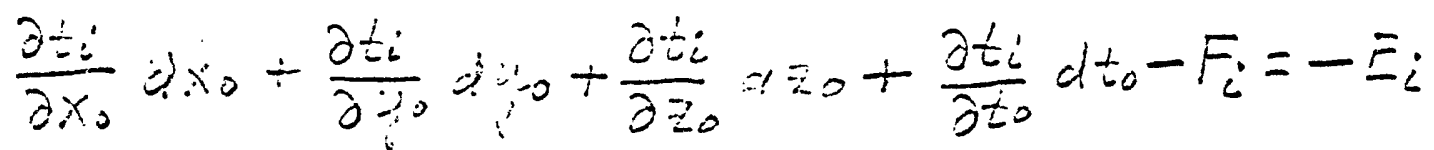

$$
\begin{aligned}
& \text { since } t_{i}=T_{i}\left(x_{0}, j_{0}, 20,\right. \text { it to, } \\
& \frac{\partial i_{i}}{\partial x_{0}}=\frac{\partial T_{i}}{\partial x_{0}}, \frac{\partial i_{i}}{\partial y_{0}}=\frac{\partial_{i}}{\partial i_{i}} ; \frac{\partial T_{i}}{\partial z_{0}}=\frac{\partial T_{i}}{\partial z_{0}} ; \frac{\partial i_{i}}{\partial i_{0}}=i
\end{aligned}
$$

Thus

$$
\frac{\partial T_{i}}{\partial x_{2}} \partial x_{0}+\frac{\partial T_{i}}{\partial y_{0}} d y_{0}+\frac{\partial T_{i}}{\partial Z_{0}}+z_{0}+d t_{0}-F_{i}=-E_{i}
$$

For convenience in writing, let

$$
\begin{aligned}
& \frac{\partial T_{i}}{\partial x_{0}}=\alpha_{i}, \frac{\partial T_{i}}{\partial y_{i}}=i_{i}, \frac{\partial T_{i}}{\partial z_{0}}=Y_{i}, \\
& d x_{0}=Y_{1}, d y_{0}=Y_{2}, d z_{0}=Y_{3}, d t_{0}=Y_{4} .
\end{aligned}
$$

Then equation ( 6$)$ becomes

$$
\alpha_{i} y_{1}+e_{i} y_{2}+\gamma_{i} y_{z}+y_{4}-F_{i}=-E_{i}
$$

6 
Following Geiger, let us calculate the adjustments $Y_{j}$ in our overdetermined system so that $\Sigma \equiv_{i}=$ is a minimum.

To have $\sum_{i}^{-}$a minimum, we must have

$$
\frac{\partial}{\partial Y_{i}}\left[\sum_{i=1}^{N} E_{i}^{i}\right]=0
$$

or

$$
\sum_{i=1}^{N} E_{i} \frac{\partial E_{i}}{\partial y_{i}}=0, j=1,4
$$

(8)

From (7)

$$
\frac{E_{i} E_{i}}{\partial Y_{i}}=-\alpha_{i}, \frac{\partial E_{i}}{\partial Y_{-}}=-\beta_{i}, \frac{\partial E_{i}}{\partial Y_{3}}=-\gamma_{i}, \frac{\partial E_{i}}{\partial Y_{i}}=-1
$$

From equations (8) and (9),

$\alpha_{1} \Xi_{1}+\alpha_{n} E_{n}+\alpha_{3} E_{3}+\cdots+\alpha_{n} E_{n}=0$ for $r=1$, etc. (10)

To assign weights $w_{i}$ to the individual stations we can modify equation (10) to

$\omega_{1} \alpha_{1} E_{1}+\omega_{2} \alpha_{2} E_{2}+\mu_{3} \alpha_{3} E_{3}+\cdots+\mu_{n} \alpha_{n} E_{n}=0$.

for $g=1$, etc.

Expanding equation (ii), we have (for $j=1$ )

$$
\begin{aligned}
& w_{1} \alpha_{1} \alpha_{1} y_{1}+w_{1} \alpha_{1} \beta_{1} y_{2}+w_{1} \alpha_{1} \gamma_{1} y_{3}+w_{1} \alpha_{1} y_{4}-w_{1} \alpha_{1} F_{1} \\
+ & w_{2} \alpha_{2} \alpha_{2} y_{1}+w_{2} \alpha_{2} \beta_{2} \gamma_{2}+w_{2} \alpha_{2} \gamma_{2} y_{3}+w_{2} \alpha_{2} y_{4}-w_{2} \alpha_{2} F_{2} \\
\vdots & \\
& +w_{n} \alpha_{n} \alpha_{n} y_{1}+w_{n} \alpha_{n} \beta_{n} y_{2}+w_{n} \alpha_{n} \gamma_{n} y_{3}+w_{n} \alpha_{n} y_{4}-w_{n} \alpha_{n} F_{n} \\
= & 0
\end{aligned}
$$

7 
Summing columns and employing the summing convention for repeated indices, we can write the foregoing equation for $j=1$ (and analogous equations for $j=2,3$, and 4 ) as follows:

$$
\begin{aligned}
& g=1 \quad\left[w_{i} \alpha_{i} a_{i}\right] Y_{i}+\left[w_{i} \alpha_{i} \beta_{i} Y_{2}+\mu_{i} \alpha_{i} Y_{i} Y_{i}+\left[w_{i} \alpha_{i}\right] Y_{i 2}-w_{i} \alpha_{i} F_{i}=0\right. \\
& z=2 \quad\left[w_{i} \beta_{i} \alpha_{i}\right] Y_{1}+\left[\mu_{i} \beta_{i} \beta_{i}\right] Y_{2}+\left[w_{i} \beta_{i} \gamma_{i} Y_{2}+\left[\mu_{i} \beta_{i}\right] y_{4}-\left[\mu_{i} \beta_{i} F_{i}\right]=0\right. \\
& \left.t=3 \quad r_{i} \gamma_{i} \alpha_{i}\right] y_{1}+\left[w_{i} \gamma_{i} \beta i\right] \gamma_{2}+\left[w_{i} \gamma_{i} \gamma_{i}\right] \gamma_{3}+\left[w_{i} \gamma_{i} \gamma_{4}-\left[\mu_{i} \beta_{i} F_{i}\right]=0\right.
\end{aligned}
$$

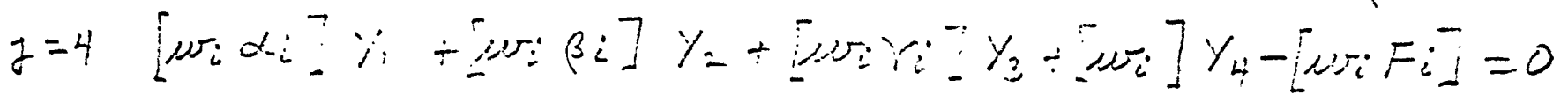

Further, let us write

(12)

$$
\begin{aligned}
& \left.A_{11}=\Gamma_{i} \sigma_{i} \alpha_{i}\right], A_{i 2}=\left[w_{i} \alpha_{i} a_{i}, A_{13}=\tilde{w}_{i} a_{i} \gamma_{i}\right], A_{H}=\left[w_{i} \alpha_{i}\right]
\end{aligned}
$$

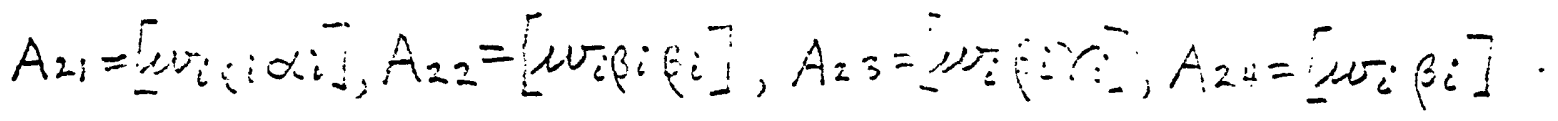

$$
\begin{aligned}
& A_{3 i}=\left[\mu_{i} \gamma_{i} \alpha_{i}{ }_{i}, A_{32}=\left[w_{i} \gamma_{i} \hat{\beta}_{i}\right], A_{3}=\left[w_{i} \gamma_{i} \gamma_{i}, A_{34}=\mu_{i} \gamma_{i}\right]\right.
\end{aligned}
$$

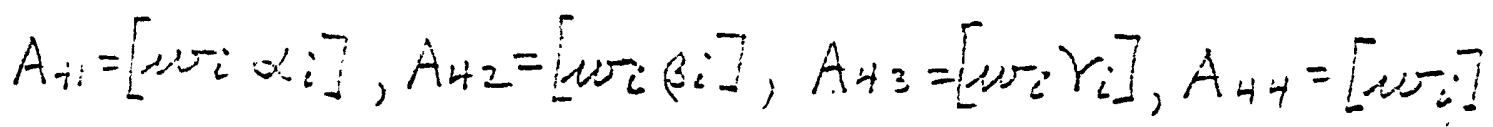

$(12+)$

$\ln \dot{i}$

$$
\begin{aligned}
B_{1}= & {\left[\omega_{i} \alpha_{i} F_{i}\right], B_{2}=\left[\omega_{i}\left(\beta_{i} F_{i}\right], B_{3}=\left[\omega_{i} \gamma_{i} \cdot F_{i}\right], B_{4}=\left[\omega_{i} F_{i}\right]\right.} \\
& i=1, N
\end{aligned}
$$

8 
Then equations (12) can be written as:

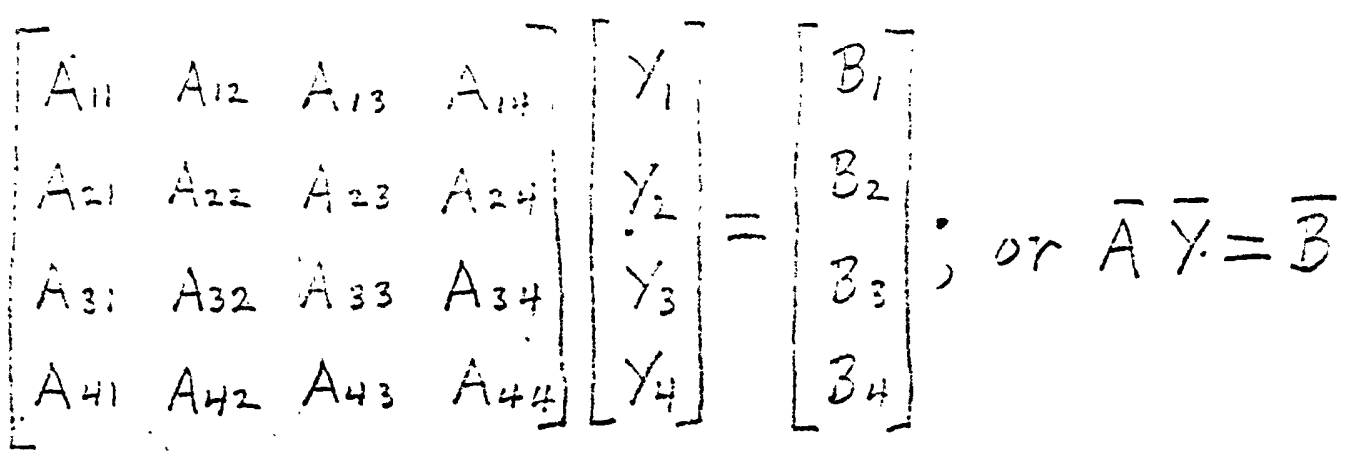

Finally

$$
\bar{Y}=\overline{A^{-1}} \bar{B}
$$

yieiding the components of the solution vector $\bar{Y}\left(Y_{1}, y_{2}, y_{2}, y_{4}\right.$ or

$$
\left.d x_{0}, t_{0}, d z_{0}, d t_{0}\right)
$$

that should result in $\sum E_{i}^{2}$ being minimized.

The procedure' outlined above is. strictly valid only if the corrections are small and if all of the derivatives $\left(\ddot{\alpha}_{i}, \beta_{i},+\gamma_{i}\right)$ are continuous in the region containing the original and corrected hypocenters. In fact, we shall apply the method to a layered medium (hence, one with discontinuities), and we shail initiate the search for a hypocenter irom a very approximate first estimate. We shall assume that a single application of the method will yield an improved (if not accurate) hypocenter, and we shall except repeated adjustments to converge on the actual hypocenter. Readjustment will be continued until the average residual, mean deviation of the residuals, and change (from one adjustment to the next) in mean deviation of the residuals all become smaller than prescribed test values, or until the number of iterations exceeds a prescribed limit. 
Under certain conditions, the normal equations (13) from which we seek to determine hypocentral adjustments, $y_{i}$, fail to be linearly independent. One such condition occurs when $\partial T / \partial z$, becomes the same (or very nearly the same) at all stations: $y_{+}\left(d_{0}\right)$ and $y_{3}\left(d z_{0}\right)$ are then linearly dependent. Adjustment can proceed only if $t_{0}$ or $z_{0}$ is held constant during the adjustment, causing one variable and one equation in (13) to disappear. Another indeterminate case occurs when the rocus is outside of the ciuster and the ratio of $\partial T / \partial \because 0$ to $\partial T / \partial y_{0}$ approaches the same value at all stations. In this case restriction of $z_{0}$ usually has already been required as per the condition described above, and an adjustment can be computed only if $i_{0}$ is also specified or its adjustment blocked--leading to further degeneracy of the normal equations.

Normaliy, z, is less strongly determined by the data than the other parameters, and its adjustment requires special consideration and control. Therefore, a strategy restricting adjustment of $z_{0}$ until the epicenter has been fairly well established has been included in the program. Furthermore, the range in values of $\partial T / \partial z_{0}$ calculated prior to each adjustment is tested, and adjustment of $Z_{0}$ is blocked if this range is smaller than a prescribed value (i.e., if effective depth control has been lost). Finally, negative focal depths are inadmissable physically; so each computed adjustment to $z_{0}$ is tested prior to application of the hypocentral adjustments. If the computed adjustment in $Z_{0}$ would result in the focus emerging above the surface, the $z_{0}$ adjustment is scaled down so that the focus moves only a fraction $(6 / 10)$ of the distance to the surface, and the other adjustments are 
scaled down somewhat less severely (to not less than $4 / 10$ of the computed values).

If the epicenter recedes from the cluster so that the nearest

station is farther than a prescribed distance or if the normal equations (even with the automatic restrictions) become indeterminate, the search for a hypocenter is terminated; and the apparent velocity and azimuth of approach of a plane wave that would explain the observed arrivaltime differences across the cluster are calculated as an alternate solution (subroutine VELAZ).

Further restrictions on the adjustment of hypocentral parameters can be cailed into play by the control variable INST $i$ Eo fixed,.

$\left.t_{0} f i x e d\right)$; and even if a free solution is specified(by INST $=0$ ), $Z_{0}$ is automatically restricted to reduce the number of normal equations if only three stations are available. 


\section{Solution of the Normal Equations for the}

\section{Hypocentral Corrections}

1. Free solution for $\left.Y(1), Y_{(2}\right), Y(z), Y(4): d x_{0}, d y_{0}, d z_{0}, d t_{0}$ 1. Calculate the matrix of cofactors, $[C(M, N)]$, of the matrix of the coefficients of the unknowns in the normal equations, $[A(\bar{i}, \bar{I})]$

2. Calculate DETA, the determinant of $[A(I, J)]$ :

$$
D E T A=A(1,1) * C(1,1)+A(2,1) * C(2,1)+A(3,1) * C(3,1)+A(4,1) \div C(4,1)
$$

3. Solve for $Y(1), Y(2), Y(3)$, and $Y(4)$ by Cramer's rule:

$$
\begin{aligned}
Y(I)= & (B(1) * C(1, I)+B(2) * C(2, I)+B(3) * C(3, I)+B(4) \div C(4, I)) / D E T t \\
I & =1,4
\end{aligned}
$$

4. Calculate the elements of the principal diagonal of the inverse matrix of coefficients of the normal equation unknowns, $[A(I, I)]_{:}^{-1}$

$$
A(I, I)^{-1}=C(I, I) / D E T A \quad I=1,4
$$

These elements are needed in the evaluation of the errors in the computed corrections, $Y(I)$.

11. Restricted solution: $y(3)=0 \quad\left(d z_{0}=0\right)$. This restriction el iminatesone of the normal equations and amounts to striking out all quantities in equation (i3) that have "3" in the subscript.

Fot convenience, define auxillary variables to simplify the expressions for the solution of the $3 \times 3$ normal equations: 


$$
\begin{aligned}
& A \|=A(2,3) A(A, H)-A(4), 2)+A(2, i)
\end{aligned}
$$

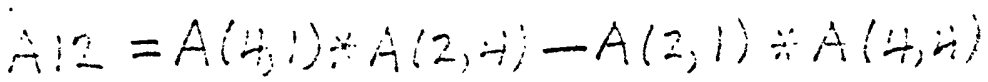

$$
\begin{aligned}
& A(H=A(2,1) \div A(4,2)-A(4,1) * A(2,2) \\
& A 21=A(4,2) \div A(4,1)-A(1,2) \div A(4,4) \\
& A 22=A(1,1) * A(4,4)-A(4,1) \div A(1,4) \\
& A 24=A(4,1) \div A(1,2)-A(1,1) * A(4,2) \\
& A H !=A(1,2) \times A(5)-A(2,2)+A(A, 1) \\
& A H 2=A(2,1) * A(1,1)-A(1,1) \div A(2,1) \\
& A H=A(1,1) * A(2,2)-A(2,1) \div A(1,2) \\
& \Sigma \equiv T A=A(1,1) * A 11+A(2,1) \div A 21+A(4,1) \div A \text { 政 }
\end{aligned}
$$

Then, solving the $3 \times 3$ normal equations for the corrections $Y(I)$,

$$
\begin{aligned}
& y(1)=(B(1) * A 11+B(2) * A 21+B(4) * A 41) / D E T A \\
& y(2)=(B(1) * A 12+B(2) * A 22+B(4) * A 42) / D E T A, \\
& y(3)=0 \\
& Y(4)=(B(1) * A 14+B(2) * A 24+B(4) * A 44) / D E T A
\end{aligned}
$$

The moduli of the elements of the principal diagonal of the inverse matrix of coefficients of normal equation unknowns can be written: $\quad A S D X=|A||/ D E T A|$

$A S D Y=|A 22 / D E T A|$ $A S D Z=1$, by arbitrary defintion $A S D T=|A 44 / D E T A|$ 
111. Restricted solution: $Y(H)=0 \quad\left(d t_{0}=0\right)$. This restriction eliminates one of the normal equations and amounts to striking out all quantities in equation (13) that have "4" in the subscript. For convenience, define auxiliary variables to simplify the expressions for the solution of the $3 \times 3$ normal equations:

$$
\begin{aligned}
& A 11=A(2,2) * A(3,3)-A(3,2) * A(2,3) \\
& A 12=A(3,1) * A(2,3)-A(2,1) * A(3,3) \\
& A 13=A(2,1) * A(3,2)-A(3,1) * A(2,2) \\
& A 21=A(3,2) * A(1,3)-A(1,2) * A(3,3) \\
& A 22=A(1,1) * A(3,3)-A(3,1) * A(1,3) \\
& A 23=A(3,1) * A(1,2)-A(1,1) * A(3,2) \\
& A 31=A(1,2) * A(2,3)-A(2,2) * A(1,3) \\
& A 32=A(2,1) * A(1,3)-A(1,1) * A(2,3) \\
& A 33=A(1,1) * A(2,2)-A(2,1) * A(1,2) \\
& D E T A=A(1,1) * A 11+A(2,1) * A 21+A(3,1) * A 31
\end{aligned}
$$




$$
\begin{aligned}
& y(1)=(B(1) * A 11+B(2) \div A 21+B(3) * A 31) / D E T A \\
& y(2)=(B(1) * A 12+B(2) * A 22+B(3) \div A 32) / D E T A \\
& y(3)=(B(1) * A 13+B(2) * A 23+B(3) * A 33) / D E T A \\
& y(4)=0 .
\end{aligned}
$$

The moduli of the elements of the principal diagonal of the inverse matrix of coefficients of the normal equation unknowns can be written:

$$
\begin{aligned}
& \text { ASDX }=|A \| /| \text { DETA } \mid \\
& \text { ASDY }=\mid A 22 / \text { DETA } \mid \\
& \text { ASDZ }=\mid A 33 / \text { DETA } \mid \\
& \text { ASDT }=\mid \text {, by arbitrary definition. }
\end{aligned}
$$

IV. Restricted solution: $Y(3)=0, y(4)=0$. These restrictions eliminate two of the normal equations and strike out all quantities in equation (13) that have "3" or "4" in the subscript.

Solving the $2 \times 2$ normal equations for the corrections $Y(I)$,

$$
\begin{aligned}
& y(1)=(B(1) * A(2,2)-B(2) * A(1,2)) / D E T A \\
& Y(2)=(A(1,1) * B(2)-A(2,1) * B(1)) / D E T A \\
& Y(3)=0 \quad \text { and } Y(4)=0 \\
& \text { DETA where }
\end{aligned}
$$


The moduli of the principal diagonals of the inverse matrix of the matrix of coefficients of. normal equation unknowns can be written:

$$
\begin{aligned}
& \text { AS DX }=|A(2,2)| D E T A \mid \\
& \text { AS DY }=|-A(1,1) / D E T A|
\end{aligned}
$$

ASIDE $Z=1.0$, for convenience.

AS OT $=1.0$, for convenience.

16 


\section{Miscell aneous Computational Routines}

\section{Calculation of Epicentral Distances}

- Richter's method for calculating short distances is used to determine epicentral distances $($ in $\mathrm{km})$. Let $\varphi_{0}, \lambda_{0}$ and $\phi_{i}, \lambda_{i}$ be latitude $(N)$ and longltude $(W)$ of the epicenter and station $i$, respectively. Let $Q Q$ be the number of kilometers per minute of latitude and $P P$ be the number of kilometers per minute of longitude at latitude $\left(Q_{0}+Q_{i}\right) / 2 \quad$.. Then the distance of station $i$ from the epicenter is approximately:

$$
\Delta_{i}=\sqrt{\left[60.0 * P P *\left(\lambda_{i}-\lambda_{0}\right)\right]^{2}+\left[60.0 * Q Q *\left(\varphi_{i}-\varphi_{0}\right)\right]^{2}}
$$

where $\lambda_{i,} \lambda_{0}, \varphi_{i}, \varphi_{0}$ are in degrees and $\Delta_{i}$ is in kilometers. $Q Q$ and $P P P\left(=\frac{P P}{\cos \bar{\phi}}\right.$, where $\left.\bar{\phi}=\frac{\varphi_{i}+Q_{0}}{2}\right)$ vary only slowly with latitude; so appropriate values of $Q Q$ and $P P P$ cobtained from Richter's "Elementary Seismology") for the location of the seismograph network are read in as parameters.

The azimuth of station I from the epicenter can be obtained from the equation:

$$
\tan A Z_{i}=\frac{P P *\left(\lambda_{i}-\lambda_{0}\right)}{Q Q *\left(\varphi_{i}-\varphi_{0}\right)}
$$

The proper range of the argument $A Z_{i}$ (between 0 and $360^{\circ}$ ) can be ascertained by considering the signs of the numerator and denominator in the foregoing equation.

\section{Calculation of Km-Grid Coordinates}

In subroutines PREHY and YELAZ it is convenient to express the locations of stations (and prel iminary hypocenter in PREHY). In cartesian 
coordinates. For this purpose portions of the Richter short-distance calculations are used. . The km-grid coordinates of station I are:

$$
\begin{aligned}
& X H_{i}=60.0 * P H *\left(\lambda_{i}-\lambda_{r}\right) . \quad \mathrm{km} \text { west of } \varphi_{r}, \lambda_{r} \\
& Y H_{i}=60.0 * Q Q *\left(\varphi_{i}-\varphi_{0}\right) \quad \mathrm{km} \text { north of } \varphi_{r}, \lambda r
\end{aligned}
$$

where $\varphi_{r}, \lambda_{r}$ are coordinates of an arbitrary point in the region of the network chosen as a "reducing" latitude and longitude and $P H=P P P * \cos Q_{\text {neat }}$

$$
\text { Qnear is the latitude of the earllest station. }
$$

The azimuth of station I from the earllest station (station "near")

can be obtalned from

$$
\tan \theta_{i}=\frac{X \cdot H_{i}-X H_{\text {near }}}{Y H_{i}-Y H_{\text {near }}}
$$

where the appropriate interval for $\theta_{i}$ (between) and $360^{\circ}$ ) can be deduced from the signs of the numerator and denominator.

Selection of Special Stations for Initial Estimate of Hypocenter or "Plane-Wave" Solution

Both the main program and the VELAZ subroutine require an initial approximate solution from which to proceed by successive adjustments. to a final solution. If the initial estimate is very poor, the adjustment routines are prone to fall; so it is desirable to obtain rellable first estimates. Because the methods used to calculate these estimates involve exact solutions for only three or four stations (with an oversimplified (model in PREAY), success depends on a good cholce of. this limited set gt stations. 
Some of the elements affecting the selection of stations are:

1. Early stations tend to have clearer, more certain, arrivals than late (more distant) ones.

2. Computations based on stations clustered too closely together or lying along or near a straight line tend to be strongly affected by small errors in arrival time.

The procedure actually employed is as follows:

1. The stations with P-wave arrival weights greater than 0.3 are ordered in terms of increasing arrival time from the first to the KOLT'th. KOLT is a parameter on the input iist.

2. The stations lying farthest toward the right and farthest toward the left of the line joining the first and the KOLT'th station ' are identified.

3a. In PREHY the first, KOLT'th, and the two stations identified under 2 above are the stations selected for the determination of the preliminary hypocenter. If only three stations are available, they are the ones that are used.

3b. In VELAZ the first, KOLT'th, and the station farthest from the line (under 2 above) are selected as the three stations for the calculation of the initial plane-wave solution. 


\section{Calculation of the Preliminary Hypocenter}

(Sübroútine PREHY).

Our earth model will consist of a uniform half space with constant P-wave velocity V. A km-grid-cartesian coordinate system will be used to specify position. Hypocentral parameters are $x_{0}, y_{0}, z_{0}$, the location, and $t_{0}$, the origin time. Station parameters are $x_{i}, y_{i}, z_{i}$, the location; and $P_{i}, S_{i}$, and $(S-P)_{i}$, the $P$ - and $S$-wave arrival times and the S-P interval; $T_{i}\left(=P_{i}-t_{0}\right)$, the $P$ traveltime; and $D_{i}$, the hypocentral distance.

Our fundamental equation (Pythagoras) is $T_{i} * V=D_{i}$

We shall consider three cases as follows:

a. Four stations available.

Eliminate $z_{0}$ by differencing station equations pair by pair and noting that $z_{i}-z_{j} \approx 0$. Solve the resulting three equations for $x_{0}, y_{0}$, and $t_{0}$. Substitute $x_{0}, y_{0}$, and $t_{0}$ in the "near" station equation and solve for $z_{0}$. if $z_{0}$ is less than $1 / 2$ the epicentral distance of the near station, set $z_{0}=z T R$.

b. Three stations, with at least one measured S-P interval available. El iminate $z_{0}$ by differencing the three equations pair by pair and solve the resulting two equations for $x_{0}$ and $y_{0}$ in terms of $T_{1}$ : the P-wave traveltime to station 1 (the nearest station). Compute the origin time from avallable S-P data: .

$$
t_{0}=\frac{1}{N} \sum_{i=1}^{N}\left[P_{i}-1.37(s-P)_{i}\right] \text {, whence. } T_{1}=P_{1}-t_{0} \text {. }
$$

Substitute $T_{1}$ into the equations for $x_{0}$ and $y_{0}$ (in terms of $T_{1}$ ) to evaluate $x_{0}$ and $y_{0} \ldots$ set $z_{0}=Z T R$. 
c. Three stations, without S-P data to establish $t_{0}$. Proceed as under b to evaluate $x_{0}$ and $y_{0}$ in terms of $T_{1}$. Substitute $x_{0}\left(T_{1}\right)$ and $y_{0}\left(T_{1}\right)$ and $z_{0}=Z T R$ into the original station 1 equation and solve the resulting quadratic for $T_{1}$. Substitute the two roots, successively, into the quadratic and select the one that satisties it. If the "residual" $\left(A T_{1}^{2}+B T_{1}+C\right)$ is less then 0.001 , use that root for $\mid T_{1}$. If not, transfer to the routine that places the hypocenter at the earliest station.

a. Four stations.

The fundamental equations for station 1 through 4 are

$$
\left(x_{1}-x_{0}\right)^{2}+\left(y_{1}-y_{0}\right)^{2}+\left(z_{1}-z_{0}\right)^{2}=v^{2}\left(p_{1}-t_{0}\right)^{2}
$$

$2 \quad\left(x_{2}-x_{0}\right)^{2}+\left(y_{2}-y_{0}\right)^{2}+\left(z_{2}-z_{0}\right)^{2}=v^{2}\left(p_{2}-t_{0}\right)^{2}$

3. $\quad\left(x_{3}-x_{0}\right)^{2}+\left(y_{3}-y_{0}\right)^{2}+\left(z_{3}-z_{0}\right)^{2}=V^{2}\left(\ddot{p}_{3}-t_{0}\right)^{2}$

$4 \quad\left(x_{4}-x_{0}\right)^{2}+\left(y_{4}-y_{0}\right)^{2}+\left(z_{4}-z_{0}\right)^{2}=v^{2}\left(p_{4}-t_{0}\right)^{2}$

By detinition $t_{0}=P_{1}-T_{1}:$ it is easy to show that

$$
\begin{aligned}
& \left(P_{2}-t_{0}\right)^{2}-\left(P_{1}-t_{0}\right)^{2}=2 T_{1}\left(P_{2}-P_{1}\right)+\left(P_{2}-P_{1}\right)^{2} \\
& \left(P_{3}-t_{0}\right)^{2}-\left(P_{1}-t_{0}\right)^{2}=2 T_{1}\left(P_{3}-P_{1}\right)+\left(P_{3}-P_{1}\right)^{2} \\
& \left(P_{4}-t_{0}\right)^{2}-\left(P_{1}-t_{0}\right)^{2}=2 T_{1}\left(P_{4}-P_{1}\right)+\left(P_{4}-P_{1}\right)^{2}
\end{aligned}
$$

$$
r_{i}^{2}=x_{i}^{2}+y_{i}^{2}+z_{i}^{2}
$$

For simplicity, let

Subtracting equation (i) from equations (2), (3), and (4), we have 


$$
\begin{aligned}
& 2\left(x_{2}-x_{1}\right) x_{0}+2\left(y_{2}-y_{1}\right) y_{0}+2\left(z_{2}-z_{1}\right) z_{0}=r_{2}^{2}-r_{1}^{2}-V^{2}\left[2 T_{1}\left(P_{2}-P_{1}\right)+\left(P_{2}-P_{1}\right)^{2}\right] \\
& 2\left(x_{3}-x_{1}\right) x_{0}+2\left(y_{3}-y_{1}\right) y_{0}+2\left(z_{3}-z_{1}\right) z_{0}=r_{3}^{2}-r_{1}^{2}-V^{2}\left[2 T_{1}\left(P_{3}-P_{1}\right)+\left(P_{3}-P_{1}\right)^{2}\right] \\
& 2\left(x_{4}-x_{1}\right) x_{0}+2\left(y_{4}-y_{1}\right) y_{0}+2\left(z_{4}-z_{1}\right) z_{0}=r_{4}^{2}-r_{1}^{2}-V^{2}\left[2 T_{1}\left(P_{4}-P_{1}\right)+\left(P_{4}-P_{1}\right)^{2}\right]
\end{aligned}
$$

since $z_{2}-z_{1} \approx 0, z_{3}-z_{1} \approx 0,+z_{4}-z_{1} \approx 0$, the terms in $z_{0}$ can be neglected.

Thus,

$$
\begin{aligned}
& \left(x_{2}-x_{1}\right) x_{0}+\left(y_{2}-y_{1}\right) y_{0}+\left(P_{2}-P_{1}\right) V^{2} T_{1}=\frac{1}{2}\left[r_{2}^{2}-r_{1}^{2}-V^{2}\left(P_{2}-P_{1}\right)^{2}\right] \\
& \left(x_{3}-x_{1}\right) x_{0}+\left(y_{3}-y_{1}\right) y_{0}+\left(P_{3}-P_{1}\right) V^{2} T_{1}=\frac{1}{2}\left[r_{3}^{2}-r_{1}^{2}-V^{2}\left(P_{3}-P_{1}\right)^{2}\right] \\
& \left(x_{4}-x_{1}\right) x_{0}+\left(y_{4}-y_{1}\right) y_{0}+\left(P_{4}-P_{1}\right) V^{2} T_{1}=\frac{1}{2}\left[r_{4}^{2}-r_{1}^{2}-V^{2}\left(P_{4}-P_{1}\right)^{2}\right]
\end{aligned}
$$

Set

$$
\begin{aligned}
& a_{11}=\left(x_{2}-x_{1}\right), a_{12}=\left(y_{2}-y_{1}\right), a_{13}=\left(P_{2}-P_{1}\right) v^{2}, b_{1}=\frac{1}{2}\left[r_{2}^{2}-r_{1}^{2}-v^{2}\left(P_{2}-P_{1}\right)^{2}\right] \\
& a_{21}=\left(x_{3}-x_{1}\right), a_{22}=\left(y_{3}-y_{1}\right), a_{23}=\left(P_{3}-P_{1}\right) v^{2}, b_{2}=\frac{1}{2}\left[r_{3}^{2}-r_{1}^{2}-v^{2}\left(P_{3}-P_{1}\right)^{2}\right] \\
& a_{31}=\left(x_{4}-x_{1}\right), a_{32}=\left(y_{4}-y_{1}\right), a_{33}=\left(P_{4}-P_{1}\right) v^{2}, b_{3}=\frac{1}{2}\left[r_{4}^{2}-r_{1}^{2}-v^{2}\left(P_{4}-P_{1}\right)^{2}\right]
\end{aligned}
$$

Finally,

$$
\begin{aligned}
& a_{11} x_{0}+a_{12} y_{0}+a_{13} T_{1}=b_{1} \\
& a_{21} x_{0}+a_{22} y_{0}+a_{23} T_{1}=b_{2} \\
& a_{31} x_{0}+a_{32} y_{0}+a_{33} T_{1}=b_{3}
\end{aligned}
$$

22 
Solve for $x_{0}, y_{0}, T_{1}$ by Creamer's rule. Then $t_{0}=P_{1}-T_{1}$ Substitute $\dot{x}_{0}, y_{0}, T_{1}$ into the station 1 equation

$$
z_{0} \approx \sqrt{V^{2} T_{1}^{2}-\left(x_{1}-x_{0}\right)^{2}-\left(y_{1}-y_{0}\right)^{2}}
$$

If $Z_{0}$ so computed is imaginary or if it is less than half the epicentral distance of the nearest station, set $z_{0}=Z T R$.

b. Three stations.

$$
\begin{aligned}
& \left(x_{2}-x_{1}\right) x_{0}+\left(y_{2}-y_{1}\right) y_{0}+\left(p_{2}-p_{1}\right) v^{2} T_{1}=\frac{1}{2}\left[r_{2}^{2}-r_{1}^{2}-v^{2}\left(p_{2}-p_{1}\right)^{2}\right] \\
& \left(x_{3}-x_{1}\right) x_{0}+\left(y_{3}-y_{1}\right) y_{0}+\left(p_{3}-p_{1}\right) v^{2} T_{1}=\frac{1}{2}\left[r_{3}^{2}-r_{1}^{2}-v^{2}\left(p_{3}-p_{1}\right)^{2}\right]
\end{aligned}
$$

Solve these equations for $X_{0}$ and $y_{0}$ in terms of $T_{1}$, and set

$$
\begin{aligned}
& R P 2=\frac{1}{2}\left[r_{2}^{2}-r_{1}^{2}-v^{2}\left(P_{2}-P_{1}\right)^{2}\right] \\
& R P 3=\frac{1}{2}\left[r_{3}^{2}-r_{1}^{2}-v^{2}\left(P_{3}-P_{1}\right)^{2}\right] \\
& D E T 3=\left(y_{3}-y_{1}\right)\left(x_{2}-x_{1}\right)-\left(y_{2}-y_{1}\right)\left(x_{3}-x_{1}\right) \\
& x_{0}=\frac{\left(y_{3}-y_{1}\right) R P_{2}-\left(y_{2}-y_{1}\right) R P_{3}}{D E T 3}-\frac{\left[\left(y_{3}-y_{1}\right)\left(P_{2}-P_{1}\right)-\left(y_{2}-y_{1}\right)\left(P_{3}-P_{1}\right)\right] V^{2}}{D E T 3} T_{1} \\
& y_{0}=\frac{\left(x_{2}-x_{1}\right) R P 3-\left(x_{3}-x_{1}\right) R P 2}{D E T 3}-\frac{\left[\left(x_{2}-x_{1}\right)\left(P_{3}-P_{1}\right)-\left(x_{3}-x_{1}\right)\left(P_{2}-P_{1}\right)\right] V^{2}}{D E T 3}
\end{aligned}
$$

Then we can write.

$$
\begin{aligned}
& x_{0}=G_{1} T_{1}+G_{2} \\
& y_{0}=G_{3} T_{1}+G_{4}
\end{aligned}
$$

23 
where

$$
\begin{aligned}
& G_{1}=\frac{\left[\left(y_{2}-y_{1}\right)\left(P_{3}-P_{1}\right)-\left(y_{3}-y_{1}\right)\left(P_{2}-P_{1}\right)\right] V^{2}}{D E T 3} \\
& G_{2}=\frac{\left(y_{3}-y_{1}\right) R P 2-\left(y_{2}-y_{1}\right) R P_{3}}{D E T 3} \\
& G_{3}=\frac{\left[\left(x_{3}-x_{1}\right)\left(P_{2}-P_{1}\right)-\left(x_{2}-x_{1}\right)\left(P_{3}-P_{1}\right)\right] V^{2}}{D E T 3} \\
& G_{4}=\frac{\left(x_{2}-x_{1}\right) R P_{3}-\left(x_{3}-x_{1}\right) R P_{2}}{\text { DET3 }}
\end{aligned}
$$

If $t_{0}$ is available from S-P data; ie., if $t_{0}=O R G S$, calculate $x_{0}$ and $y_{0}$ and set $z_{0}=z T R$.

If $t_{0}$ is not available, set $z_{0}=z T R$ and substitute $\dot{x}_{0}$ and $y_{0}$ (in terms of $T_{1}$, into the station 1 equation.

where

$$
G_{5} T_{1}^{2}+G_{6} T_{1}+G_{7}=0
$$

$$
\begin{aligned}
G_{5} & =\left(G_{1}^{2}+G_{3}^{2}-V^{2}\right) \\
G_{6} & =-2\left[G_{1}\left(x_{1}-G_{2}\right)+G_{3}\left(y_{1}-G_{4}\right)\right] \\
G_{7} & =\left(x_{1}-G_{2}\right)^{2}+\left(y_{1}-G_{4}\right)^{2}+z T R^{2} \\
\text { set } \quad G_{8} & =G_{6}^{2}-4 G_{5} G_{7} \\
G_{9} & =\sqrt{G_{8}}
\end{aligned}
$$

The two roots of the quadratic are

$$
\begin{aligned}
& T / M=\frac{-G_{6}-G_{9}}{2 G_{5}} \\
& T I P=\frac{-G_{6}+G_{9}}{2 G_{5}}
\end{aligned}
$$

24 
Substitute TIM and TIP, successively, Into the quadratic, Select the root that leaves the smallest "resldual! and test whether that residual $<0.001$. If so, set $T_{1}$ equal to that root. If not, go to the routine that places the hypocenter at the nearest station. 
Calculation of Traveltimes, Derlvatives, and

Angles of Incidence

(Subroutines TPAR and TRVDRV)

Program TRVORV, on which these subroutines are based, was designed to calculate traveitimes and derivatives of traveltimes with respect to epicentral distance and focal depth for events in an "earth" consisting of $\mathrm{N}-\mathrm{l}$ flat layers above a homogeneous half space. The earth model is described by the depth to the top of layer $L$ and the P-velocity in layer $L$; l.e., by $D(L), V(L), L=1, N$; where the index $N$ refers to the half space.

The course of the program can be outlined as follows:

1. Determine the layer, J, that contains the focus at depth, $H$.

2. Determine which of the several possible waves (direct, and refractions from successively lower horizons) is the first arrival at distance DELTA.

3. Calculate the traveltime and derivatives by an appropriate method: for refracted waves these calculations are straightforward, but for the direct waves a numerical solution must be employed.

Because the traveltime, derivative, and angle of incidence calculations are a critical central part of the hypocenter determination, these subroutines are treated more thoroughly than other subroutines in the program. This writeup describes a somewhat more elaborate version of the subroutine that constitutes a self-contained program as well as a test of the program on an actual earth model (the 3-layer "Hawall B" structure). It is supplemented by an independent flow chart and a FORTRAN listing of the TRVDRY program. The varlobles used in the program 
and flow chart are identified in the accompanying list. The same notation will be used, generally, in the following section of the writeup, which outlines the mathematical formulation of the program and discusses some of the principal problems that must be solved. The notation used in this section is nearly identical (but not exactly) to that used in HYPOLAYR and its subroutines.

Travel time of Refracted Waves

(See Sketch A)

The traveltime, to distance DELTA, of seismic waves from a focus in layer $J$ that are refracted along the top of layer $M$ can be written:

$$
T=\operatorname{TINJ}(M)+D E L T A / V(M)
$$

The intercept, $T I N J(M)$, can be written:

$$
\operatorname{TINJ}(M)=\operatorname{TID}(J, M)-\frac{T K J * \cos \theta_{M}^{J}}{V(J)}
$$

where $T I D(J, M)$ is the intercept of a wave with its focus at the top of layer $J$ (at depth $D(J)$ ? that is refracted. along the top of layer $M$ (at depth $D(M))$.

Finally,

$$
\operatorname{TID}(J, M)=\sum_{L=J}^{M-1} \frac{T H K(L) * \cos \theta_{M}^{L}}{V(L)}+\sum_{L=1}^{M-1} \frac{T H K(L) * \cos \theta_{M}^{4}}{. . V(L)}
$$

In these equations, $\theta_{M}^{4}$ is the angle of incidence in layer $L$ of a wave that is refracted horizontally in layer $M$.

27 
Notation used to specify model

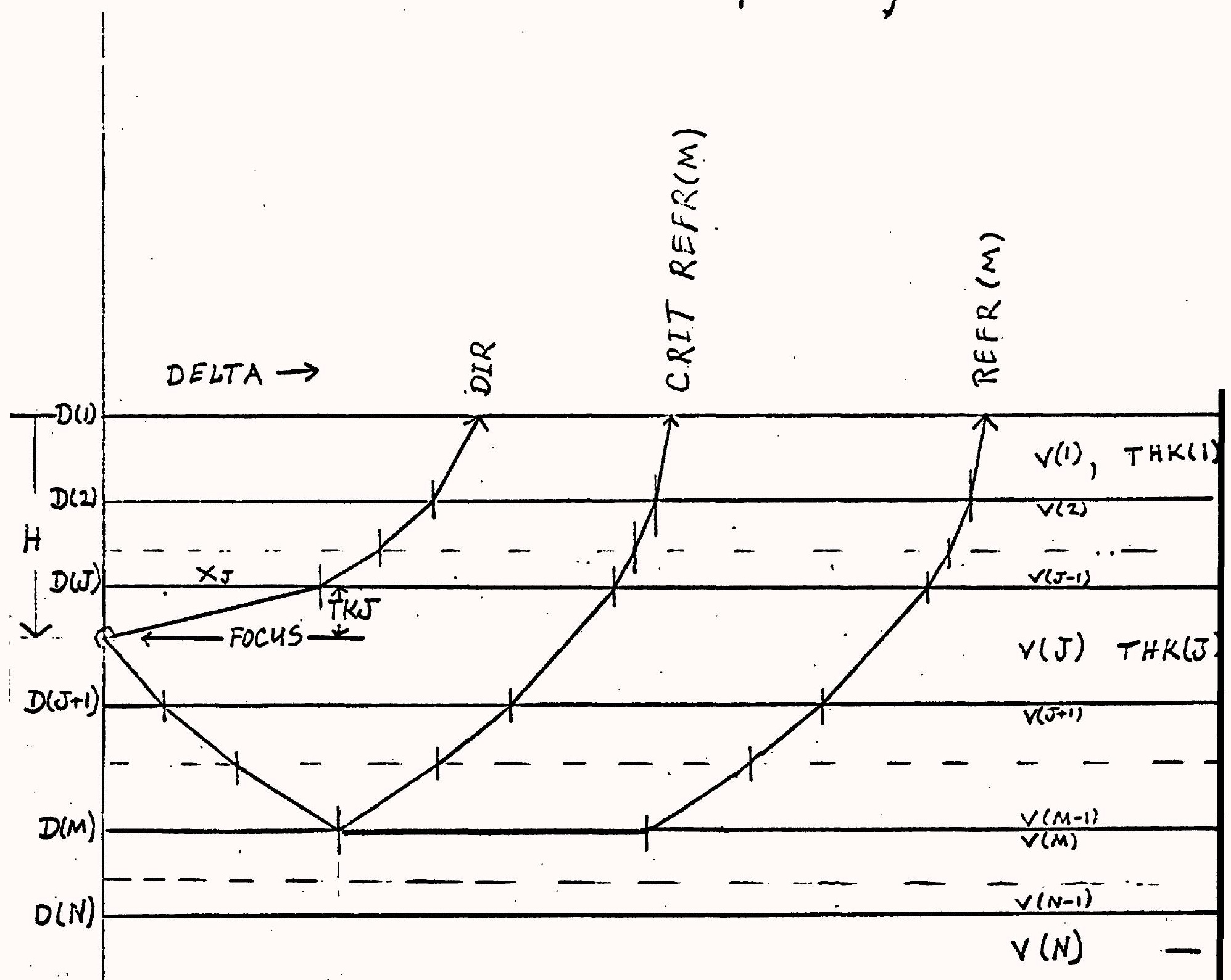


Critical Distance (Initial Point) of Refracted Waves

Analogous equations can be written for the distance to the initial point (distance of critical reflection) of the wave from a focus at depth $H$ (in layer $J)$ that is refracted along the top of layer M.

$$
\begin{aligned}
& \operatorname{DIDJ}(M)=\operatorname{DID}(J, M)-T K J * \tan \theta_{M}^{J}, \text { and } \\
& \operatorname{DID}(J, M)=\sum_{L=J}^{M-1} T H K(L) * \tan \theta_{M}^{J}+\sum_{L=1}^{M-1} T H K(L) * \tan \theta_{M}^{J}
\end{aligned}
$$

where $\operatorname{DID}(J, M)$ is the critical distance for a wave with a focus at the top of layer $J(d e p t h D(J))$ that is reflected from the top of layer $M($ depth $D(M))$.

For waves that are refracted along or critically reflected from the top of layer $M$, the angle of incidence in layer $M$ is $\pi / 2$.

Critical Distance and Intercept Formulas in Terms of Layer Velocities and Thicknesses

$$
\begin{aligned}
& \text { From Snell's law } \sin \theta_{M}^{L}=\frac{V(L)}{V(M)} \cdot \text { Hence, } \\
& \begin{aligned}
\cos \theta_{M}^{L} & =\left(1-V(L)^{2} / V(M)^{2}\right)^{1 / 2}=\frac{\sqrt{V(M)^{2}-V(L)^{2}}}{V(M)}, \\
& \begin{aligned}
\tan \theta_{M}^{L} & =\dot{V}(L) / \sqrt{V(M)^{2}-V(L)^{2}}
\end{aligned}
\end{aligned}
\end{aligned}
$$

The expressions for TID $(J, M), D I D(j, M) T I N(M), \cdots$ and DIDJ $(M)$ can be written:

$$
\operatorname{TID}(J, M)=\sum_{L=J}^{M-1} \frac{T H K(L) * \sqrt{V(M)^{2}-V(L)^{2}}}{V(M) * V(L)}+\sum_{L=1}^{M-1} \frac{T H K(L) * \sqrt{V(M)^{2}-V(L)^{2}}}{V(M) * V(L)}
$$




$$
\begin{aligned}
& \operatorname{DID}(J, M)=\sum_{L=J}^{M-1} \frac{T H K(L) * V(L)}{\sqrt{V(M)^{2}-V(L)^{2}}}+\sum_{L=1}^{M-1} \frac{T H K(L) * V(L)}{\sqrt{V(M)^{2}-V(L)^{2}}} \\
& \operatorname{TINJ}(M)=\operatorname{TID}(J, M)-\operatorname{TK} J * \frac{\sqrt{V(M)^{2}-V(J)^{2}}}{V(M) * V(J)} . \\
& \operatorname{DIDJ}(M)=\operatorname{DID}(J, M)-T K J * \frac{T K J * V(J)}{\sqrt{V(M)^{2}-V(J)^{2}}}
\end{aligned}
$$

In these equations, TKJ is the depth of the focus below the top of layer J, le., TKJ $=H-D(j)$.

Traveltime of the Di.rect Wave

The traveltime of the direct wave to distance DELTA from a focus in the first layer is simply:

$$
T=\sqrt{H^{2}+D E L T A^{2}} / V(1)
$$

For a focus in a deeper layer $(J=2, N)$ the expression for $T$ as a function of DELTA is too complex to be useful, if it can be obtained at all. However, both $T$ and DELTA are relatively simple functions of $\sin \theta_{J}$, where $\theta_{J}$ is the angle of incidence of the ray at the focus in layer J. In the program "DIRECT", a simple method for determining $\sin \theta_{J}$ and then calculating $T$ for any specifled DELTA was developed. This routine is employed in the present program to compute the traveltime of the direct ray to distance DELTA for $J>1$. 
Maximum Distance at Which the Direct Wave Can Be a First Arrival.

\section{(See Sketch B)}

Because the traveltime of the direct wave is more time-consuming to calculate than the traveltimes of refracted waves, a preliminary test is made to determine whether DELTA is beyond the range of possible direct-wave first arrivals. Consider a focus at depth $H$ in layer $J$. At large DELTA the direct wave is asymptotic to the refraction line for a focus at the very top of layer $J$; but the direct wave is always later than the asymptote. Let the crossover distance between the wave refracted along the top of $J$ from a focus at the top of $J$ and the wave refracted along the top of $J+I$ from a focus at depth $H$ be XOVMAX. . Then the crossover between the direct wave and the refracted wave from $J+1$ will be smaller than XOVMAX, and the first arrival at DELTA larger than XOVMAX must be a refracted wave, if $\mathrm{J}<\mathrm{N}$.

Because the Initlal point of the refraction from layer $K+1$ is coincident with the critical reflection from the top of $K+1$ (or the . bottom of $K$ ) and because the reflection from the base of $K$ must. be later than the direct wave (if $K=J$ ) or a refracted wave from the top of $K$, the initial point of the $K+1$ refraction curve must lle above the K-refraction curve (or the direct-wave curve if $K=J$ ). Hence, for DELTA greater than XOVMAX and $J<N$ the first arrival must be a refracted wave recorded beyond its initial point.

Determination of Which Wave is the First Arrival at DELTA $<$ XOVMAX

For DELTA less than XOVMAX the first arrival may be the direct wave: so the trayeltime of the direct wave must be computed and 


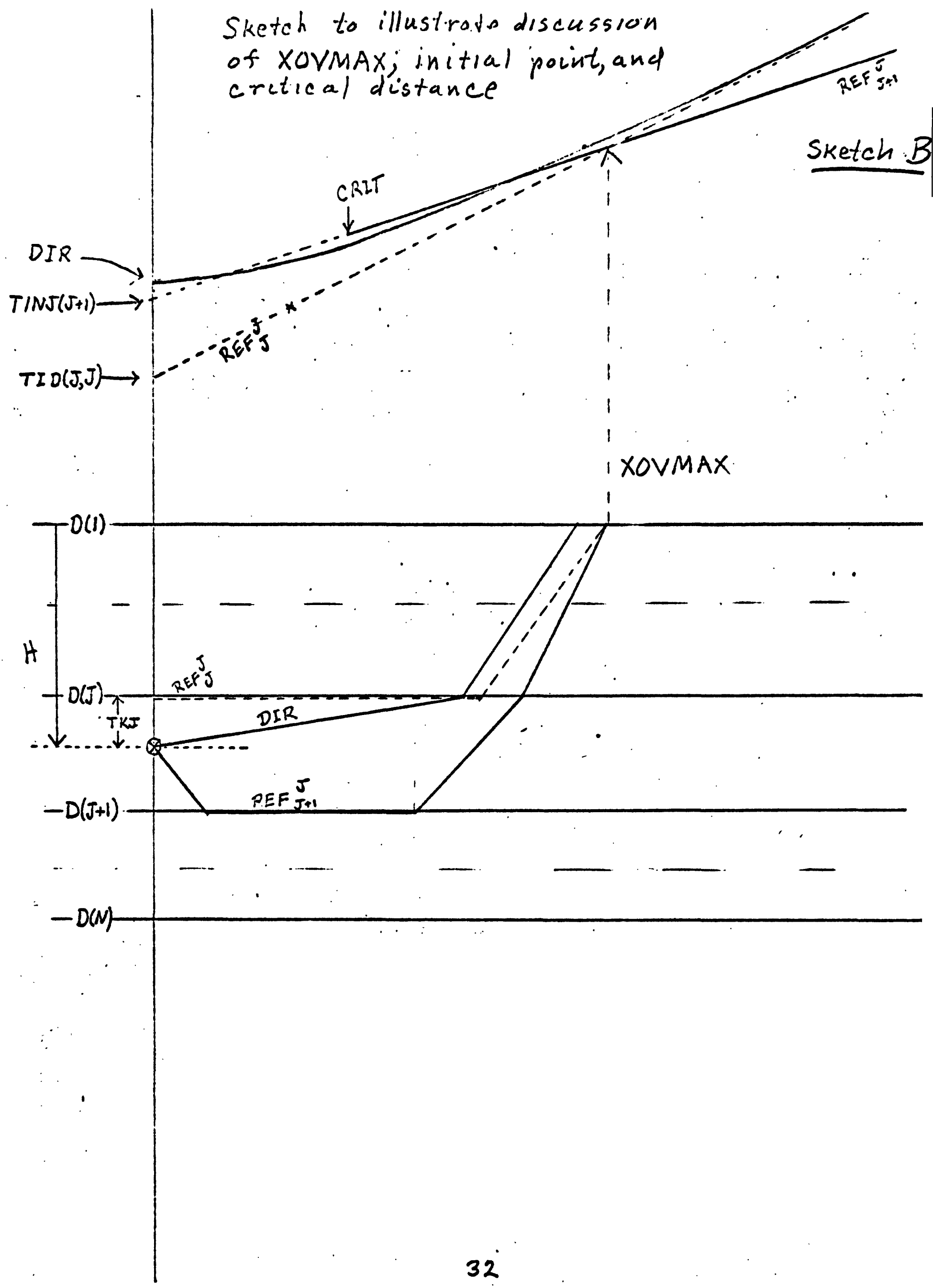


compared with the traveltimes of possible refracted phases to establish which arrival is earllest. In this range of DELTA, however, it must be established that any prospective refracted first arrival actually exists at the specific value of DELTA considered; i.e., is DELTA beyond the initial point of the refracted wave?

Derivatives of Traveltime with Respect to Epicentral Distance and Focal Depth. - When the nature of the first arrival at distance DELTA has been established, the traveltime of that arrival is set equal to $T$ and derivatives of the traveltime with respect to DELTA and $H$ are computed by methods that are appropriate for the first-arrival wave type.

Derivatives of refracted-wave traveltimes with respect to DELTA and H.--For refracted waves, by differentiation of the equation for $T$ as a function of DELTA and $\mathrm{H}$ :

$$
\begin{aligned}
& \partial T / \partial D E L T A=\frac{1}{V(M)} \\
& \partial T / \partial H=\frac{-\sqrt{V(M)^{2}-V(J)^{2}}}{V(M) * V(J)}
\end{aligned}
$$

Derivatives of first-layer direct arrivals.--for the direct wave through layer 1:

$$
\begin{aligned}
\frac{\partial T}{\partial D E L T A} & =\frac{D E L T A}{V(1) * \sqrt{H^{2}+D E L T A^{2}}} \\
\frac{\partial T}{\partial H} & =\frac{H}{V(1) * \sqrt{H^{2}+D E L T A^{2}}}
\end{aligned}
$$


Derivatives of direct-wave travel times: $J>1 .--$ (See sketch $C_{.}$)

Because both $T$ and DELTA for the direct wave from layers below the first can be expressed in terms of the parameter $\sin \theta_{\mathrm{J}}$

$\frac{\partial T}{\partial D E L T A} \quad$ can be computed as

$\frac{\partial T}{\partial \sin \theta_{J}}$

$\frac{\partial D E L T A}{\partial \sin \theta_{J}}$

$\frac{\partial T}{\partial D E L T A}=$
$\frac{T K J * U /\left(V(J) *\left(1.0-U^{2}\right)^{3 / 2}\right)+\sum_{L=1}^{J-1} T H K(L) * V(J) * U /\left(V(L)^{2} *\left(\frac{V(J)^{2}}{V(L)^{2}}-U^{2}\right)^{3 / 2}\right)}{T K J /\left(1.0-U^{2}\right)^{3 / 2}+\sum_{L=1}^{J-1} T H K(L) * V(J)^{2} /\left(V(L)^{2} *\left(\frac{V(J)^{2}}{V(L)^{2}}-U^{2}\right)^{3 / 2}\right)}$

where

$$
u=\sin \theta_{J}
$$

34 


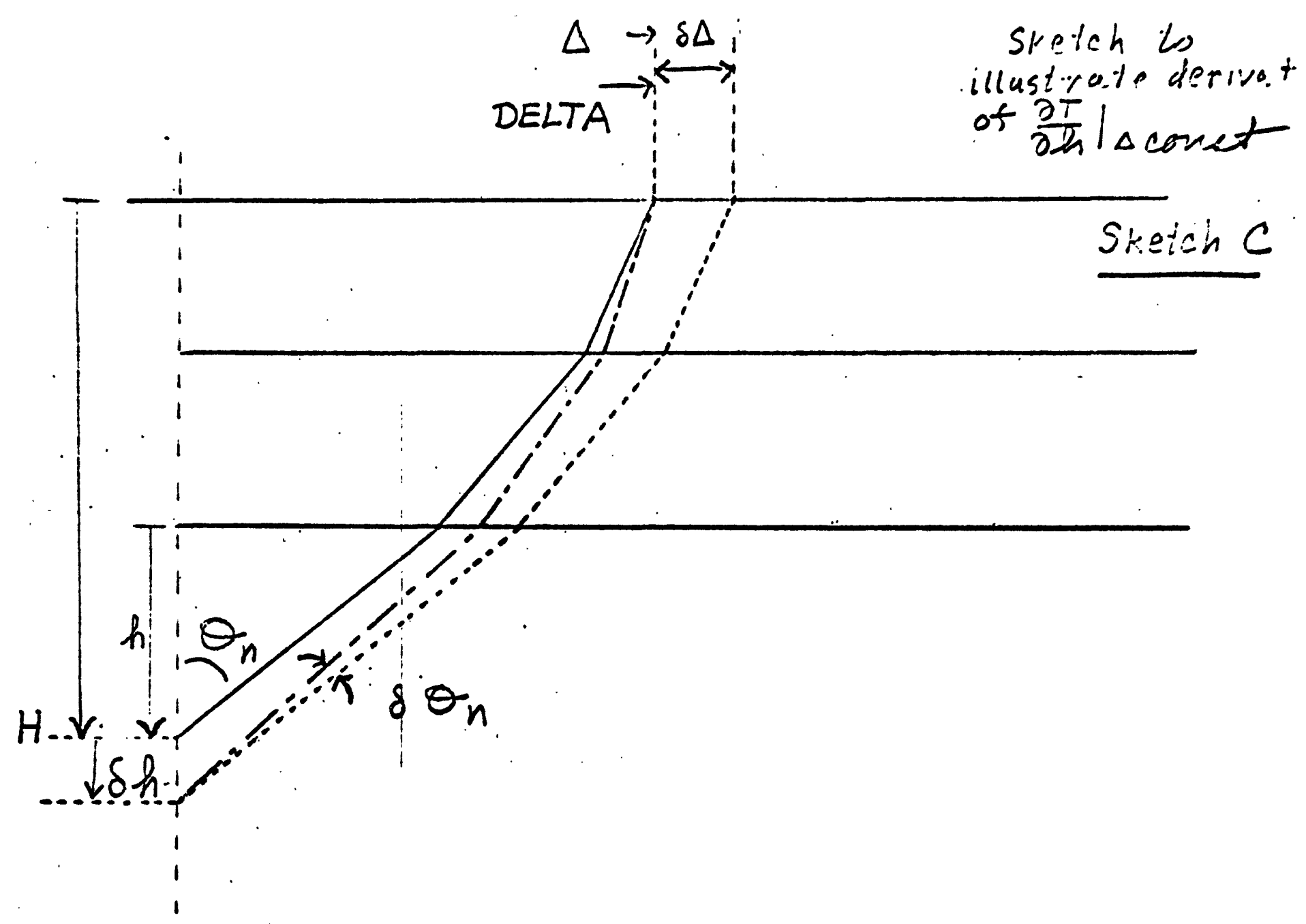


Next, we must calculate $\left.\frac{\partial T}{\partial H}\right|_{\text {DELTA }}$ for the direct arrival from layer $\mathrm{J}$.

$$
\begin{aligned}
& \text { Letting } U=\sin \theta_{J} \text {, and } h=T K J=H-D(J) \text {, and DELTA }=\Delta, \\
& T=\frac{h}{V(J) * \sqrt{1 \cdot 0-U^{2}}}+\sum_{L=1}^{J-1} \frac{T H K(L) * V(J)}{V(L)^{2} \times\left(\frac{V(J)^{2}}{V(L)^{2}}-U^{2}\right)^{1 / 2}} \\
& \Delta=\frac{h * U}{\sqrt{1.0-U^{2}}}+\sum_{L=1}^{J-1} \frac{T H K(L) * U}{\left(\frac{V(J)^{2}}{V(L)^{2}}-U^{2}\right)^{1 / 2}}
\end{aligned}
$$

Holding $U=\sin \theta_{J}=$ canst, increase $h$ by an amount. Sh. The corresponding changes in $T$ and $\Delta$ are

$$
\begin{aligned}
& \delta T_{1}=\left.\frac{\partial T}{\partial h}\right|_{u} * \delta h \\
& \delta \Delta_{1}=\left.\frac{\partial \Delta}{\partial h}\right|_{u} * \delta h
\end{aligned}
$$

Next, change $U$ by an amount $\delta U$, holding h constant so that the change in $\Delta, \delta \Delta_{2}$, is equal and opposite to that caused by the previous change in $h$.

$$
\delta \Delta_{2}=\left.\frac{\partial \Delta}{\partial u}\right|_{h} * \delta u \doteq-\left.\frac{\partial \Delta}{\partial u}\right|_{u} * \delta h=-\delta \Delta_{1}
$$

36 
: Thus, the required 64 is:

$$
\delta u=-\frac{\left.\frac{\partial \Delta}{\partial h}\right|_{u}}{\left.\frac{\partial \Delta}{\partial u}\right|_{h}} * \delta h
$$

The corresponding change in $T$ is

$$
\delta T_{2}=\left.\frac{\partial T}{\partial U}\right|_{h} \delta U
$$

Substituting the previous expression for $\delta U$

$$
\delta T_{2}=-\left.\frac{\partial T}{\partial u}\right|_{h} * \frac{\left.\frac{\partial \Delta}{\partial h}\right|_{u}}{\left.\frac{\partial \Delta}{\partial u}\right|_{h}} * \delta h
$$

The total change in $\Delta$, i.e., $\delta \Delta_{1}+\delta \Delta_{2}=0$, and the total change in $T$ is

$$
\begin{aligned}
& T \text { is } \\
& \delta T=\delta T_{1}+\delta T_{2}=\left.\frac{\partial T}{\partial h}\right|_{u} * \delta h-\left.\frac{\partial T}{\partial u}\right|_{h} * \frac{\left.\frac{\partial \Delta}{\partial h}\right|_{u}}{\left.\frac{\partial \Delta}{\partial u}\right|_{h}} * \delta h \\
& \left.\frac{\delta T}{\delta h}\right|_{\Delta}=\left.\frac{\partial T}{\partial h}\right|_{u}-\left.\frac{\partial T}{\partial u}\right|_{h} * \frac{\left.\frac{\partial \Delta}{\partial h}\right|_{u}}{\left.\frac{\partial \Delta}{\partial u}\right|_{h}}
\end{aligned}
$$

We have previously calculated

$$
\frac{\left.\frac{\partial T}{\partial u}\right|_{h}}{\left.\frac{\partial \Delta}{\partial u}\right|_{h}}=\left.\frac{\partial T}{\partial \Delta}\right|_{h}
$$

Passing to the lImit

$$
\left.\frac{\partial T}{\partial h}\right|_{\Delta}=\left.\frac{\partial T}{\partial h}\right|_{u}-\left.\left.\frac{\partial T}{\partial \Delta}\right|_{h} * \frac{\partial \Delta}{\partial h}\right|_{u} .
$$

But $\left.\frac{\partial T}{\partial h}\right|_{u}=\frac{1}{v(J) \sqrt{1.0-u^{2}}} ;\left.\frac{\partial \Delta}{\partial h}\right|_{u}=\frac{u}{\sqrt{1.0-u^{2}}}$ and

37 


$$
\left.\frac{\partial T}{\partial h}\right|_{\Delta}=\frac{1.0}{V(J) * \sqrt{1.0-u^{2}}}-\left.\frac{U}{\sqrt{1.0-U^{2}}} * \frac{\partial T}{\partial \Delta}\right|_{h}
$$

Thus

$$
\begin{aligned}
\left.\frac{\partial T}{\partial h}\right|_{\Delta}=\frac{1.0-\left.V(J) * U * \frac{\partial T}{\partial \Delta}\right|_{h}}{V(J) * \sqrt{1.0-u^{2}}} \\
\text { in the notation used in the FORTRAN program } \\
\text { DTDH }=\frac{1.0-v(J) * U * D T D D}{V(J) * \sqrt{1.0-U^{2}}}
\end{aligned}
$$


Notation Used in the TRVDRV Program

HIN

DELH

MAXH

KREC

N

$V(L)$

$D(L)$

DELTA(I)

THK(L)

$\operatorname{TID}(K, M)$

$D \mid D(K, M)$

H

J

TKJ

TINJ (L)

DIDJ (L)

$\operatorname{TR}(M)$

$\begin{array}{ll}\text { initial focal depth } & \text {; } \\ \text { increment in focal depth } & \text {; Used In test of } \\ \text { maximum focal depth } & ; \text { program }\end{array}$

total number of stations considered)

number of layers plus one

P-velocity in layer $L$

depth to top of layer $L$

epicentral distance to station I

thickness of layer $L$

intercept of refracted wave from a focus at

boundary $D(K)$ and refracted along boundary

$D(M) ; M \geqslant K$.

critical distance of refracted wave described above; i.e., epicentral distance of the initial point of the refraction curve.

focal depth

layer containing focus

distance of focus from top of layer $J$

intercept of wave from depth $\dot{H}$ (in layer $J$ ) and refracted along boundary $D(L) ; L \geqslant J$.

critical distance of wave from depth $H$ (in layer $J$ ) and refracted along $D(L)$.

traveltime of refracted wave from focus at depth $\mathrm{H}$ to distance DELTA(i) 
TMIN $=999.99 .$. arbitrarlly large traveltime for use in scheme to identify first arrival at distance DELTA(I)

XOVMAX

$T(I)$

DTDD(I)

DTDH(I)

$\operatorname{MODE}(I)=1$

TOJ1

$\operatorname{MODE}(I)=2$

XBIG

XLIT

UL

UB

DELBIG

DELLIT

XTR

U "safe" estimate of maximum distance at which the first arrival might be the direct wave traveltime of wave from focus at depth $\mathrm{H}$ to epicentral distance DELTA(I)

$$
\text { วT(I) / DDELTA }
$$$$
\partial T(I) / \partial H
$$

identifles "refracted" arrivals. - traveltime of direct wave from a focus in layer 1. identifies a direct arrival from a focus in layer 1.

upper limit of interval containing the point at whlch the direct wave from a focus in $J$ leaves layer. J

lower limit of interval containing. the point at which the direct wave from a focus in $J$ leaves layer J.

value of $\sin \theta_{J}$ computed from XLIT

value of $\sin \theta_{J}$ computed from XBIG

value of DELTA corresponding to XBIG value of DELTA corresponding to XLIT trial value of $X_{j}$, the eplcentral distance at which the direct ray leaves layer $J$ value of $\sin \theta_{J}$ computed from XTR $\left(\theta_{J}=\right.$ angle of incldence in layer $\mathrm{d}$ ). 
DELXTR the value of DELTA that corresponds to XTR TEST = DELTA(I) - DELXTR

LL Iteration counter in loop to find $X_{j}, \sin \theta_{j}$, etc.

TDC asymptote approached by TOIR when DELTA(I) $\gg$ TKJ

$\operatorname{MODE}(I)=3$ Indicates direct traveltime and derivatives calculated on the basis of TOC for DELTA(I) $\gg$ TKJ

ALFA ) Sums required in the calculation of DTDO(I) for the BETA f direct wave

$\operatorname{MODE}(I)=4$ Indicạtes direct arrival

TDIR : traveltime of direct wave 
TRAVORIV FLOWCHABT

START

$$
\begin{aligned}
& \text { READ } N, H I N, D E L H, H M A X \text {, } \\
& (V(L), D(L), L=1, N) \text {, - } \\
& K R E C_{2}(D E L T A(L), L=1, K R E C) \\
& T H K(L)=D(L+1)-D(L) \\
& L=1, N-1 \\
& \operatorname{TID}(1,1)=0.0 \\
& \operatorname{DID}(1,1)=0,0 \\
& \begin{array}{l}
\text { SUMI }=\sum_{L=1}^{K-1} \operatorname{THK}(L) * \sqrt{V(M)^{2}-V(L)^{2}} / V(M) * V(L) \\
\text { SUMA }=\sum_{L=1}^{K-1} T H K(L) \times V(L) / \sqrt{V(M)^{2}-V(L)^{2}} \\
\operatorname{suM2}=\sum_{L=K}^{M-1} T H(L) * \sqrt{V(M)^{2}-V(L)^{2}} / V(M) * V(L) \\
\text { suM } B=\sum_{L=K}^{M-1} \operatorname{THK}(L) * V(L) / \sqrt{V(M)^{2}-V(L)^{2}}
\end{array} \\
& \left.\begin{array}{l}
\operatorname{TID}(M, M)=\text { suM.1 } \\
\operatorname{DID}(M, M)=\operatorname{suMA}
\end{array}\right\} K=M \quad K=2, N \\
& \begin{array}{l}
\operatorname{TID}(1, M)=2 \operatorname{sum} 2 \\
D I D(1, M)=2 \operatorname{suMB} .
\end{array}\left\{\begin{array}{l}
k=1 \\
M=2, N
\end{array}\right. \\
& \operatorname{TID}(K, M)=\operatorname{suM1} 1+2 \operatorname{sum} 2\} K=2, N-1 \\
& \text { DID }(K, M)=\sin A+254 M B\}\{=K+1, N \\
& 51 \frac{H=A I N}{t}
\end{aligned}
$$

II

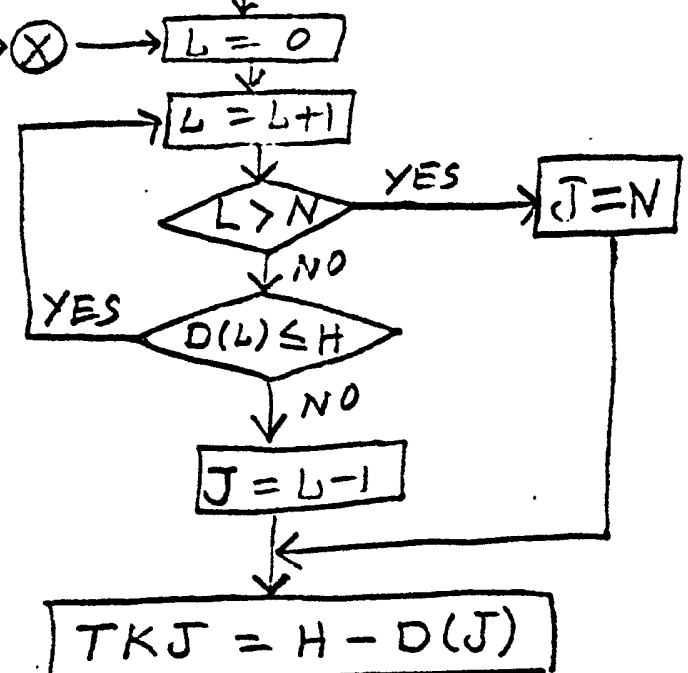

$$
T K J=H-D(J)
$$

(A) $57^{\circ}$

42

(1) 


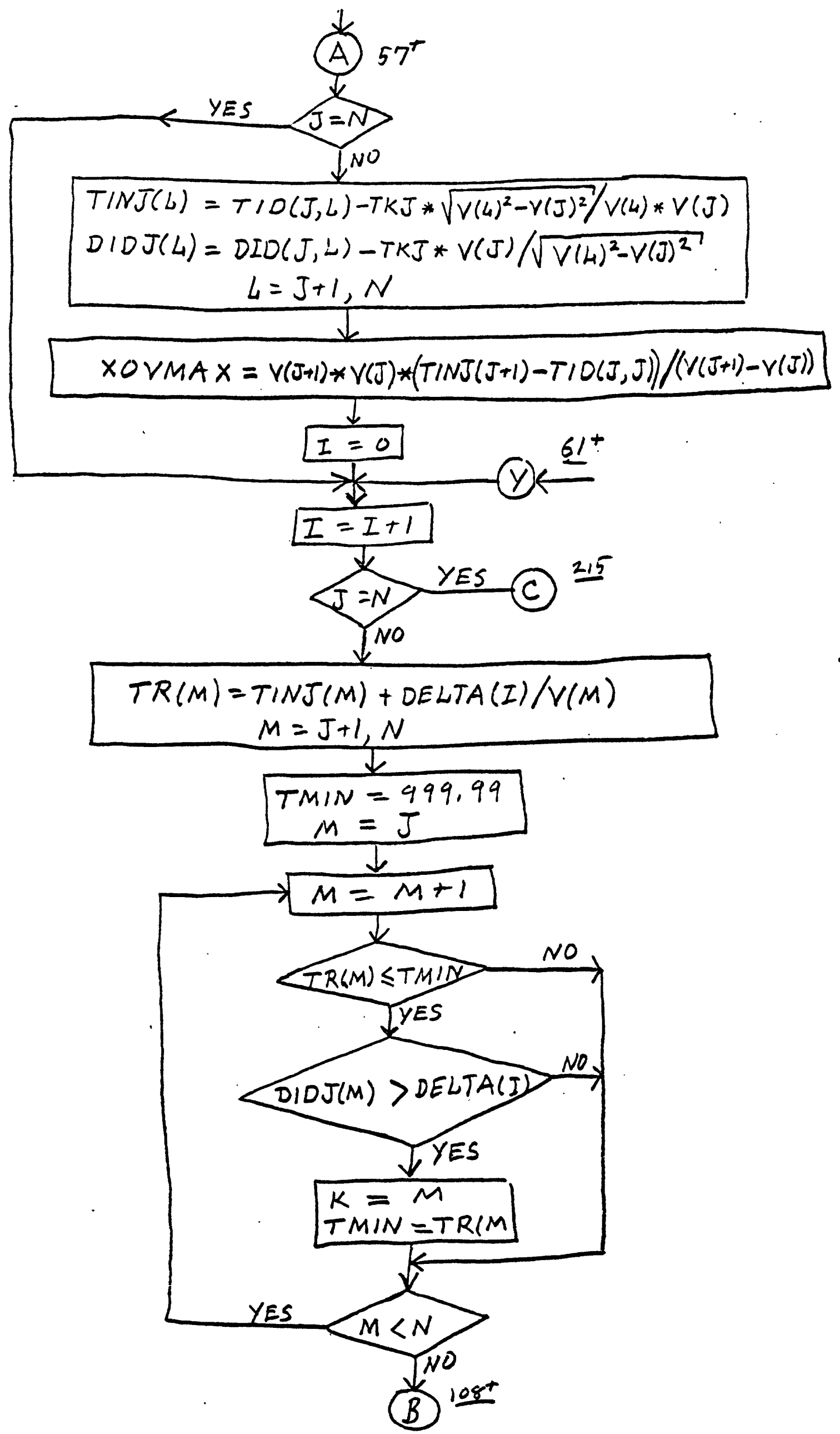




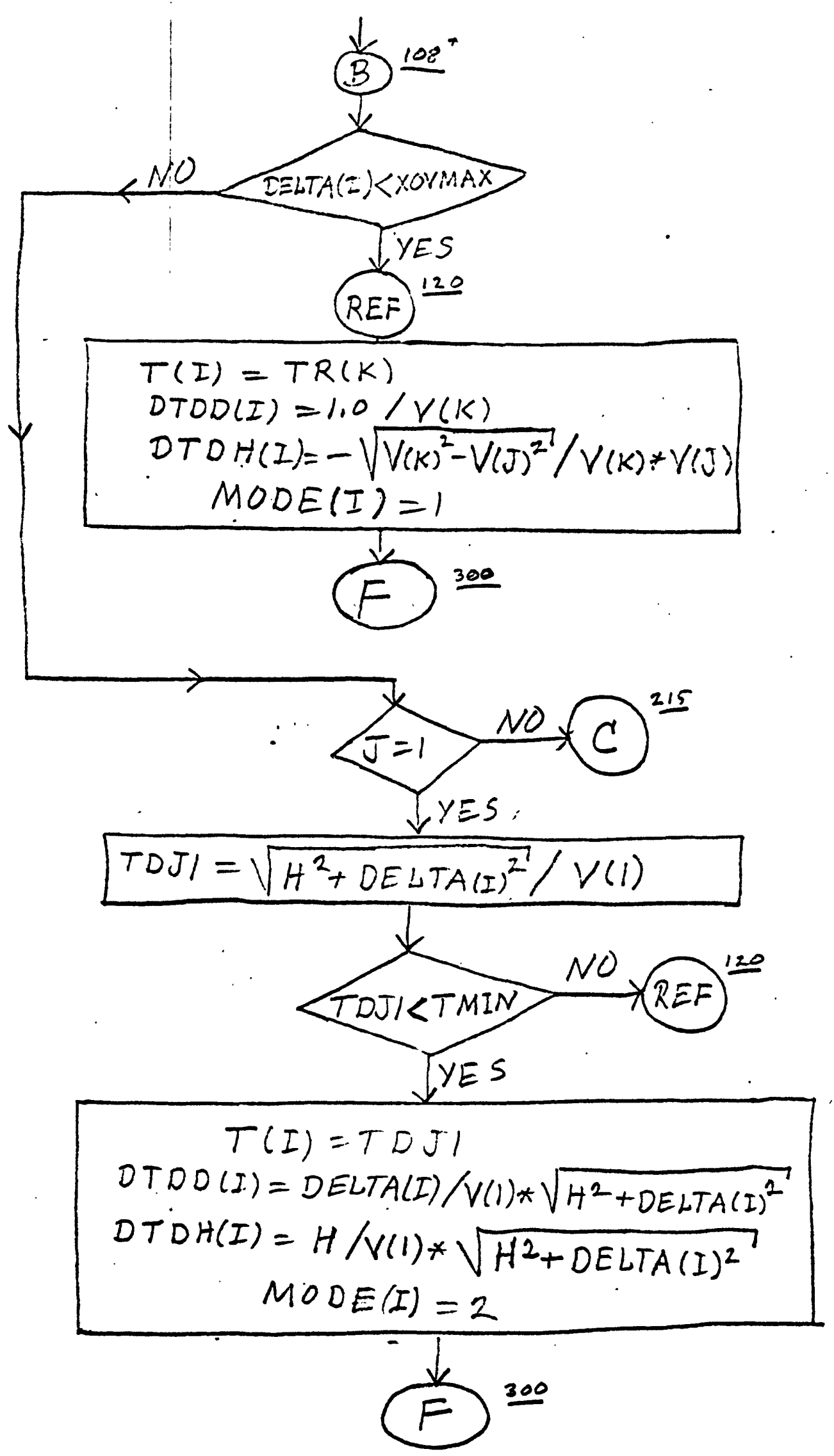




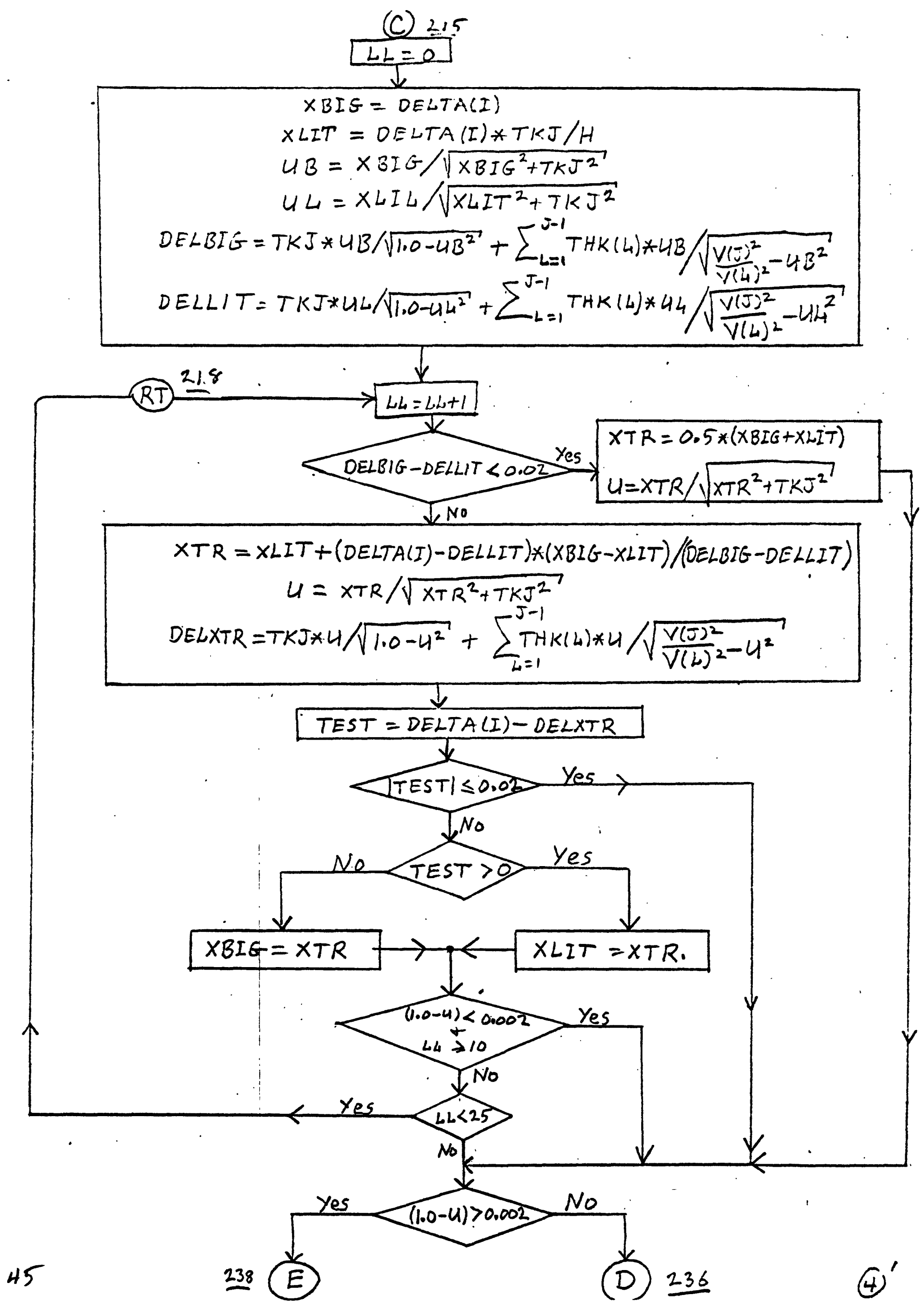




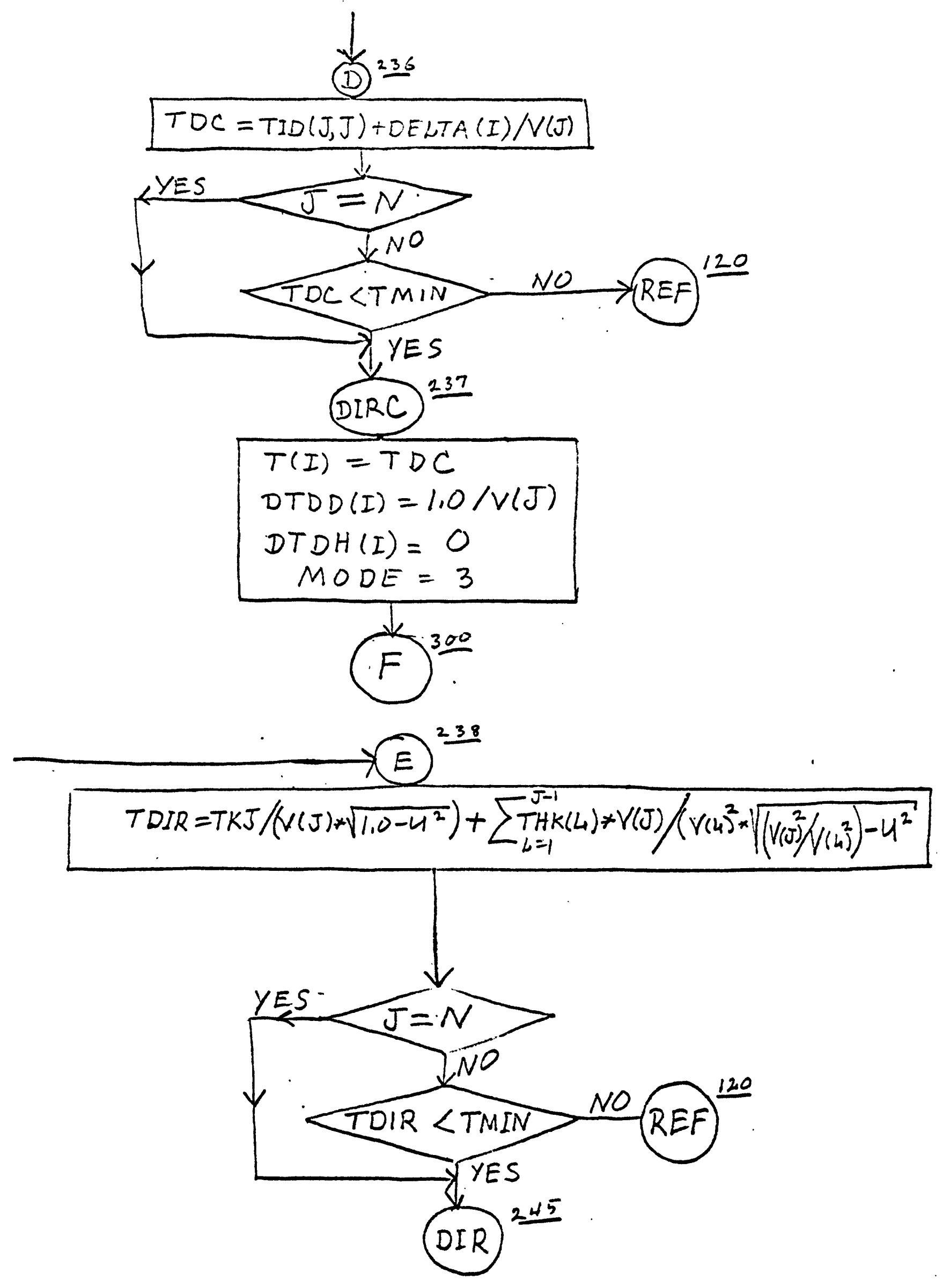




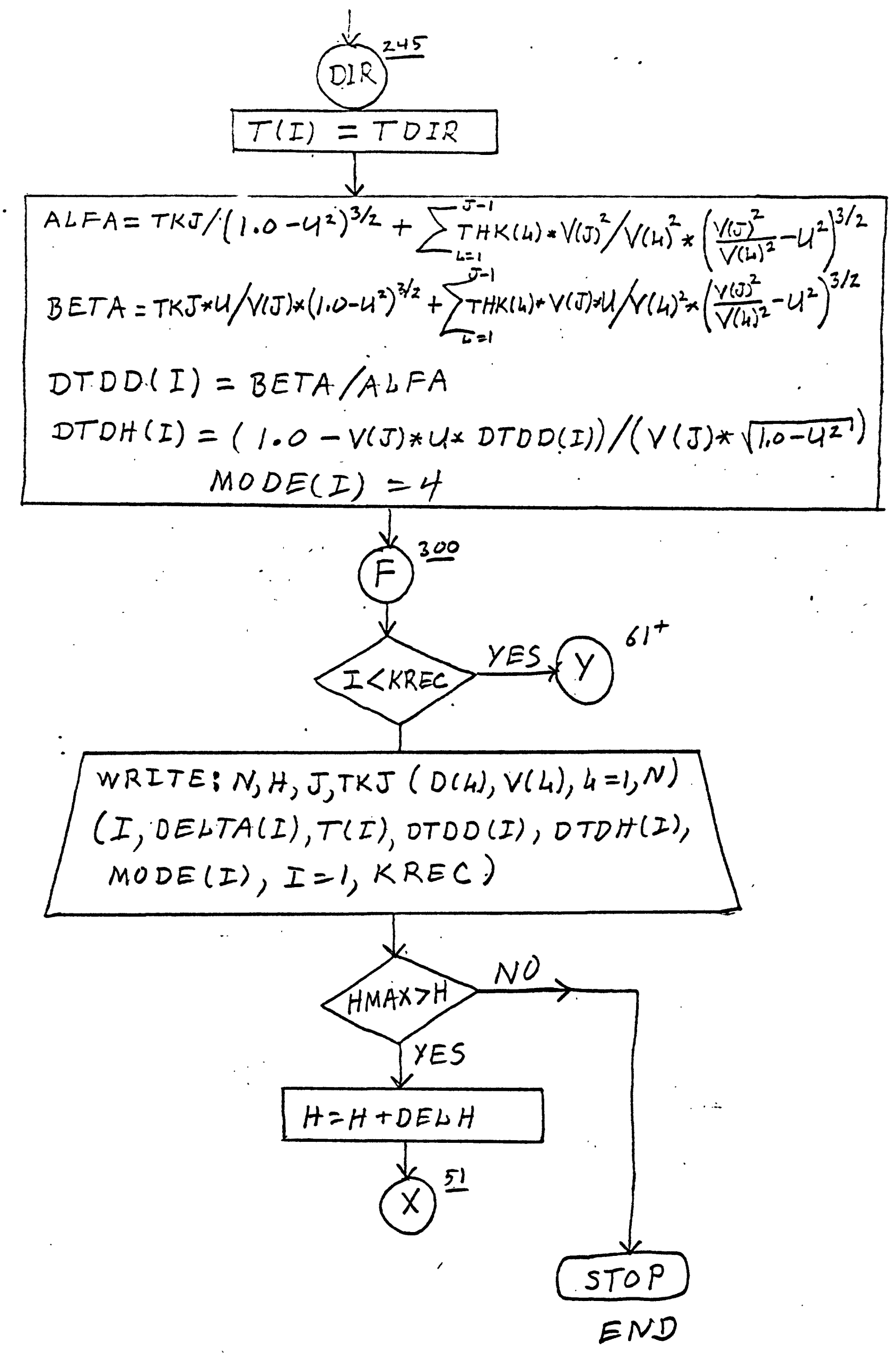


TRAVDRIV bistall (BCD interpoter

YTTRAVORIV JOB [C488,437,3,3], 948 EATON:,MSGLEVELX1

17 EXEC FOKTHCLG,PARM.FORTX IMAP, NODECK, BCD:

IIFORT.SYSIN DD *

C traveltime and oefivatives n-1 layers

DIMENSION V(10), O(10), THK(10), TID 10,10$), T I N J(10), T R(10)$,

1DID $(10,10)$, DIDJ $(10)$, OELTA $(20), T(20), D T D O(20), 0 T O H(20), M O D E(20)$

$S R T B K(X, Y, Z)=S Q R T((X * X) /(Y \star Y)-(Z \star Z))$

REAO(S,500)N,HIN,DELH,HMAX

500 FORMAT $(I 5,3 F 10.3)$

READ (5,505) (V(L),O(L),L=1,N)

505 FORMAT (2F 10.3)

C REAO LIST UF DELTAS FOR TRIAL CALCULATIONS

AEAO $(5,510) K R E C$, ODELTA.(L) OL=1,KREC)

510 FORMAT $(15,(5 F 10.3))$

C. COMPUTE THK(L)

$\operatorname{THK}(N)=0.0$

DO $10 \quad K=2, N$

$L=K-1$

$\operatorname{THK}(L)=D(K)-O(L)$.

10 CONTINUE

C COMPUTE INTERCEPTS AND GRITICAL DISTANCES FOR BOUNOARY FOCI

$T I D(1,1)=0.0$

$\operatorname{DID}(1,1)=0.0$

$N 1=N-1$

DO $15 M=2, N$

$M 1=M-1$

SUM $1=0.0$

SUMA $=0.0$

DO $12 L=1, M 1$

SUM1 $=\operatorname{SUM} 1+T H K(L) * S Q R T(V(M) * V(M)-V(L) * V(L)) /(V(M) * V(L))$

SUMA $=S U M A+T H K(L) * V(L) / S Q R T(V(M) * V(M)-V(L) * V(L))$

12 CONTINUE

TID $(M, M)=S U M 1$

$D I O(M, M)=$ SUMA

15 CONTINUE

DO $20 \quad M=2, N$

$M 1=M-1$

SUM2 $=0.0$

SUMB $=0.0$

DO $18 L=1, M 1$

SUM2 $=S U M 2+T H K(L) \star S Q R T(V(M) * V(M)-V(L) * V(L)) /(V(M) * V(L))$

$S U M B=S U M B+\operatorname{THK}(L) * V(L) / S Q R T(V(M) * V(M)-V(L) * V(L))$

18 CONTINUE

$\operatorname{TIO}(1, M)=2.0 *$ SUM 2

$D I D(1, M)=2.0 *$ SUMB

20 CONTINUE

DO $50 \quad K=2, N 1$

$K K=K+1$

$K 1=K-1$

DO $50 \quad M=K K, N$

$M 1=M-1$

$\operatorname{SUM} 1=0.0$

SUM2 $=0.0$

SUMA $=0.0$.

SUMB $=0.0$ 
DO $30 L=1, K 1$

SUM1 $=S U M 1+T H K(L) * S Q K T(V(M) * V(M)-V(L) * V(L)) /(V(M) * V(L))$

SUMA $=S U M A+T H K(L) * V(L) / S G R T(V(M) * V(M)-V(L) \star V(L))$

30 CONTINUE

DO $40 \quad L=K, M 1$

SUM2 $=S U M 2+T H K(L) * S Q K T(V(N) * V(M)-V(L) * V(L)) /(V(M) * V(L))$

$S U M B=S U M B+T H K(L) * V(L) / S Q R T(V(M) * V(M)-V(L) * V(L))$

40 CONTINUE

$\operatorname{TI}(K, M)=S U M 1+2,0 * S U M 2$

$D I D(K, M)=S U M A+2.0 * S U M B$

50 CONTINUE

C COMPUTE LAYER J CONTAINING FOCUS AT DEPTH H AND DEPTH.TKJ OF FOCUS

C BELOW TOP OF. LAYER J

$H=H I N$

$51 L=0$

$53 L=L+1$

IF $(L . G T \cdot N) G O$ TO 56

IF $(D(L)-H) 53.53,55$

$55 \mathrm{~J}=\mathrm{L}-1$

GO TO 57

$56 \quad J=N$

57 TKJ $=H-O(J)$

IF $(J . E Q . N) G O$ TO 61

CCOMPUTE THE INTERCEPT OF WAVE FROM FOCUS IN LAYER J AND REFRAGTED

C ALONG THE TOP OF LAYER L

DO $58 L=1, N$

$\operatorname{TINJ}(L)=0.0$

DIDJ $(L)=0,0$

58 CONTINUE

$J J=J+1$

DO $60 \mathrm{~L}=\mathrm{JJ}, \mathrm{N}$

- $T I N J(L)=T I D(J, L)-T K J * S Q R T(V(L) * V(L)-V(J)+V(J)) /(V(L) * V(J))$

$D I D J(L)=D I D(J \cdot L)-T K J * V(J) / S Q R T(V(L) * V(L)-V(J) * V(J))$

60 CONTINUE

C COMPUTE DELTA BEYOND WHICH ALL IST ARRIVALS ARE REFRACTIONS

61 CONTINUE XOVMAX $=V(J J) * V(J) *(T I N J(J J)-T I O(J, J)) /(V(J J)-V(J))$

C BEGIN CALCULATIONS FOR DEPTH H ANO DELTACI) I=1,KREC DO $300 \quad I=1$, KREC

C DETERMINE WHICH BRANCH OF THE TT CURVE CORRESPONOS TO DELTACI) DO $90 L=1, N$

$T R(L)=0.0$

90 CONTINUE

IF (J.EQ.N)GO TO 215

$10000102 M=J J . N$

$T R(M)=T I N J(M)+O E L T A(I) / V(M)$

102 CONTINUE

TMIN $=999.99$

$M=J$

$104 M=M+1$

IF $(T R(M)-T M I N) 106,106,108$

106 IFPDIOJ (M) .GT. DELTACIS) GO TO 108

$K=M$

TMIN=TR(M)

108 IF(M .LT. N) GO TO 104 
IF (OELTAC I )-XOVMAX)202,120,120

C CALGULATE TT AND DERIVS FOR WAVES RECORDED BEYOND XOVMAX $120 T(T)=T R(K)$

OTDO $(I)=1.0 / V(K)$

$D T D H(I)=-S Q R T(V(K) * V(K)-V(J) * V(J)) /(V(K) * V(J))$

MODE $(I)=1$.

GO TO 300

C. COMPUTE TT OF OIRECT. WAVE THROUGH LAYER $J$

202 IF (J.NE. 1)GO TO 215

TDJ1 $=S Q R T(H \star H+D E L T A(I) \star D E L T A(I)) / V(1)$

203 IF (TOJI-TMIN) $205,120,120$

$203 T(I)=T 0 J 1$

DTDD (I) $=$ DELTACI $/(V(1) \star S O R T(H \star H+D E L T A(I) \star D E L T A(I)))$

DTDH $(I)=H /(V(I) * S O R T(H * H+D E L T A(I) * D E L T A(I)))$

$M O D E(I)=2$

$215 L L=0$

GO. TO 300

C BEgIN ROUTINE TO FINO ROOT OF REFRACTION EOUATION $X B I G=O E L T A(I)$

$X L I T=O E L T A(I) * T K J / H$

$U B=X B I G / S Q R T(X B I G * X B I G+T K J * T K J)$

$U L=X L I T / S A R T(X L I T+X L I T+T K J * T K J)$

DELBIG $=T K J \star U B / S Q R T(1.0-U B * U B)$

DELLIT $=T K J * U L / S Q R T(1.0-U L * U L)$

$J 1=J-1$

DO $216 L=1, J 1$

$D E L B I G=D E L B I G+(T H K(L) * U B) / S R T B K(V(J), V(L), U B)$

DELLIT $=D E L L I T+(T H K(L) * U L) / S R T B K(V(J), V(L), U L)$

216 CONTINUE

$218 L L=L L+1$

IF (DELBIG-OELLIT .LT. 0.02$)^{\circ}$ GO TO 231

$X T R=X L I T+(O E L T A(I)-O E L L I T) *(X B I G-X L I T) /(D E L B I G-O E L L I T)$

$U=X T R / S Q R T((X T R * X T R)+(T K J * T K J))$

DELXTR $=T K J * U / S Q R T(1 \cdot 0-U * U)$

DO $220 \quad L=1, J 1$

$D E L X T R=D E L X T R+(T H K(L) \star U) / S R T B K(V(J), V(L), U)$

220 CONTINUE

TEST =DELTA (I) - OELXTR

IF (ABS (TEST) -0.02$) 235,235,221$

221 IF (TEST) $222,235,226$

$222 \times B I G=X T R$

DELBIG $=D E L X T R$

GO TO 230

$226 \times L I T=X T R$

OELLIT=OELXTR

IF(1.0-U.LT. 0.0002 .AND. LL.GE. 10) 60 TO 235

230 IF (LL ILT. 25) GO TO 218

GO TO 235

$231 \times T R=0.5 *(X B I G+X L I T)$

$U=X T R / S Q R T((X T R \star X T R)+(T K J+T K J))$

235 CONTINUE

IF (1.0-U.GT. 0.0002) GO TO 238

C IF $U$ IS TOO NEAR 1.0 COMPUTE TDIR AS WAVE ALONG. TOP OF LAYER $J$ $236 T O C=T I D(J, J)+D E L T A(I) / V(J)$

IF (J.EO. N)GO TO 237 
IF TUC-TMIN)237,120,120

$T(T)=T D C$

$\operatorname{OTDO}(1)=1.0 / \mathrm{V}(\mathrm{J})$

$\operatorname{OTOH}(I)=0.0$

$\operatorname{MODE}(1)=3$

$G 0$ TO 300

C COMPUTE TOIR FROM ROOT OF OELTACU) EAUATION

238 TOIR $=T K J /(V(J) \star S Q R T(1.0-U * U))$

$23900240 \mathrm{~L}=1, \mathrm{~J} 1$

TOIR $=T D I R+(T H K(L) \star V(J)) /(V(L) * V(L) * S R T B K(V S J) \circ V(L), U)$.

240 GONTINUE

IF(J .EQ. N)GO TO 245

243 IF (TOIR-TMIN)245,120,120

$245 T(T)=T O I R$

C COMPUTE OTOD(I) AND DTDH(I)

ALFA $=$ TKJISART $(1,0-U * U) \star * 3$

BETA $=T K J \star U /(V(J) * S A R T(1.0-U * U) \star * 3)$

DO $247 L=1, J 1$

$A L F A=A L F A+T H K(L) * V(J) * V(J) /(V(L) * V(L) \star S R T B K(V(J), V(L), U) * * 3)$

247 CONTINUE

DTOD (I) $=$ BE TA/ALFA

$\operatorname{DTDH}(I)=(1.0-V(J) * U * D T D D(I)) /(V(J) * \operatorname{SORT}(1.0-U * U))$

$\operatorname{MODE}(I)=4$

300 CONTINUE

310 WRITE $(6,530) N, H, J, T K J, C D(L), V(L), L=1, N)$

530 FORMAT $(1 H-, 7 X, 2 H N=, 13,5 X, 2 H H=, F 7,2,3 X, 2 H J=, 13,2 X, 4 H T K J=, F 7,2,11$ $110 X, 5 H D E P T H, 10 X, 8 H V E L O C I T Y, 1,(8 X, F 7,3,10 X, F 7,3))$

315 WRITE $(6,535)(I, D E L T A(I), T(I)$, DTDD $(I)$, OTDH $(I), M D O E(I), 1=1, \operatorname{KREC})$

535 FORMAT $(1 H O, 4 X, 1 H I, 5 X, 8 H D E L T A(I), 10 X, 4 H T(I), 7 X, 7 H O T O D(I)$.

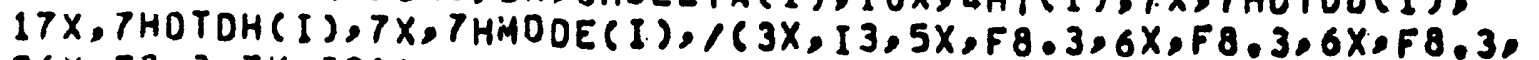

$26 x, F 8,3,7 x,(3))$

6 TEST FOR COMPLETION OF RUNS WITH DIFFERENT DEPTHS

320 IF $(H M A X-H) 325,325,321$

$321 H=H+D E L H$

322 GO TO 51

325 STOP

END

$1 *$

//GO.SYSIN OD *

$3.900^{1.000} 0.000^{2.500} 25.000$

$5.000 \quad 3.100$

$6.800 \quad 11.200$

8.25014 .800

$30.000^{10.000} 50.000^{5.000} 80.000^{10.000} 100.000^{15.000} 150.000^{20.000}$

11 
IEF 28.5I

IEF 295 I

IEF 28 5 I

IEF285 I

IEF 285I

IEF285 I

IEF285I

IEF285 I

IEF285 I

IEF 285I

IEF285I

IEF295 I

$1 / 60$

I/FTO IFOO

//FTO2F0OL

I/FTOSFOOI

I/FTD 4 FOO I

I/FTOSFOOI DD

//FTOGFOOL DD

//FTOTFOOI DD UNIT=SYSCP

//GO.SYSIN DD *

IEF236I ALLOC. FOR TRAVORIV, GO

IEF237I $P G M=* . D O$ ON 3.30

IEF237I FTOIFIOI ON ICO

IEF 237 FT $22 F 001$ ON 330

IEF237I FTO3FDOI ON 330

IEF237I FTO4FOOI ON 330

IEF237I FTOSFDOI ON OOC

IEF237 I FTO7FOOI ON 000

IEF 237 I FT13FO01 ON 330
DELETED

KEPT

KFPT

KEPT

PASSEO

SYSOUT

coson

0300

nO०००

joco

noon

onons

0000

0000

0000

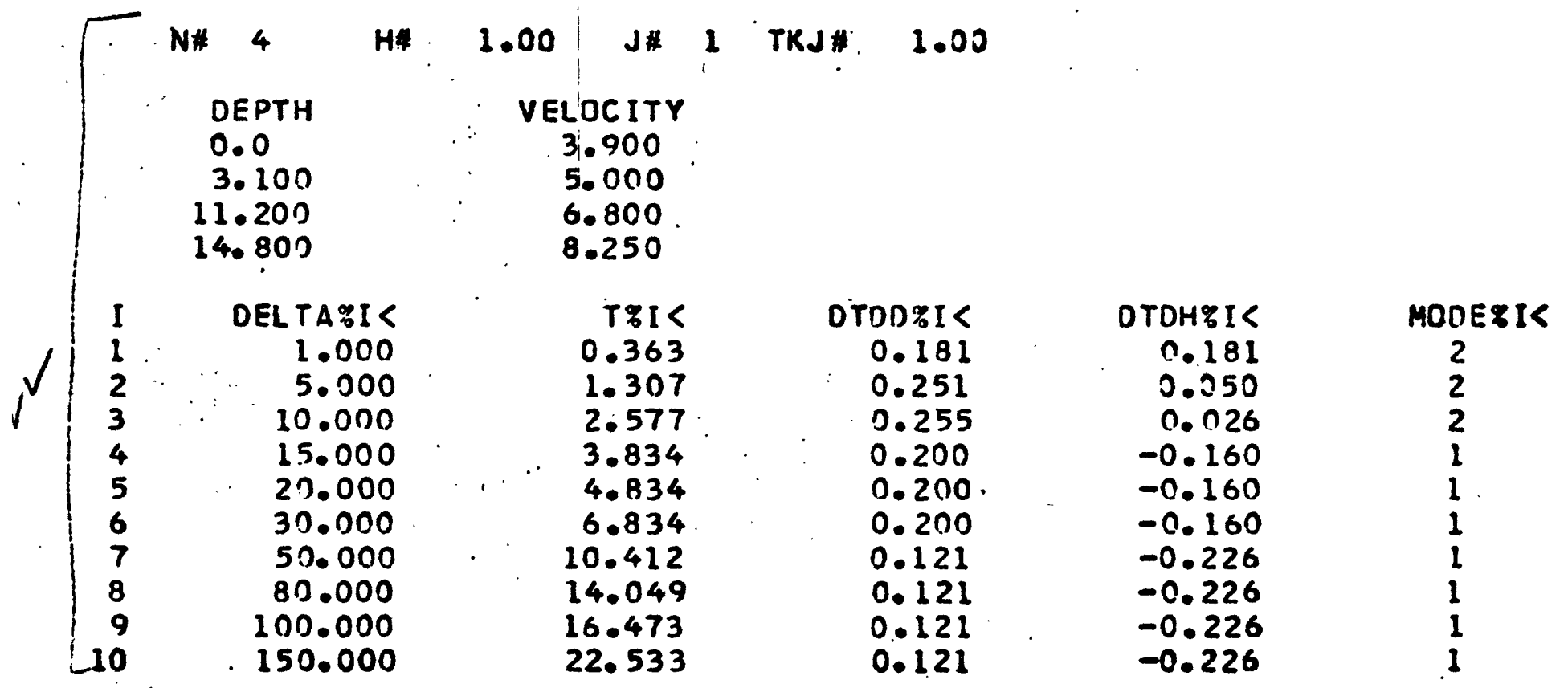




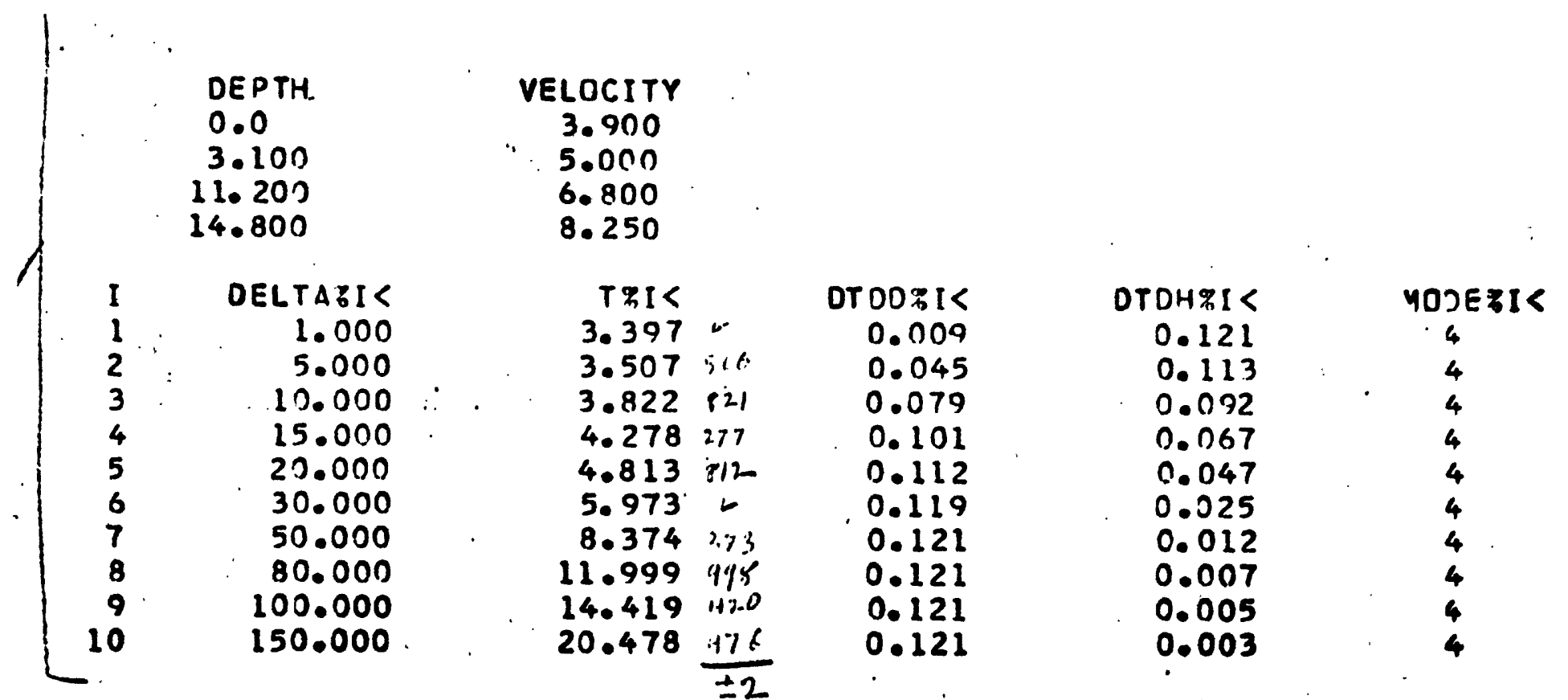

H* 21.00 J\# 4 TKJ\# 6.20

\section{DEPTH}

0.0

3. 100

11.200

14. 80 n

DELTA: I $<$

1.000

5.000

10.000

15.000

20.000

30.000

50.000

80.000

100.000

150.000
VELOCITY

3.900

5.000

6.800

8. 250
DTDH\%I $<$

0.121

0.115

0.100

0.081

0.063

0.039

0.020

0.011

0.009

0.005

\section{MOJE\%IL}

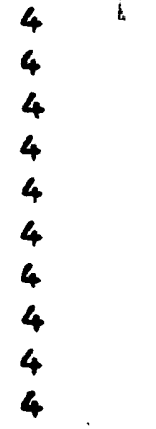

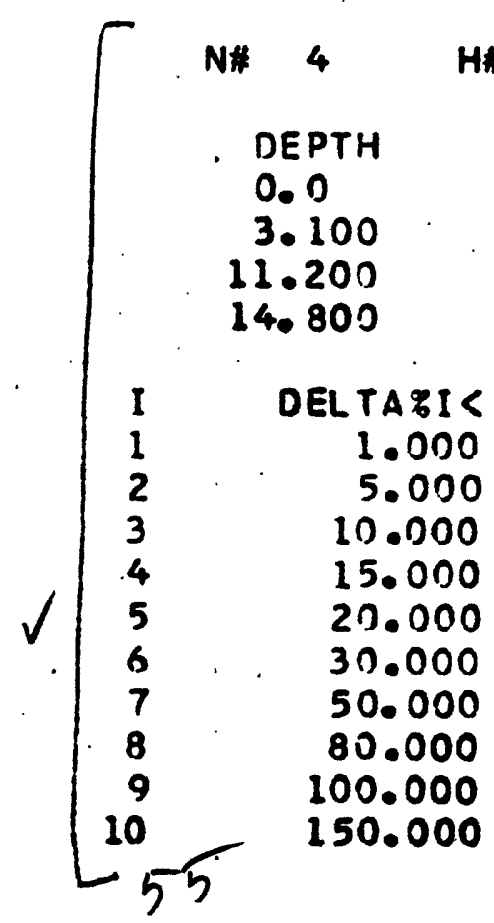

H\# 23.50 J\# 4 TKJ\# 8.70

$$
\begin{gathered}
\text { VELOCITY } \\
3.900 \\
5.000 \\
6.800 \\
8.250
\end{gathered}
$$

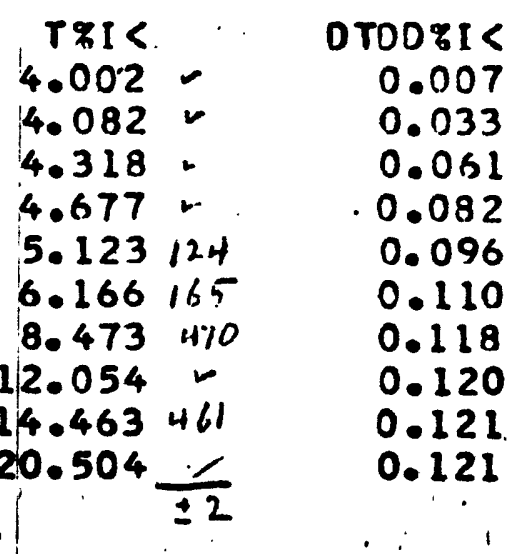

DTOH\%I<

0.121

0.117

0.105

$0.09 n$

0.074

0.050

0.027

0.016

0.012

0.008
MODEFTL

4

4

4

4

4

4

4

4

4 
NH 4 H* 26.00 J\# 4 TKJ* 11.20

DEPTH

0.0 .

3.100

11.200

14. 800

VELDC ITY

3.900

5.000

6.800

8.250

DELTATI

T\%I

DTDD\% I <

0.006

5.000

$4.305 \leftarrow$
$4.375=$

10.000

$4.585 \mathrm{~s} \pi 4$

0.029

4.910 inf

0.054

0.074

20.000

0.089

6.303304

30.000

0.106

8.550 544

0.116

80.000

$12.099 \sim$
14.497498

0.120

150.000

$20.526 \quad 525$

DTDH\%I

0.121

0.118

0.108

0.096

0.082

0.060

0.034

0.020

0.015

MONEYIS

4

4

4.

4

4

4

4

4

0.010

4

0.121 
Calculation of the plane-wave substitute solution

(YELAZ)

Let a plane wave, from a distant source at an azimuth $\psi$ from the cluster and with a speed of $V$ across the cluster strike station 1 at $t_{1}$ (nearest), station 2 at $t_{2}$ (farthest) and station 3 at $t_{3}$ (intermediate). Let the azimuths and distances of stations 2 and 3 (from station 1) be $\theta_{2}, l_{2}+\theta_{3}, l_{3}$, respectively. Let $\varphi\left(=\psi-\frac{3}{2} \pi\right)$ be the azimuth parallel the advancing wave front.

$$
\begin{aligned}
& t_{2}-t_{1}=l_{2} \sin \left(\theta_{2}-\varphi\right) / V \\
& t_{3}-t_{1}=l_{3} \sin \left(\theta_{3}-\varphi\right) / V
\end{aligned}
$$

whence, el imitating $V$ and setting $Y=\frac{t_{3}-t_{1}}{t_{2}-t_{1}} * \frac{l_{2}}{l_{3}}$

$$
\begin{aligned}
& \sin \left(\theta_{3}-\varphi\right)=r \sin \left(\theta_{2}-\varphi\right) \\
& \tan \varphi=\frac{\sin \theta_{3}-r \sin \theta_{2}}{\cos \theta_{3}-r \cos \theta_{2}^{\prime}}
\end{aligned}
$$

(See sketch D)

Thus,

$$
\begin{aligned}
& \varphi=\tan ^{-1}\left(\frac{\sin \theta_{3}-r \sin \theta_{2}}{\cos \theta_{3}-r \cos \theta_{2}}\right) \\
& V=\frac{l_{2} \sin \left(\theta_{2}-4\right)}{t_{2}-t_{1}}
\end{aligned}
$$


VELAR SKETCH D

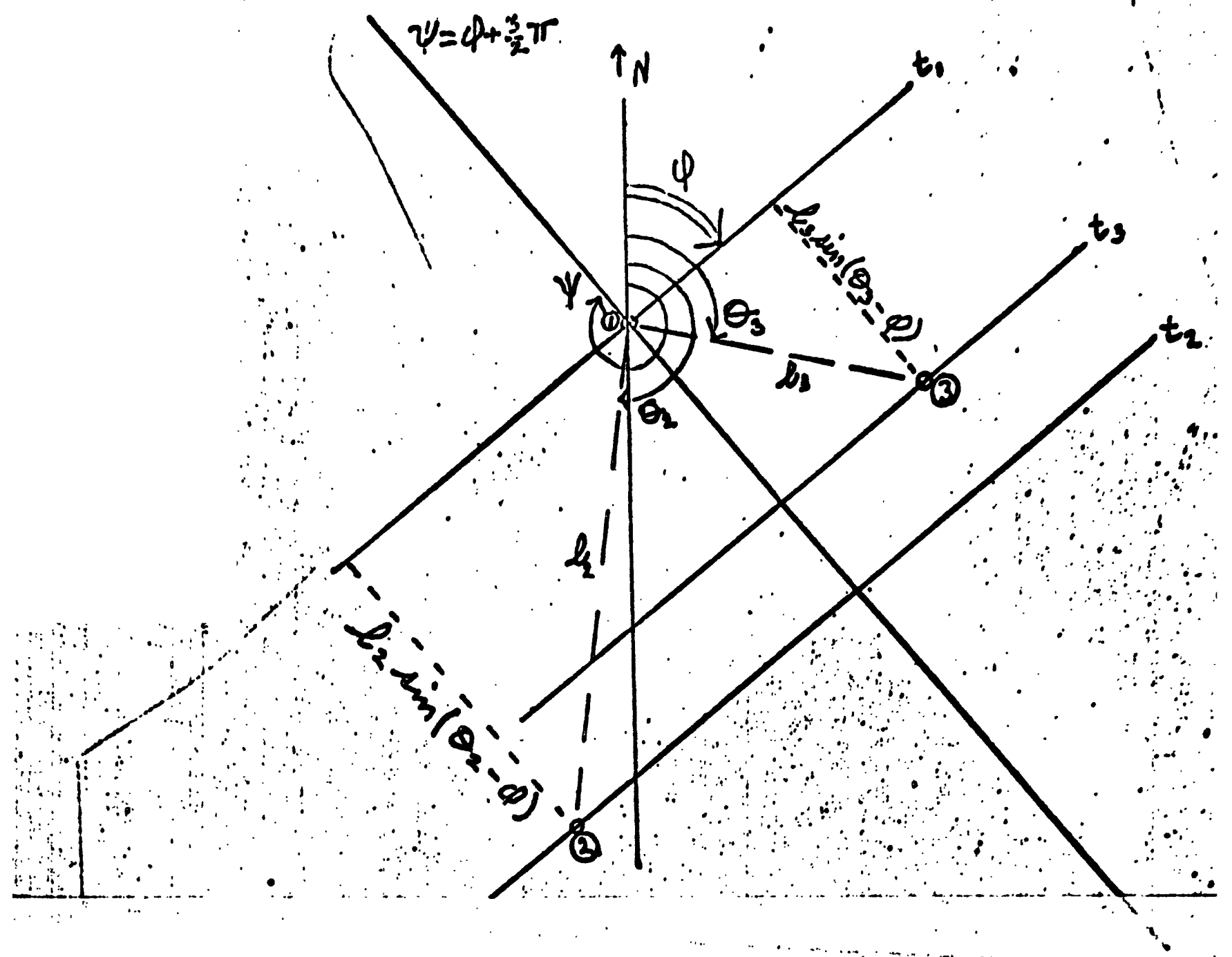

Diagram illustrating notation used. in the VELAZ subroutine

58 
Let $T_{i}=l_{i} \sin \left(\theta_{i}-\varphi\right) / V=\left(t_{i}-t_{1}\right)_{c}$ be the calculated traveltime between stations 1 and $i$.

Let $\tau_{i}=\left(t_{i}-t_{1}\right)$ be the corresponding observed traveltime.

Let $F_{i}=\tau_{i}-T_{i}$, the station 1 to station $i$ travel time anomaly.

$T_{i}$ is a function of $V$ and $\phi$ (and hence $F_{i}$ is also). In any adjustment of $V$ and $\varphi, \quad d F_{i}=-d T_{i}$.

Let $E_{i}$ be the residual that remains after an adjustment of $T_{i}\left(E_{i}=F_{i}+d F_{i}\right)$. Then

$$
\begin{aligned}
E_{i} & =F_{i}-d i T_{i} . \\
d T_{i} & =\frac{\partial T_{i}}{\partial V} d V+\frac{\partial T_{i}}{\partial \phi} d \phi \\
\frac{\partial T_{i}}{\partial V} & =-\frac{l_{i} \sin \left(\theta_{i}-\varphi\right)}{V^{2}}, \frac{\partial T_{i}}{\partial \varphi}=-\frac{l_{i} \cos \left(\theta_{i}-\varphi\right)}{V} \\
E_{i} & =F_{i}+\frac{l_{i} \sin \left(\theta_{i}-\varphi\right)}{V^{2}} d V+\frac{l_{i} \cos \left(\theta_{i}-\varphi\right)}{V} d \phi .
\end{aligned}
$$

Let $\quad \alpha_{i}=\frac{l_{i} \sin \left(\theta_{i}-\varphi\right)}{V^{2}}, \quad \beta_{i}=\frac{l_{i} \cos \left(\theta_{i}-\phi\right)}{V}$, $y_{1}=d V$, and $y_{2}=d \varphi$.

Then $E_{i}=F_{i}+\alpha_{i} Y_{1}+\beta_{i} Y_{2}$

To minimize $\sum E_{i}^{2}$ we must have

$\frac{\partial}{\partial y_{1}} \sum E_{i}^{2}=0$ and $\frac{\partial}{\partial y_{2}} \sum E_{i}^{2}=0$.

Thus

$$
\sum \frac{\partial E_{i}}{\partial Y_{1}} * E_{i}=0 \text { and } \sum \frac{\partial E_{i}}{\partial Y_{2}} * E_{i}=0 \text {. }
$$

59 


$$
\begin{aligned}
& \frac{\partial E_{i}}{\partial y_{1}}=\alpha_{i}, \frac{\partial E_{i}}{\partial y_{2}}=\beta_{i} \\
& \sum \alpha_{i} E_{i}=\left[\alpha_{i} \alpha_{i}\right] y_{1}+\left[\alpha_{i} \beta_{i}\right] \gamma_{2}+\left[\alpha_{i} F_{i}\right]=0 \\
& \sum \beta_{i} E_{i}=\left[\beta_{i} \alpha_{i}\right] y_{1}+\left[\beta_{i} \beta_{i}\right] \gamma_{2}+\left[\beta_{i} \dot{F}_{i}\right]=0
\end{aligned}
$$

Let

$$
\begin{array}{ll}
A_{11} & =\left[\alpha_{i} \alpha_{i}\right], A_{12}=\left[\alpha_{i} \beta_{i}\right], B_{1}=-\left[\alpha_{i} F_{i}\right], \\
A_{21}=\left[\beta_{i} \alpha_{i}\right], & A_{22}=\left[\beta_{i} \beta_{i}\right], B_{1}=-\left[\beta_{i} F_{i}\right] .
\end{array}
$$

Then

$$
\begin{aligned}
& A_{11} y_{1}+A_{12} y_{2}=B_{1} . \\
& A_{21} y_{1}+A_{22} y_{2}=B_{2}
\end{aligned}
$$

Let

$$
D E T=A_{11} A_{22}-A_{21} \cdot A_{12} \text {. }
$$

Finally

$$
\begin{aligned}
& y_{1}=\frac{B_{1} * A_{22}-B_{2} * A_{12}}{D E T}=d V \\
& y_{2}=\frac{A_{11} B_{2}-A_{21} B_{1}}{D E T}=d \varphi
\end{aligned}
$$

Apply these corrections to $V$ and $Q$, and then recalculate the residuals $F_{i}$ and proceed with another round of correction. When the adjustment in $Q, d Q$, falls below 0.0001 rad, discontinue the adjustment.

$$
\text { calculate } A A F=\sum_{i=1}^{N}\left|F_{i}\right| / N \text { as a measure of "fit+". }
$$

60 
Determination of Magnitudes of Mlcraearthquakes Recorded at Small Epicentral Distances

(MAGNTD)

In his pioneering studies of southern Callfornla earthquakes during the early l930's, C. F. Richter observed that the manner in which the maximum trace amplitude, recorded by a standard short-period Wood-Anderson seismograph, diminished with increasing epicentral distance was independent of the size of the earthquake. Thus, $\log B$ vs $\Delta$ plots $(B=$ maximum trace amplitude recorded on the Wood-Anderson and $\Delta=$ epicentral distance) for earthquakes of various sizes were of a single shape but were displaced, without rotation, relative to each other parallel to the $\log B$ axis: the vertical separation of the curves for two earthquakes being equal to the logarithm of the ratlo of their amplitudes. The separation of the curves for two earthquakes is a convenient measure of their difference in size, or (as it was defined by Richter) their difference in magnitude.

Richter (1935) defined magnitude as follows: "The magnitude of any shock is taken as the logarlthm of the maximum trace amplitude, expressed in microns, with which the standard short-period torsion sel smometer (To $=0.8 \mathrm{sec}, V=2800, h=0.8$ ) would register that shock at an epicentral distance of 100 kilometers." He plotted $\log B$ vs $\Delta$ curves for earthquakes recorded on the southern Callfornla network during January 1932 (about 50 earthquakes with magnitudes between 0.5 and 4.5). He then fitted a curve to the $\log B$ vs $\Delta$ dlagram which, at every distance, was parallel the dota curves and crossed the $\log B$ axis at $\Delta=100 \mathrm{~km}$. Thls curve (cal! it the $\log B_{0}$. vs $\Delta$ curve) corresponds 
to that for an eàrthquake with magnitude zero. The "kit" for computation of earthquake magnitudes was then complete. For an - earthquake recorded with maximum amplitude $B_{1}$ at distance $\Delta_{1}$, $M_{1}=\log B_{1}-\log B_{0}$, where $\log B_{0}$ is read from the curve at distance $\Delta, \cdot$

To check the validity of the $\log B$ vs $\Delta$ curve, Richter applied the method outlined above to calculate magnitudes for 21 previously studied southern California earthquakes, with magnitudes from 3.2 to 5.2, recorded at distances between 44 and $520 \mathrm{~km}$. He found that data from these earthquakes did not suggest any need to revise the $\log B$ vs $\Delta$ curve but did show the need for individual station corrections that ranged from +.25 unit (Pasadena N-S) to - .40 unit (Tinemeha E-W). Richter cautioned that the $\log B$ vs $\Delta$ curve was only poorly established for distances léss than $50 \mathrm{~km}$; and below $25 \mathrm{~km}$ it was not established at all.

An attempt to establish the curve for smaller epicentral distances was described by Gutenberg and Richter (1942) in conjunction with further manipulation of the magnitude concept. They showed that $\log B^{\prime}-M+2 \log D \approx$ const for $\triangle$ between 22 and $525 \mathrm{~km}$ Cassuming a focal depth, $h$, of $18 \mathrm{~km}$, with $D=\sqrt{\Delta^{2}+18^{2}}$, where $M$ is the earthquake magnitude and where $B^{\prime}$ is the maximum trace amplitude of short-period waves on the strong-motion torsion sei smometers at Pasadena). Thus, $B^{\prime} D^{2} \approx$ const, and this relationship can be used to calculate $\log B_{0}$ for $\Delta$ less than $50 \mathrm{~km}$ if we assume a standard focal depth $118 \mathrm{~km}$ was chosen). For an earthquake with a focal depth significantly different from $18 \mathrm{~km}$ recorded at a smoll eplcentral distance, the magnitude computed 
on the basis of the extended $\log B_{0}$ curve could be grossly in error. We might also protest that the method used to establish the relationship $B^{\prime} D^{2} \approx$ const involved the use of only one instrument and a whole serles of earthquakes of increasing magnitude and distance. Thus, varlations in the relative excltation of long-vs short-period waves, variations in the rate of attenuation with distance. of long- vs short-period waves, etc., are inextricably involved in the relationship obtained, which in turn is used to extend the $\log B 0$ vs $\Delta$ curve to short distances for use with very small earthquakes.

Several extremely thorny problems arise when one attempts to compute magnitudes for microearthquakes recorded on modern seismographic equipment at short distances. These problems include:

1. focal depth, cannot properly be Ignored at short distances so we need a relationship between amplitude and hypocentral (not epicentral) distance for the zero magnitude earthquake.

2. the response of the Wood-Anderson seismograph is implicitly included in Richter's definition of magnitude. These Instruments are quite inadequate for the study of microearthquakes. Moreover, their sensitivity is so much lower than most instruments used in microeorthquake studies that it is difficult to "callbrate" the new systems for magnitude calculations by simple overlap of observations.

3. the Wood-Anderson records, horlzontal ground motion, whereas the most widely deployed microearthquake sel smographs are vertical component Instruments.

4. unlike teleselsms, for which quite specific wave types can be identifled (P, PP, $\left.S_{,}, \varphi_{,}, C_{i}\right)$ and used for assignment of magnitudes, local 
earthquakes generally cannot be reliably resolyed into their component waves. The waves which are largest in any given range of distance (indeed those which can be identified at alil) vary from region to region depending on the detalls of crustal structure. In very general terms, the direct S-wave (through the upper crust) is usually largest from 0 to $100-200 \mathrm{~km}$. Between 100 and $200 \mathrm{~km}$ (varying with crustal structure and focal depth) the S-wave reflection from the base of the crust emerges with much larger (up to 10 times) the amplitude of the direct S-wave. Beyond the point of emergence of $S_{M} S$, this phase diminishes rapidly; and within the next $100 \mathrm{kn}$ it has dropped into the background and waves with more complex paths become the largest on the sel smogram.

5. attenuation of seismic waves within the crust varies widely from region to region, and assignment of magnitudes on the basis of waves with paths predominantly within the crust will be strongly affected by such varlations: the $\log B_{0}$. vs $\Delta$ curve, in short, should vary.. from region to region.

Subroutine MAGNTD was written to assign magnitudes compatible with the Richter "local" magnitude to microearthquakes recorded on the USGS portable seilsmograph cluster. The method employed to achieve this goal can be outilined as follows:

1. the exponent, $k$, of hypocentral distance in a law $A D^{k}=$ const ( $A=$ ground amplitude corresponding to the maximum vertical component trace amplitude, $D=$ hypocentral distance) was evaluated on the basis of about 100 eerthquakes recorded on the portable cluster in central Callfornle at distances of 0 to $150 \mathrm{~km}$ and for focal depths of $\approx 0$ to 
$14 \mathrm{~km}$. It was found that $k=1.7 \mathrm{fit}$ the data (earthquake by earthquake) quite closely and that $k$ does not appear to depend on focal depth nor on magnitude.

2. the $\log B_{0}$ vs $\Delta$ curve of Richter was converted to a $\log B_{0}$ vs $\log D$ plot (where $D=\sqrt{\Delta^{2}+18^{2}}$ ) and lines with slopes of 1.5, 1.7, and 2.0 were drawn through the plotted points to test the adequacy of a relationship of the form $B_{0} D^{k}=$ const to express the zero magnitude earthquake amplitude vs distance relationship. Beyond $200 \mathrm{~km}$

$k$ is greater than 2. Between 50 and $150 \mathrm{~km}$, a value $k=1.5$ fits the data quite well. For $K=1.7$, the overall flt from $30 \mathrm{~km}$ to nearly $300 \mathrm{~km}$ is adequate: no point lies more than 0.10 unit ( of $\log B_{0}$ ) off the curve. The plotted points lle above the curve for $D$ less than $40 \mathrm{~km}$ and $D$ between 80 and $250 \mathrm{~km}$. Between 40 and $80 \mathrm{~km}$ and beyond $250 \mathrm{~km}$, they lie below the $k=1.7$ curve. At distances smaller than 30 or $40 \mathrm{~km}$, the $B_{0}$ values are too poorly established to be considered seriously.

If we divide $B_{0}$ by 2800 (i.e., by the static magnification of the Wood-Anderson) to obtain $A_{b_{\mu}}$. the equation representing the ground amplitude (in microns) of the zero magnitude earthquake can be written $A_{0 \mu} \times D^{1.7}=0.71 \quad$. This relationship is not independent of the WA response curve because for earth perlods greater then $0.8 \mathrm{sec}$, the magnification of this instrument falls rapidiy from its static magnification of 2800 .

The difference in response of the USGS portable systems from that of the Wh results from severol factors: (a) gross difference in sensitivity, (b) restricted passband of the portable system electronics- 
ca 17 cps to 0.5 cps, (c) displacement "velocity" response of the EVI7 selsmometers in the portable system ys displacement response of the WA. As in the derivation of the equation in $A_{0}$ above, it is convenlent to ignore the portion of the perlod-dependency in the EVIT response that results from the tendency of the suspended mass to "follow" the ground motion at earth perlods that are longer than the free period of the seismometer $(1.0 \mathrm{sec})$. Such a simplification in the reduction of recorded amplitude to ground amplitude in the case of the portable system introduces an error that is very nearly the same as that introduced. in the derivation of $\mathrm{Aog}_{\mu}$, above. Consequently, the logarithm of the maximum recorded ground motion, as calculated from the portable system selsmogram, minus the logarithm of $A_{0 \mu}$ for the corresponding value of $D$, should yield the same magnitude as would have been obtained from a super-sensitive Wood-Anderson.

4. Since the WA measures the horizonta! component of ground motion and the EVI7 measures the vertical component, we must correct the computed magnitudes for a systemmatlc difference in maximum horizontal and vertical recorded amplitudes. A number of the portable systems employed to establish the value of $k$ included horizontal (EVI7-H) seismographs as well as verticals. At those stations the ratios $X_{H} / P_{Z}$ and $X_{H} / X_{Z}$ were measured for annumber of events. The first ratio varied from less than 0.5 to about 8 , with a median value of 2.5 (the distribution was bimodal, with peaks at 1.2 and 3.3$)$. The second ratio varled from 0.2 to 8 , with a median value of 1.75 (irode $=1.25$ ). As only about 90 observations were used In this study, further work is required. Tentative corrections are +.40 to magnitudes based on $P_{z}$ and + 25 to magnitudes based on $X_{z}$. 
An analysis of the portable system response shows that record amplitude can be converted to ground-motion amplitude by the relationship

$$
A_{\mu}^{\prime}=1.03 *\left(T \times S / C_{10}\right) * 10^{-2}
$$

for earth perlods shorter than about 1.0 sec, where

$$
\begin{aligned}
& A_{\mu}^{\prime} \equiv \text { ground amplitude in microns } \\
& S \text { = maximum trace amplitude in } \mathrm{mm} \text { (peak to trough). } \\
& C_{10}=\text { trace amplitude in } \mathrm{mm} \text { (peak to trough) resulting } \\
& \text { from a } 10 \mu V \text { (rms) signal introduced into the. } \\
& \text { seismic amplifier in lleu of the seismometer } \\
& \text { output. } \\
& T=\text { period (in seconds) of the wave with amplitude } s \text {. }
\end{aligned}
$$

The logarithm of $A_{\mu}^{\prime} / A_{b_{\mu}}$ is the magnitude of the earthquake. Thus,

$$
M_{\text {ag }}=\log A_{\mu}^{\prime}-\log A_{0 \mu}=\log \left(1.03 \times \frac{S \times T}{C_{10}} \times D^{1.7}\right)-1.85
$$

This relationship would apply to the calculation of magnitude using the maximum amplitude on the horizontal EVI7-H trace. To shift to the EV17 vertical trace the constant should be changed from -1.85 to -1.60 If the maximum vertical amplitude is used or to -1.45 if the P-wave amplitude is used.

In subroutine MAGNTD provision is made for the use of both P and the maximum (nxp) on the vertical component for the computation of magnitude. The megnitude equation is written in the form: 
$M A G P=\log \left(C N S T * \frac{S \times T}{C_{10}}\right)+P W R P \times \log D^{2}-Z P M A G$ for $P$, and

$M A G X=\log \left(C N S T * \frac{S \times T}{C_{10}}\right)+P W R X \times \log D^{2}-Z \times M A G$

for $x$.

The parameters CNST, PWRP, ZPMAG, PWRX, and ZXMAG are read into the program at execution time. Thus, the exponent of $D$ and the constants (composed of many factors, including instruments sensitivity. etc.) can be adjusted as required by variations in instrumentation and region.

The constant $(0.71)$ in the equation $A_{0 \mu} \times D^{1.7}=0.71$ is sensitive to the distance range over which we choose to fit the power law most closely to the zero magnitude reference data. Because magnitude is "defined" at $\Delta=100 \mathrm{~km}$. It is tempting. to draw the power-law curve through the $\log B_{0}$ point at $\Delta=100 \mathrm{~km}$. For the microearthquakes recorded by the portable system, most observations are at distances smaller than $100 \mathrm{~km}$--averaging $30 \mathrm{~km}$ or so. Thus, the curve resulting in the constant 0.71 was drawn to match the $B_{0}$ vs $D$ data in the range of 30 to $100 \mathrm{~km}$.

In view of the difference in attenuation from region to region, it seems that $100 \mathrm{~km}$ is unfortunately large for a magnitude-reference distance if we truly wish an earthquake's magnitude to be simply related to the energy radrated from the focus. Use of a smaller reference distance would require a higher precision in depth determination that is generally attainable at present, however. 


\section{Statistical Calculations}

Statistical Calculations for Individual Earthquakes:

To characterize the quality and rellabllity of individual: hypocentral solutions, a variety of residuals and statistical parameters are calculated. These include:

$F_{i}=\tau_{i}-t_{i}=$ the arrival time residual at station $t$ $A A F=\sum_{i=1}^{N}\left|F_{i}\right| / N=$ the mean devlation

$A V R=\sum_{i=1}^{N} F_{i} / N=$ the average residual

SDP $=\left(\frac{\sum_{E=1}^{N} F_{i}^{2}}{N-M M-1}\right)^{1 / 2}=$ the standard deviation of the arrival time residuals

$S D X=S D P_{x}\left(A_{11}^{-1}\right)^{1 / 2}=$ standard error in longitude $(\mathrm{km})$

SDY $=\operatorname{SDP} \times\left(A_{22}^{-1}\right)^{1 / 2}=$ standard error in latitude $(\mathrm{km})$

$S D Z=S D P \times\left(A^{-1} 3\right)^{1 / 2}=$ standard error in depth (km)

$$
\begin{aligned}
& \text { SOT }=\operatorname{SOP}_{\times}\left(A_{44}^{-1}\right)^{1 / 2} \text { standard error in origin time (sec) } \\
& N=\text { number of observations. (with combined weights } \\
& \text { greater than } 0.11 \text {. } \\
& M M=\text { number of hypocentral parameters adjusted. } \\
& A_{11}^{-1}, e^{2} c_{3}=\text { appropriate elements on the principal diagonal } \\
& \text { of the inverse matrix of coefficients of the } \\
& \text { unknowns. } \\
& \text { (RSPMG) } i=\text { station } 1 \text { P-mag-average P-mag. } \\
& (R S \times M G)_{i}=\text { station } 1 \times \text {-mag-overage } x \text {-meg. }
\end{aligned}
$$




\section{Statistical Summary Calculatlons for a Batch of Earthquakes}

A number of counters and sum registers and a variety of tests have been included in the main program to permit the calculation of average residual, standard deviation of the residual, and standard error of the mean residual for the residuals of arrival time, Pmagnitude, and X-magnitude at each station for which an adequate number of observations are avallable in a batch of earthquakes.

For station 1 (arrival-time-residual statistics):

$$
\begin{aligned}
& \operatorname{AVRES}_{i}=\sum_{j=1}^{L}\left(F_{i}\right)_{j} / L \\
& \text { SDRES }_{i}=\left[\frac{\left(L \times \sum_{j=1}^{L}\left(F_{i}\right)_{j}^{2}\right)-\left(\sum_{j=1}^{L}\left(F_{i}\right)_{j}\right)^{2}}{4(4-1)}\right]^{1 / 2} \\
& \text { SEM }_{i}= \\
& \text { SDRES. } / L^{1 / 2}
\end{aligned}
$$

The equations for $P$-magnitude and $X$-magnitude are analogous.

For inclusion in the statistical summary, an earthquake must be recorded by at least KTTA stations, have an AAF less than TAAF, and have been located with fewer than IIT iterations. For an individual observation to be included in the summary it must not be larger than TFR (for an arrival-time residual) or AMTST (for a magnitude residual) and must have a combined weight (of the P-phase) of at least TWT (for an arrival-time tosidual).

KTTA, TAMF, IIT, TFR, AMTST, and TWT are parameters read in at execution time. 
These data can be used to correct for obvlaus persistent station anomalies. For the arrival-time residual this correction can be made by adding the average residual for a station to the "station delay" on the station parameter IIst.

Provision has also been made to include a station and its data in a batch of earthquakes in such a manner that it is not used in the adjustment of the hypocenter but is treated normally in other respects, including the calculation of summary statistical parameters. Stations listed in the "KOMIT" list on the parameter card extension DX2 are treated in this manner.

Restrictions and Termination Conditions Applied in the Adjustment of .. Hypocentral Parameters in HYPOLAYR

1. Depth is not adjusted:

a. on the first iteration.

b. if the range in $\partial T / \partial Z$, RAH, is less than 0.02 .

c. If the previous adjustment in epicenter is greater than $10 \mathrm{~km}$ :

2. Depth is not permitted to become negative (focus in air). Any calculated correction that would place the hypocenter above ground is scaled down so that the hypocenter is ralsed $6 / 10$ of the distance to the surface. Horizontal and time adjustments are also scaled down, but no farther than $4 / 10$ of the values originally computed.

3. Adjustment is not terminated prior to the 5th iteration.

4. If depth control has been lost by the 4th Iteration, the depth is returned to ZTR before the 5th.

5. If $\mid$ AVR $\leqslant$ AYLT $(\ddot{0.0 .0 .} \leqslant 0.002)$, 
$\therefore$ a. adjustment is terminated after 5 iterations it AAF < AFLT

$(0.9 .,<0.10)$ and DAAP $<$ ADLT $(. . .9 .,<0.005)$.

b. adjustment is terminated after 8 iterations if AAP $<$ AFLP $(0.9 .,<0.30)$ and DAAF $<$ ADLP $(. .9 .,<0.003)$.

6. If $\mid$ AVR $\mid \geqslant$ AVLT

a. adjustment is terminated if DAAF. < AVLT, i.e., for a stationary solution. II is set equal to "14", AVR is added to the origin time, and the arrival-time residuals and solution statistics are recalculated.

b. $\quad$ II $=12$

II is set equal to "13", AVR is added to the origin time, and the arrival-time residuals and solution statistics are recalculated. 
HYPOLAYR

List of variables

NSTA $(2,99)^{\circ}$

A4

Station name (on station list)

LAT $(2,99)$

F2.0

Station latitude, degrees

Y.AT $(2,99)^{\circ}$

F5.2

Station latitude, minutes

LON $(2,99)^{\circ}$.

F3.0

station longitude, degrees

XON $(2,99)^{\circ}$

F5, 2

station longitude, minutes

EL $(2,99)$

F4.0

station elevation, meters

OLY $(2,99)$

F5.2

station delay, seconds

MDL $(2,99)$

II

Crustal model used with station

KSITE

Number of stations in station list

VI(25)

F7.3

Layer velocity, model 1

DP1 (25)

F7.3

Depth to top of layer, model 1

NLI

Number of layers, model 1

V2(25)

F7.3

Layer velocity, model 2

.DP2(25)

F7.3

Depth to top of layer, model. 2

NL2

Number of layers, model 2

LATR

F2.0

Trial latitude, degrees

YATTR

F5.2

Trial latitude, minutes

LOTR

F3:0

Trial longitude, degrees

XONTR

F5.2

Trial longltude, mlnutes

ZTR

F5.2

Trial focal depth, km

LARED

F2.0

Latitude reduction, degrees

LORED

F3.0

Longltude reduction, degrees

DELAZ

F6.1

Test distance for colling VELAZ 
VB

MODE

LPC

'INPRIN'

IFMT

QQ

PPP

ISTS

KOLT

SMP

XNEAR

XFAR

HILO

CNST

PWRP

ZPMAG

PWRX

F5.2

F5.2

F5.2

F5.2

F5.2 equation

Multipller to convert low-gain-trace amplitudes

System sensitivity factor

Distance exponent in "pn amplitudedistance law

Constant depending on "0" magnitude earthquake P-amplitude

Distance exponent in " $X$ " amplitudedistance law

F5.2 Constant depending on "0" megnitude earthquake P-omplltude 


\begin{tabular}{|c|c|c|}
\hline AVLT & F5.2 & Test value for average residual (AVR) \\
\hline AFLT & 95.2 & Pirst test value for mean deviation (MF) \\
\hline AFLP' & P5.2 & $\begin{array}{l}\text { Second test value for mean deviation } \\
\text { (AAP) }\end{array}$ \\
\hline ADLT & P5.3 & $\begin{array}{l}\text { Pirst test value for change in mean } \\
\text { deviation (DAAP) }\end{array}$ \\
\hline ADLP' & F5.3 & $\begin{array}{l}\text { Second test value for change in mean } \\
\text { deviation (DAAF) }\end{array}$ \\
\hline
\end{tabular}

F10.3 Test value for mean deviation in station section

TFR

F10.3

Test value for station residual in station section

TWT

FI0.3

Test value for combined weight in station section

AMTST

Fio.3

Test value for magnitude residual in station section

IIT

Test value for number of iterátions

in station section

KTTA

I5

Test value for number of observations

in station section

KOMIT

Number of stations on "neglect" list

NOMIT(99) 
NL

$V(25)$

$D P(25)$

THK(25)

$\operatorname{TID}(25,25)$

$D 10(25,25)$

THK1 (25)

$\operatorname{TID1}(25,25)$

$\operatorname{DID1}(25,25)$

THK2(25)

$\operatorname{TID2}(25,25)$

$\operatorname{DID} 2(25,25)$

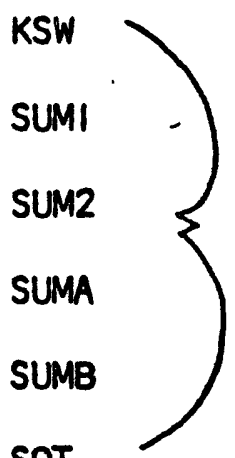

SQT

MSTA (99)

QSABE(99)

$W(99)$

KDATE(99)

JHR(99)
Number of layers

Velocity of $P$ in layer

Depth to top of layer

Thlckness of layer

"Boundary" source intercept

"Boundary" source critlcal distance)

distance

Layer thickness, model 1

"Boundary" source Intercept, model 1

"Boundary" source critical distance, model 1

Layer thlckness, model 2

"Boundary" source Intercept, model 2

"Boundary" source critical distance

model 2

TPAR Internal utility variables

Station name on phase list

Alphameric tag, e.g., "IPU"

F2:1

Weight (quality of Parrival)

Date (year, month, day)

12
Hour 


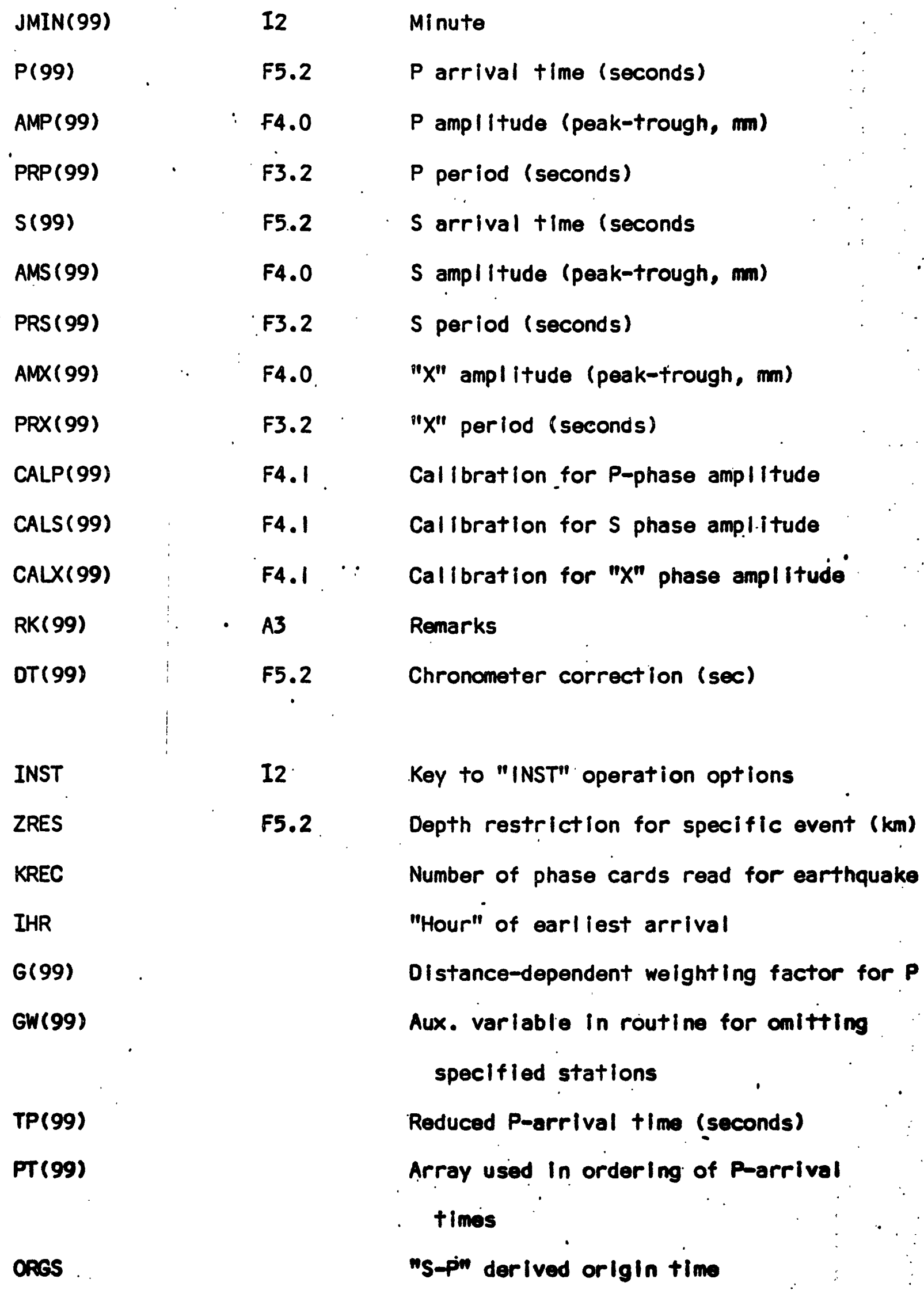


KOLT

KO(99)

NEAR

PMIN

MFAR

PFAR

KALX

LHY

ORG

LONEP

XONEP

LATEP

YATEP

Z

ZHLAT

PH

DIST1 199:

TH1(99)
Flag indicating existence of ORGS

Number of stations in ordered Petime array

Array of indices of stations in ordered $\ddot{p}$-time array

Index of earl lest station

P-arrival time at earllest station

Index of latest station in ordered

P-array

P-arrival time at latest station in ordered P-array

Index of ordered array station farthest from line jolning station NEAR. and station MFAR

Flag Indicating PREHY option used

Origin time in seconds (reduced)

Eplcenter longitude (degrees)

Epicenter longitude (minutes)

Epicenter latitude (degrees)'.

Epicenter latitude (minutes)

Focal depth $(\mathrm{km})$

Reduced latitude (mInutes) of station NEAR

$\mathrm{Km}$ per minute of longitude at ZHLAT

Distance of station from station NEAR

Azimuth of given station from station NEAR 
KALMX

KaLMN

ALTMX .

ALTMN

XH(99)

YH(99)

$\operatorname{AP}(3,3)$

$B P(3)$

DETAP

XNOT

YNOT

T1

ZSQ

DST1

DST2
Distance from line between station NEAR and station KOLT

Index of station farthest to "right" : of Iline between station NEAR and station KOLT

Index of station farthest to "left" of line between station NEAR and station KOLT

Distance of station KALMX from line between station NEAR and station. KOLT

Distance of station KALMN from line between station NEAR and station KOLT

Distance of station (in km) west of station NEAR

Distance of station (in km) north of station NEAR

Coefficlents of unknowns in Inglada's equation

Known's in Inglada's equation

Determinant of AP's

Epicenter X-coord (km)

Eplcenter Y-coord $(\mathrm{km})$

Traveltime of $P$ to station NEAR

Utility variable in PREIXX

utllity varlable in PREHY

Utillity varlablo in PREHY 
Determinant of unknowns in "reduced problem

RP2

Combination of knowns in "reduced" problem.

RP3

combination of knowns in "reduced" problem.

G1

G2

G3

G4

G5

G6

Combination of knowns in "reduced" problem

Combination of knowns in "reduced" problem

Combination of knowns in "reduced" problem

Combination of knowns in "reduced" problem

Combination of variables in "reduced" problem

Combination of variables in "reduced" probiem

G7

Combination of varlables in "reduced" problem

G8

Combination of variables in "reduced" problem

G9

Combination of variables in "reduced" problem

T1P

T1, using $-\sqrt{ }$

T1M

T1, using $+\sqrt{ }$

AG5

Utllity variable in PREHY

QSM

AQSM

QSP

AQSP

Utility variable in PREHY

UtIlity variable in PREHY

Utility varlable in PREHY

UtIllty varlable in PREHY

DEDN weighting factor 
KAZ

KZSW

II

XEP

YEP

DELMN.

.ZLAT

PP

DX(99)

DY(99)

DELTA(99)

KEY

TKJ

TINJ (25)

DIDJ (25)

XOVMax

TR(99)

$T(99)$
Flag indlcating routine used in VELAZ Switch to inhibit focal depth adjustment Iteration counter in hypocenter adjustment loop

Epicenter "N-S" grid coordinate $(+=N)$ Epicenter "E-W" grid coordinate $(+=W)$ Smallest epicenter-to-station distance Mean of epicenter and station latitudes Longitude scale factor--minutes to $\mathrm{km}$ Difference in station and epicenter $x$-grid coord

Difference in station and epicenter Y-grid coord Epicentral distance. $(\mathrm{km})$

Utility variable for selecting model

in TRVDRV

Depth of focus below top of layer Intercept of wave refracted along top - of layer from a focus in layer JL Critical distance of wave reflected from top of loyer $L$ from a focus in layer JL

Distance beyond which first arrival must be a heed wave

Colculated refrection time (tentetive) first arrival traveltime 
! DTOD

DTDH

ANIN(99)

TOJ1

LL

XBIG

XLIT

UB

UL

ARGB

ARGL

DELBIG

DELLIT

XTR

U

ARGJ

DELXTR

TEST

TDC

TOIR

ALFA

BETA

$$
\begin{aligned}
& \partial T / \partial \Delta \\
& \partial T / \partial Z
\end{aligned}
$$

Angle of incidence at the focus

Calculated traveltime of direct wave

In layer J

Iteration counter in loop to find root

of refraction equation

Utility variable in TRVDRV

Utility variable in TRVDRV

Utility variable in TRVDRV

Utility variable in TRVDRV

Utility varlable in TRVORV

utility variable in TRVDRV

utility varlable in TRVDRV

Utility variable in TRVDRV

Utility varlable in TRVDRV

Root of refraction equation

Utility variable in TRVDRV

Utility variable in TRVDRV

Utility variable in TRVDRV

Traveltime of wave from focus very

near top of layer.

Traveltime of wave from focus inside.

layer

utility varlable in TRVORV

Utility variable in TRVORV 


\begin{tabular}{|c|c|}
\hline$A X(99)$ & $\partial T / \partial X$ \\
\hline AY (99) & $\partial T / \partial y$ \\
\hline$A H(99)$ & $\partial T / \partial z$ \\
\hline$F(99)$ & Arrival-time residual \\
\hline AAF & Mean deviation of arrival times \\
\hline AAFI & Previous value of AAF \\
\hline DAAF & Change in AAF \\
\hline AWF & "Woighted" mean deviation \\
\hline KSTA & Number of stations used in a solution \\
\hline WSTA & $\begin{array}{l}\text { Sum of weights of stations used in a } \\
\text { solution }\end{array}$ \\
\hline AVR & Average residual \\
\hline ABVR & Absolute value of average residual \\
\hline WT & Combined weight $(W(1) * G(1))$ \\
\hline AVR1 & "Saved" value of AVR \\
\hline$[A(4,4)]^{\prime}$ & $\begin{array}{l}\text { Coefficient of unknowns in normal } \\
\text { equation }\end{array}$ \\
\hline$[B(4)]$ & $\begin{array}{l}\text { Coefficient of knowns in normal } \\
\text { equation }\end{array}$ \\
\hline AtMX & Maximum AH \\
\hline AHMN & MInimum AH \\
\hline RAH & Range of $A H$ \\
\hline$[0(3,3]$ & Cofactor of $A(1, j)$ \\
\hline$[C(4,4)]$ & Cofactor matrix of $[A(4,4]$ \\
\hline DETA & Determinant of cofactor matrix \\
\hline
\end{tabular}


$[Y(4)]$

MM

KOUT

- ASDX

ASDY

ASDZ

ASDT

A11 . A44

GAM

DENOM

TH1(99)

PFI

VA

KAZ

$\kappa T$

$Y 1$

Y2

FT1 (99)

AT (99)

BT(99)

AT11
Hypocenter correction vector

Renk of matrix of coefficlent of adjustment equations

Flag indicating HYCOR routine used in adjustment of hypocenter (which components adjusted)

Absolute values of the elements of the principal diagonal of the Inverse matrix of the matrix of normal equation coefficlents

Utllity variables in "reduced" HYCOR

- routines

Utility variable in VELAZ

Utility varlable in VELAZ

Azimuth of station from earliest station Angle (cW) between north and wave front Average velocity of wave front across net

Flag indicating which VELAZ routine was used

Iteration counter in adjustment loop

Adjustment in VA

Adjustment. In PFI

Residual in traveltime from earllest station to another

$\partial T / \partial V$

$\partial T / \partial \varphi$

Coefficlent in normal equations 
AT12

AT22

BT1

BT2

DEAT

PSY

'R

VH

LREC

SDP

SDX

SDY

SDZ

SDT

oso

KHR

FHR

KMIN

FMIN

SEC

TS(99)

A2(99)
Coefficient in normal equations

Coefficient in normal equations

Coefficient in normal equations

Coefficient in normal equations

Determinant of coefficient of unknowns

in normal equations

Azimuth toward source of plane wave

Depth adjustment restriction factor

Horizontal shift in epicenter

Number of stations summed in error estimate

Standard error in individual P-arrivai time

Standard error in X-coord ( km).

Standard error in Y-coord (km)

Standard error in depth $(\mathrm{km})$.

Standard error in origin time (sec)

Utility variable in M/Prog

Origin hour (reduced)

Origin hour (reduced)

Origin minute

Origin minute

Origin second

Traveltime of S-wave

Azimuth of station from epicenter 


\begin{tabular}{|c|c|}
\hline EPMG (99) & P-magnitude residuals \\
\hline EXMG(99) & $X$-magnitude residuals \\
\hline MC & Utrlity variable in MAGNTD \\
\hline MP & Utility variable in MAGNTO \\
\hline SXMAG & Utllity varlable in MAGNTD \\
\hline SPMAG & Utility varlable in MAGNTD \\
\hline RAD2 & Square of hypocentral distance \\
\hline ARGP & Utility varlable in MAGNTD \\
\hline ARGX & Utility variable in MAGNTO \\
\hline PMAG(99) & $\begin{array}{l}\text { Magnitude computed from Paphase at } \\
\text { station }\end{array}$ \\
\hline XXMG(99) & $\begin{array}{l}\text { Magnitude computed from X-phase at } \\
\text { station }\end{array}$ \\
\hline PPMG & Average PMAG \\
\hline XMAG & Average XXMG \\
\hline WGJ & Combined "saved" welght \\
\hline$A B F J$ & $\begin{array}{l}\text { Absolute value of arrival-time residual } \\
\text { at station }\end{array}$ \\
\hline MPC(99) & $\begin{array}{l}\text { Utility variable In summary statistical } \\
\text { colculation }\end{array}$ \\
\hline SCOF $(99)$ & $\begin{array}{l}\text { Utility variable in summary statisticai } \\
\text { calculation: }\end{array}$ \\
\hline scof2(99) & $\begin{array}{l}\text { Utility varlable in summary statistical } \\
\text { calculation }\end{array}$ \\
\hline ABEPM & $\begin{array}{l}\text { Utility variable in summary statistical } \\
\text { calculation }\end{array}$ \\
\hline
\end{tabular}


MPCP (99)

SCOP (99)

SCOP2 (99)

ABEXM

MPCX (99)

$\operatorname{scox}(99)$

Sc0X2(99)

KPLUS

AVRES(99)

SDRES( 99 )

SEM(99)

AVREP (99)

SDREP(99)

SEMP(99)
UtIllty variable in summary statistical calculation

UtIlity variable In summary statistical calculation

Utility varlable in summary statistical calculation

Utility variable in summary statistical calculation

Utility varlable In summary statistical calculation

utility variable in summary statistical. calculation

Utillty variable in summary statistical calculation

Switch for extra summary card Average arrival-time residual at station Standard deviation of arrival-time, residual at station

Standard error of mean of average arrivaltime residual at station

Average residual in P-magnitude at station

Standard deviation of P-magnitude residual at station

Standard error of mean of P-magnitude residual at station 
AVREX(99)

SDREX( 99 )

$\operatorname{SEMN}(99)$
Average residual of $X$-magnitude at station

Standard deviation of X-magnitude residua! at station

Standard error of mean of $X$-magnitude residual at station 
HYPOLAYR OUTPUT

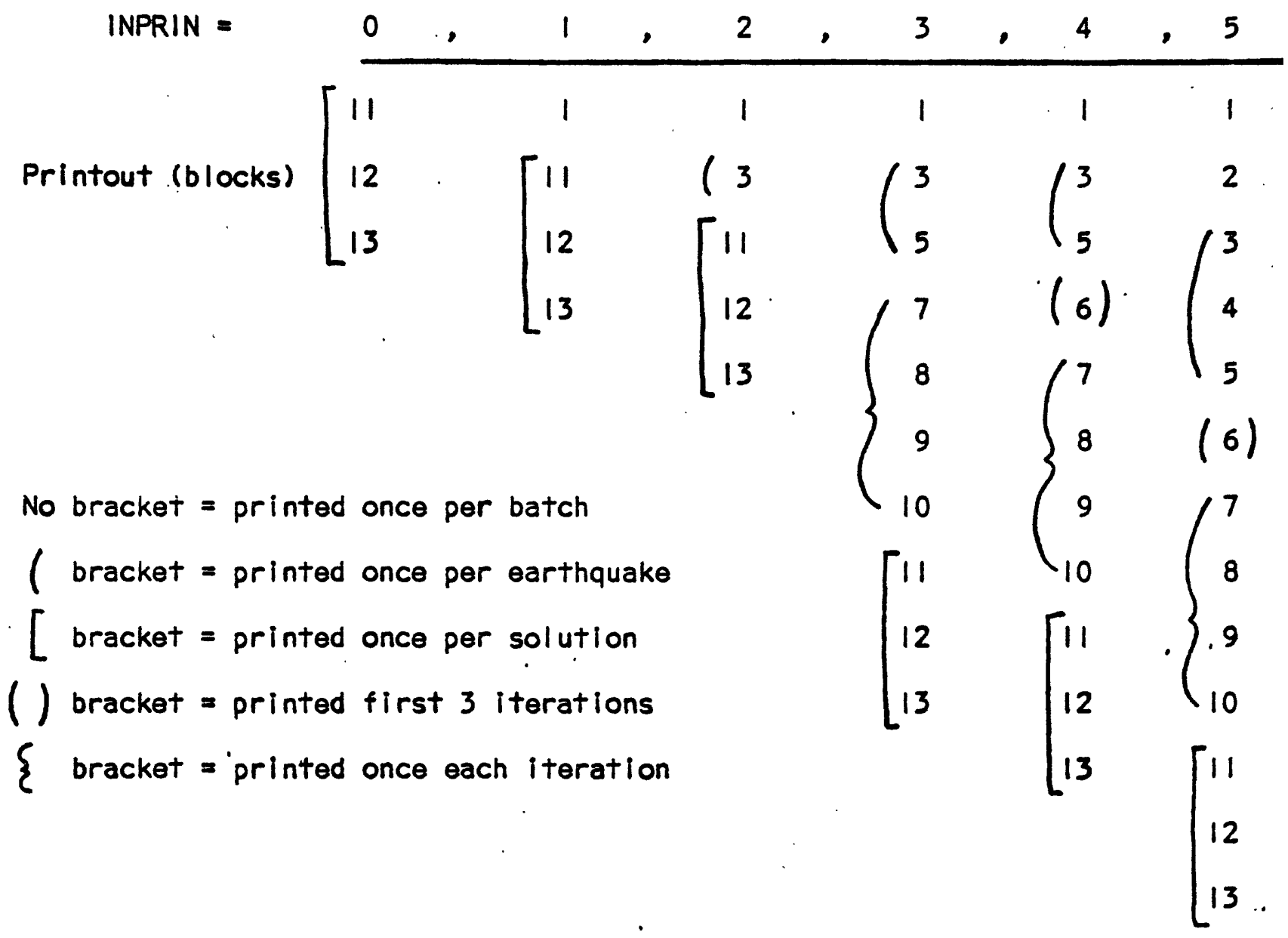

The normal INPRIN is 2, which provides a listing of station data, model parameters, and control parameters as well as a listing of the input data for each earthquake and the output results for each solution.

Card punch

output

LPC =

$\frac{0}{\text { none }}$

Output blocks punched as

P2

1

2 3

indicated, once per solution

P3

P2 


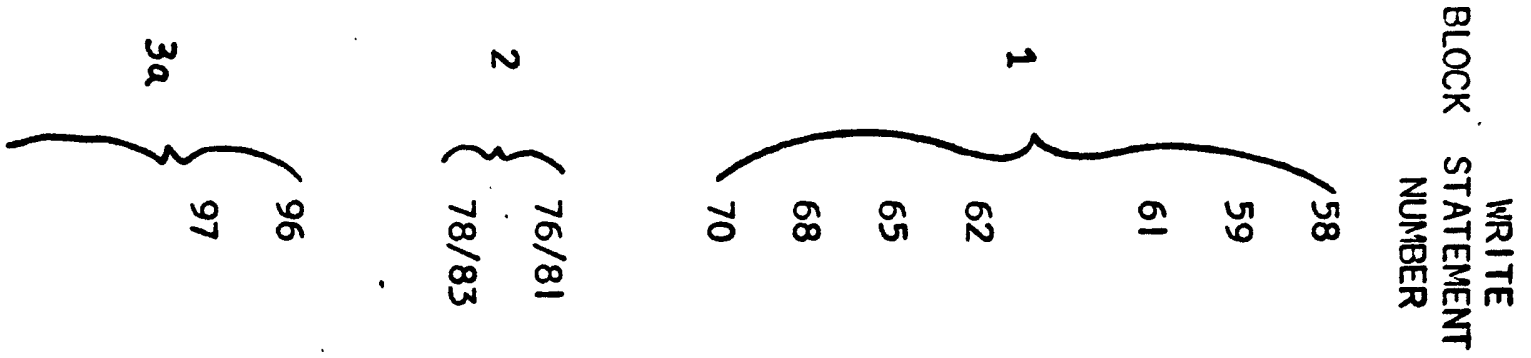

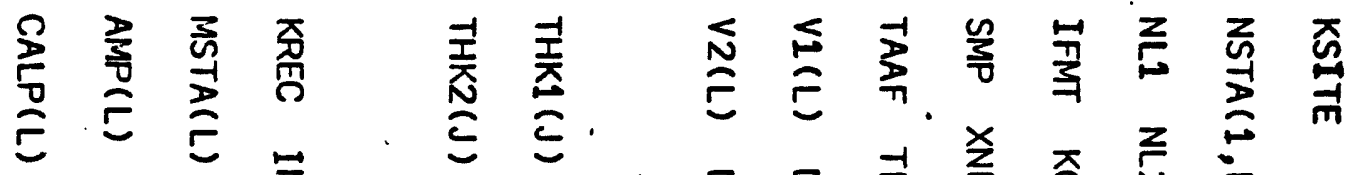

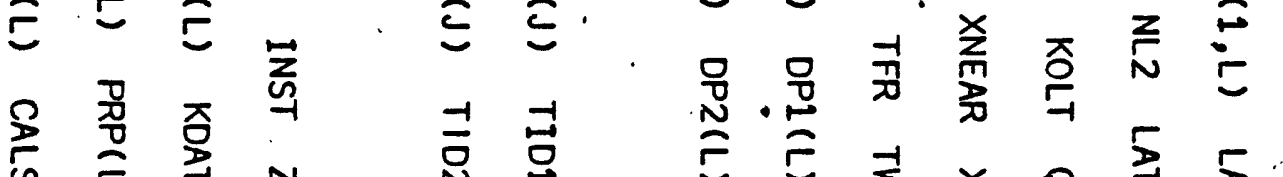

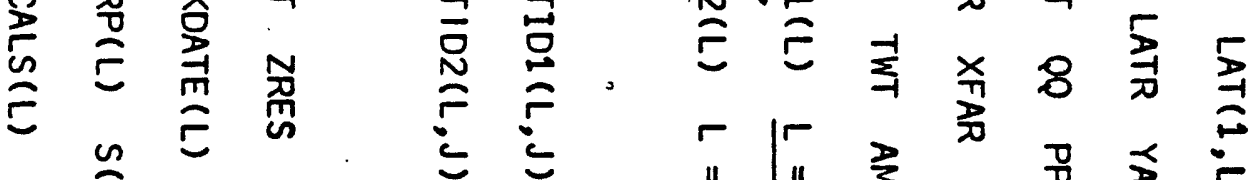

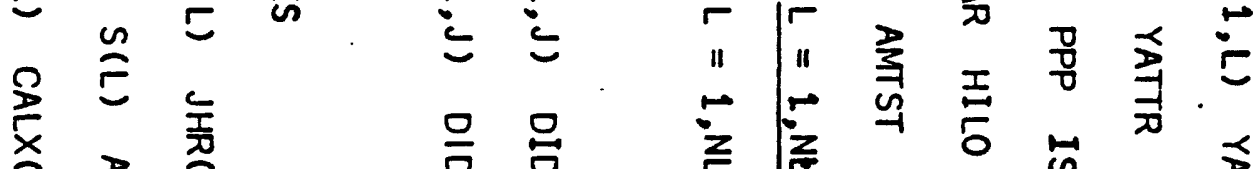

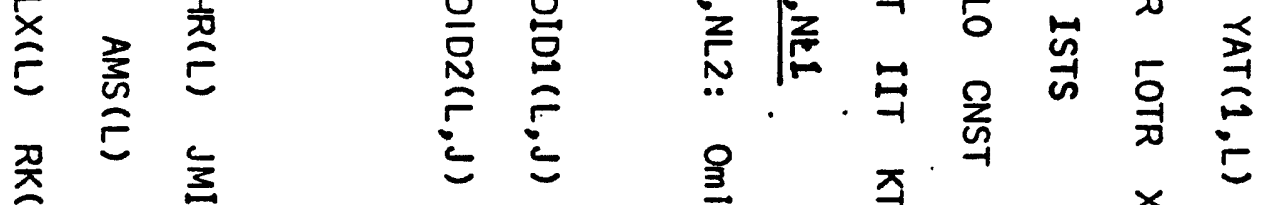

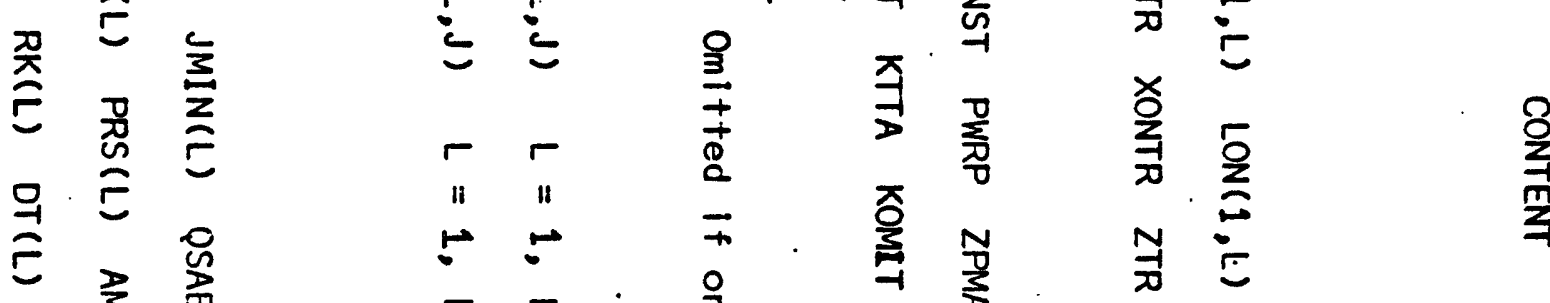

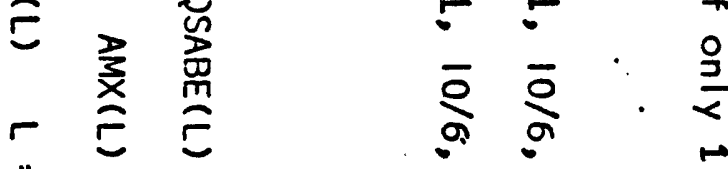

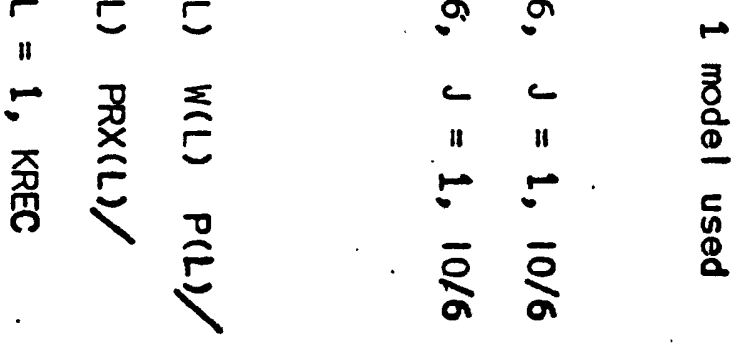

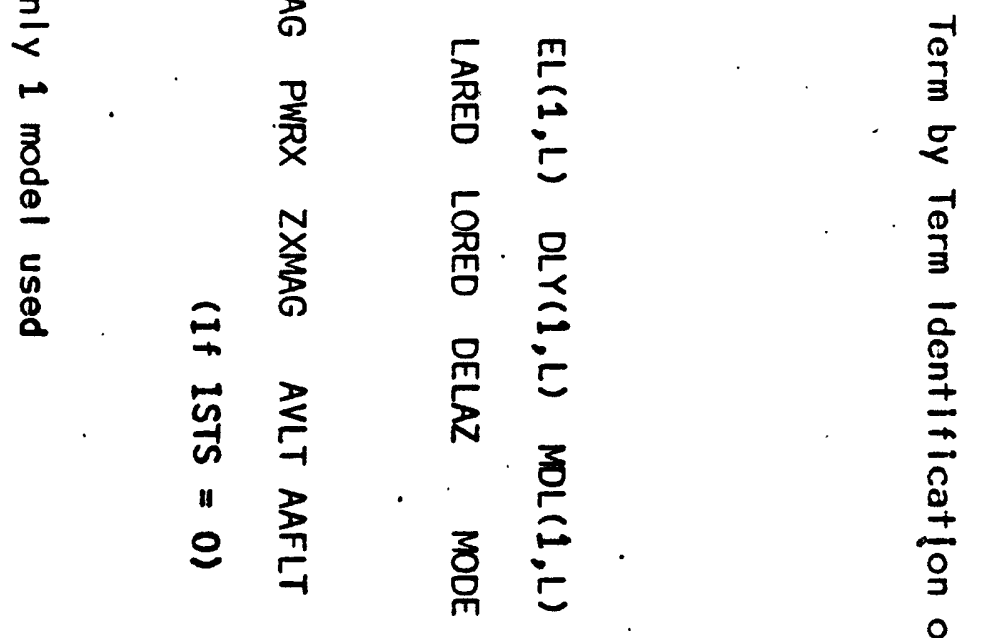

咅

요

文

患 

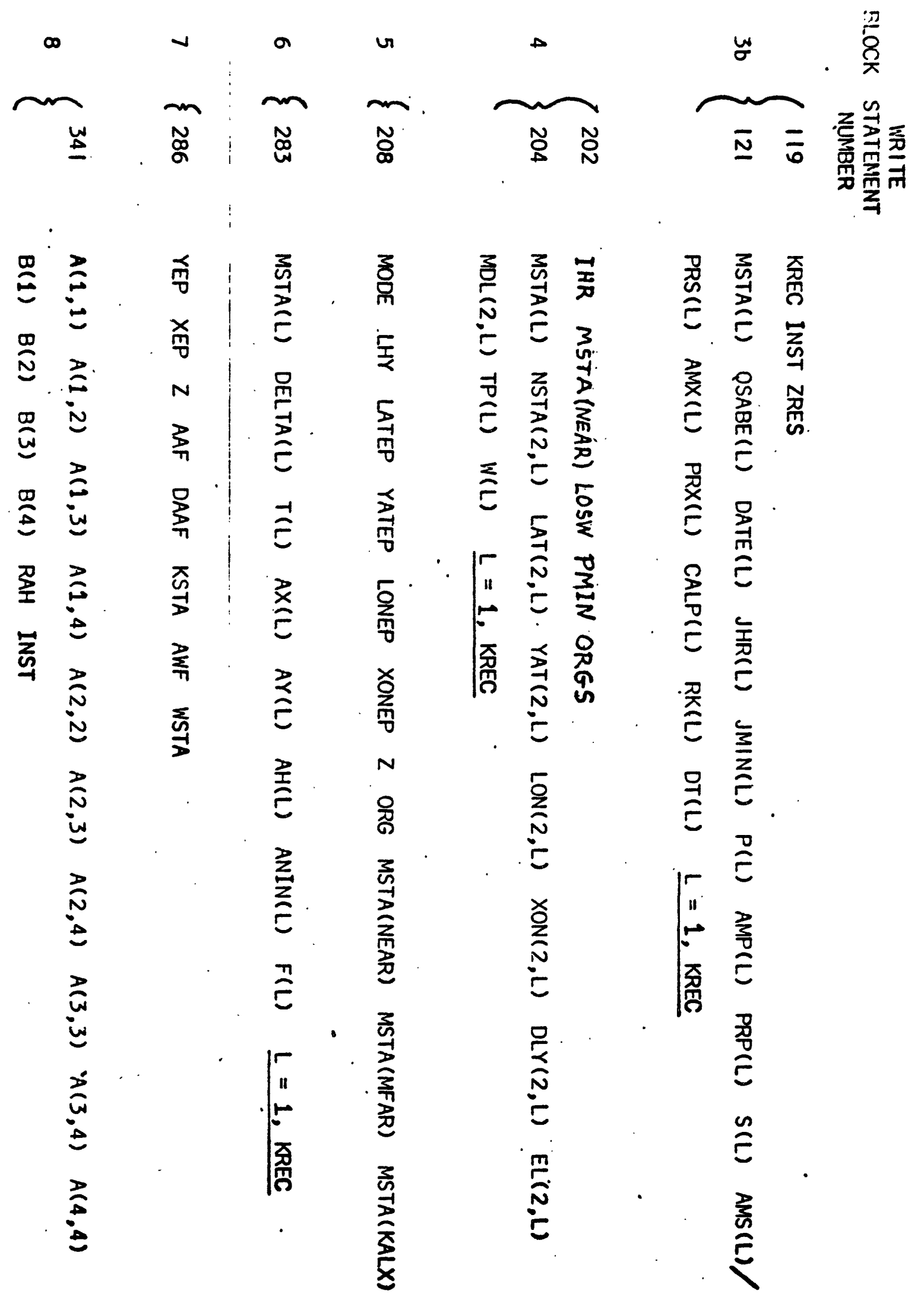

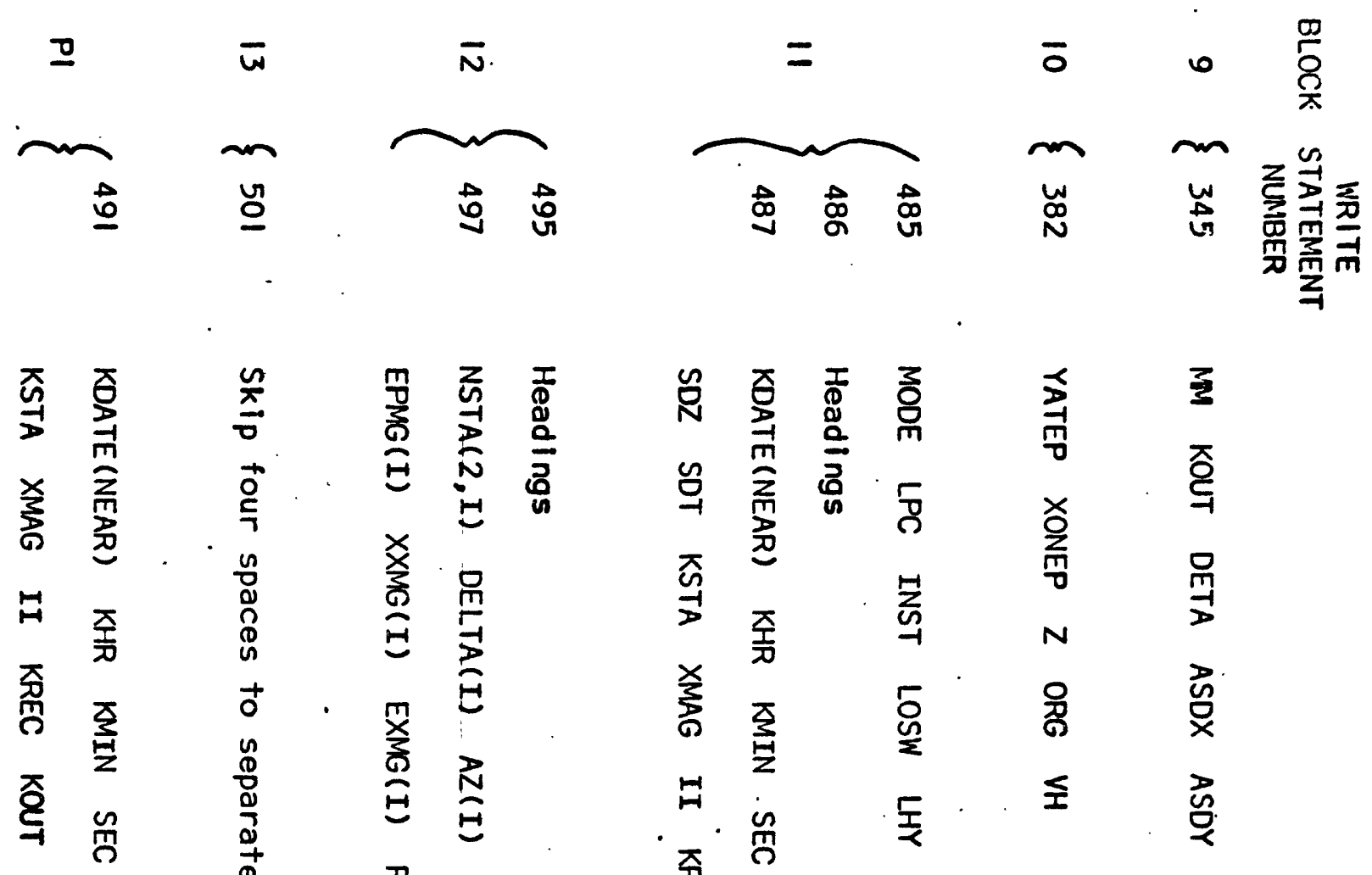

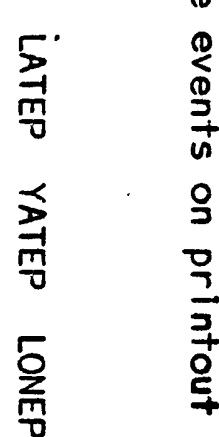

吝

㔻 5

직

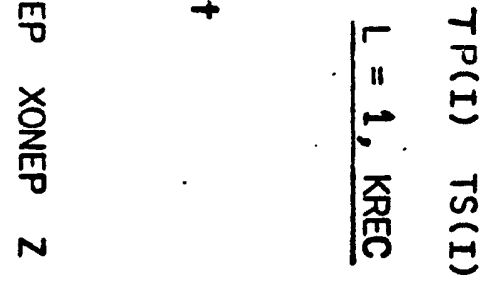

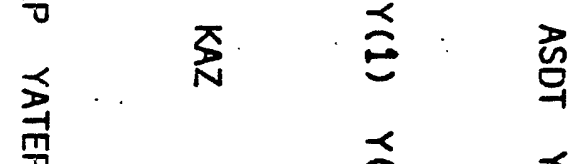

の㟨

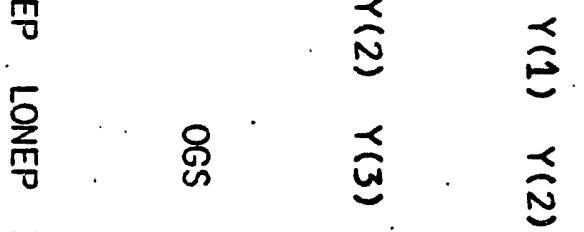

3

$\stackrel{\pi}{\exists}$

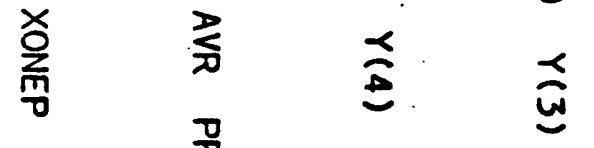

N $\frac{0}{0}$

$£$

g

电

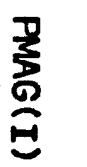

ğ

辗

몽

:

$\tilde{y}$

\&్t

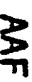

존

号

?

兑.

总

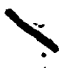



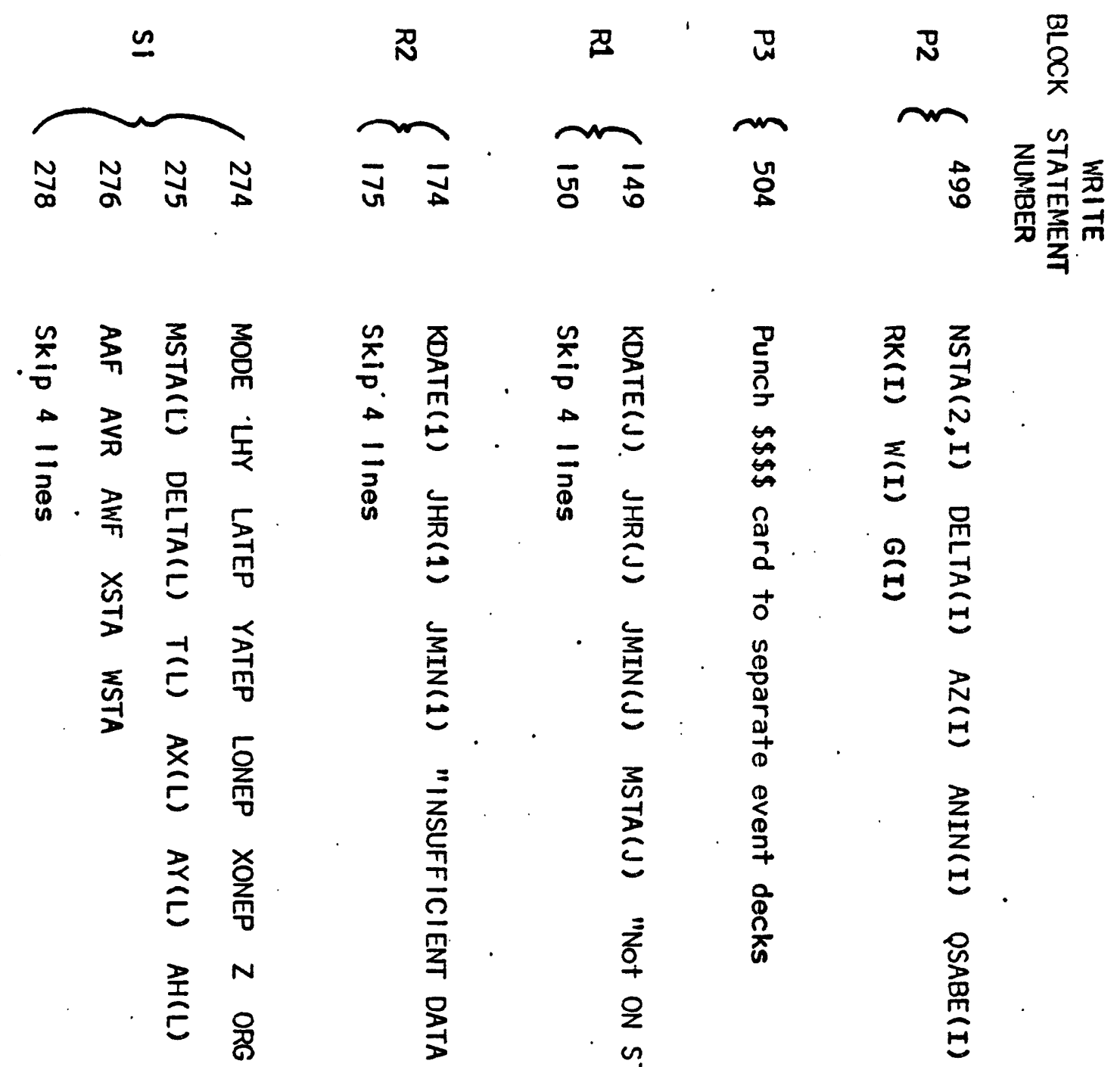

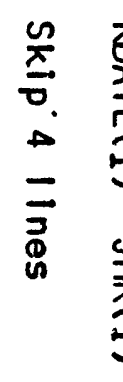

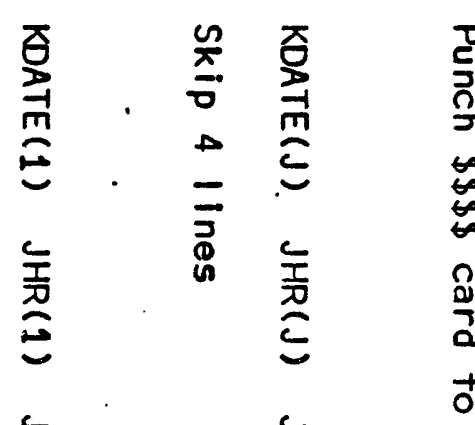

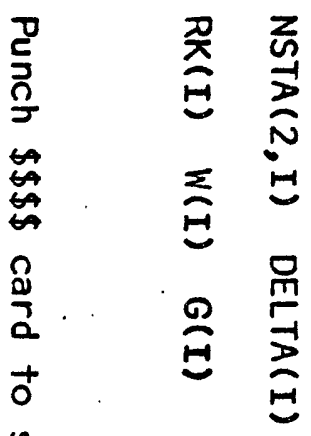
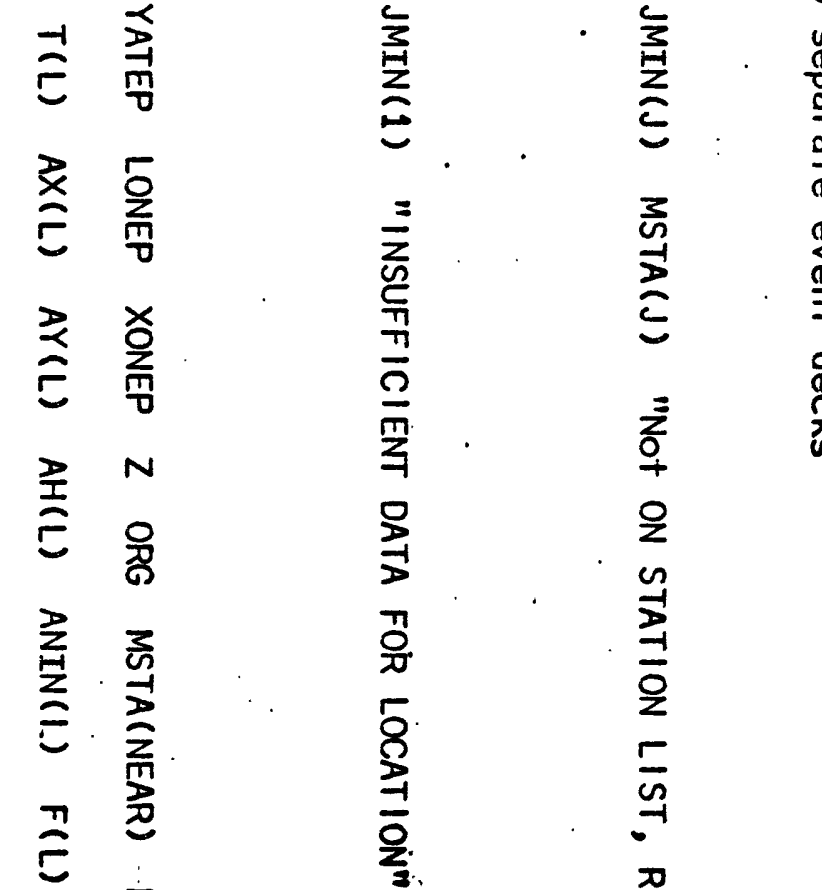

点

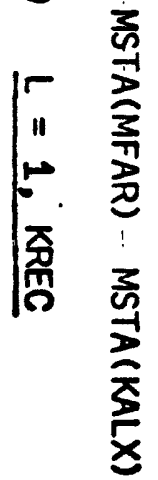

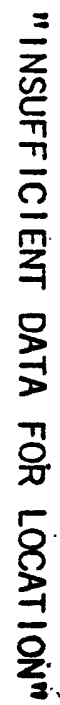

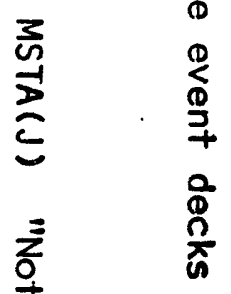

宔

疂

$\frac{1}{5}$

$\frac{1}{E}$

空

곹

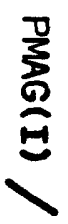



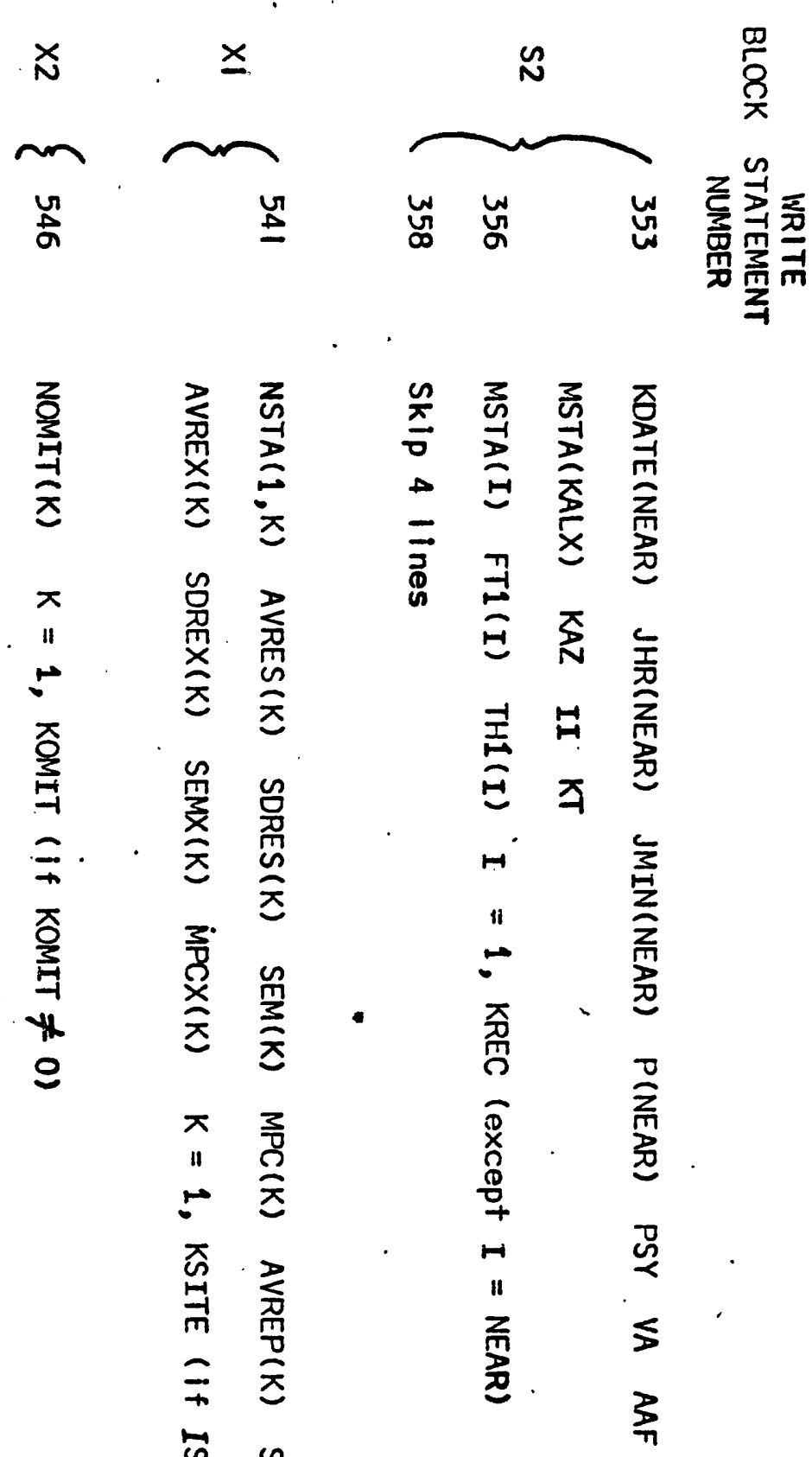

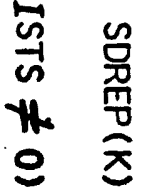

$\frac{n}{\frac{n}{3}}$

离

$\frac{3}{\overline{7}}$

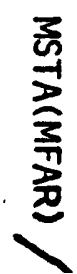


CONTENT

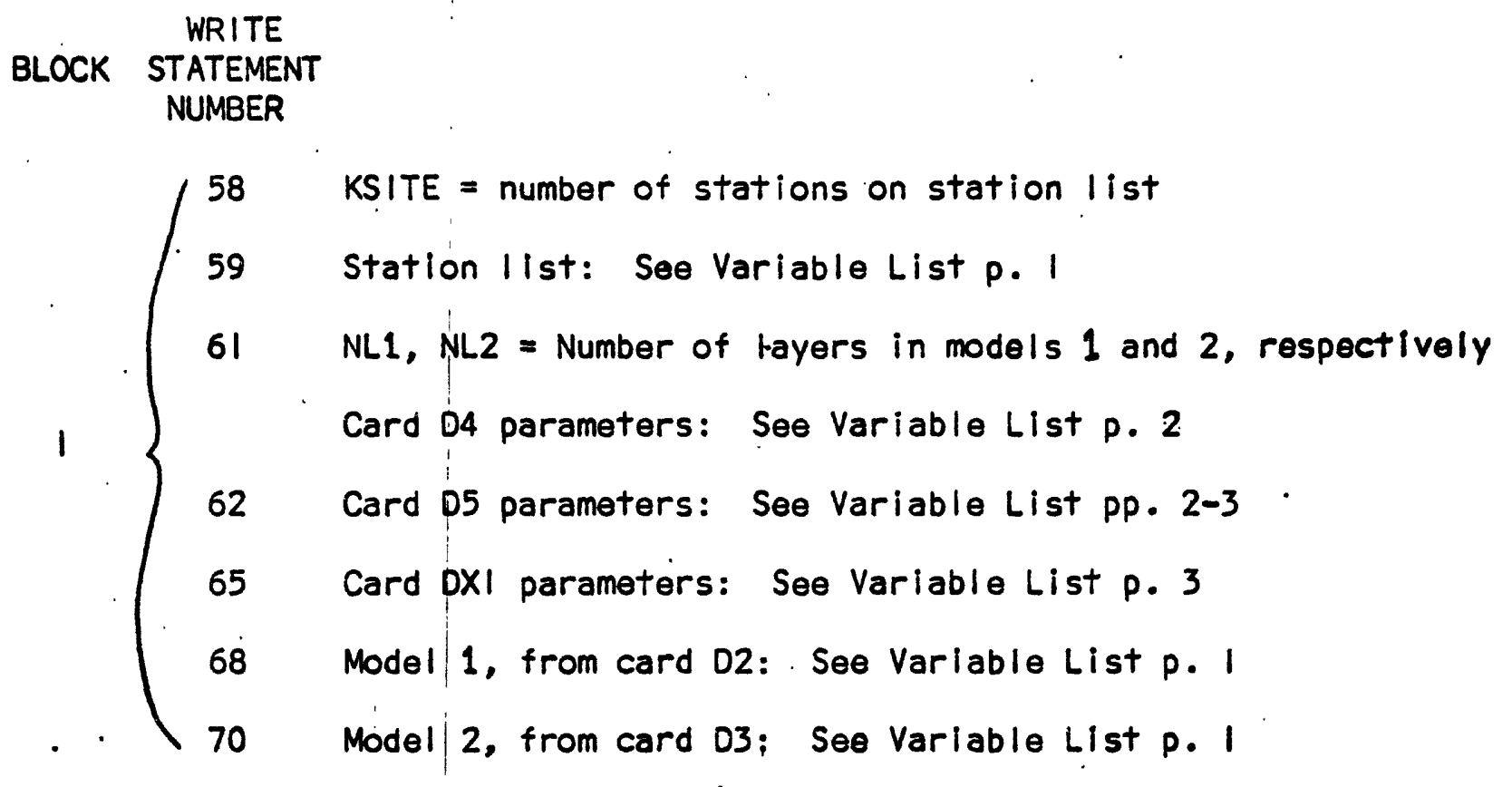

$2\left\{\begin{array}{lll}76 / 81 & \text { Model } 1 \text { arrays from TPAR: } & \text { See Variable List p. } 4 \\ 78 / 83 & \text { Módel } 2 \text { arrays from TPAR: } & \text { See Variable List p. } 4\end{array}\right.$

97 Format 2 phase card (D6-2) parameters: See Variable List pp. 4-5

121 Format 1 phase card (06-1) parameters: See Varlable . List Pp. 4-5

$4 \begin{cases}202 & \text { See Variable List, p. } 5 \\ 204 & \text { Match station-phase IIst: See Variable List Pp. 1, 4, } 5\end{cases}$ 
WRITE

BLOCK STATEMENT

NUMBER

$5 \begin{cases}208 & \text { Results on preliminary hypocenter from PREHY: See } \\ & \text { Variable List Pp. } 5,6 .\end{cases}$ $6\left\{\begin{array}{c}283 \text { Results from TRVDRV and arrival-time residuals: See } \\ \text { Variable List PP. 8-10 }\end{array}\right.$

$7\left\{\begin{array}{c}286 \quad \text { Location of hypocenter, and statistical parameters: See } \\ \text { Varlable List pp. 8-10. }\end{array}\right.$

$8\left\{\begin{array}{r}341 \text { Coefficients and constants in normal equations plus range } \\ \text { in JT/JZ, RAH, and INST value: See Varlable List p. } 10\end{array}\right.$

$9\{345$ Results of HYCOR subroutine: See Variable List pp. 10-11

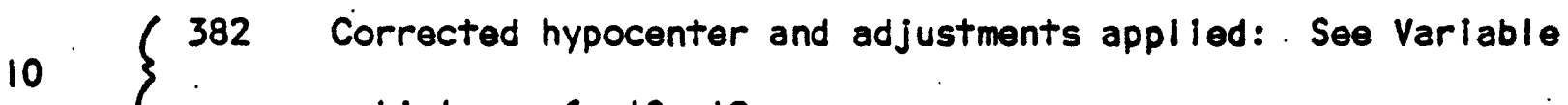
List pp. 6, 10, 12

485 Condition codes plus "S-P origin time," average residual,

11 and mean P-magnitude: See Variable List

487 Summary card printout: See Varlable List, especially Pp. 8, 10, 12, 13

$12 \begin{cases}497 & \text { Station data printout: See Variable List, especially } \\ & \text { pp. } 8,10,12,13\end{cases}$ 
WRITE

BLOCK STATEMENT

NUMBER

P1 $\{491$ Card punch summary card: cf 11

P2 $\{499$ Card punch station data card: ef 12 RI $\left\{\begin{array}{cc}149 & \text { Printout indicating phase card--station card matching } \\ \text { fallure }\end{array}\right.$

R2 $\left\{\begin{array}{c}174 \quad \text { Printout indicating too little data for location--this } \\ \text { condition can result from event receding from net until } \\ \text { too many stations have G-weights }=0\end{array}\right.$

SI $\begin{cases}274 & \text { Printout for special "solution" in which program is } \\ 275 & \text { used to compute traveitimes, derivatives, etc., for a } \\ 276 & \text { specifled focus and model }\end{cases}$

S2 $\left\{\begin{array}{l}353 \\ 356\end{array}\right.$ Printout for the VELAZ subroutine

$X 1\left\{\begin{array}{cc}\text { Printout of statistical data on arrival-time residuals and } \\ 541 \quad & P \text { - and X-magnitude residuals at Individual stations }\end{array}\right.$

$\times 2\left\{\begin{array}{cc}546 & \text { Printout of list of stations that were not used in } \\ \text { hypocentral adjustments }\end{array}\right.$ 
Condition Codes

MODE:chooses method of preliminary hypocenter assignment

= 0 : Put hypocenter at depth ZTR beneath the earliest station

$=1$ : Put hypocenter at depth ZTR beneath the trial epicenter

$$
\text { (LATR, YATTR, LOTR, XONTR) }
$$

- 2 : Calculate preliminary hypocenter from reduced data set using a half-space model

LHY: Identifles the PREHY section used in assignment of the preliminary hypocenter.

$=1$ MODE $=0$; etc.

$=2$ Mode $=1$; etc.

$=3$ MODE $=2 ; 4$ station solution for $x_{0}, y_{0}, z_{0}, t_{0}$

$=4$ MODE $=2 ; 3$ station solution for $x_{\bullet}, y^{\circ}$ :

$t_{0}$ computed from S-P data, $Z_{0}=$ ZTR.

$=5$ MODE $=2 ; 3$ station solution for $x_{0}, y_{0}, t_{0} ; z_{0}=$ ZTR LPC:Card punch instruction

= 1 : Punch 1 summary card, 1 station card per station, and 1 separator card

= 2 : Punch 1 summary card and 1 separator card

= 3 : Punch 2 summary cards, 1 station card per station, and

1 separator card

$=0$ : No card punch output

INST: Controls type and number of solutions for a single earthquake

$=0$ : FREE solution; adjust $x_{0}, y_{0}, z_{0}, t_{0}$

$=1:$ ZFIX solution; adjust $x_{0}, y_{0}, t_{0}$

$=2$ : $T \dot{F} \mid X$ solution; adjust $x_{0,} y_{0,} z_{0}$ 
$=4$ : first. a ZFIX solution, second a FREE solution .

$=5$ : first a TFIX solution, second a ZFIX solution

= 6 : first a TFIX solution, second a ZFIX solution, third a FREE solution

$=8:$ go to subrout ine VELAZ

= 9 : Printout first TRVDRV results and other data recording parameters of hypocenter and statistics of residuals LOSW:indicates availabillity of S-P origin time

$=0:$ ORGS not available

= 1 : ORGS available

KOUT:identifies the HYCOR routine used in the last adjustment of the: . hypocenter.

= 1 : Free adjustment of all variables

$=2: Z F \mid X$ adjustment of $x_{0}, y_{0}, t_{0}$ only

$=3$ : TFIX adjustment of $X_{0}, y_{0}, z_{0}$ only:

$=4: Z F I X-T F I X$ adjustment of $X_{0}, y_{0}$ only

KAZ: indicates which VELAZ routine was used

$=0:$ VELAZ not used

= 1 : 3-station solution for velocity and azimuth only

= 2 : least-squares adjustment of velocity and azimuth 


\section{Appendix 3}

Data card varlables, and a short explanation of their use and significance.

DI. "NSTA" IIst--one per station $\operatorname{NSTA}(1, L) \quad$ Station L name $\operatorname{LAT}(1, L) \quad$ Station L latitudę (degrees).

YAT $(1, L)$ : Station L latitude (minutes)

LON $(I, L)$ : Station L longitude (degrees

$\therefore$ XON $(1, L)$ Station L longitude (minutes)

$E L(1, L)$ Station L elevation (meters)

$\operatorname{OLY}(1, L) \quad$ Station $L$ delay (seconds)

$\operatorname{MDL}(1, L)$ Crustal model to be used with station $L$

02. Model 1 list

V1(L)

Velocity in layer $L(\mathrm{~km} / \mathrm{sec})$

DP1 (L)

Depth to top of layer $L(\mathrm{~km})$

D3. Model 2 list

V2(L) Velocity in layer $L(\mathrm{~km} / \mathrm{sec})$

DP2(L) Depth to top of layer $L(\mathrm{~km})$

D4. Parameter card 1

LATR

Trial hypocenter latitude (degrees)

YATTR

Trial hypocenter latitude (minutes)

LOTR

Trlap hypocenter longltude (degrees)

XONTR

Trial hypocenter longitude (minutes)

ZTR

LARED

Trial hypocenter depth $(\mathrm{km})$

"LORED

Latitude reduction (degrees).

DELAZ

Longitude reduction (degrees)

Distance (in km) to nearest station beyond whjch VELAz

subroutine is called 
Half-space velocity used in MODE = 2 solution

(below).

MODE

$0,1,2$ Keys mode of PREHY hypocenter determi nation

0 - prel iminary hypocenter placed at depth ZTR beneath nearest station

1 - "trial" hypocenter assigned

2 - prel iminary hypocenter computed from 4 (or 3) selected stations on the basis of a uniform half-space model

LPC

$0,1,2,3$ Keys punch-card output

0 - no cards punched

1 - cards punched

2 - summary cards and $\$ \$ \$ \$$ only

3 - duplicate summary cards, station cards, and \$\$\$

INPRIN

0 (or blank), $1,2,3,4,5$

Different output levels can be obtained by use of

different INPRIN commands. The levels range from

final results only ( 0 ) to step-by-step printout of

the results of read and calculate operations (5).

0 Hypocenter summary and station summary list

1 + "NSTA" station list, parameters, and model lists

2 + "MSTA" phase list

3 + PREHY hypocenter, and adjustment data (1/iteration)

4 + Time and derivative lists (first 3 iterations)

5 + TPAR arrays and match-list

(DO not, use "5" if NLL. or NL2 > 10; 888 FORMAT (nadequate) 
IFMT

Indicates "MSTA" phase li ist format that wjll be used

1 "HYPOLO" format

2 "HYPOLAYR" format--provides for weighting of reading and for independent calibration for $S$ and $\max (X)$.

OXI Test values needed in the section providing a statistical sumary of Individual station time and magnitude residuals

TAAF If AAF $\geqslant$ TAAF earthquake is skipped

TFR

AMTST

If $F(J) \geqslant T F R$
if $W(J) * G(J) \leqslant T W R$$\left\{\begin{array}{l}\text { station is skipped in section } \\ \text { on traveltime residuals }\end{array}\right.$

If $|\operatorname{EPMG}(J)|>$ AMTST, station is skipped in section on P-mag residuals

AMTST

If $|\operatorname{EXMG}(\mathrm{J})|>$ AMTST, station is skipped in section on ' $X$ mag residuals

IIT

If II. > IIT, earthquake is skipped

KTTA

If KSTA $<$ KTTA, earthquake is skipped

KOMIT

Number of stations (Iisted on card OX2) that are to be ignored in the determination of the hypocenter but treated normally otherwise.

OX2 List of stations to be ignored as specified under "KOMIT" above

05 Parameter card 2 KOLT

In order of increasing P-arrival times, stations 1 through KOLT are considered in the selection of stations for use in calculating the preliminary hypocenter, in PREHY, and in calculating the preliminary velocity and azimuth in VELAZ.

SMP

Ta calculate $P$ traveltimes from measured S-P intervals, the equation $P-O=\operatorname{SMP} *(S-P)$. is used. If Polsson's 
ratio is $0.25, \operatorname{SMP}=1.37$

XNEAR $(\mathrm{km})$ For DELTA $(I)<$ XNEAR, the distance--dependent weighting factor, $G(I)$, is 1.0 .

$\operatorname{XFAR}(\mathrm{km})$ For DELTA $(I)>\operatorname{XFAR,} G(I)=0.0$. For XNEAR $<$ DELTA(I)

$<X F A R, G(I)=1.0-$ (DELTA $(I)-X N E A R) /[$ XFAR XNEAR) / 0.9$]$

HILO : Sensitivity ratio between high and low channels on playback (if same calibration. is used for both levels).

CNST

Proportionality constant used in reducing record amplitude to ground amplitude.

PWRP

Exponent of hypocentral distance used in the calculation of "P" magritudes

ZPMAG

Reference constant used in calculation of "p" magnitudes.

PWRX Analogous to PWRP, but for $X$ phase.

ZXMAG

Analogous to ZPMAG, but for $X$ phase

AVLT

Small value for AVR (average residual) used in. solution convergence tests.

AFLT

Small value for AAF (average absolute residual) used

in solution convergence tests

AFLP

Second small value for AAF (average absolute residual) used in solution convergence tests

AOLT

Small value for DAAF (change in AAF) used in solution convergence tests

ADLP

Second small value for DAAF (chainge in AAF) used in solution convergence tests. 
D6. $(D 6-1=$ HYPOLO format; $06-2=$ HYPOLAYR forma +$)$

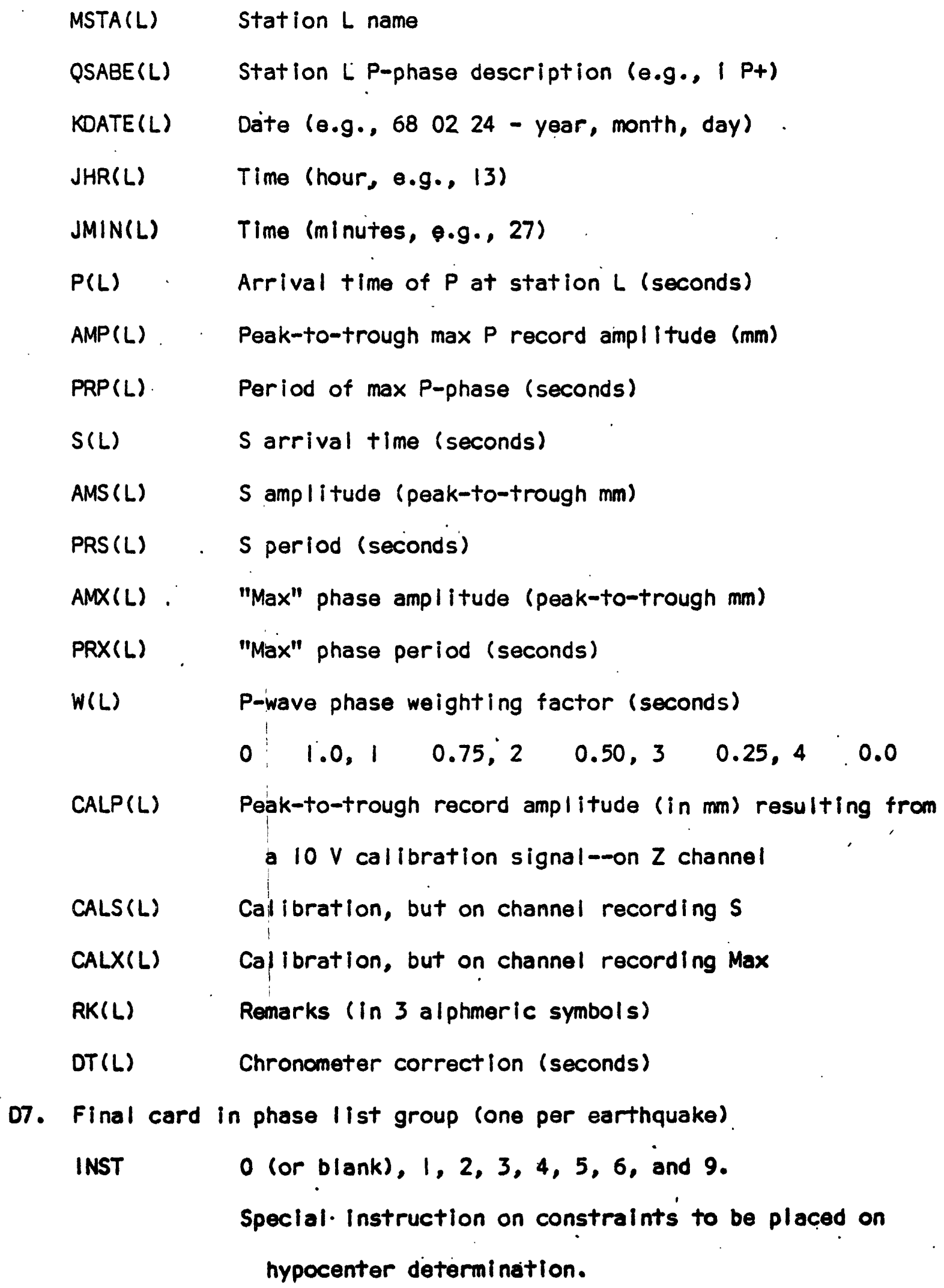


- FREE solution

I ZFIX (restrict depth to ZRES)

2 TFIX (restrict origin time to that computed from S-P data)

3 First TFIX, then FREE

4 First ZFIX, then FREE

5 First TFIX; then ZFIX

6 First TFIX, second ZFIX, third FREE

9 Requires program to compute only traveltimes, residuals, etc., for a specified focus (MODE $=1$ ), with no subsequent adjustment of focus.

(km) Depth at which hypocenter is restricted under the INST equal 1, 4, and 6 commands. 


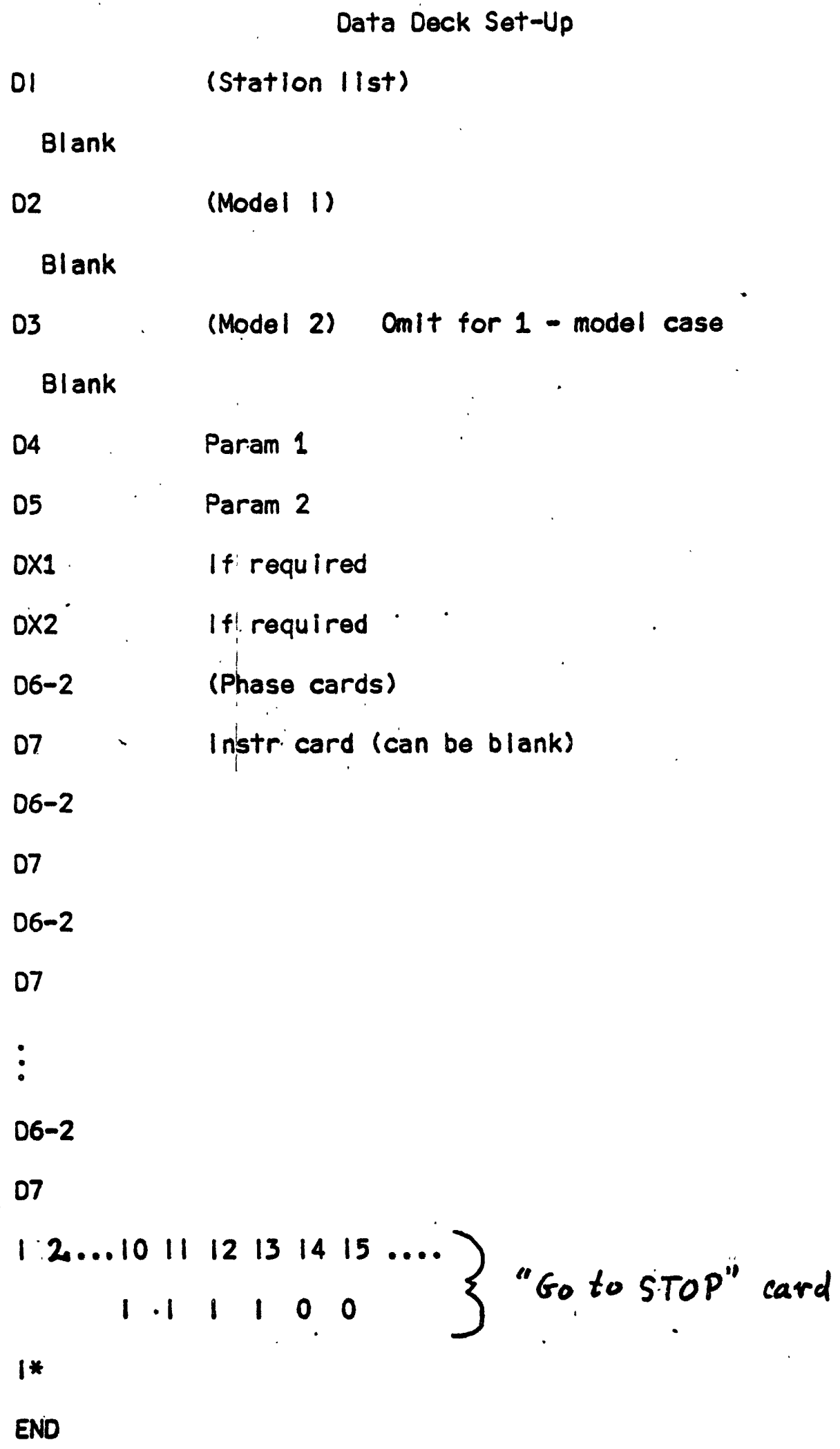




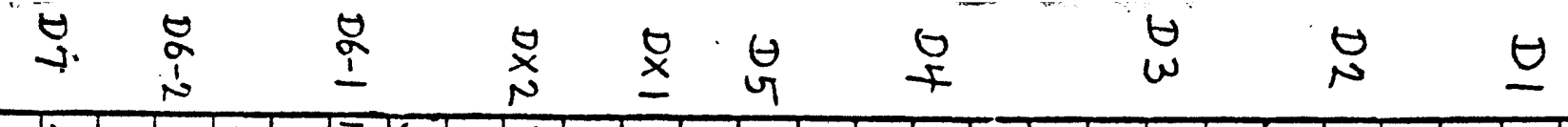

武:

或

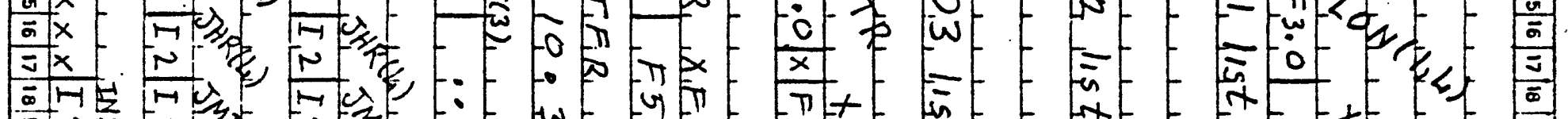

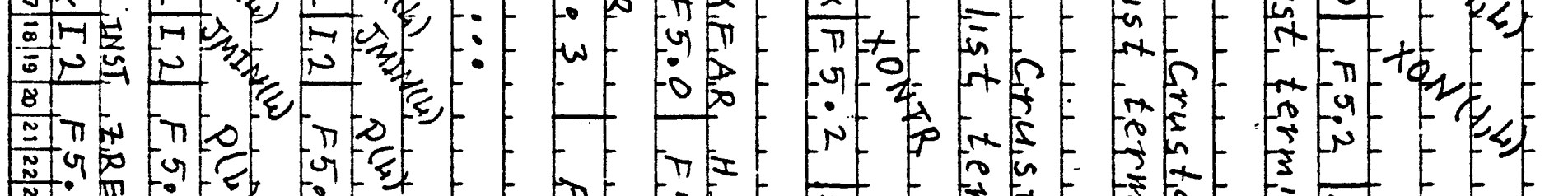

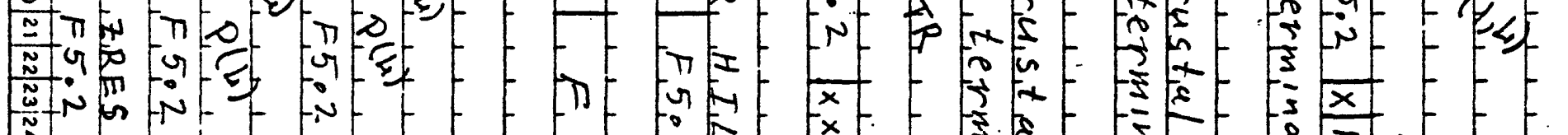

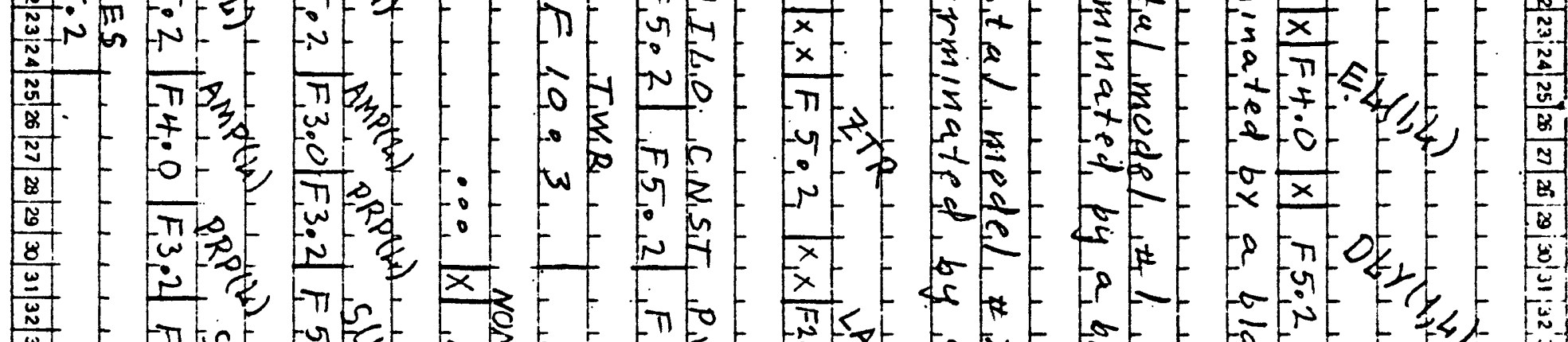

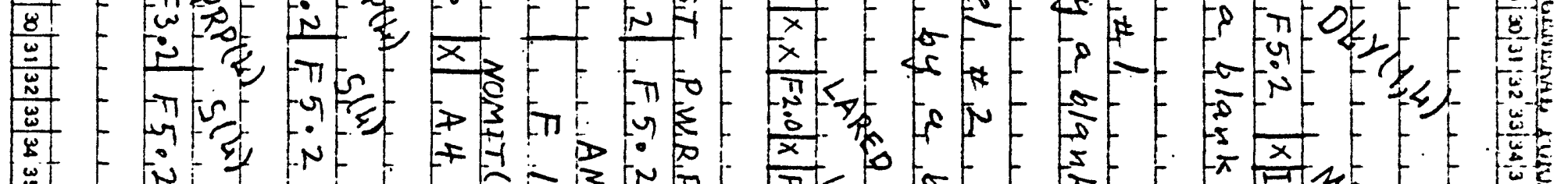

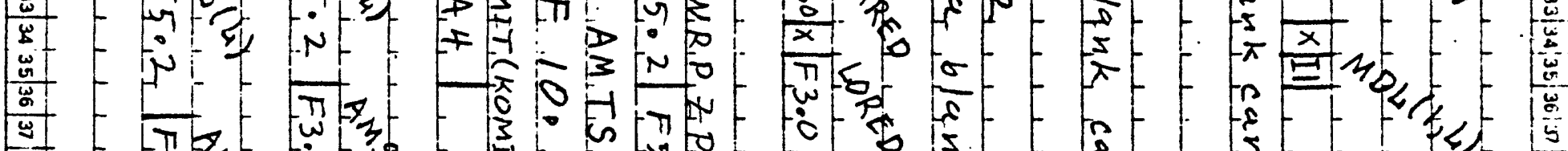

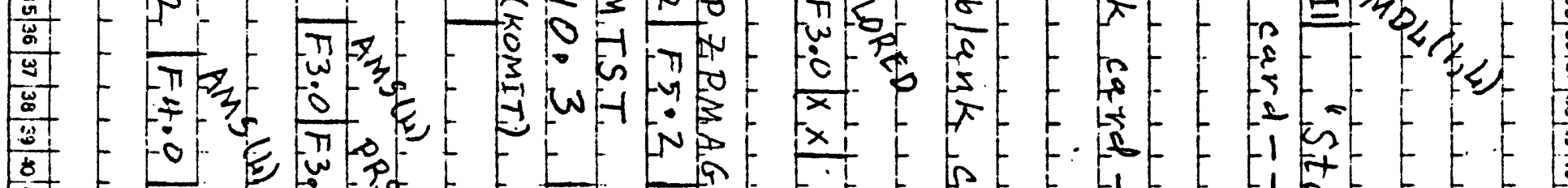

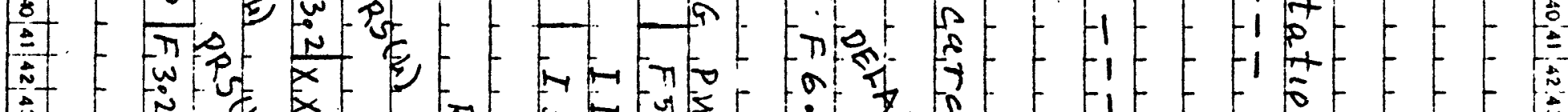

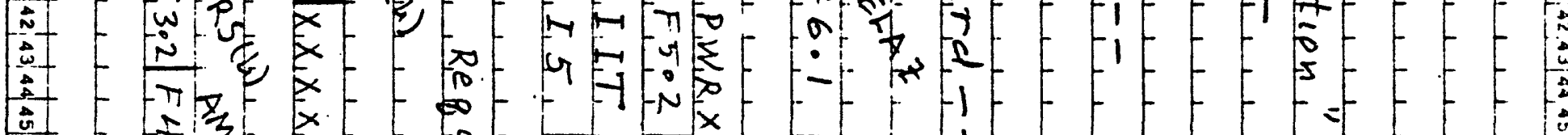

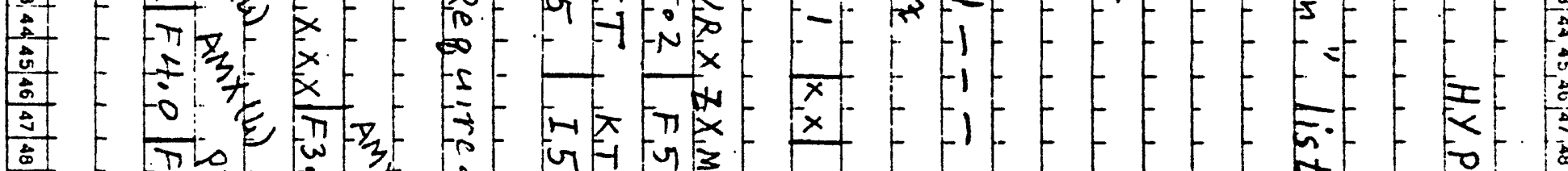

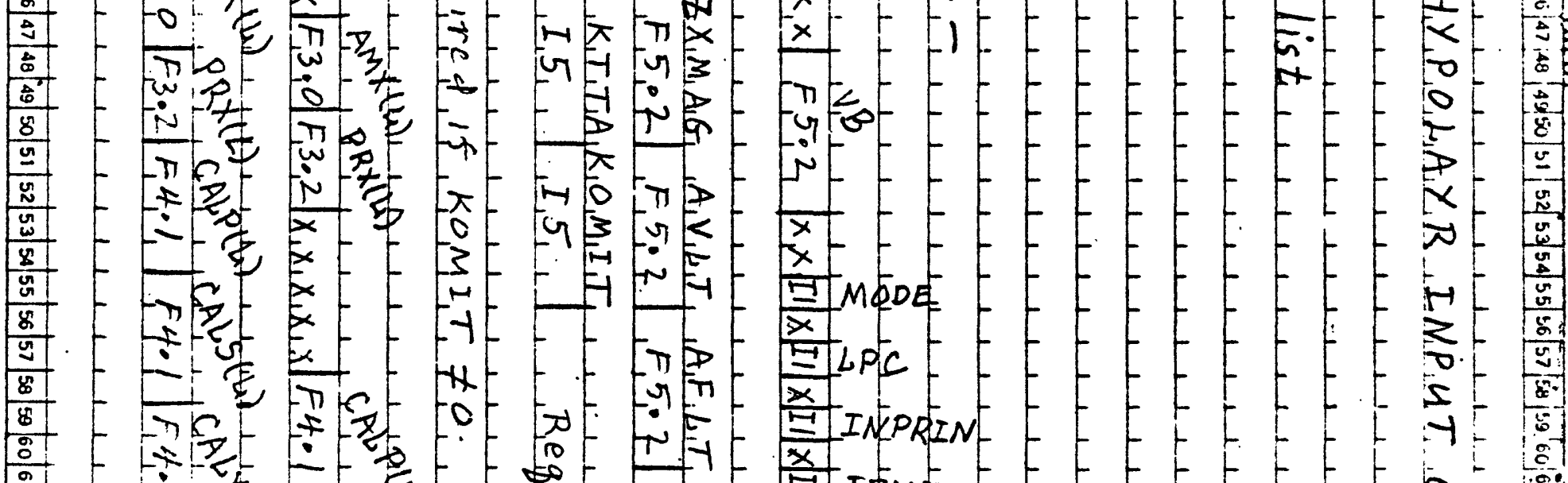

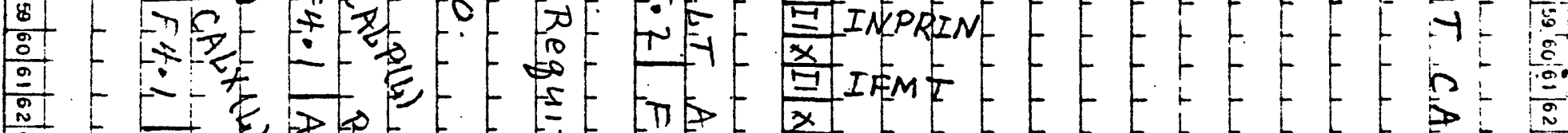

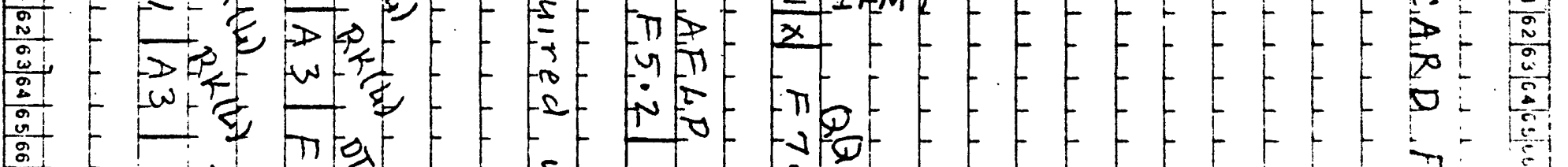

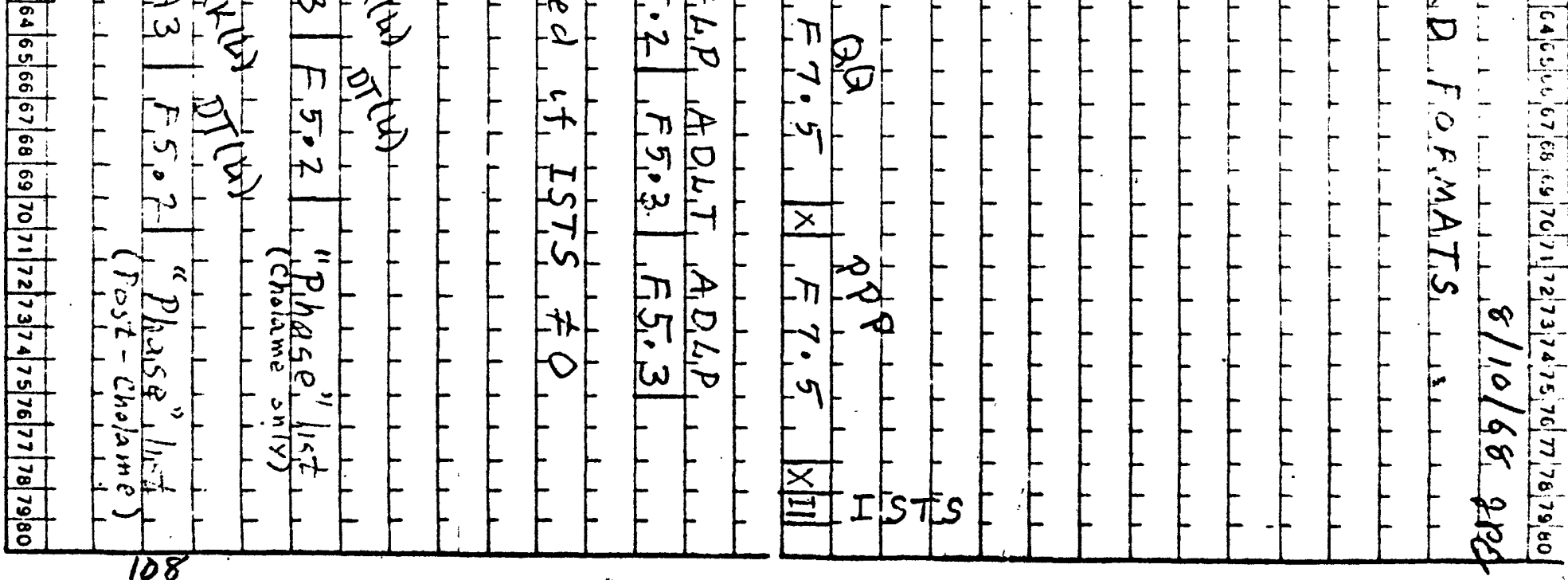


Appendix it

Fesitry friew region

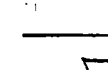$$
\rightarrow \quad 6
$$

Feenitap for new model

$$
\begin{aligned}
& \underset{\mathrm{Read} \text { incdil specitication: }}{\longrightarrow} \\
& \text { Read Parancter lists }
\end{aligned}
$$$$
\text { puramcters }
$$

Reentru for new

$\downarrow$

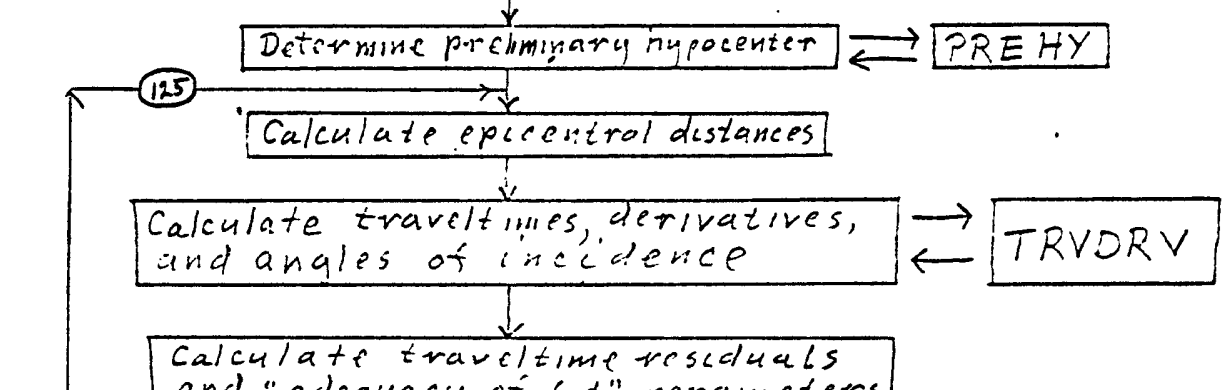

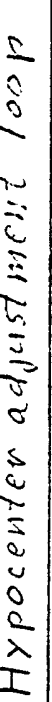

and "achequacy of fict" parameters

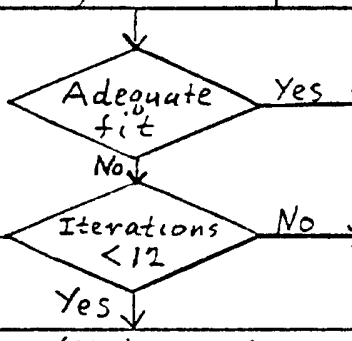

Calculate coefficicris of normal equations

for computing inapocentral adpustiments
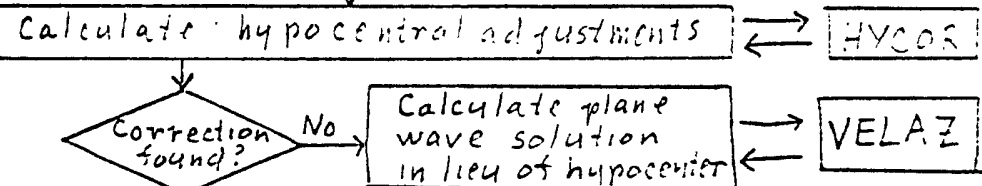

Calculate plane

wave solution $\longleftrightarrow$ VELA.Z

I Yes

Yes

in lien of hupoieriet

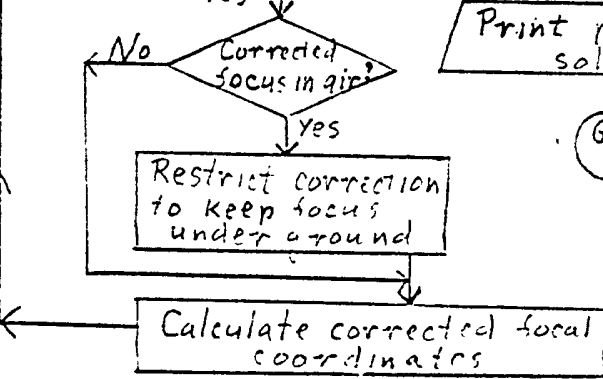

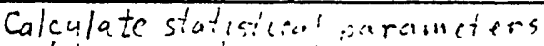

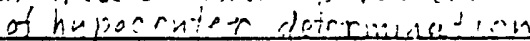

$$
\downarrow
$$

Convert hyposinteal courdinates

traveltunes, destanecs, angles, itc.

to correct forms for printact 


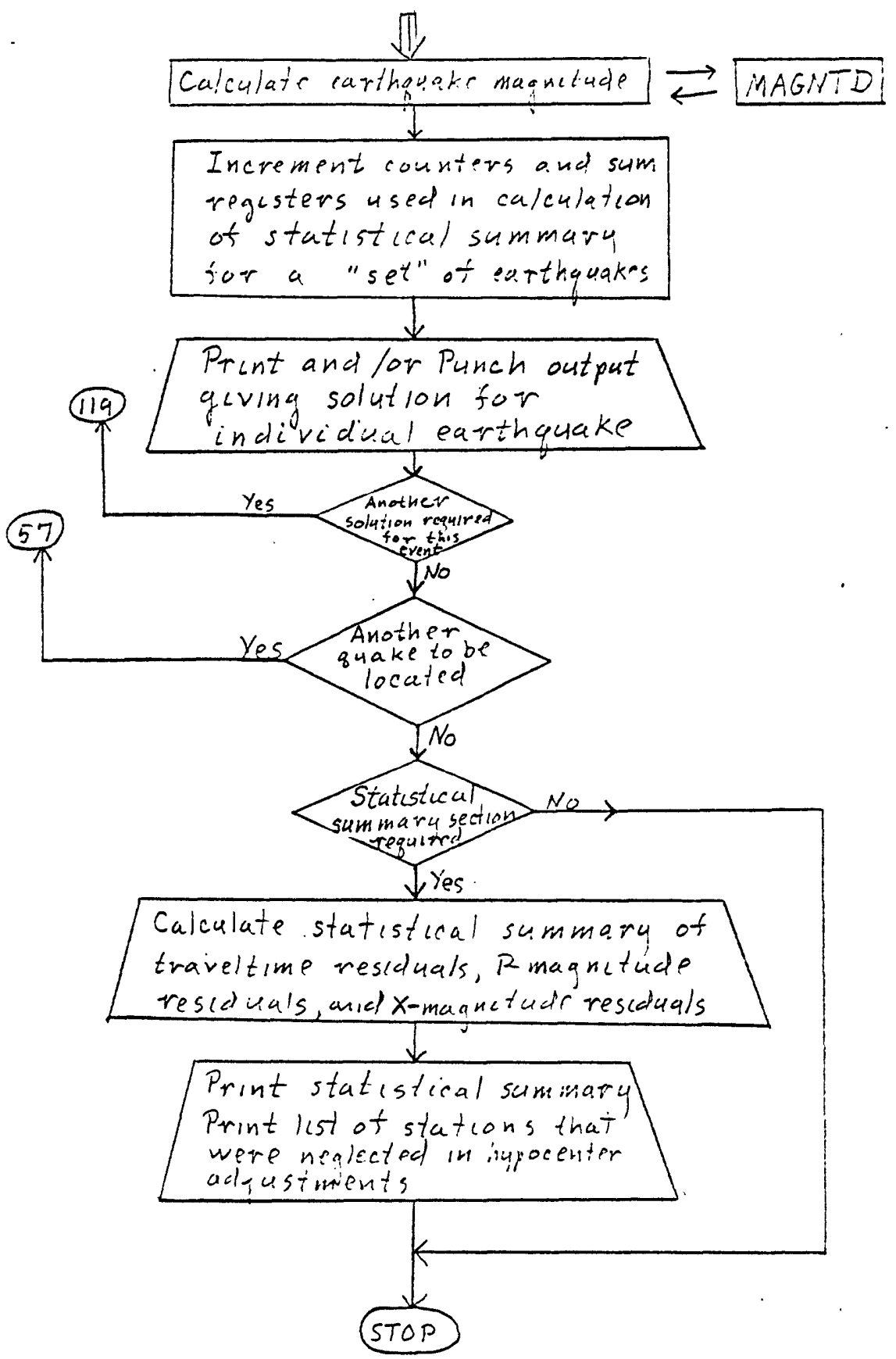




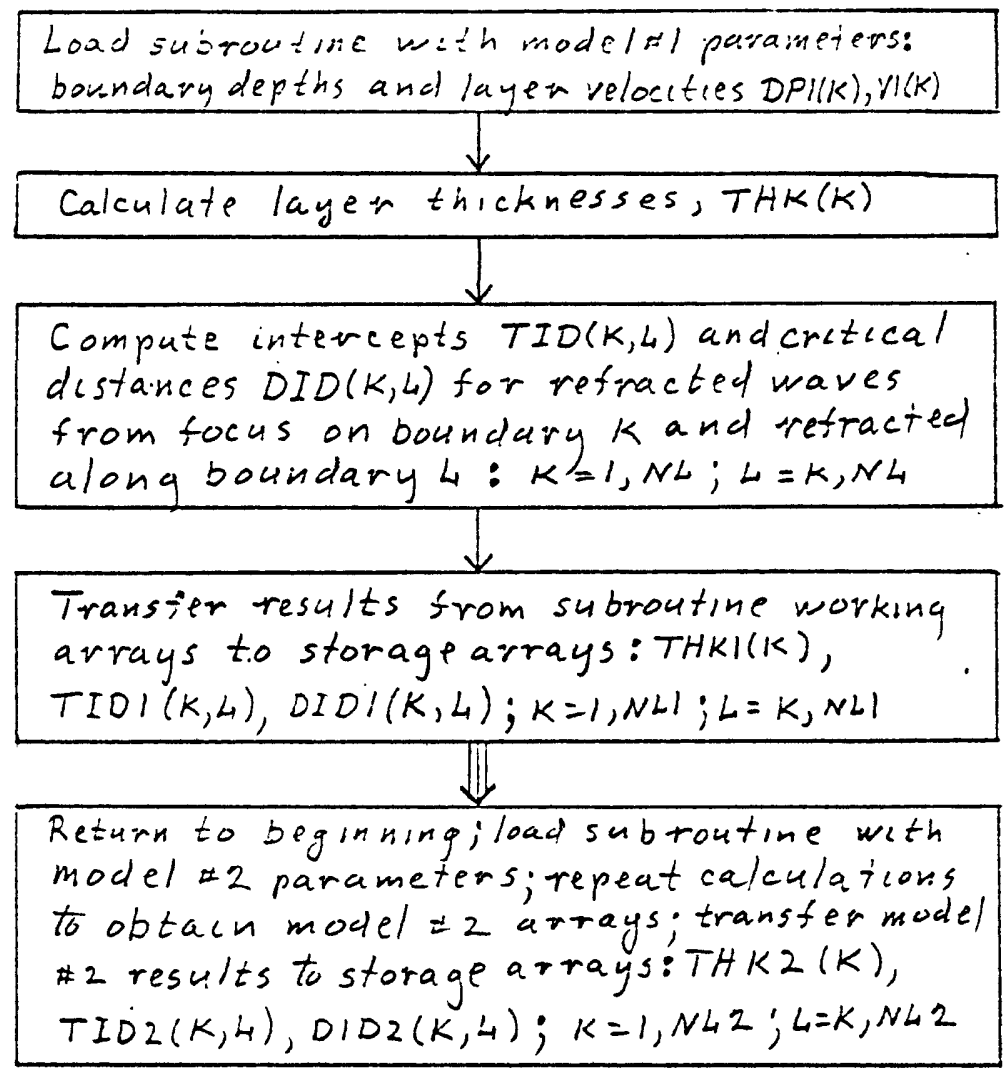




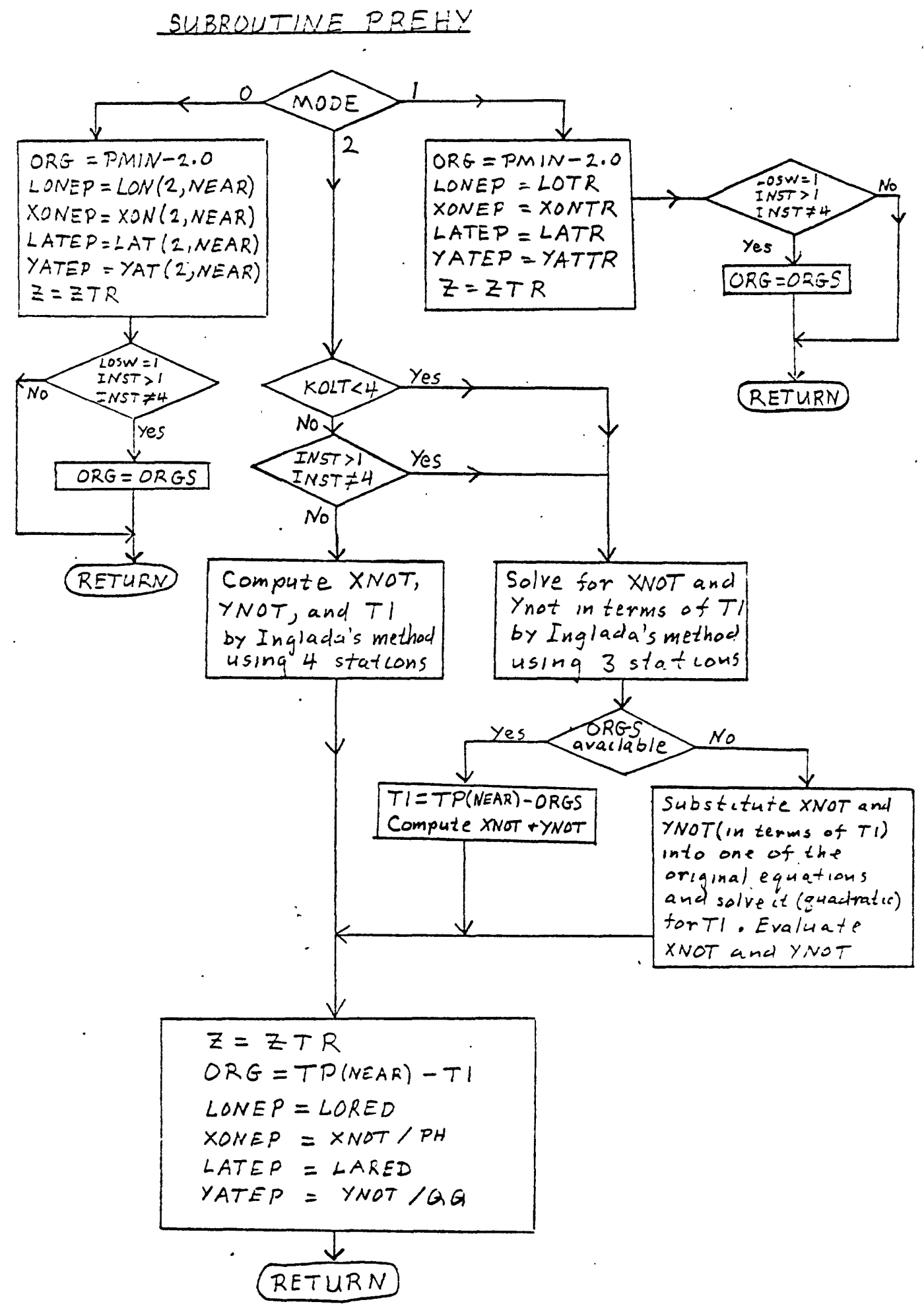




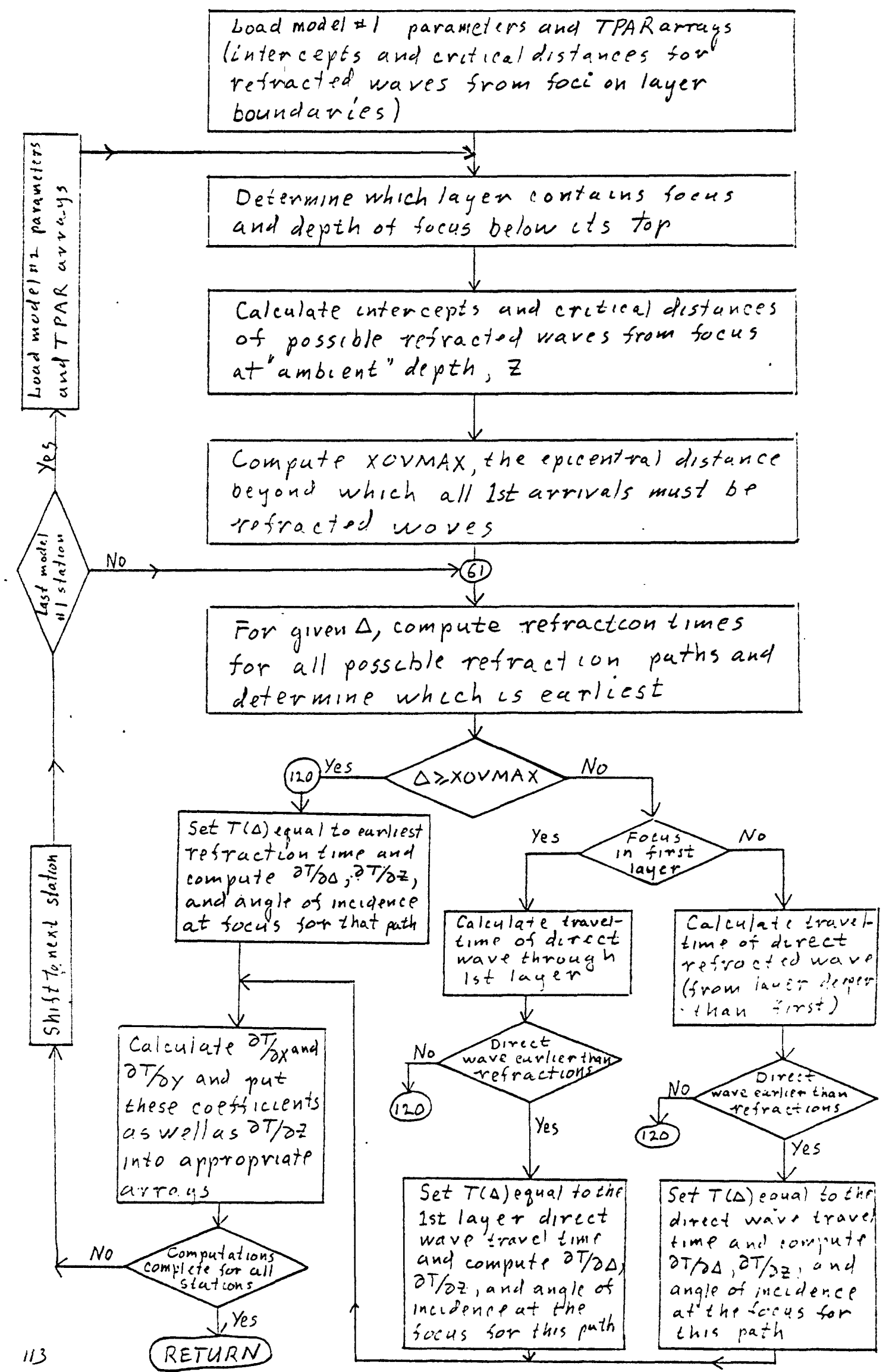




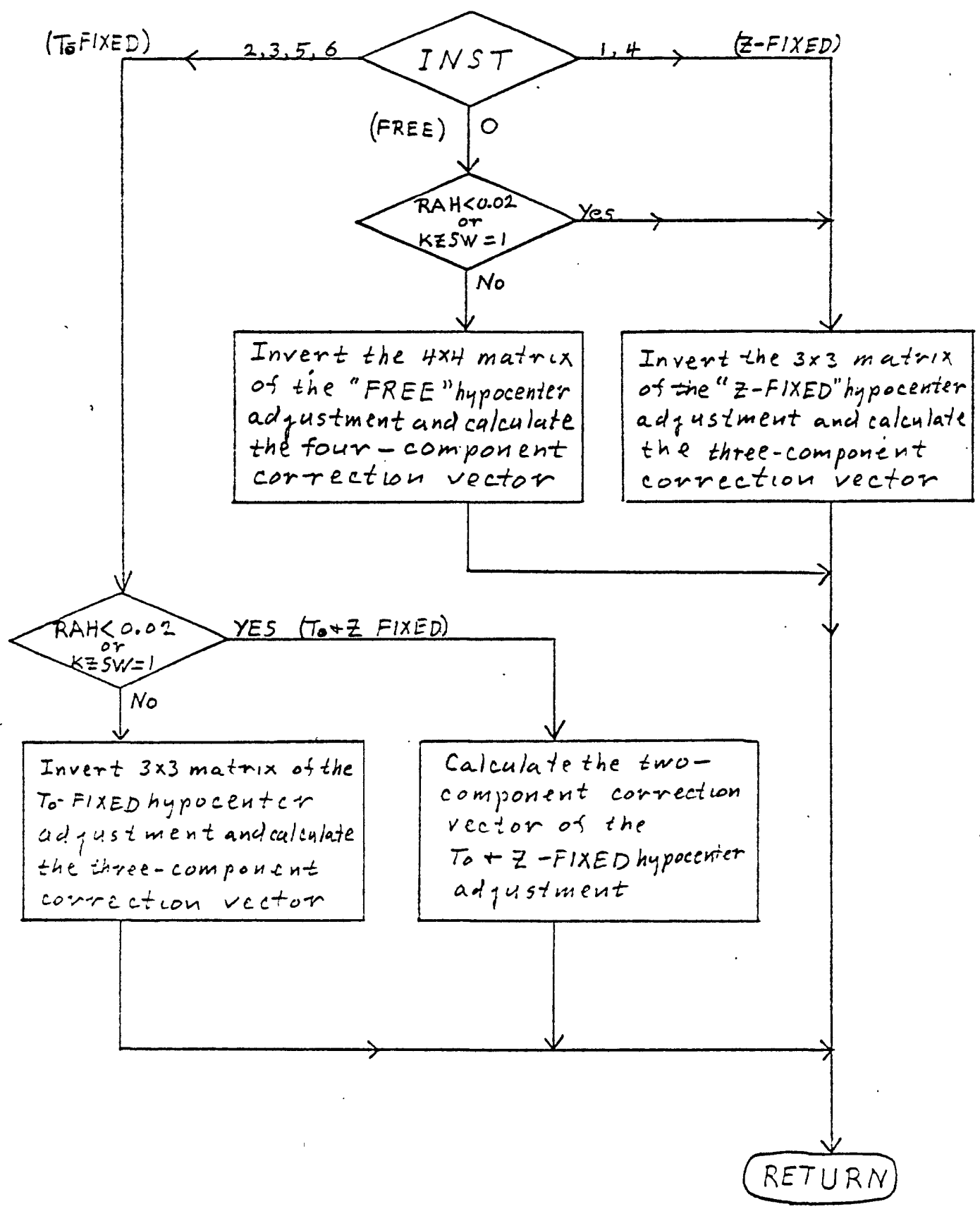




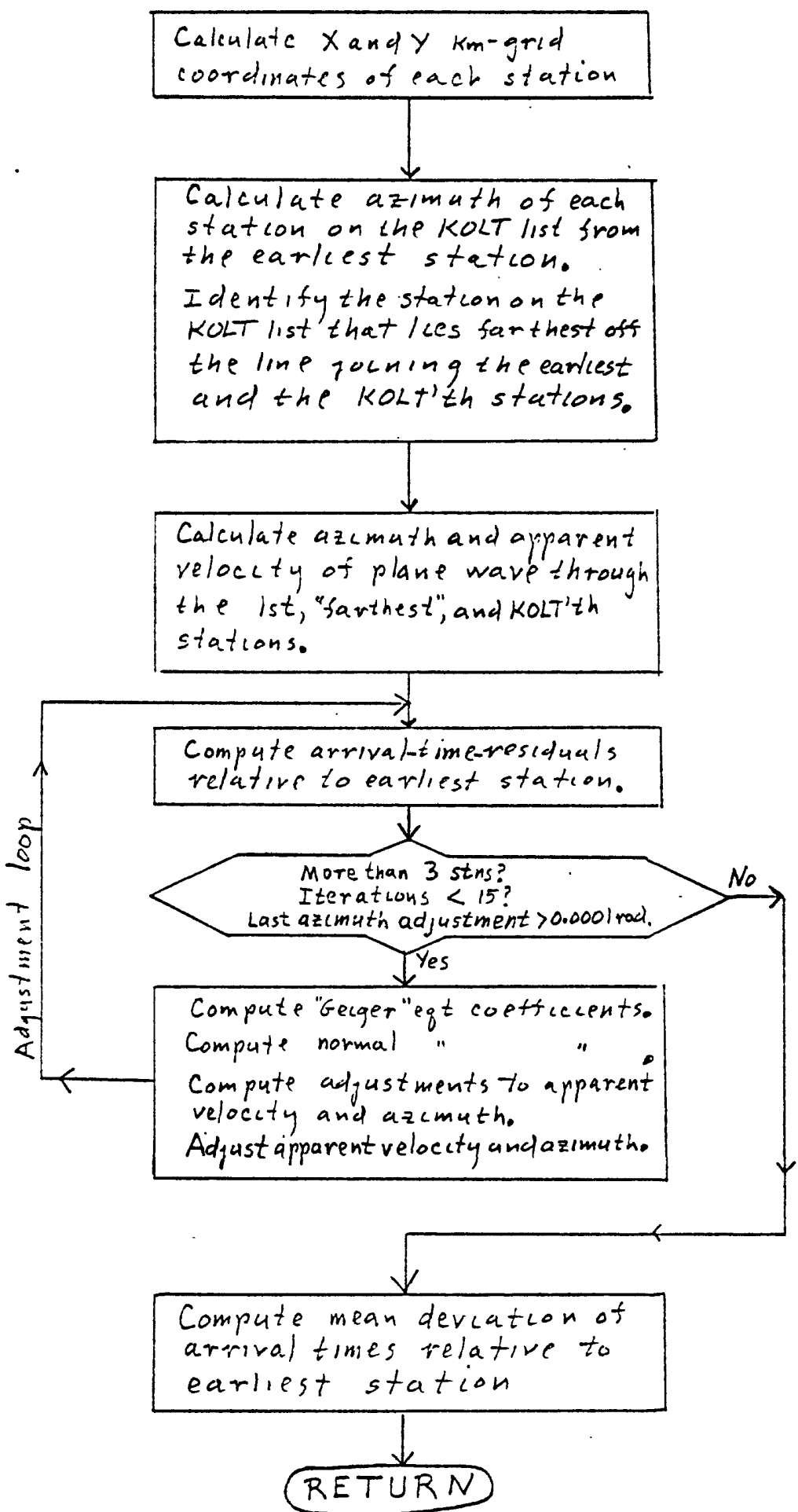




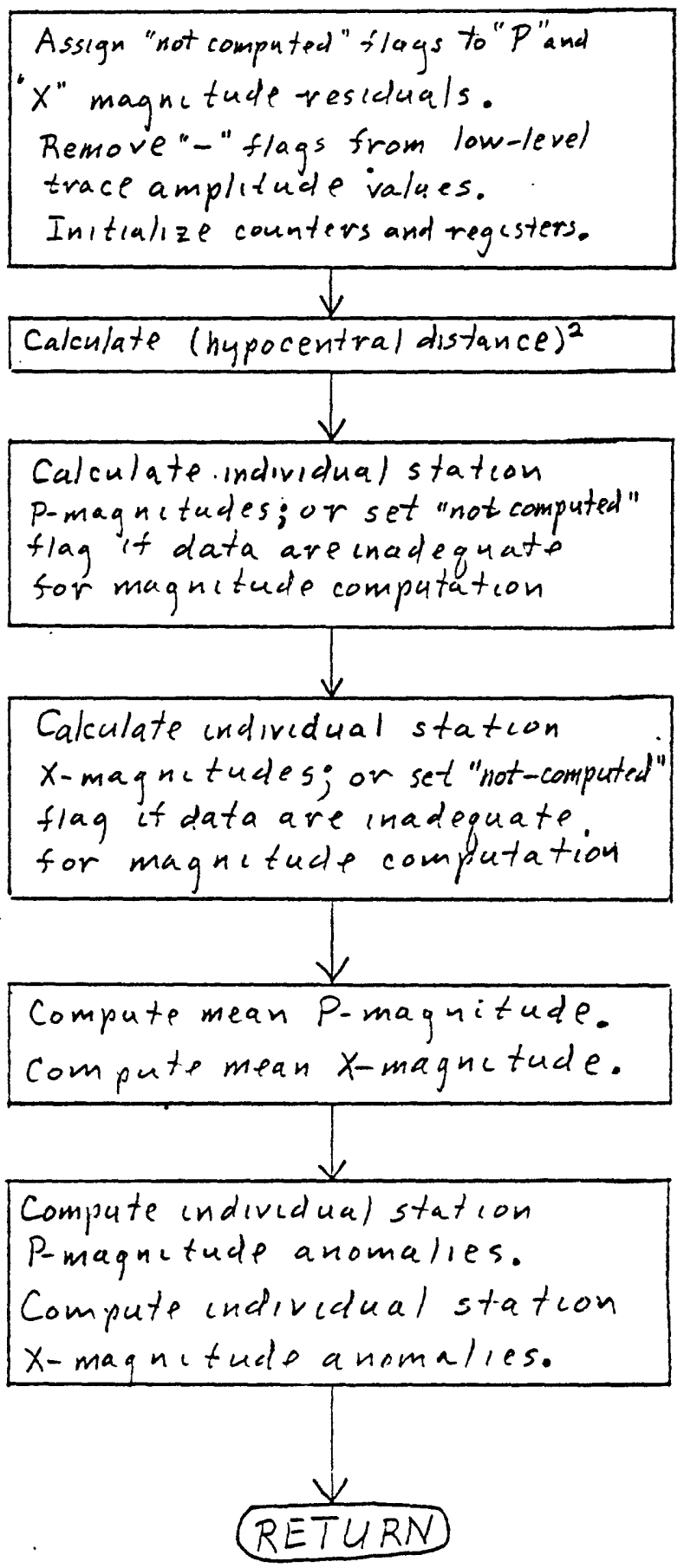




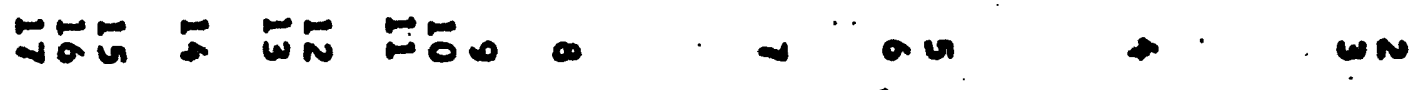

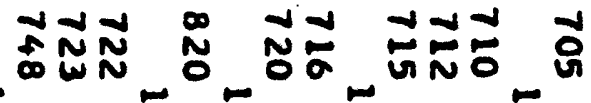

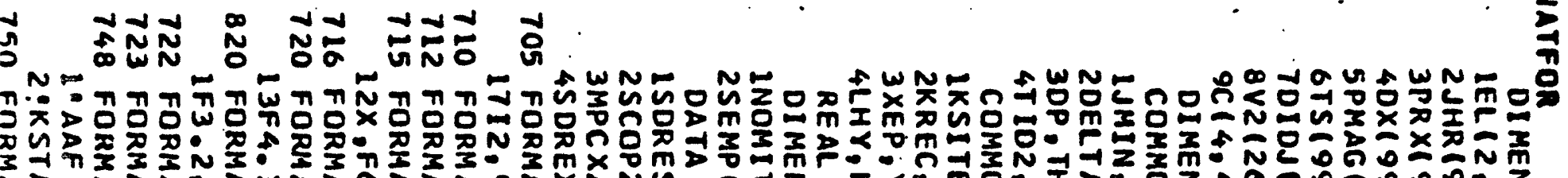

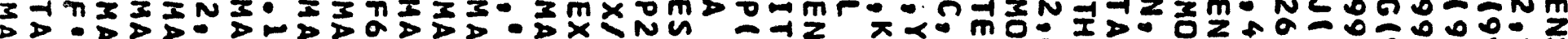

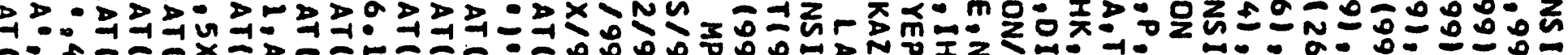

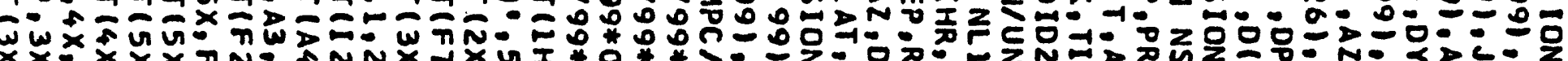

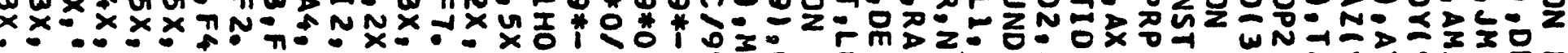

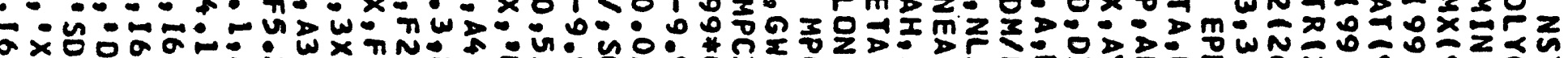

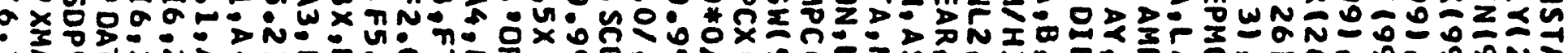
年 - w - XNNAX-OII

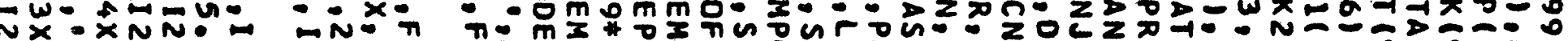
-

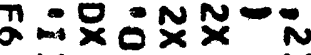
$\therefore=0$ 0 $x \times \geq z=$

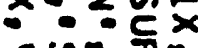

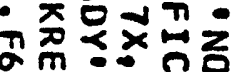

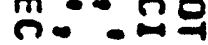
$0 \times \geq \geq 0$ $x$ (a) $\leq 5 \times 12$

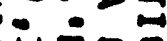

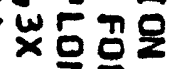
: $n \cdot r \operatorname{mon}$

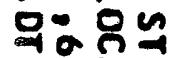

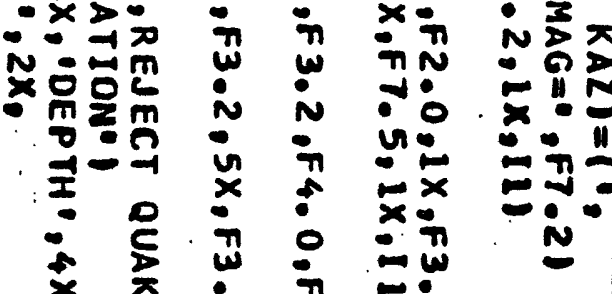

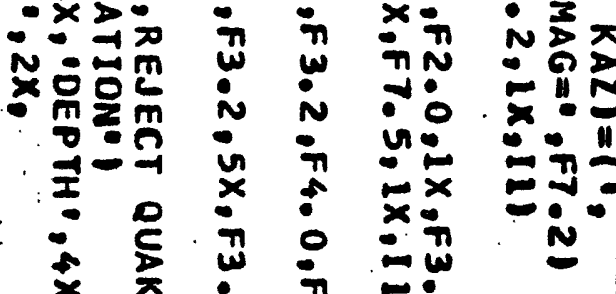

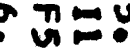
$n \cdot 0$ N - 0000000 “ N

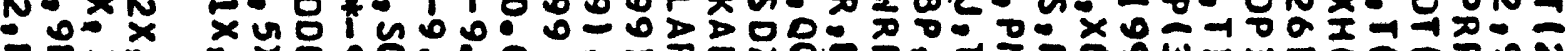
- Xmpo

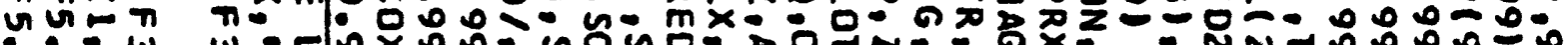

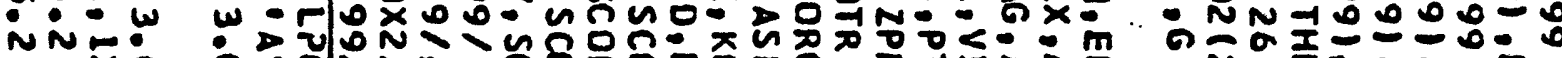
的0 :

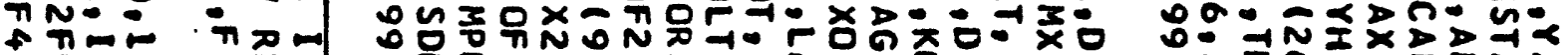

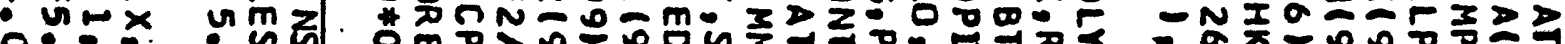
约 O $\sim M-10000$

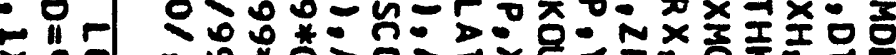
0. $-1-0=-100000$

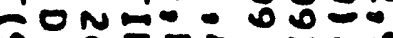
$00000-000$

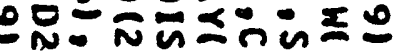

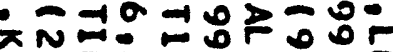

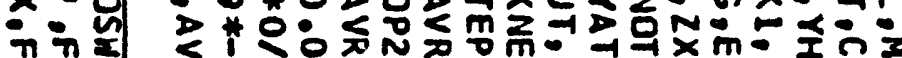
ñ

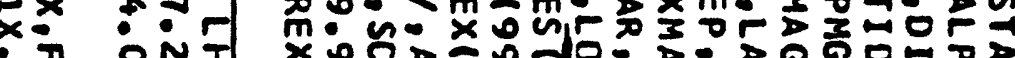

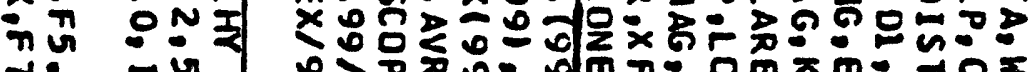

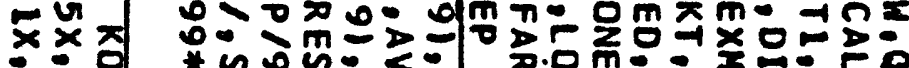
$\pi \cdot$ i mondu

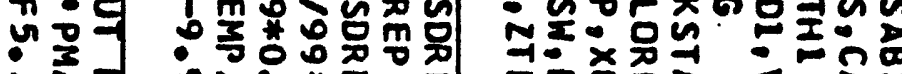

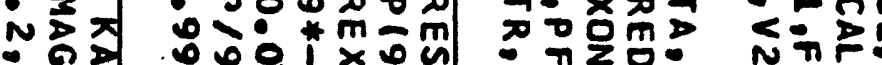

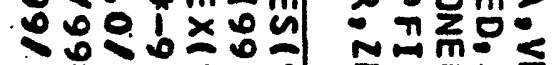
N

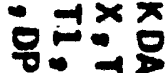

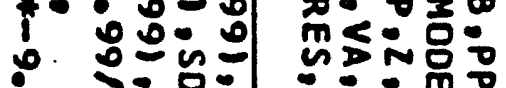

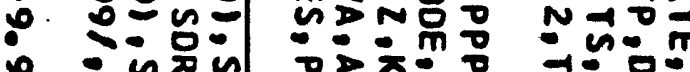

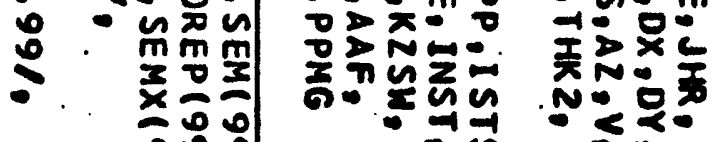

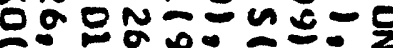

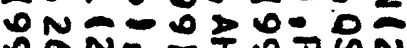

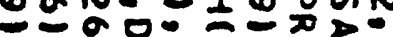

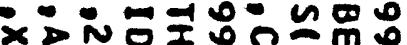

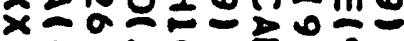
$3=-n=0 \leqslant 0$.

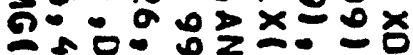
60 $0.000 z 03 \pi 2$

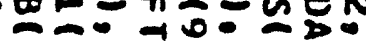
ANAEO-10 - $=0-20$ m. <放: $\leq \alpha \frac{2}{2}=\frac{\pi}{0} 00: 0$ 


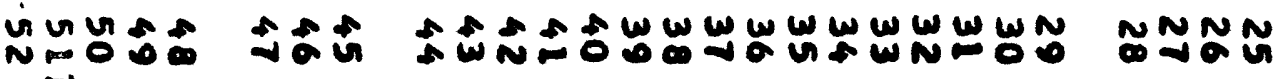

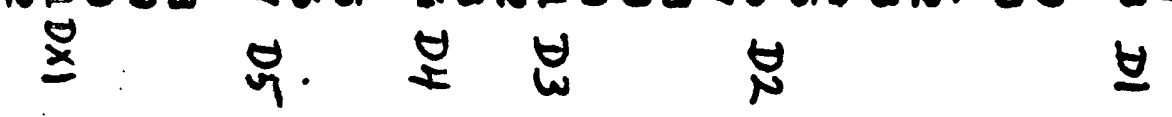

\section{$\infty \infty$}

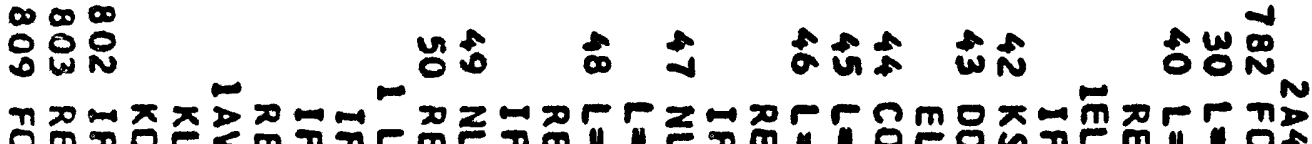

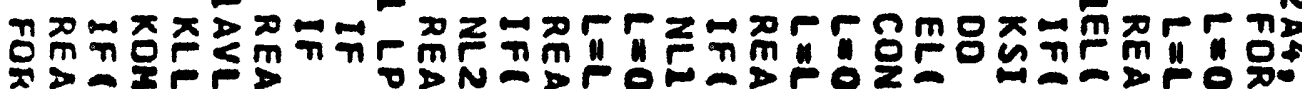

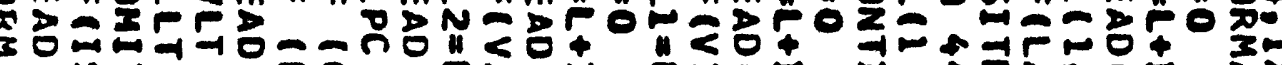

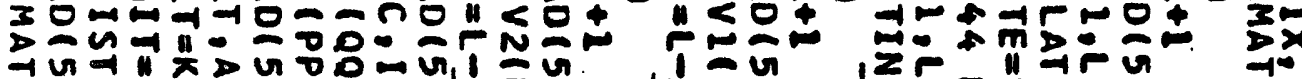

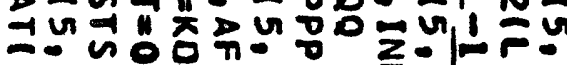

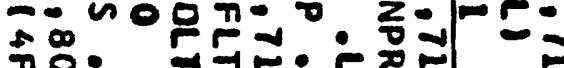

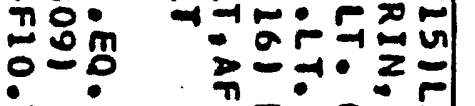
(1)

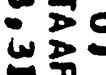

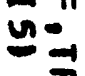

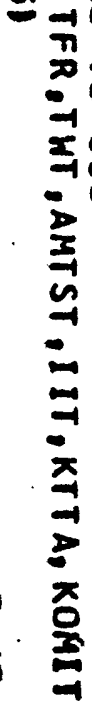

$-1$ $\infty$

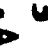

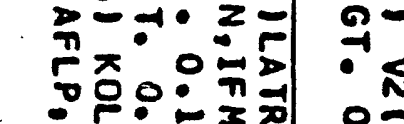

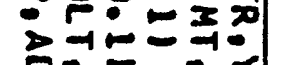
再 080

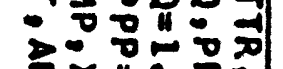
을 i

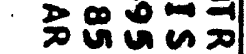

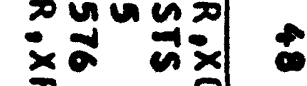

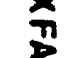
? İ

6 $\sum_{\substack{0 \\ 0}}^{0}$ $\sum_{-1}^{\infty}$

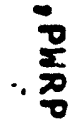

i⿱丶万仒

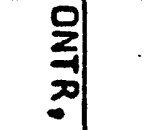

$0^{-1}$ 음 ㅇํㅁำ

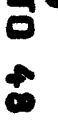

bFज

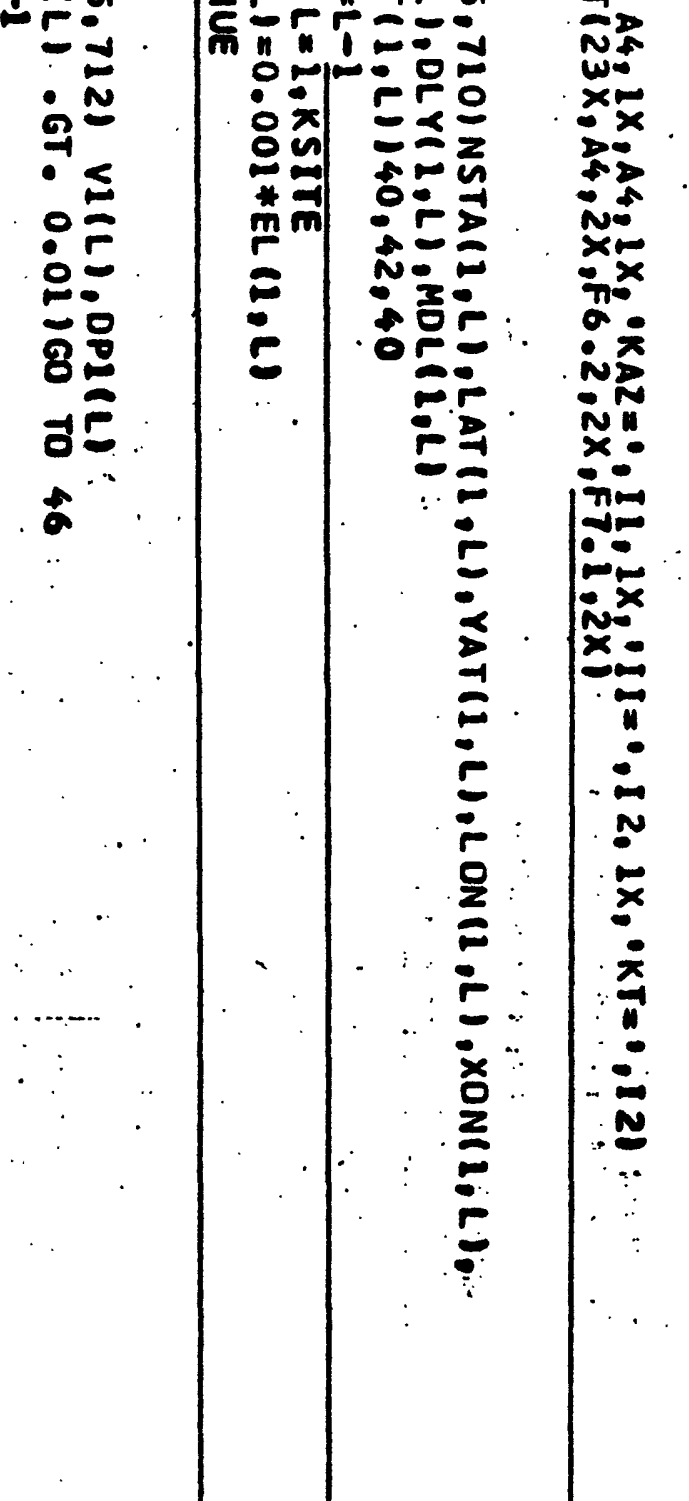

NNN N O

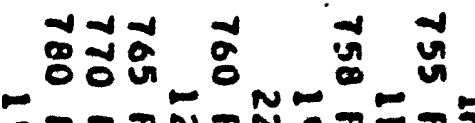

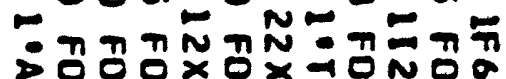

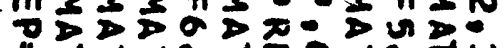
11

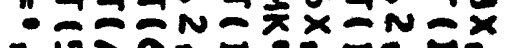

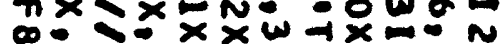
- $-2-x \times n-N N$

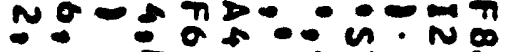

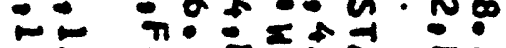
$x \times \therefore N \pi \times x \geqslant \pi$

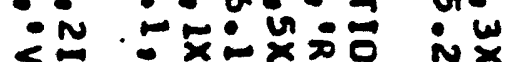

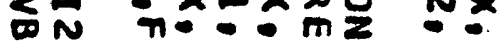

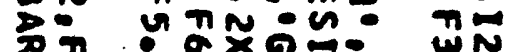

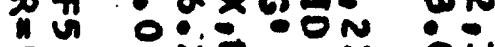
$\because n$ in $n-\because x: w$

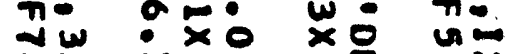
nx =ni 的 蓶 $\times=-\pi \pi$ 要 $\pi$

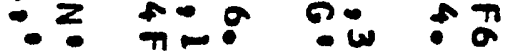
iv

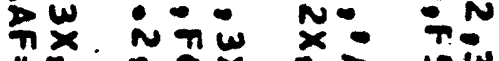
$11: 0 x-2$ U.

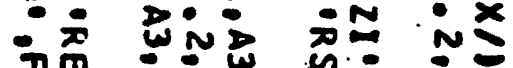

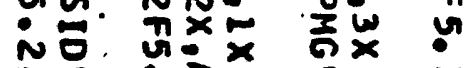
$\because$ : .

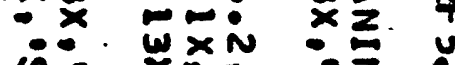

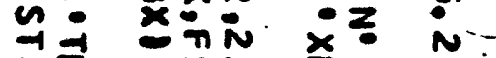

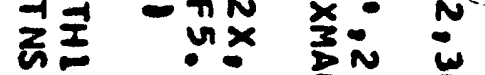
zE: N

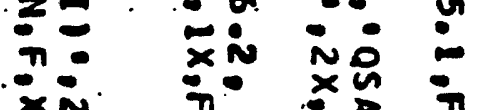
$x$ .

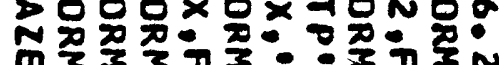
ज्a-n. Un. NND DE in

$+\frac{1}{4}$

$\stackrel{x}{a}$ 


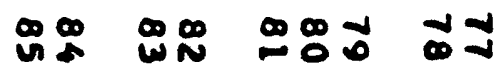

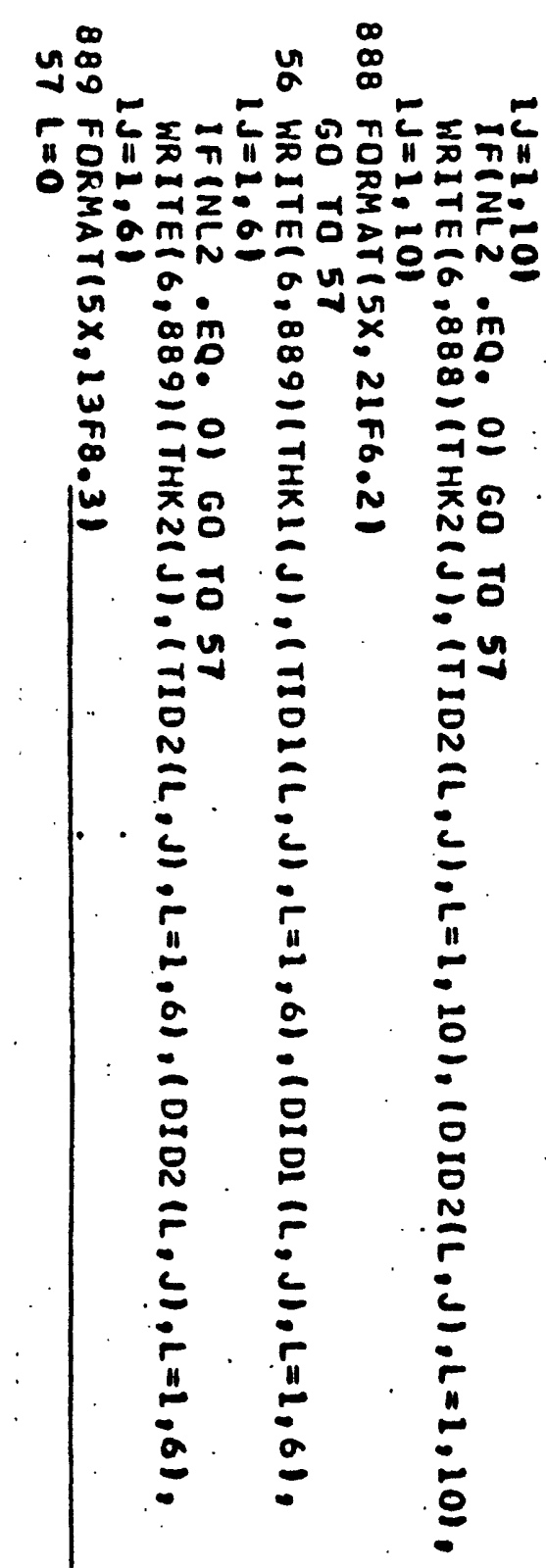

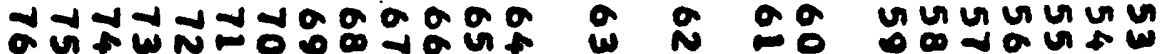
疍

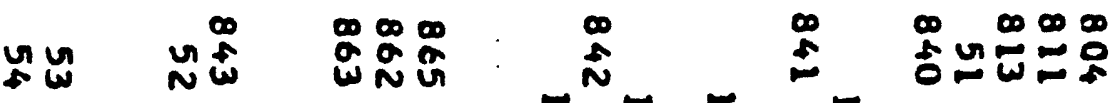

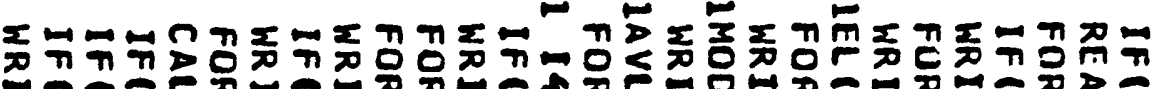

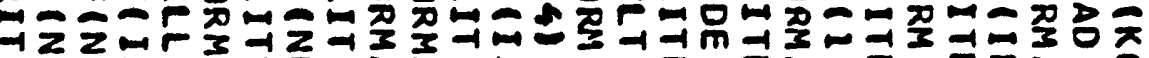

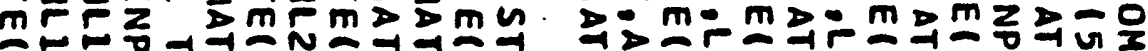

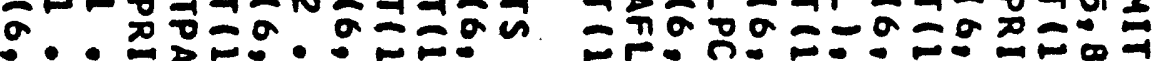

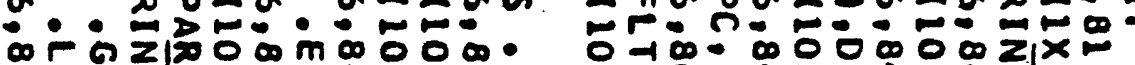

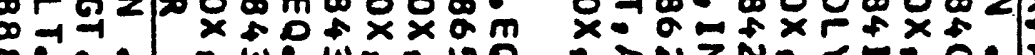

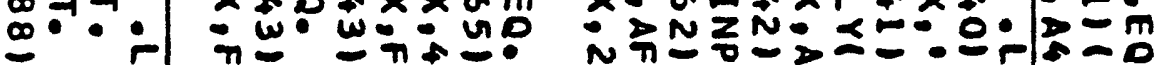

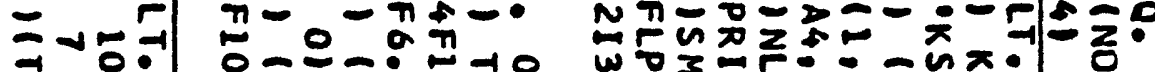

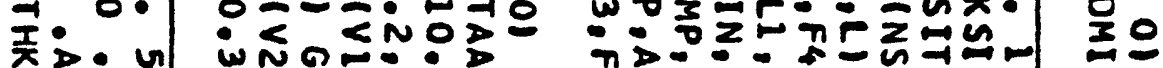

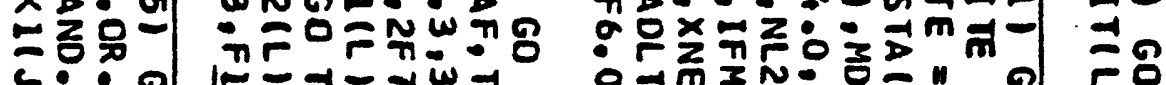
이

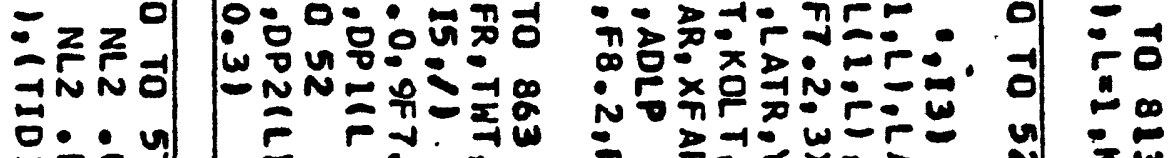

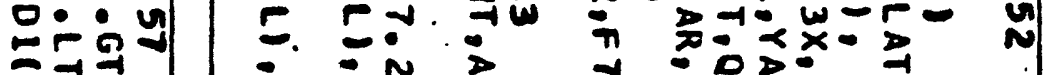
こニ5

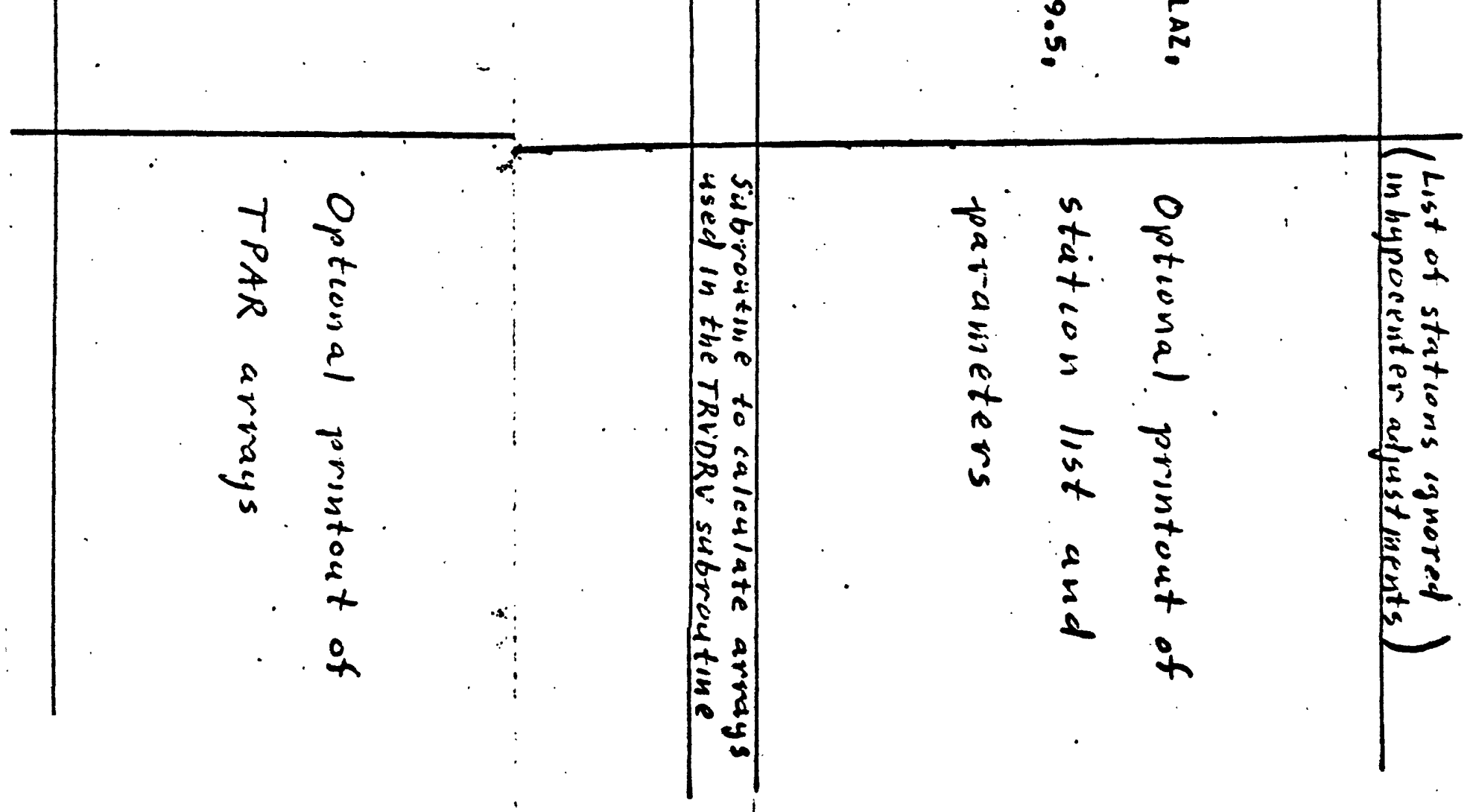




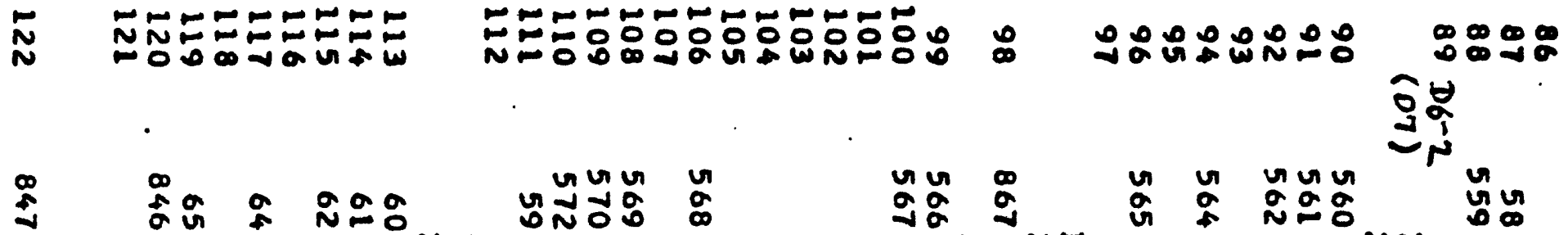

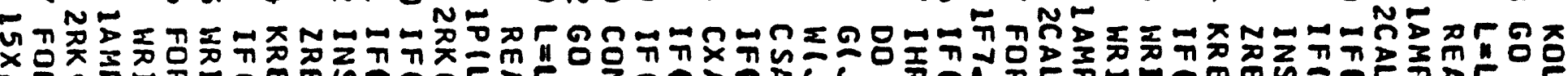

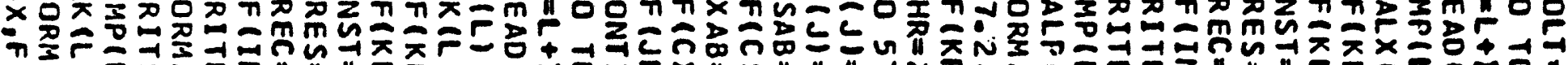

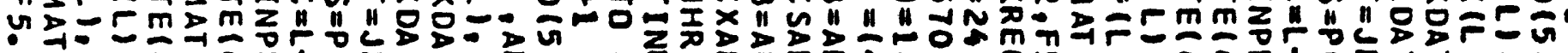

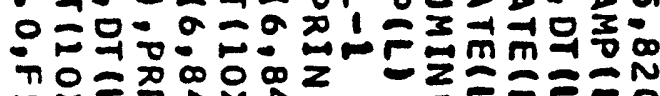

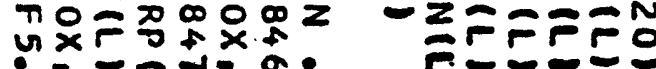
ni=

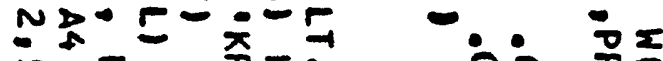

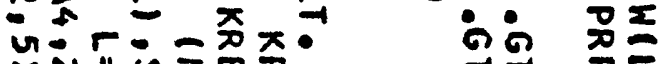

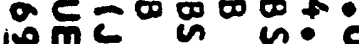

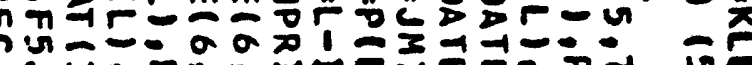
ज㛡

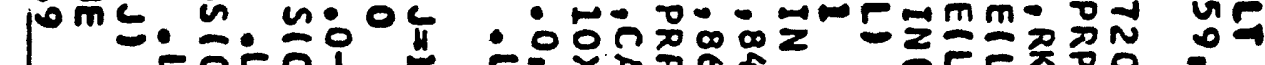
rล்

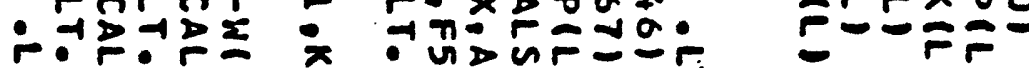
-

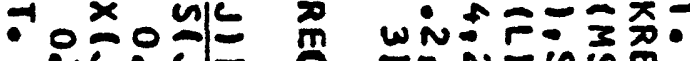

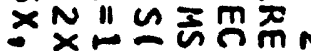

x的向

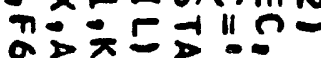

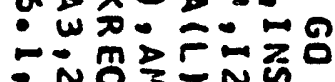

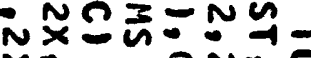
$x=-10 D_{0}^{-1}$

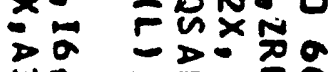

w. $=>0$

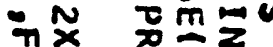

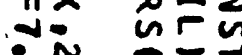

$N \cong E=-1$

공

II

i $\frac{x}{F} \frac{m}{x}$

जก. $=$

- D促

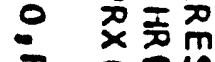

ज $=5 "$

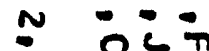

$\therefore \quad 5 z N$

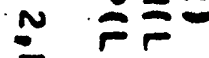

in -

u

जु

$\because-2$ EA

용요 등

응으 든

은

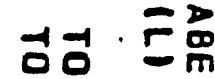

옹

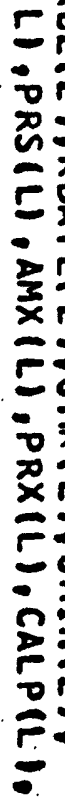

17 zbmeof poad

$\because$
ก $\sum \frac{1}{3}$ -0ㅇㅇㅇㅡ.

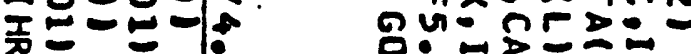

व:글

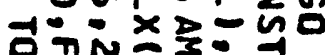
v들

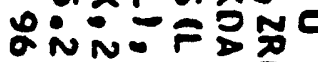

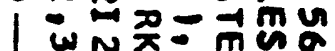

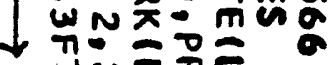
ด 2 N

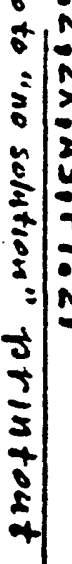

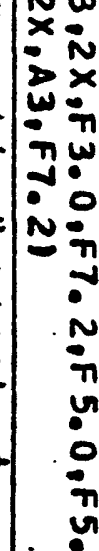

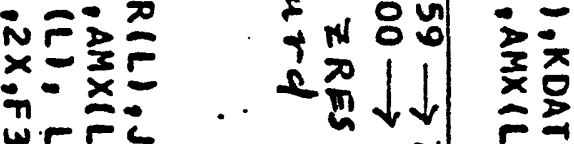

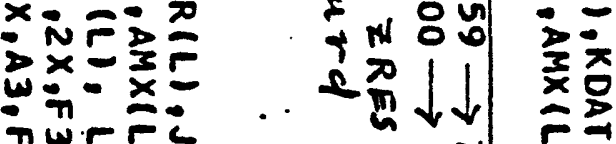
a $n=00 \overline{0}$.

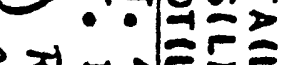
$20 \pm 5=5$ 18 용 $x$ 이 幺出 : र 눙요 $s$ \& s 两分

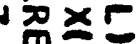
$\dddot{z}$ ID: $n$
0
$n$
$n$
0 .

5

를

i 
- R-

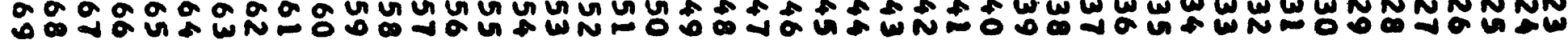

: ®®心



กั่อี ถัข

å

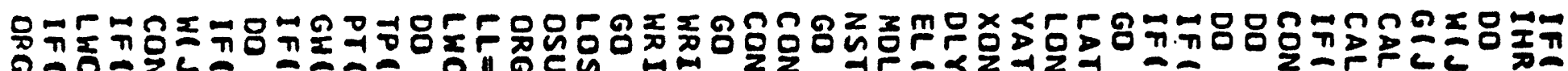

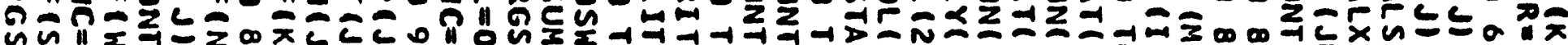
แU

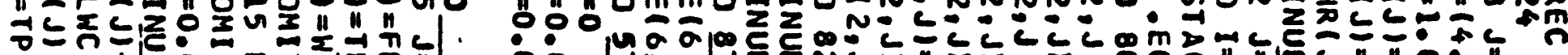

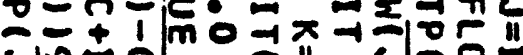

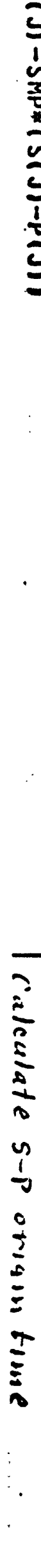
준.

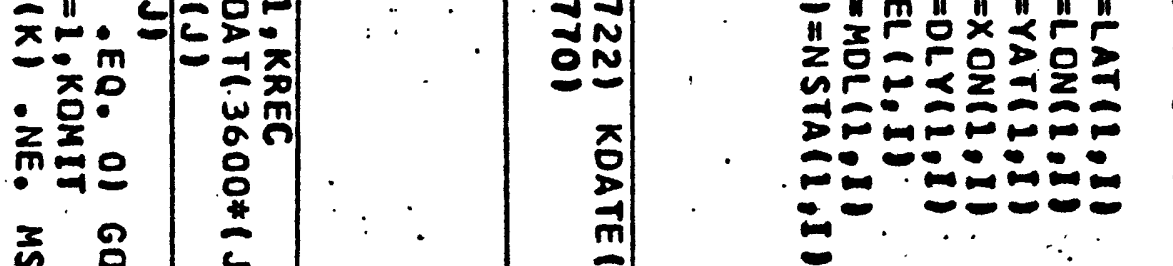

3
$\vdots$
$\vdots$
0
0
0
0
0
0

:

.

th

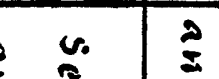

$30 \sin 2$

$+$

$=0$

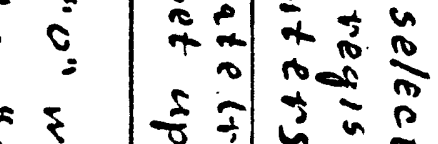

$\sum^{2}$

$-$

$y=$

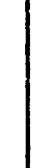

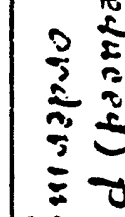

E.

h

?

8

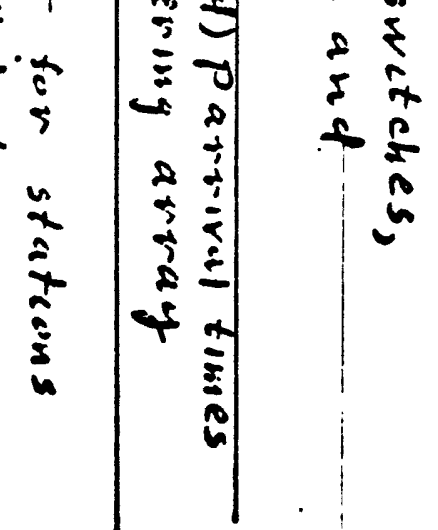

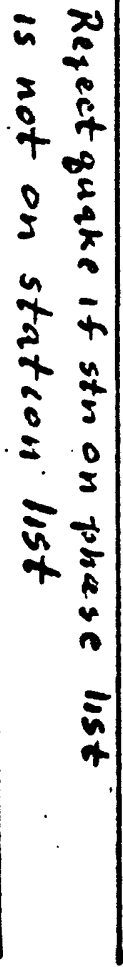

$\begin{array}{ll}n & 3 \\ x & 0 \\ 2 & 0 \\ + & = \\ 0 & \frac{5}{7} \\ = & 5 \\ = & 5 \\ 4 & 0\end{array}$ 
NNNNNNNNNNNNN

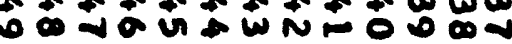

ثิ

$\underset{\infty}{\omega}$

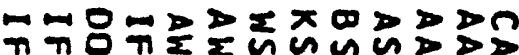

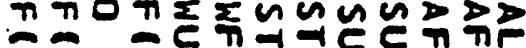

ठठ一

m m in

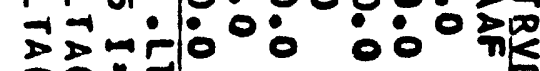

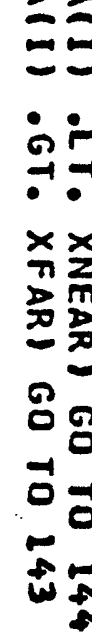

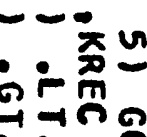

$\times \times \quad$ -

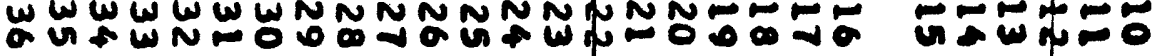

wั

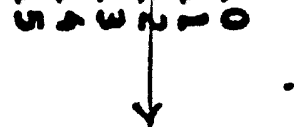

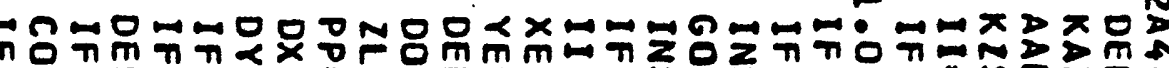

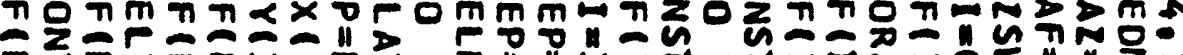

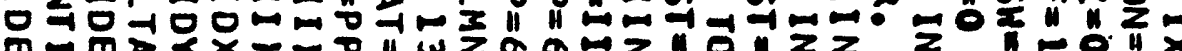
m

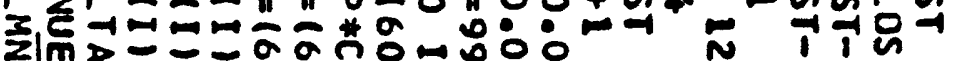
* *

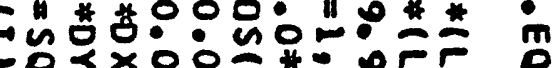

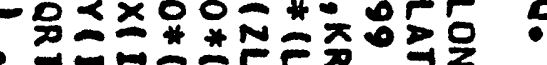

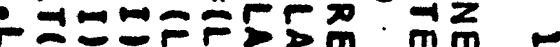

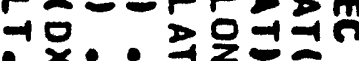

-xiraż

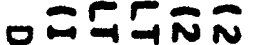

m—・

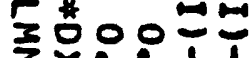
$-085 r$

$=080$

m+o이요

둥ㅇㅇㅇㅁ음

$\sum_{i}=-\div+$

000

向

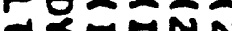

$-2-0$.

- $-00=$

-0.0 11 8이ำ

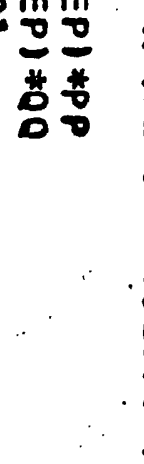

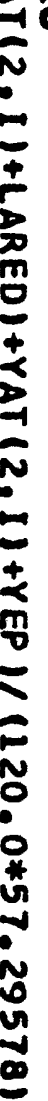

i

$5 \frac{1}{0}$

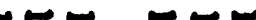

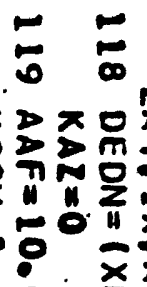
: . 
NNNNNNNNNN NNNNNNNN N NNNNNNNNNNNNNNNNNNNNNNNMN W

牙苟

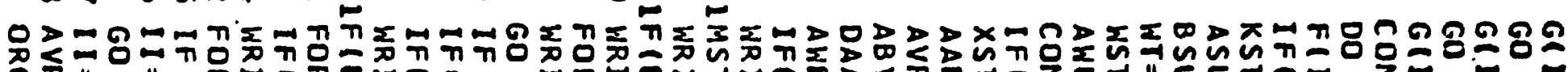

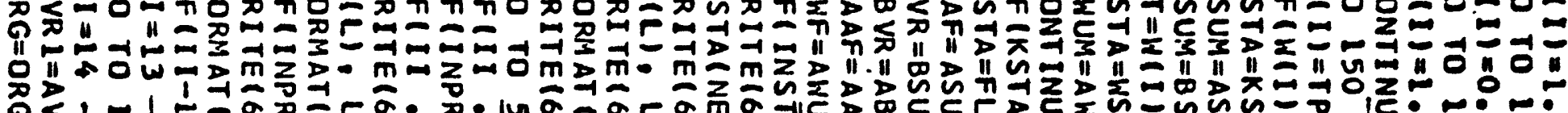

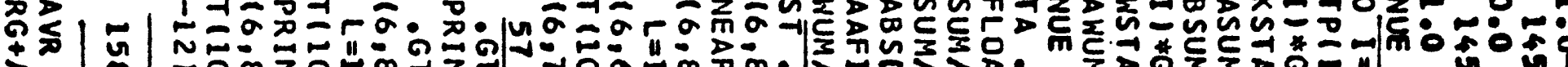
$\downarrow$

$$
\sqrt{ }=
$$

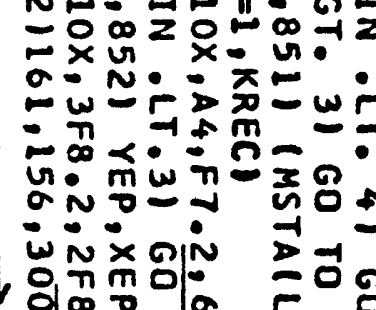

Oी:

$-1$

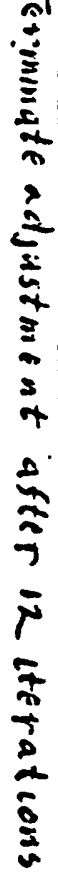

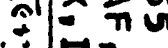

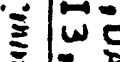

年

N

$-\infty$

文

4.

(a)

2

a

$\underline{\xi}$

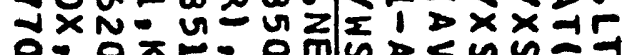

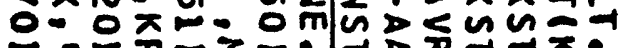

舟-

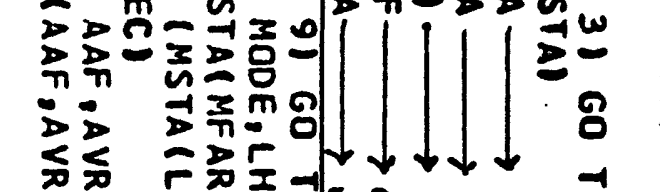

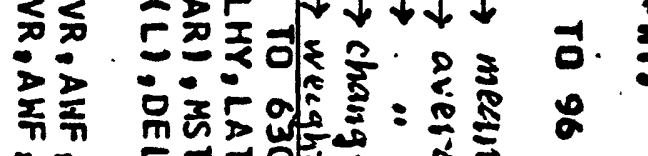

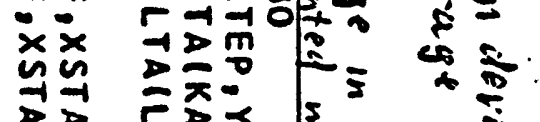

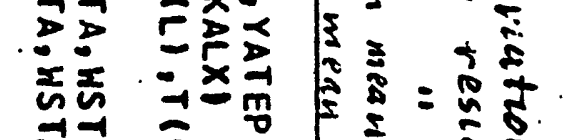

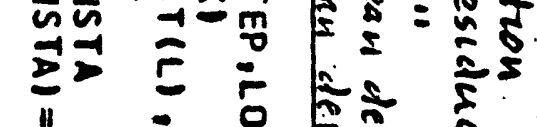

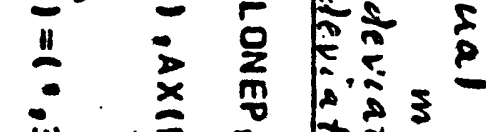

i

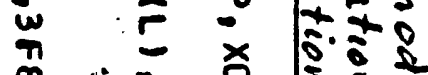

$: \cdots$

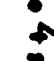

ก̃

గ్ర

$\stackrel{\infty}{n}$

$\because \quad \hat{r}$

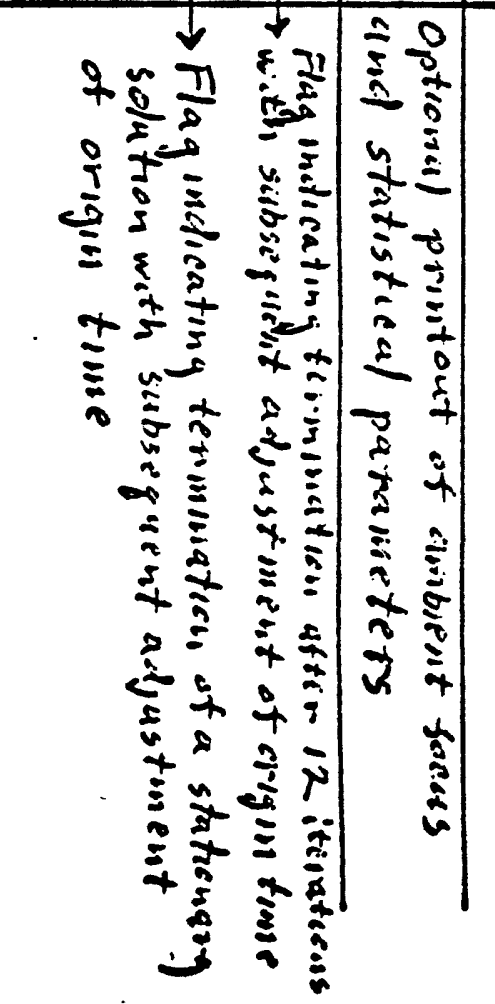

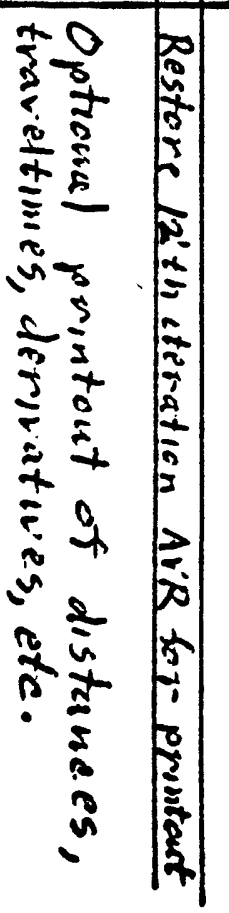

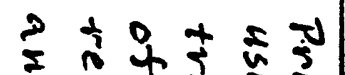

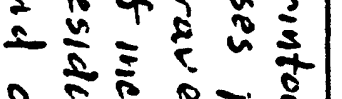

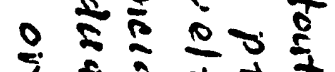

$\frac{1}{2}=5$

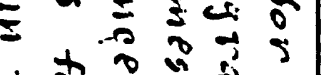

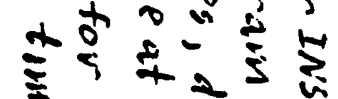

ڤ

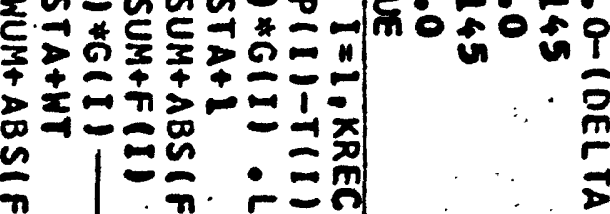

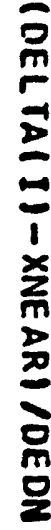




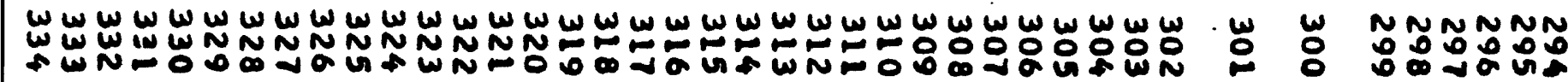
$\Xi \quad 5$

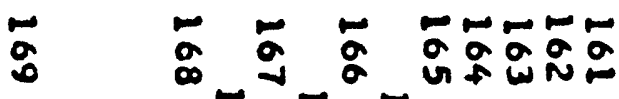

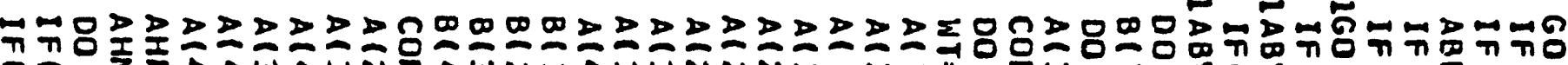

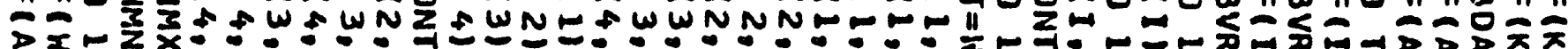

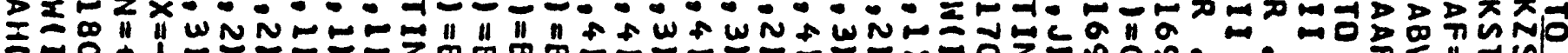
$=-0 \pm 1$ "

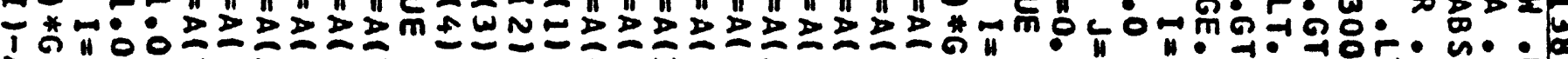

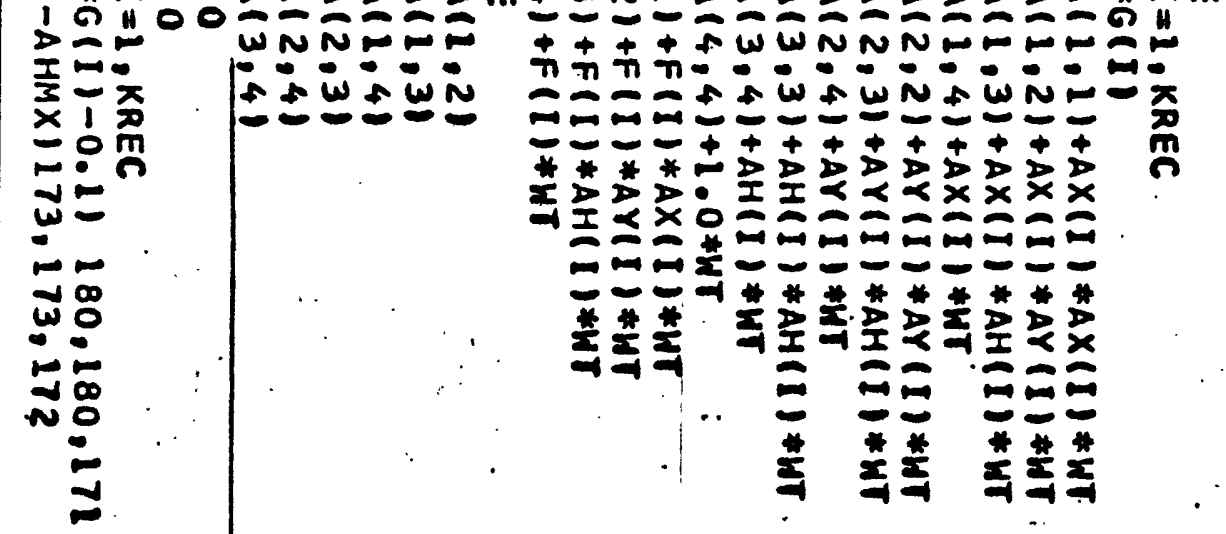

on $\because+\sum_{0} \geq \infty$ $\rightarrow \geq$

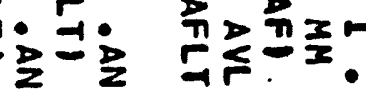

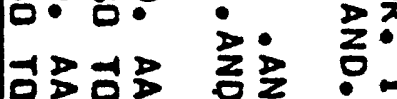

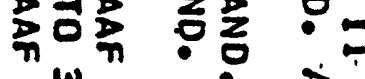

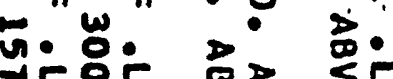
- $-400 \%$

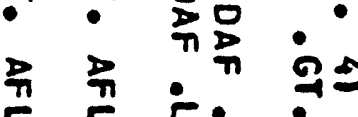
\%

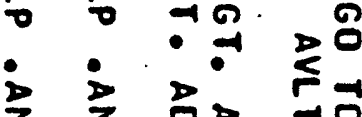

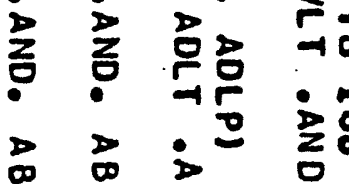

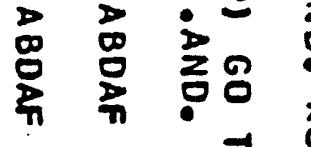

- $\therefore$ \& द. 万人.

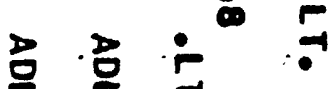
$5 \div \quad \underline{0}$

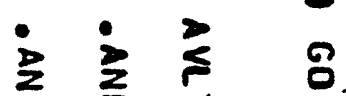

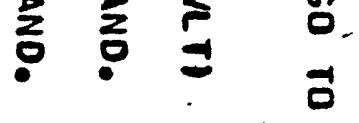

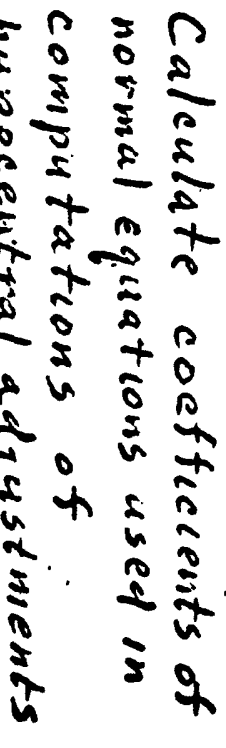

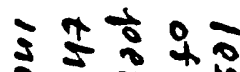
is

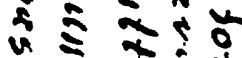
in

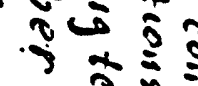

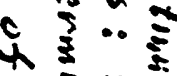
$x+\frac{10}{20}$

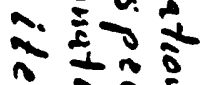
คิ $2.2 \frac{1}{2}$ i. (3) 2

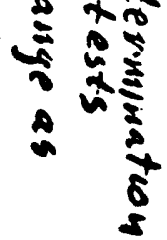




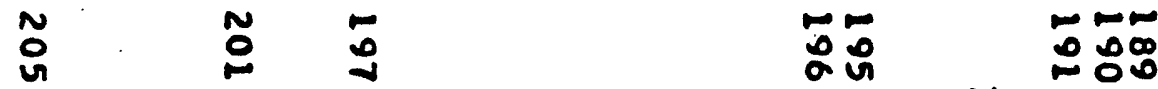

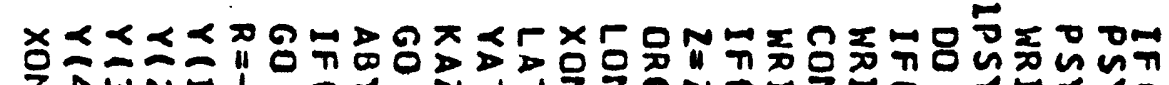
之NWN=1 m눈

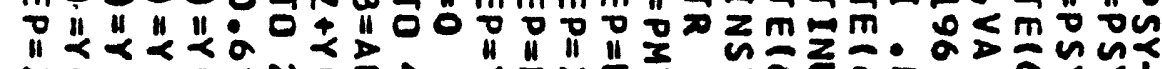

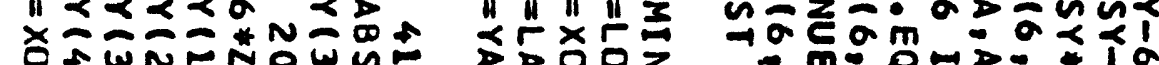
OE m***\#物

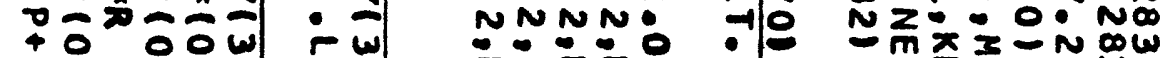
这

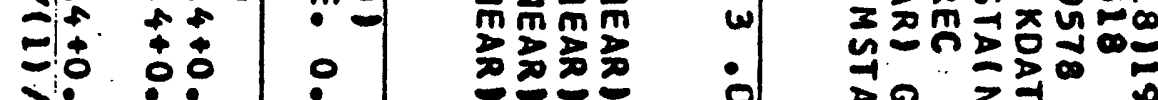
7:

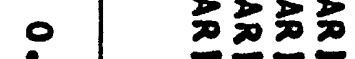

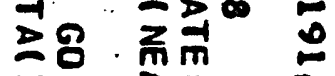

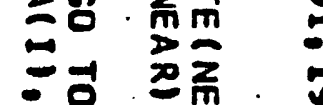

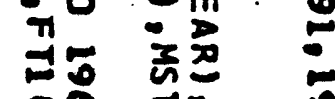

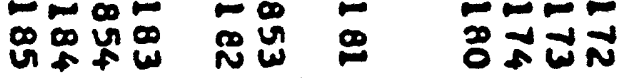

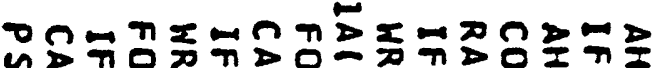

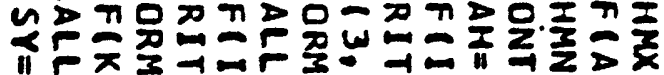

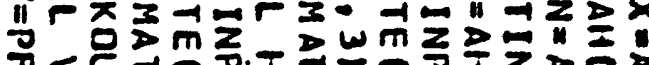

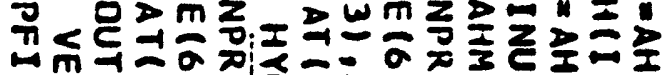

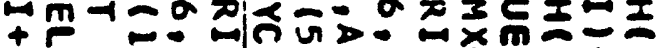
+ .

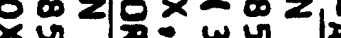

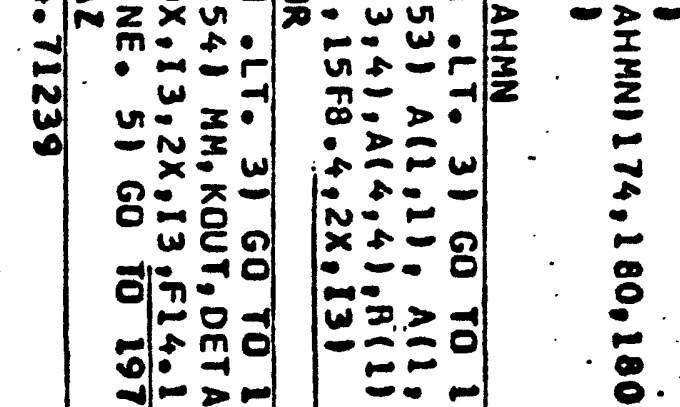

$=2 \underset{1}{2}:$

至 $\quad \frac{\pi}{\pi} \frac{1}{2}$

要

$\therefore \quad=\frac{\pi}{5}$

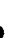

$\rightarrow \frac{1}{3}$

진

空而

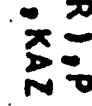

$\pm \sum_{m}$

$\sum_{0}^{m}$

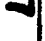


ft

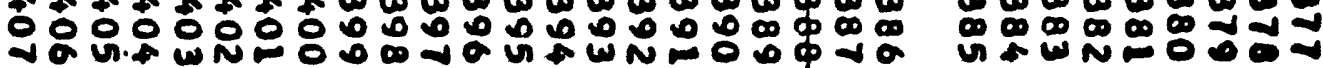

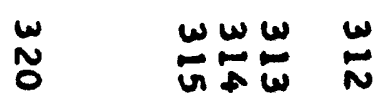

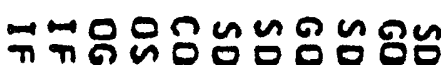

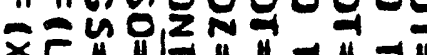

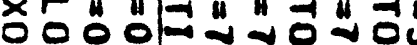
ㄴ. miseng

wi ND N:

$\omega-$

$\omega=$

ㄴ.

$\omega n$

जo

ㅇำ

号

昼

另

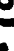

즘
พั
일

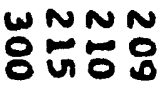
N N

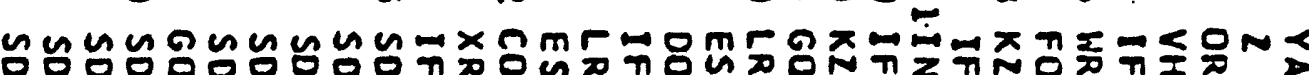

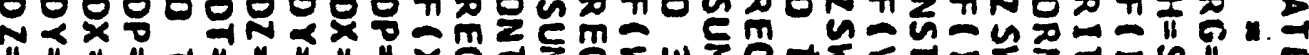
" $\|$ " 4 " W "

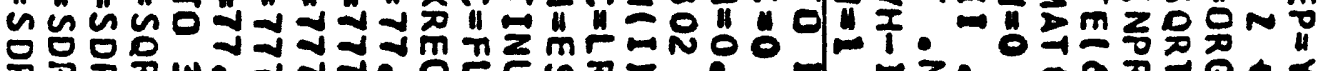

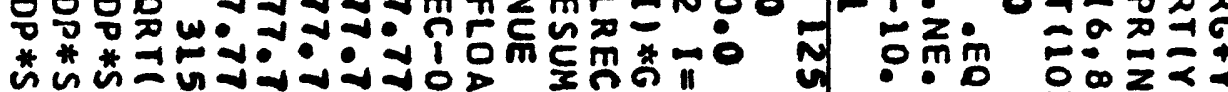
is nim $\not \boldsymbol{D} \boldsymbol{D} \backsim$

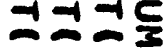

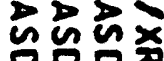
잉요

wô Ned

a.

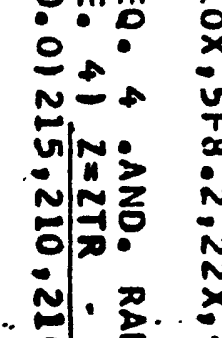

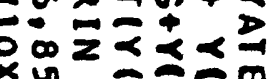

$x u \cdot=-\frac{\pi}{n}$

$n-F|-1| \frac{1}{n}$
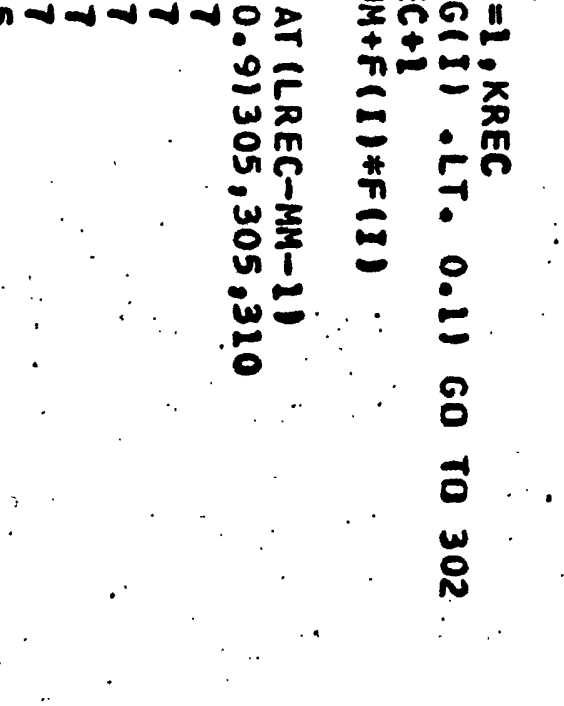


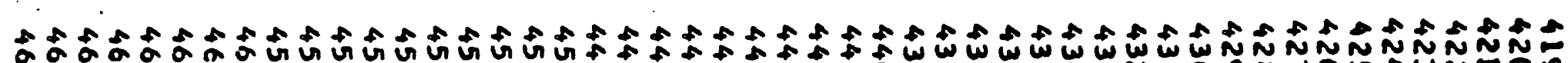

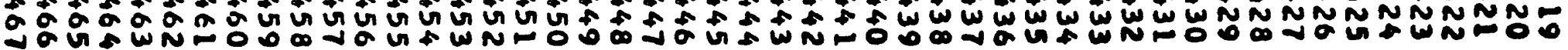

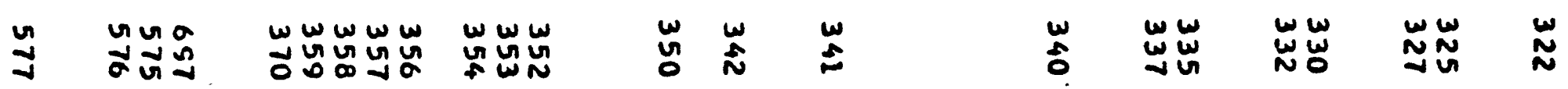

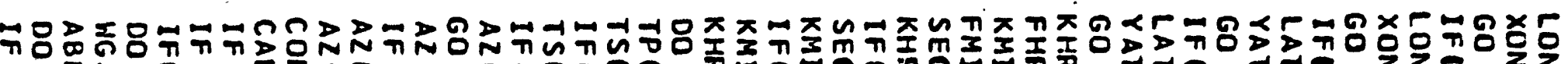

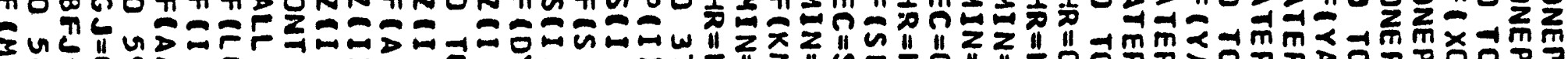

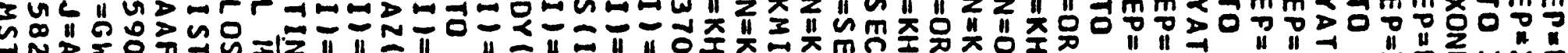

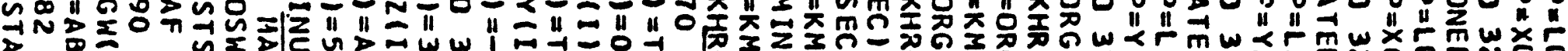

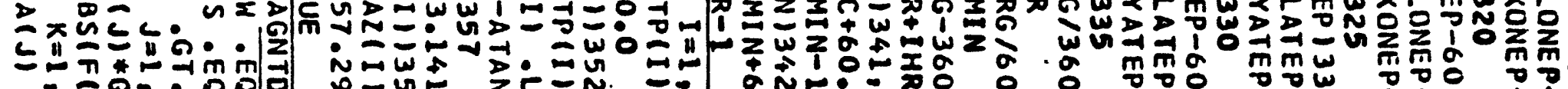

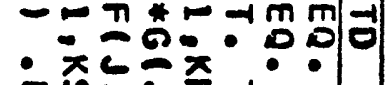

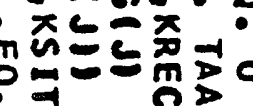

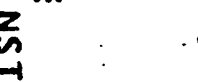

品象

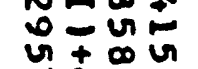

ज.:

* Nus

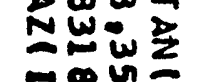

․․

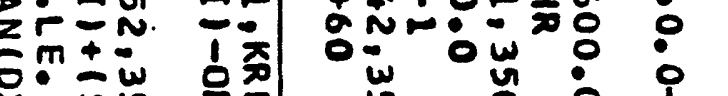
葆岕

厂

近

证

2

즌

2

$-1$

o

邑

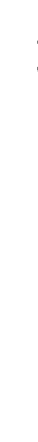

-

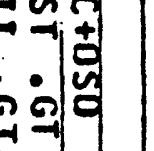

an $\quad$ =

$\therefore$

.

중

$\overrightarrow{2}$

$\dot{\vec{r}}$

$\stackrel{-1}{3}$

oี

离

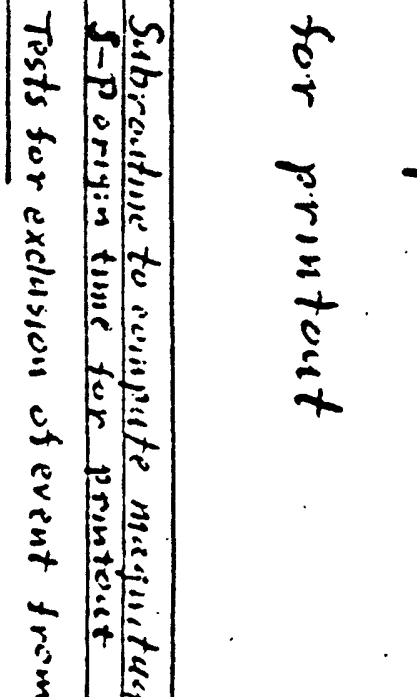

|

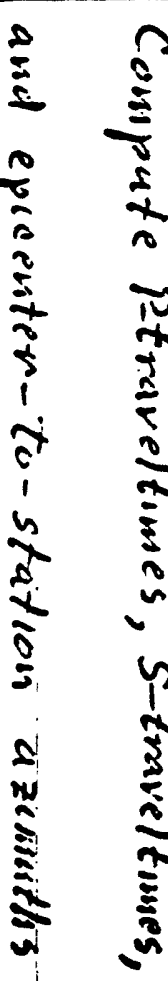

फ़

*

- :0:

品些

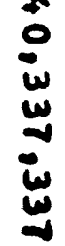

. 


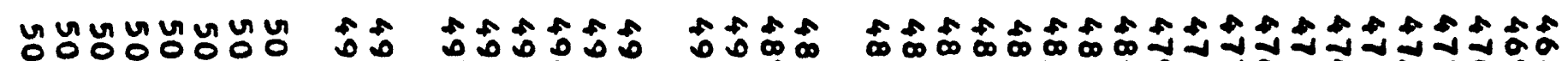

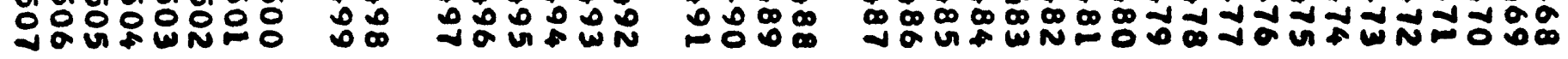

葛

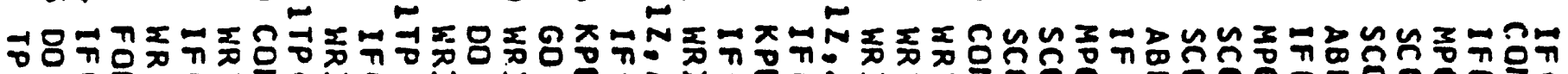

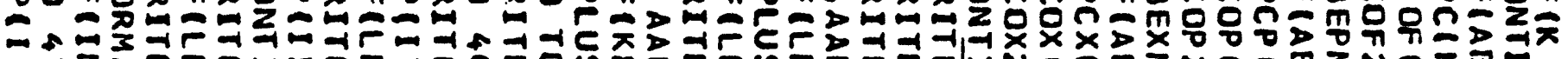
-

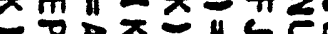
ง-

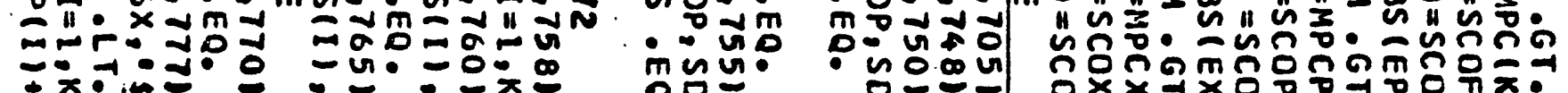

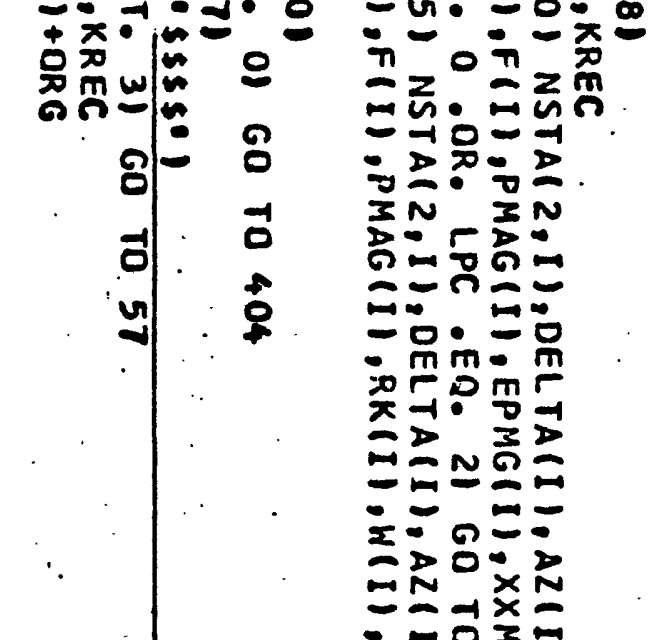

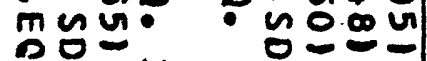

นิํำ

- $x+\omega$

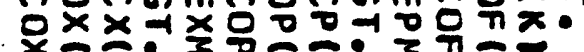

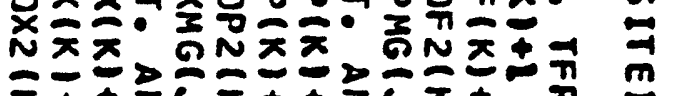

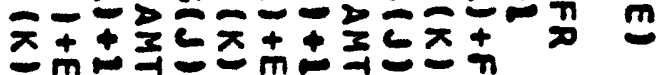
管 $\cdot$ モேำ 2:

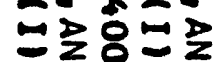

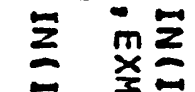

$=\equiv$

总点

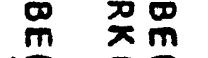

$\Xi \equiv \equiv$

. 일중 ơा 즈 政 - 0 ō은 w角

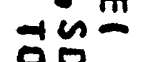
०० wis

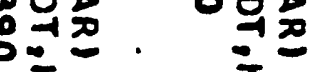

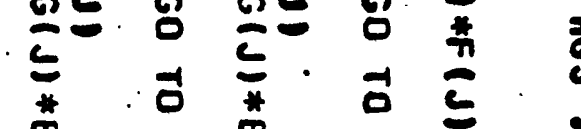

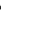


4 年

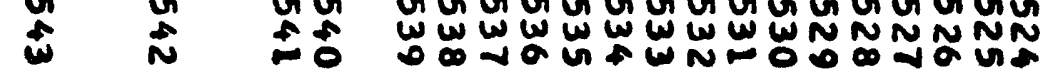

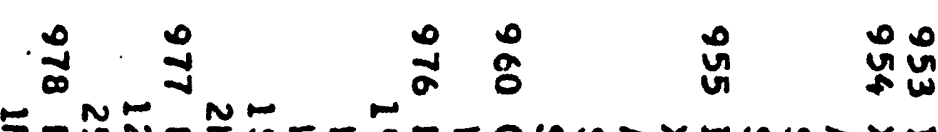

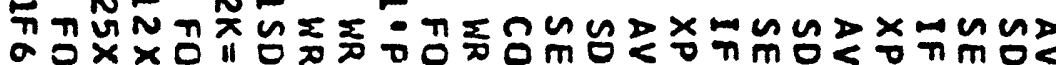

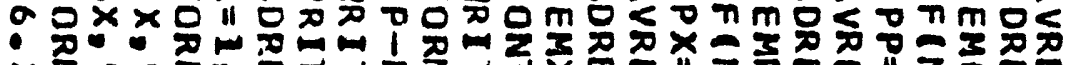

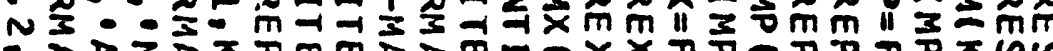

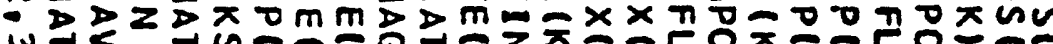

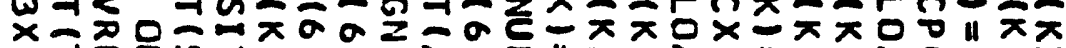
x

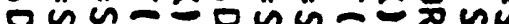
P...- isfing xix.

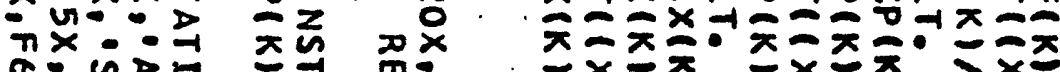

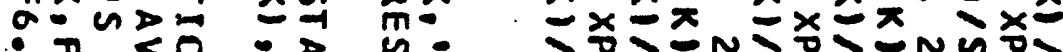

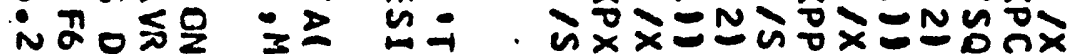

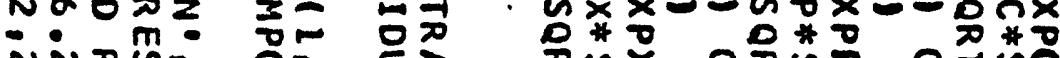

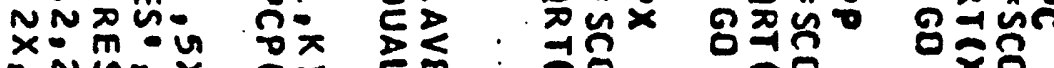
3
3 $a x=x$.

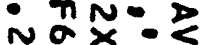
$\rightarrow N \cdots \ln$ $x=$ in in $m>0$ m

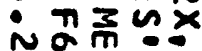
$\omega \sim \geq N$ in $x=x$ $\min _{-\infty} \times{ }_{0}$ m

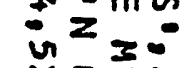
$x \circ \overline{0}$ ing $\because=-\dot{n}$ N. $\tilde{x}_{m}$ $\tilde{x}$

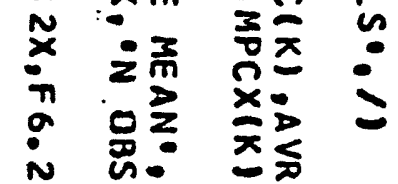

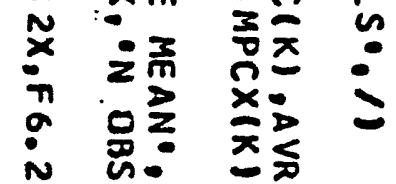

安.

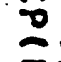

政

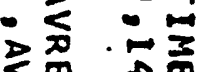

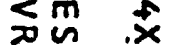

me

䇉

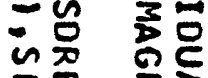

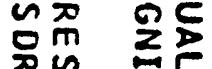

要

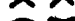

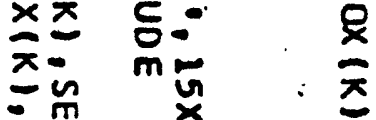

的政

等 $\bar{x}$

$\bar{x}=\bar{x}$

$\bar{x} z$ \&

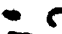

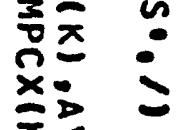

章
政

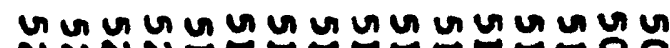

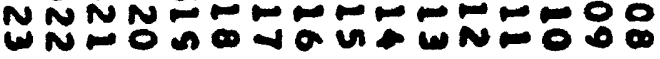

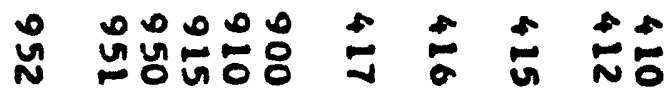

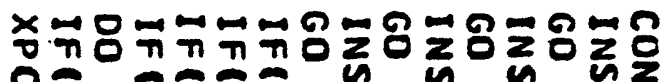
Q

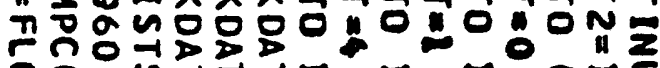

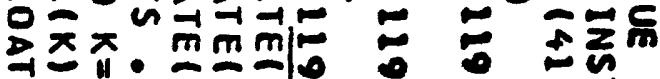
辛

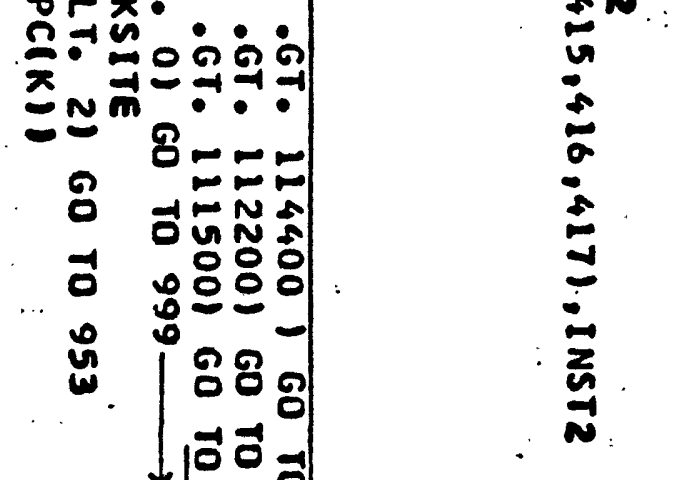

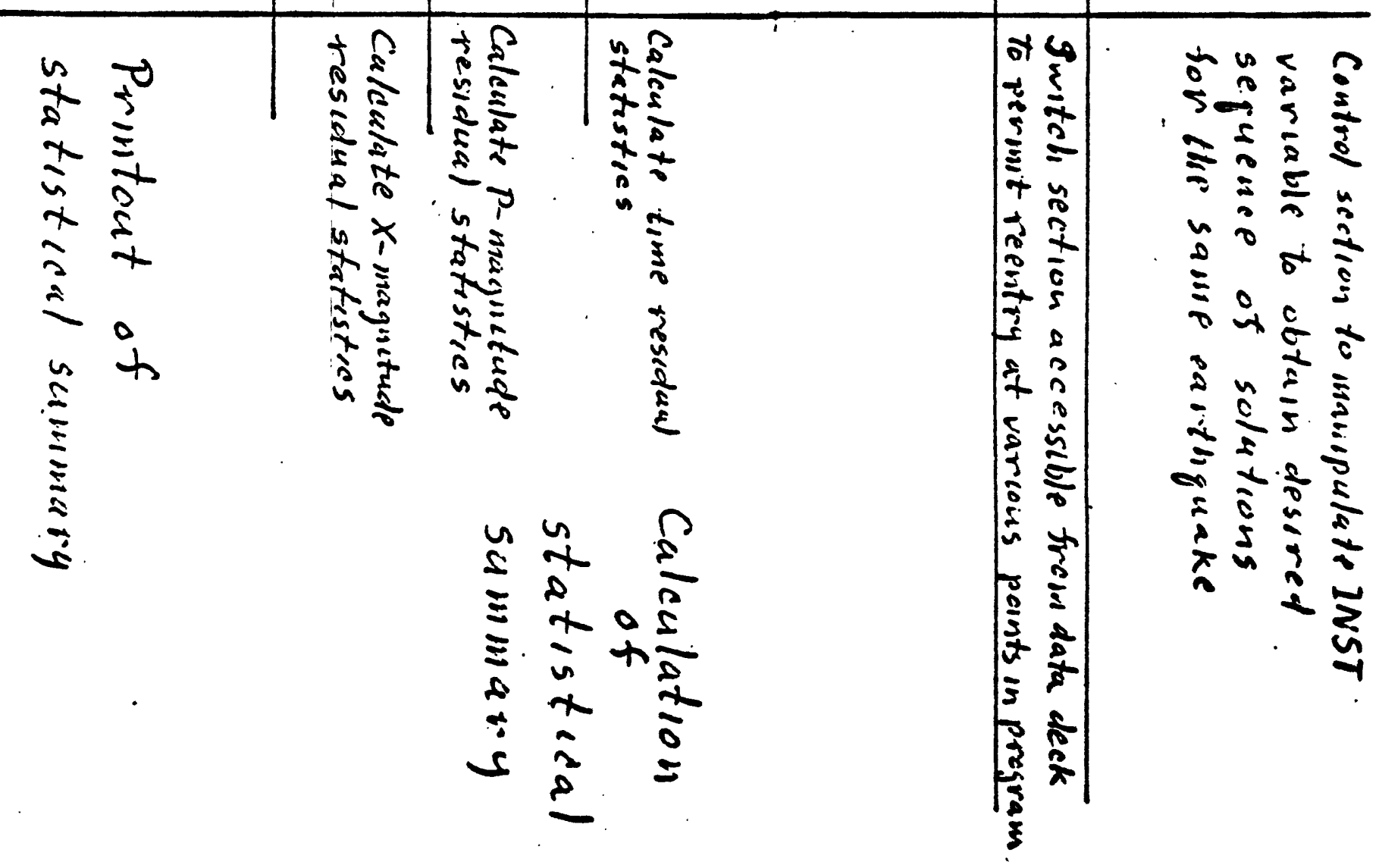




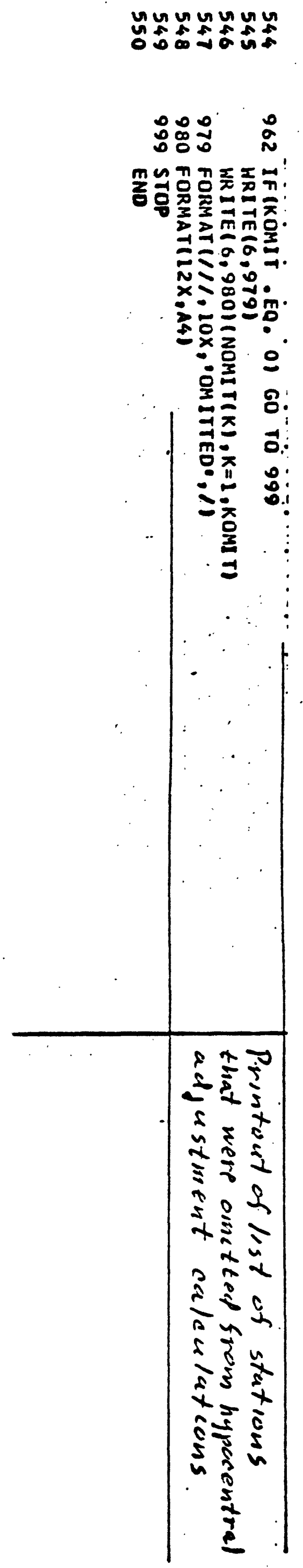




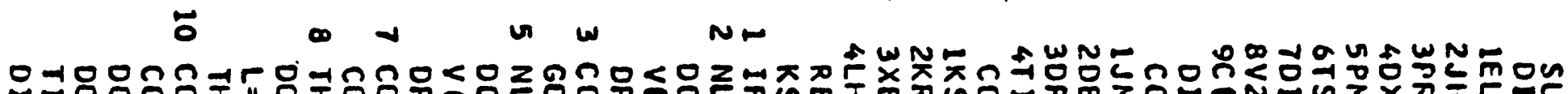

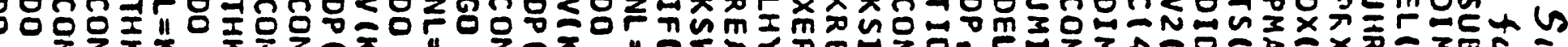

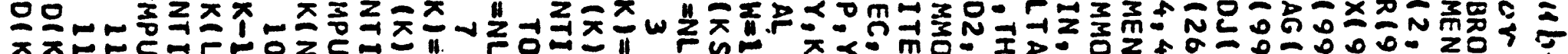

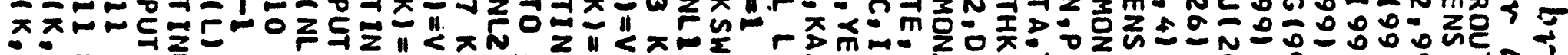

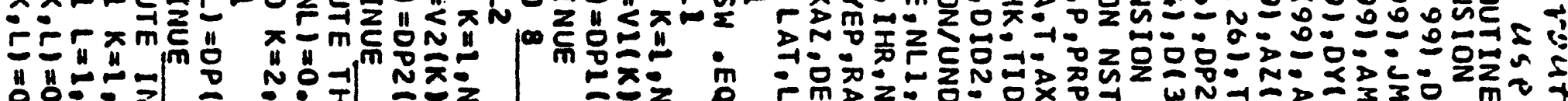

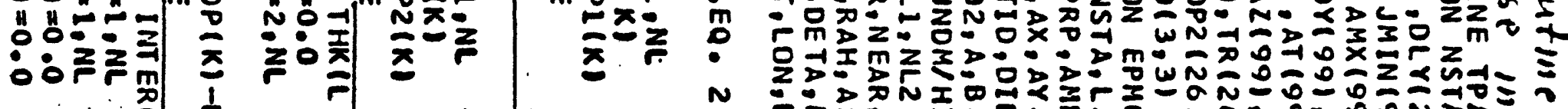

N Z Z

- $r$ U.

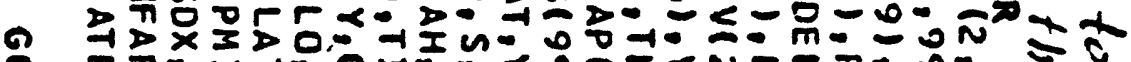

- Do

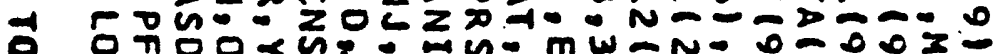

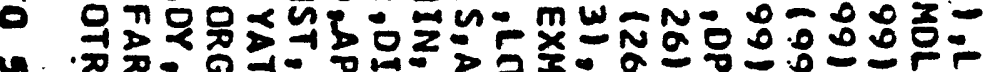

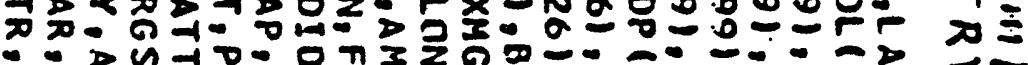

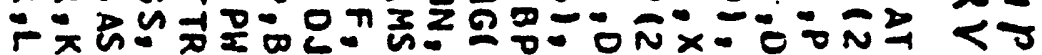

>

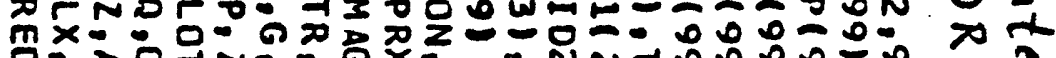

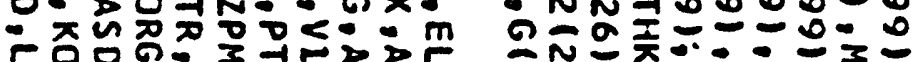

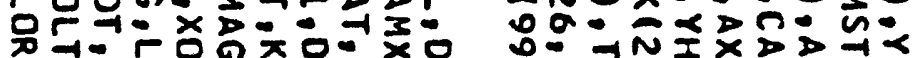

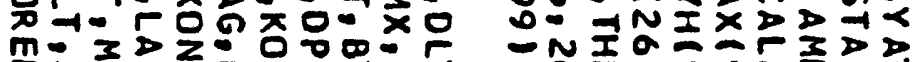

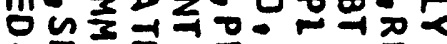

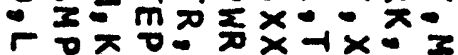

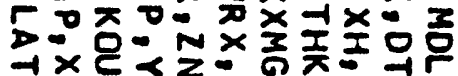

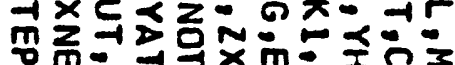

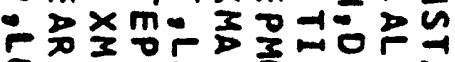

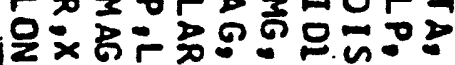

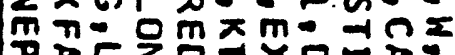

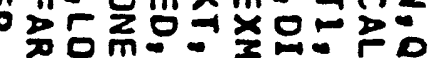

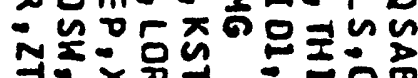

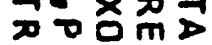
- 구요

Nim

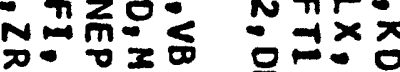

ofo

mड

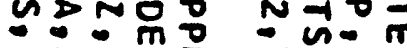

D更

- -000000

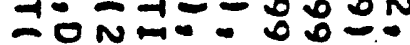

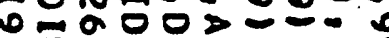

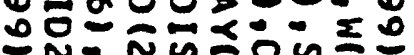

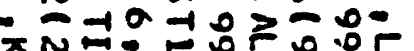

윰으므는

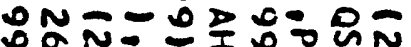

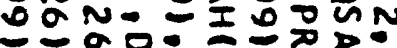

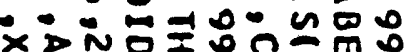

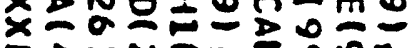

$3+-n=2500$

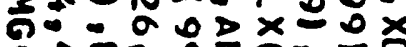

$\frac{1}{0} \pm 0+0 \sum \frac{0}{0}=0$

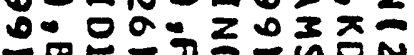

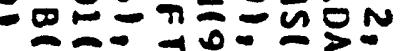
$\therefore N=-10=20$

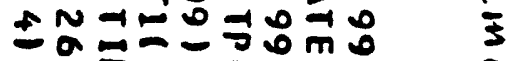

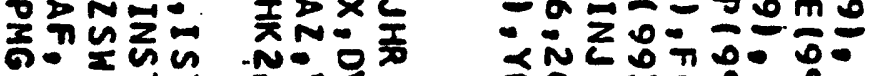
$\pm 0 N=0$

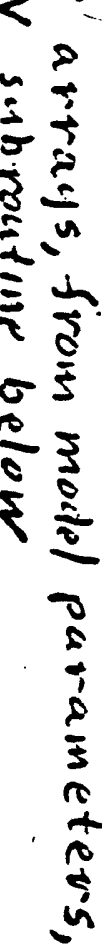

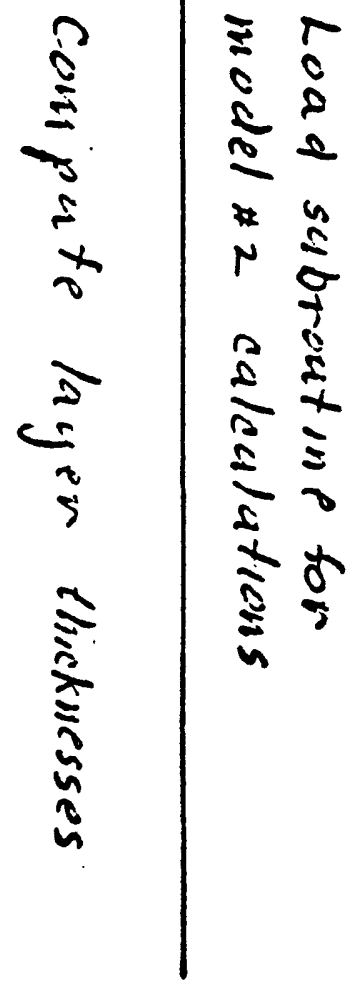

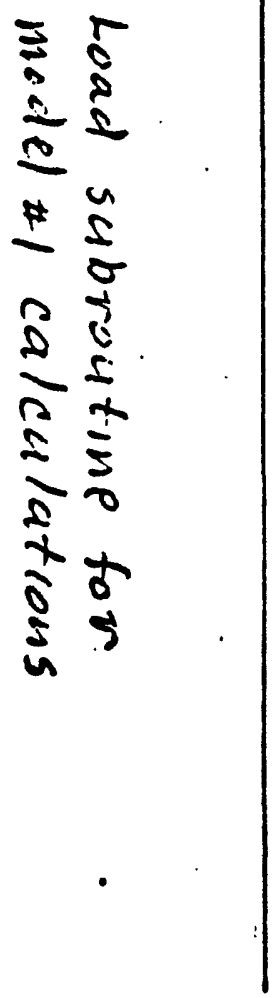

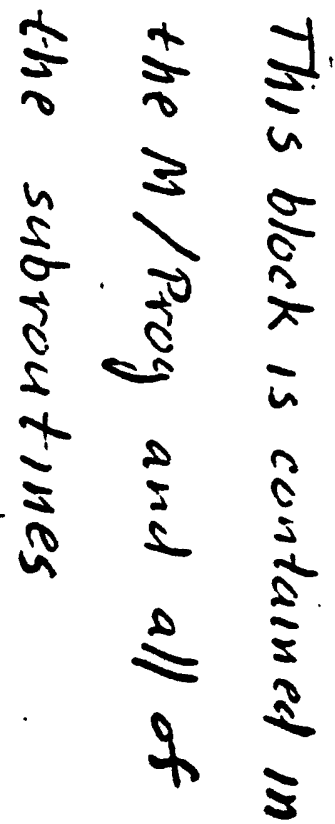




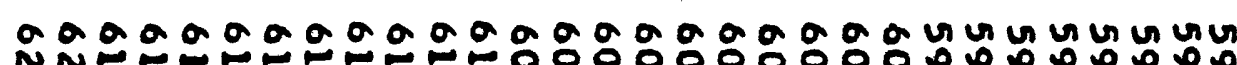

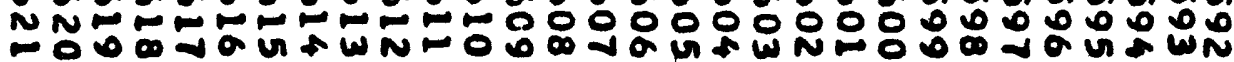

\%

กั

E

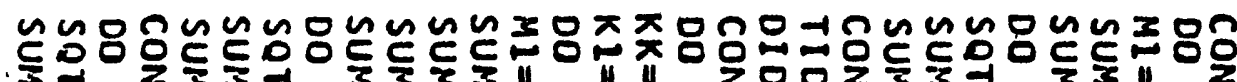
N" "

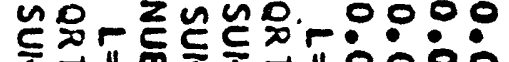

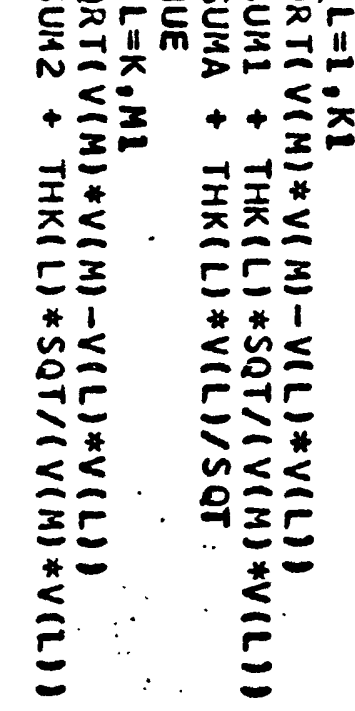

unu unu un unu un

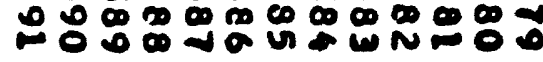

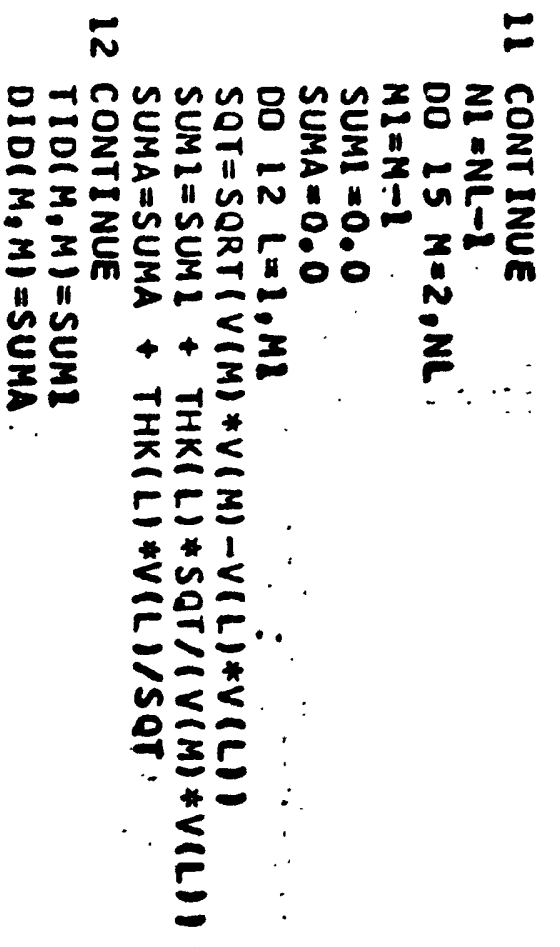

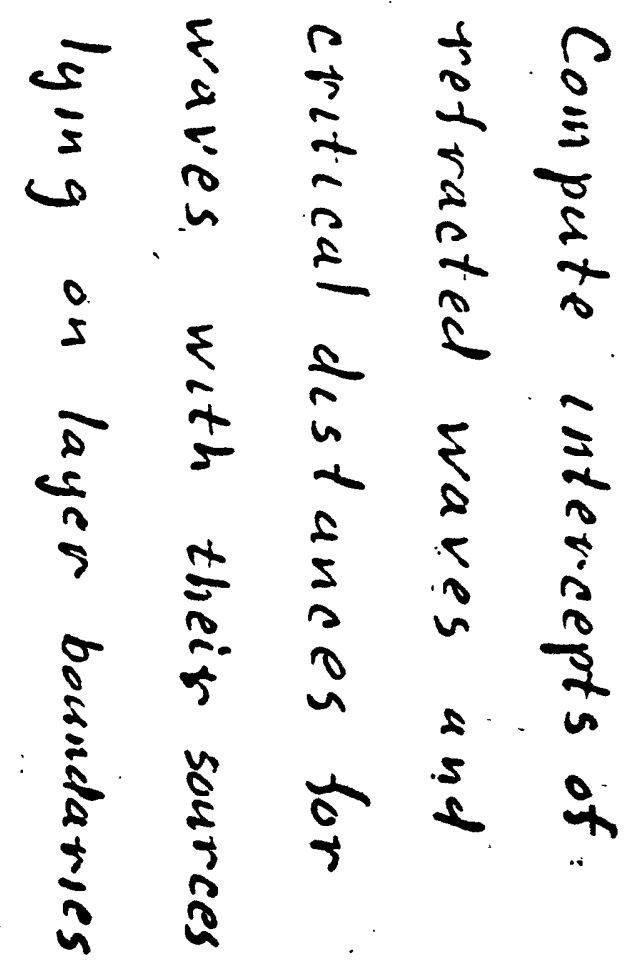


$\stackrel{0}{0}$

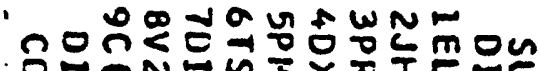

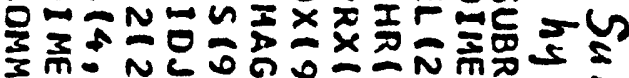

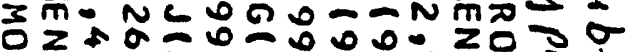

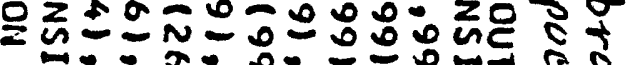
20000

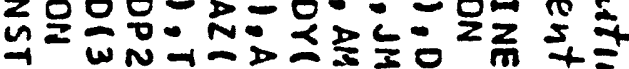

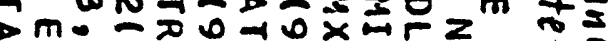

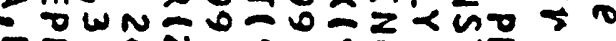

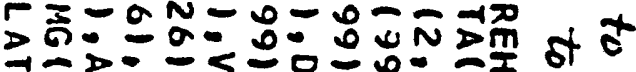

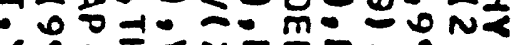

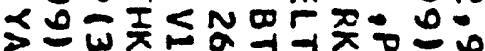

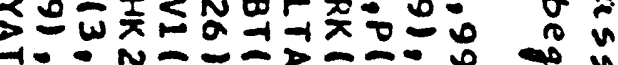

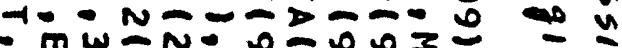
cरำ

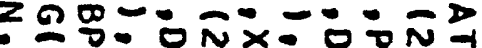

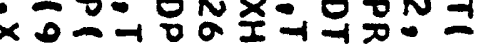

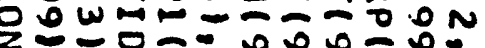
$=0 \bar{N}=000 \div 0$ $\because N N=0000=0$

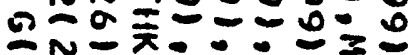
0月-

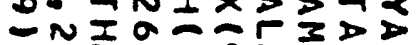
40.

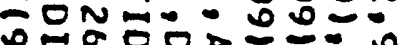

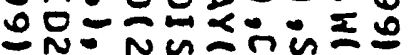

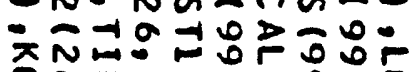

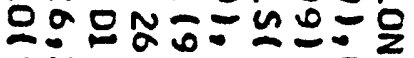
ONN으으.

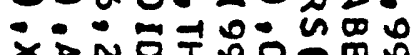

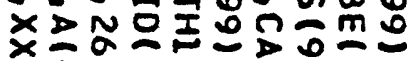

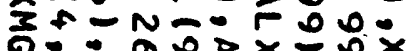

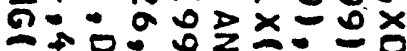
$0=0,0=0$

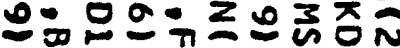

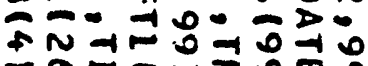
更 <is: $200=0$

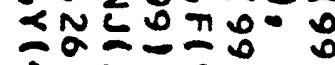
fก:

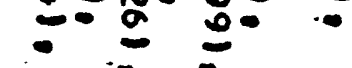

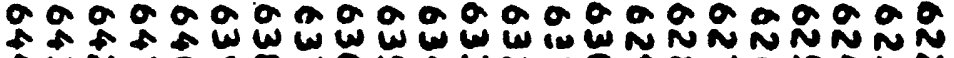

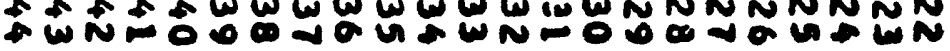

‡ま

$\$ \hat{\omega} \hat{N}$

$\neq \hat{0} \quad \ddot{n}$

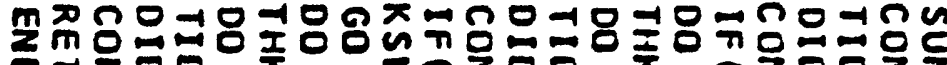
-

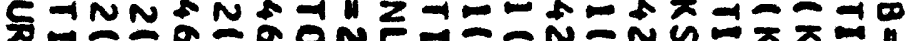

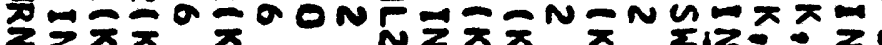

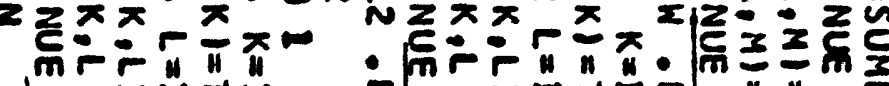

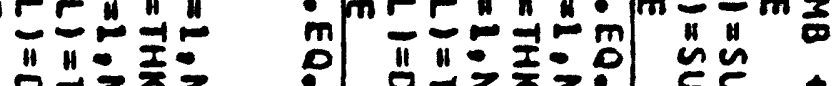

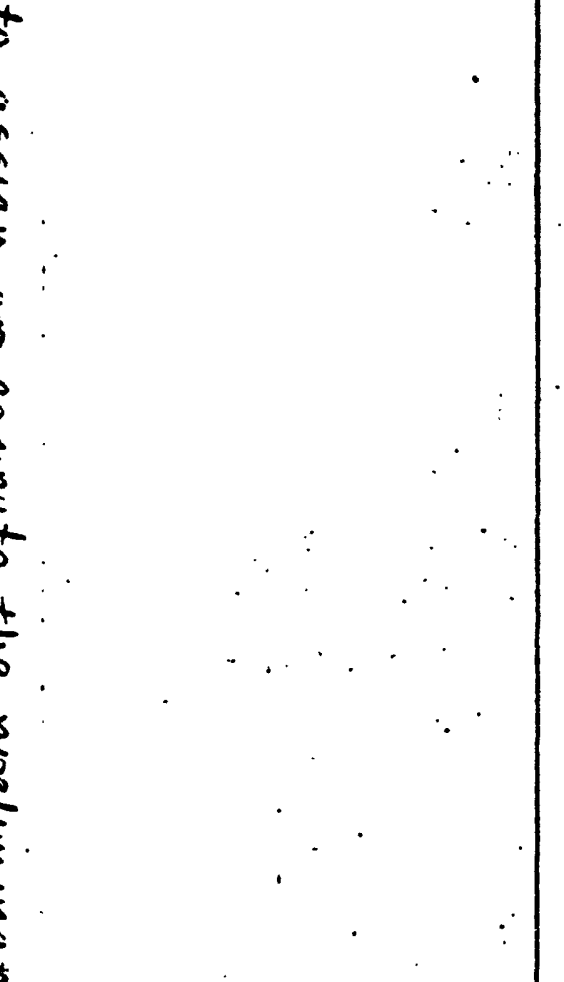

$\frac{5}{2}$

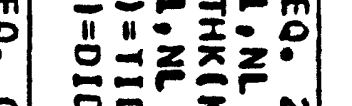

cट 4

- $\therefore$ व

$\operatorname{in}_{i}^{+} \overline{\frac{1}{X}}$

更

*

도ㅇㅗㅛ

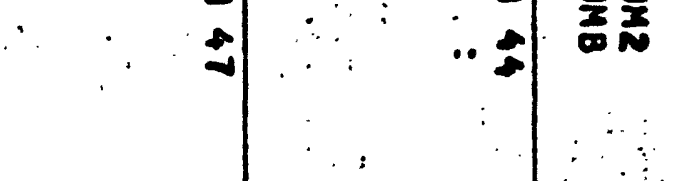




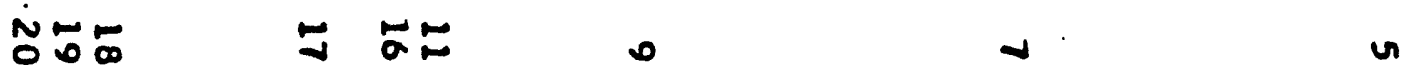

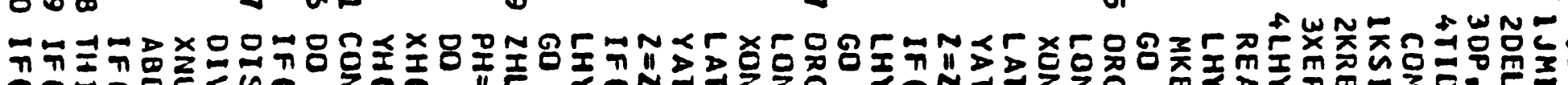

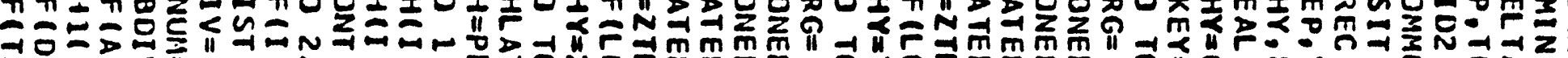

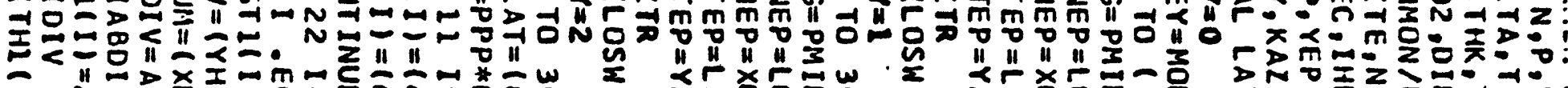

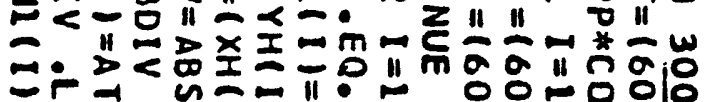

-

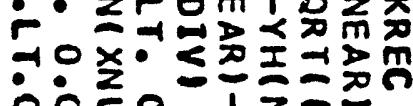

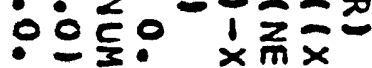

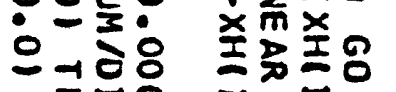

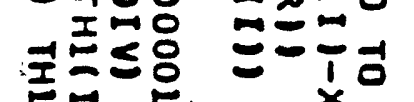

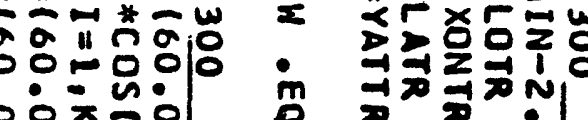

:ㅜㅜㅇ:

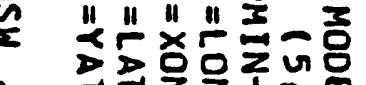

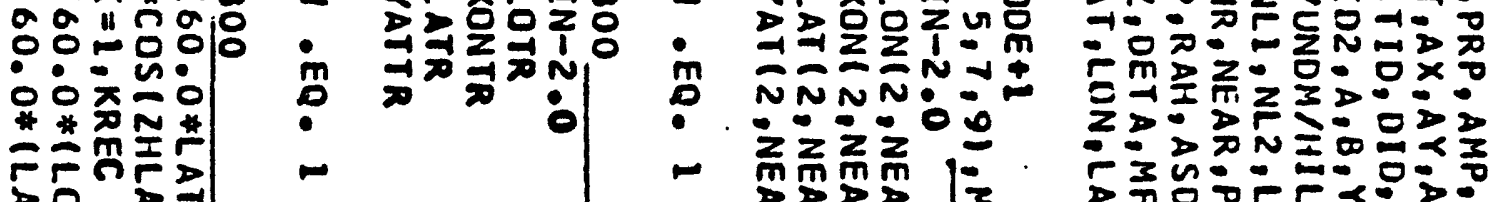

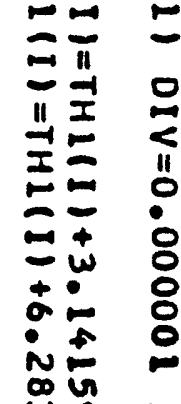

xN

$\frac{1}{n} \quad \exists=$

i

in: $\sum_{m}$

$\underset{\omega}{\mathbb{S}}$

1 1

另

而

8

负吕

$=$

$\stackrel{4}{x}$

$\stackrel{*}{*}$

언을

$\underline{N}$

峦

$=$

a

苔苦

$\Rightarrow>0 N \sum 00<3$

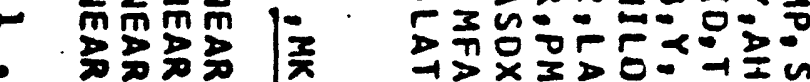

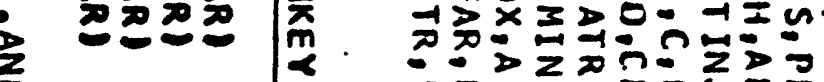

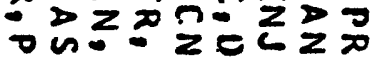

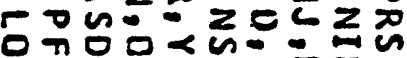

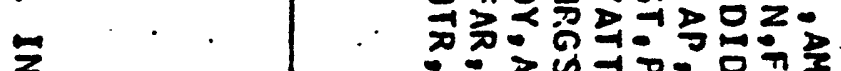

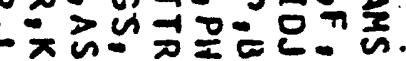

$>00=000$

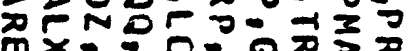

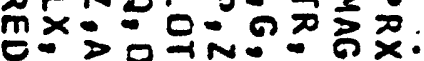

:-

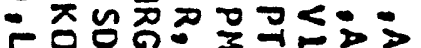

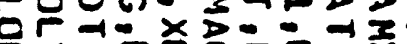

牙-

min $\frac{3}{3} \geq$

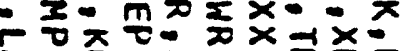

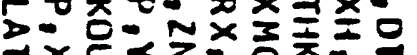

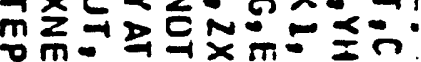

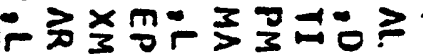

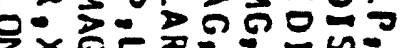

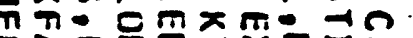

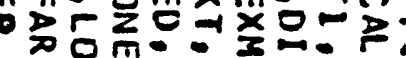

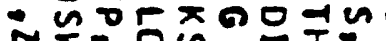

NEx음

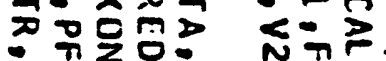

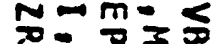

m

ㄴㄷㅇㅇ

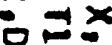

궁이

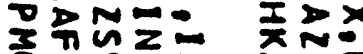

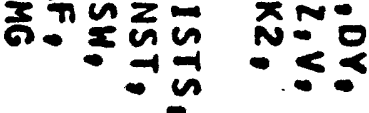
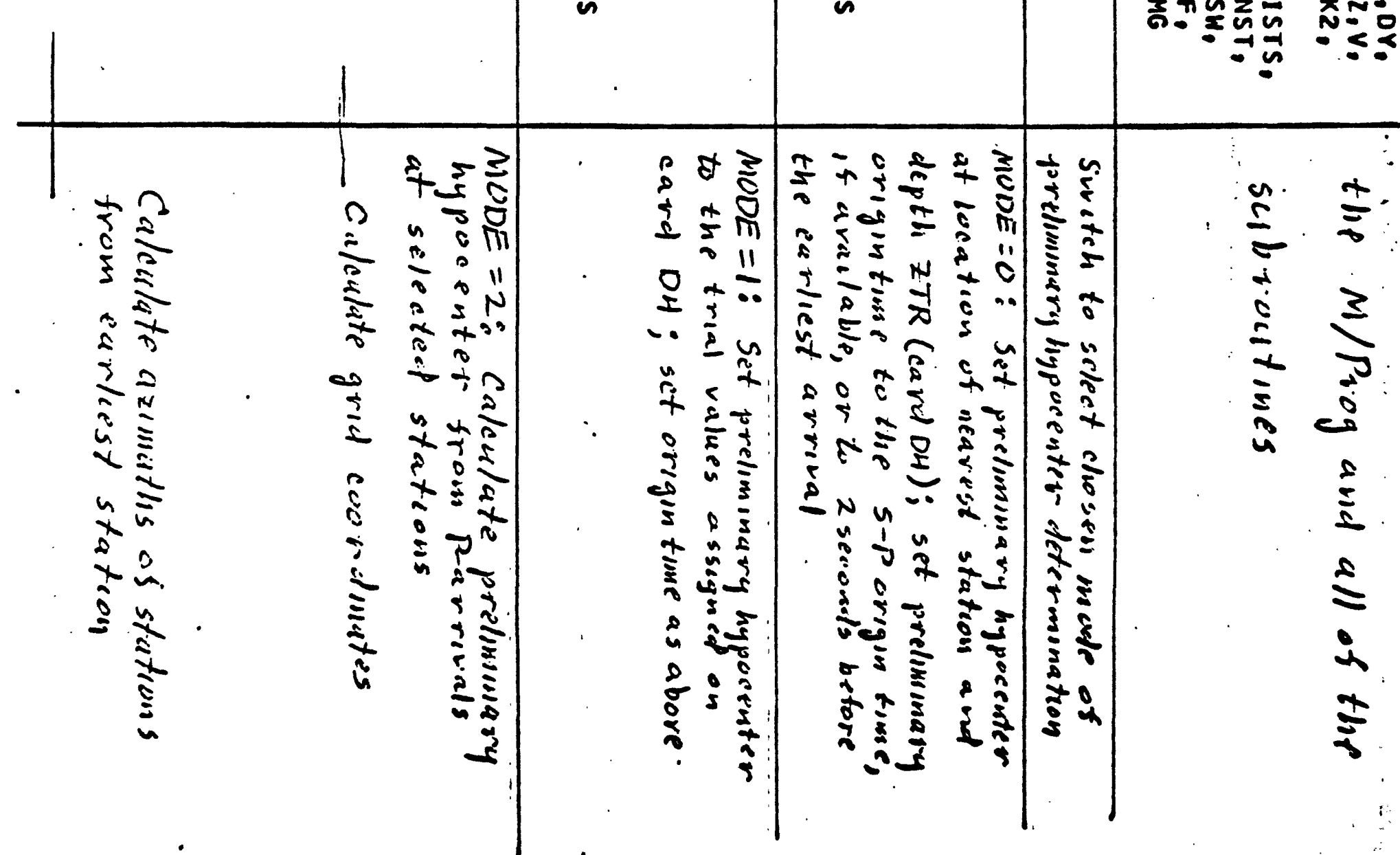


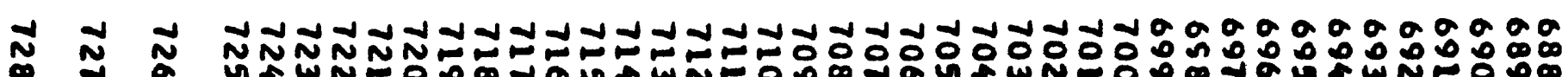

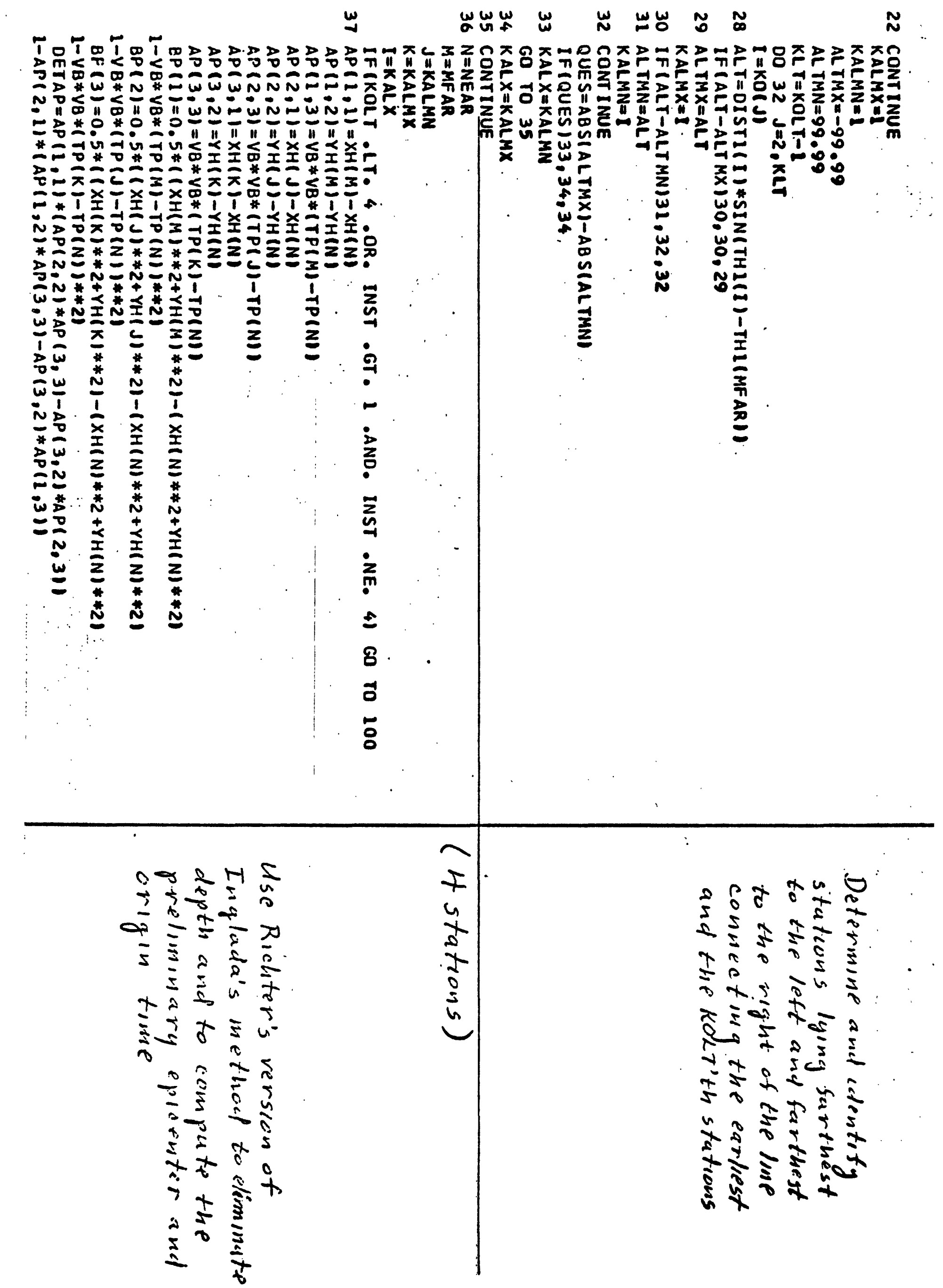




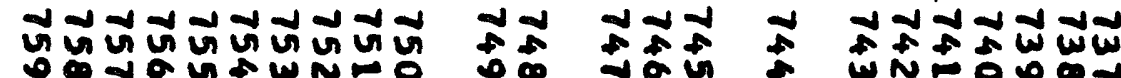

$\overline{5}$

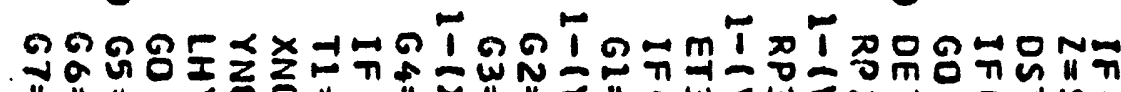
II"

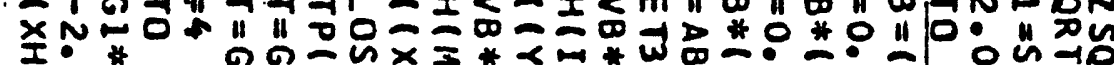
王: 居造 **

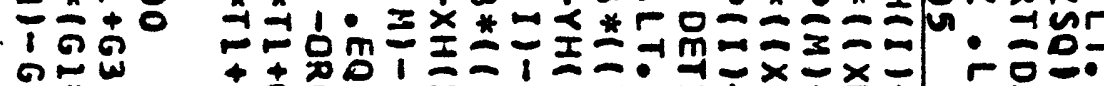

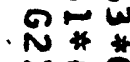

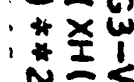

法羁

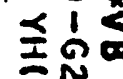

$\sum \frac{1}{4}$

i⿱宀女

$\pm$

*a

$\stackrel{+}{ \pm}$

尚

*

$\underset{3}{2}=$

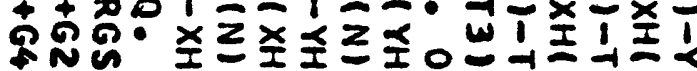

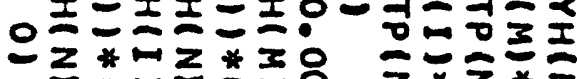

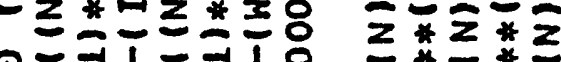

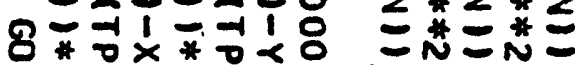

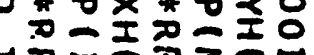

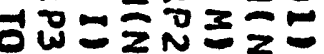

OWIITIZZ

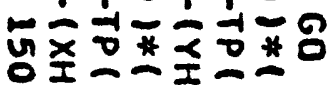

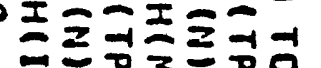

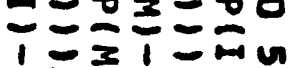

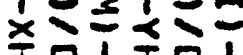

全品尘品!

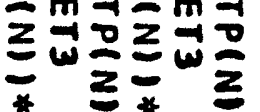

2

号 ro-

N :

용

$\Xi$

- g

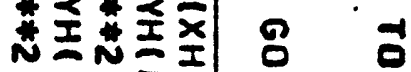

*

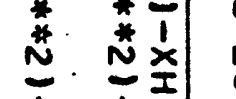

$\frac{1}{x} \frac{1}{x}$

王

z

$\stackrel{*}{ \pm}$

$\pm$

$\underline{\Xi}$

$\omega$

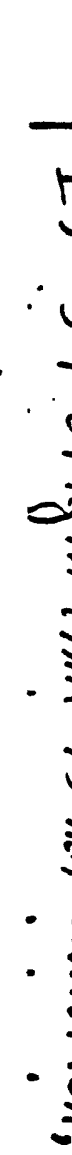

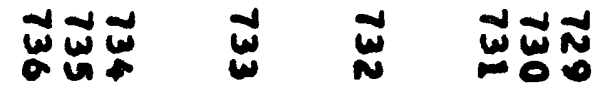

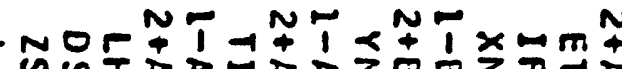

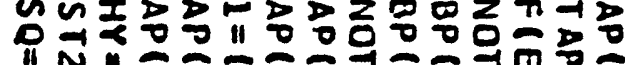

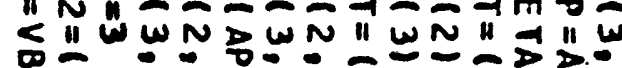

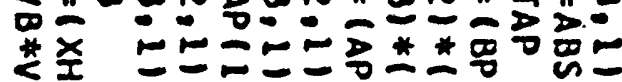

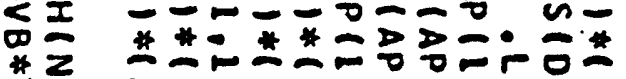

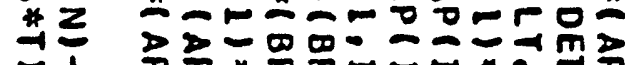

*

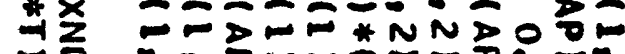

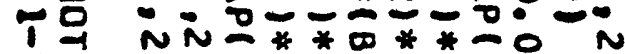

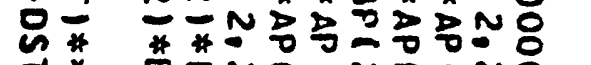

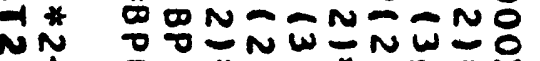

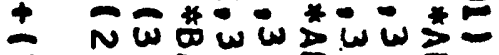

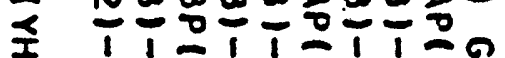

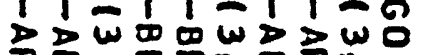

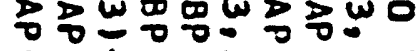

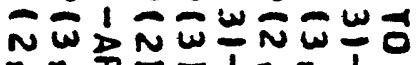

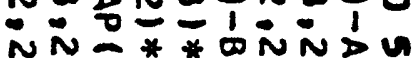

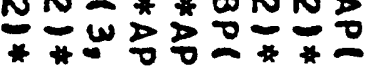

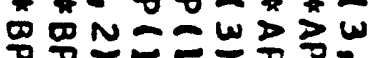

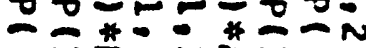

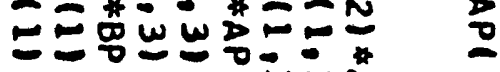

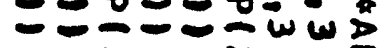

$=N \Sigma N=\Sigma 0$

家

意

st

举

兽

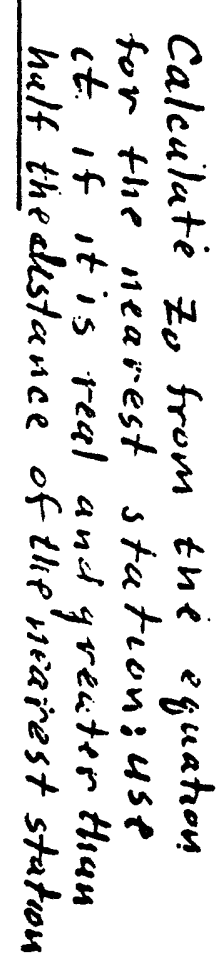


an

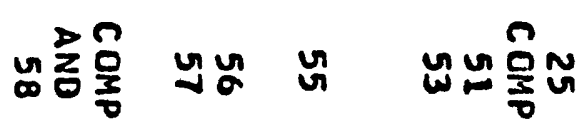

ก

o in

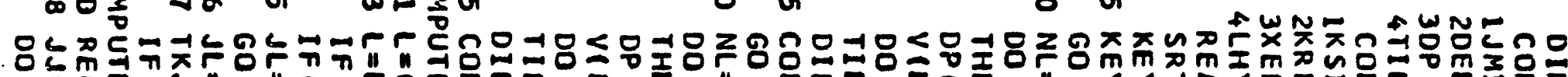

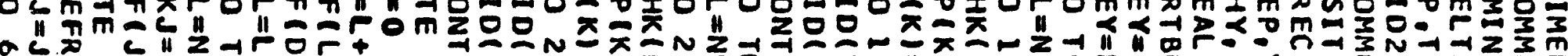

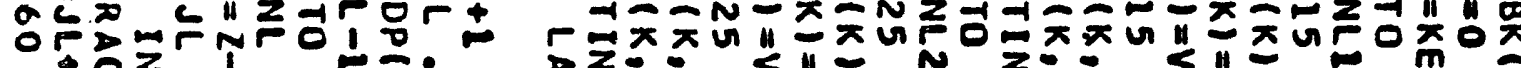

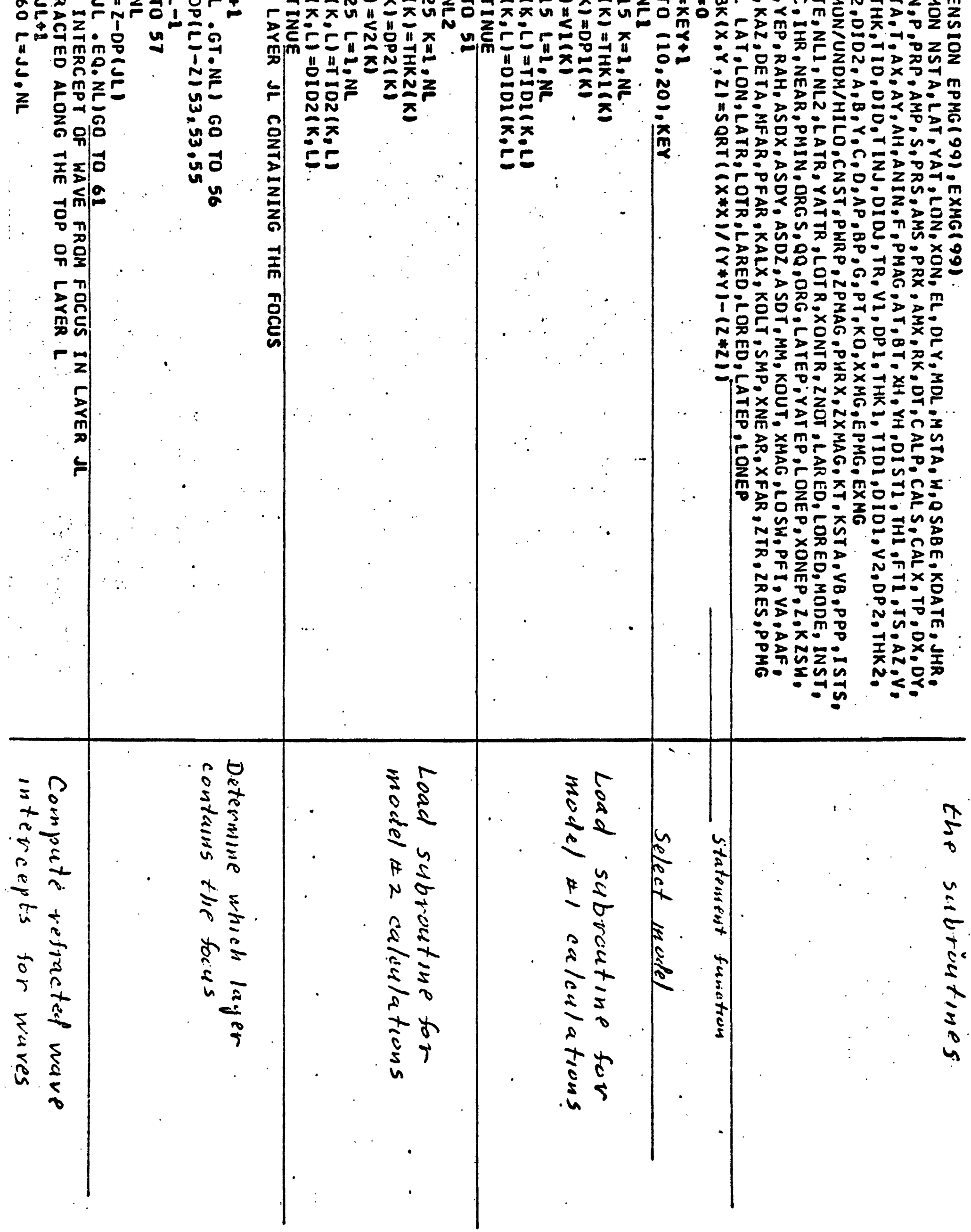




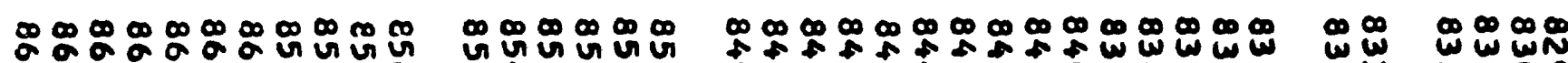

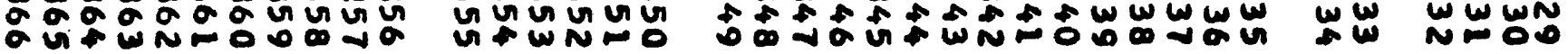

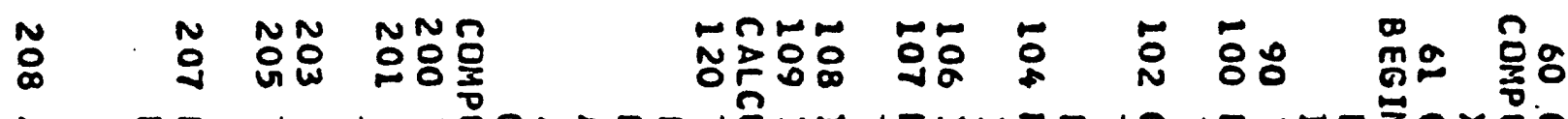

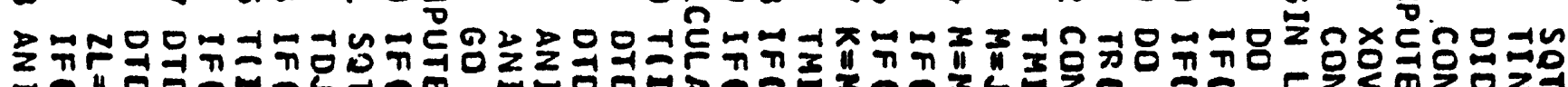

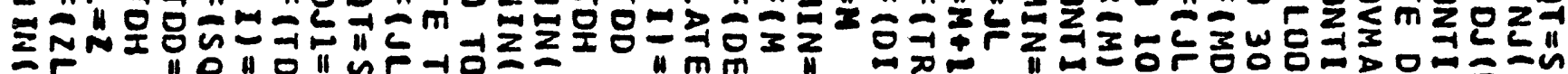
等,

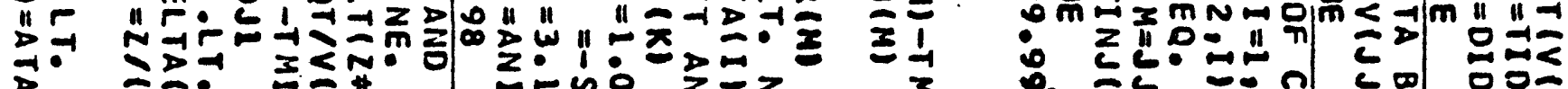

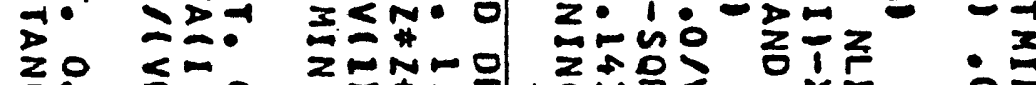

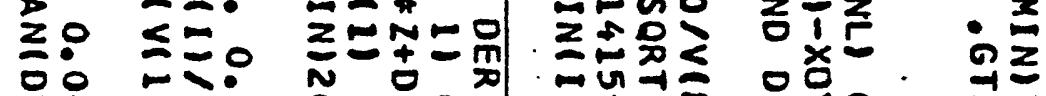
票送

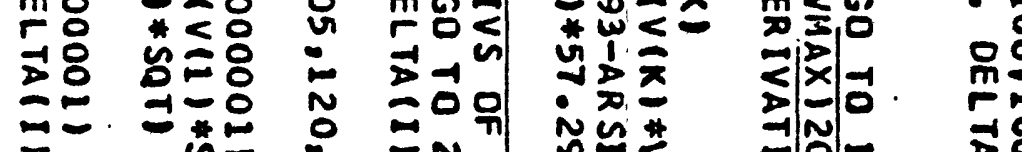
满

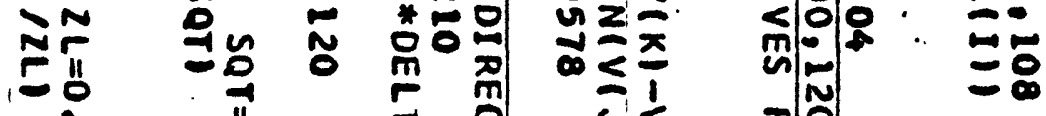
:

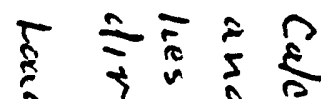

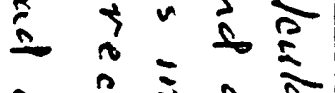

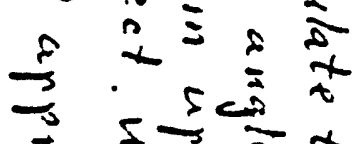

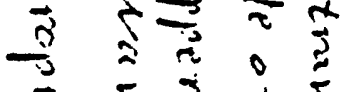

$\frac{5}{2} i+\frac{5}{2}$

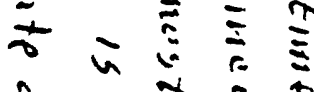

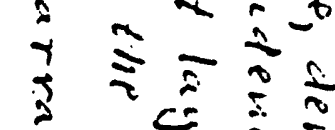

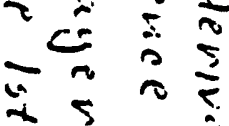

$\Rightarrow=\overline{1}$

ind

空草

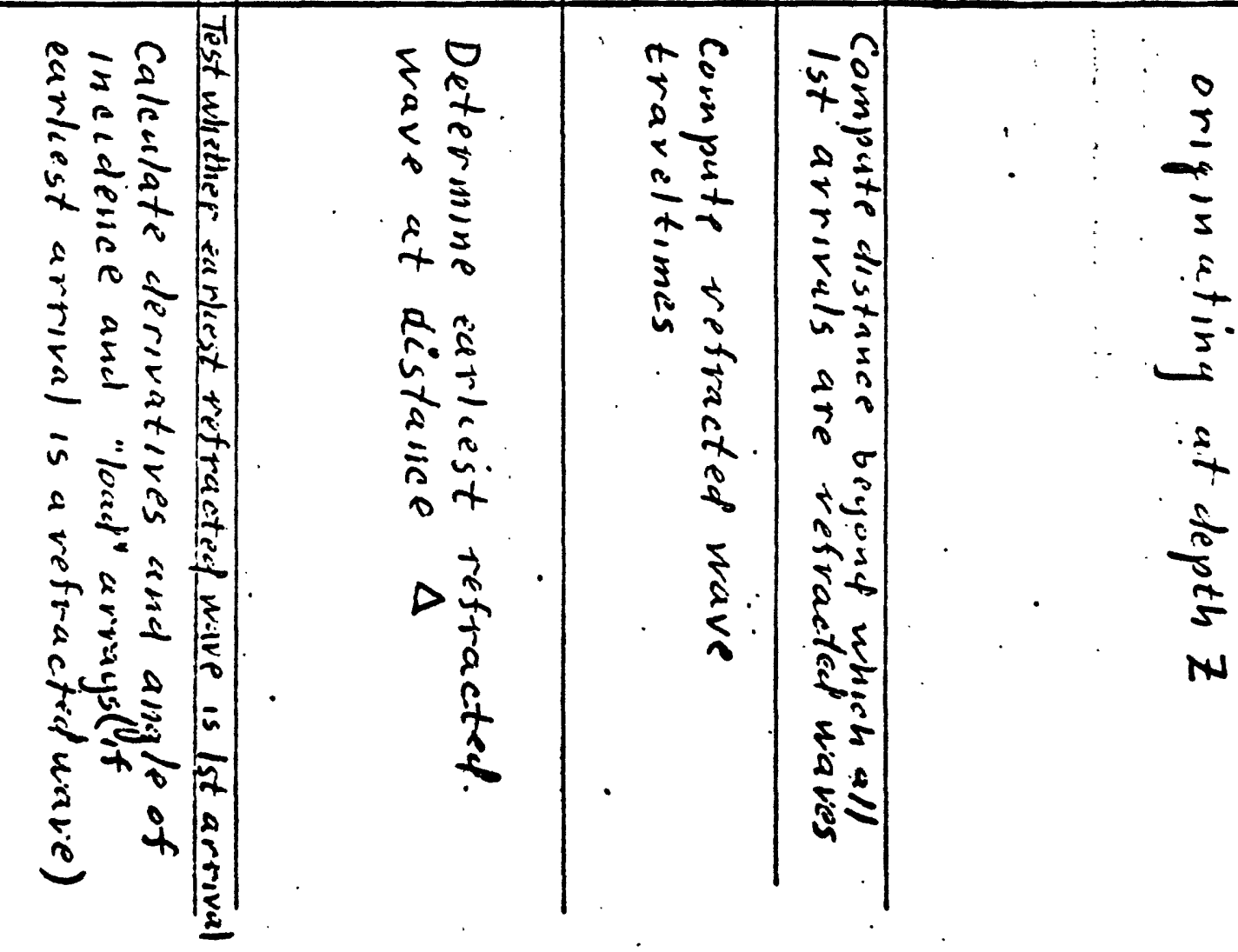




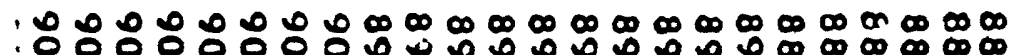

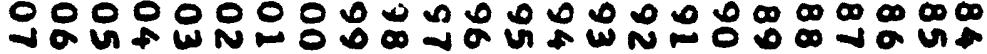

$\begin{array}{lllllll}N N & N & N N & N & N & N & N \\ O N & N & N & N & N & N & N\end{array}$

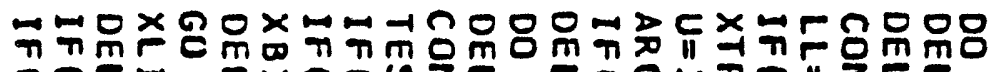

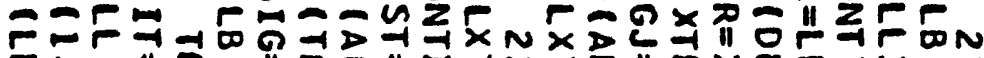

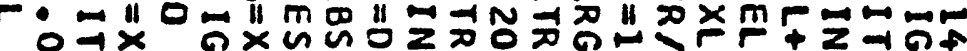
- 1 "

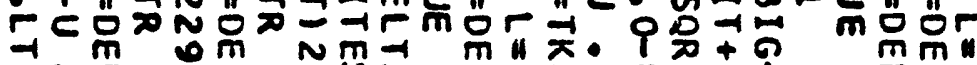

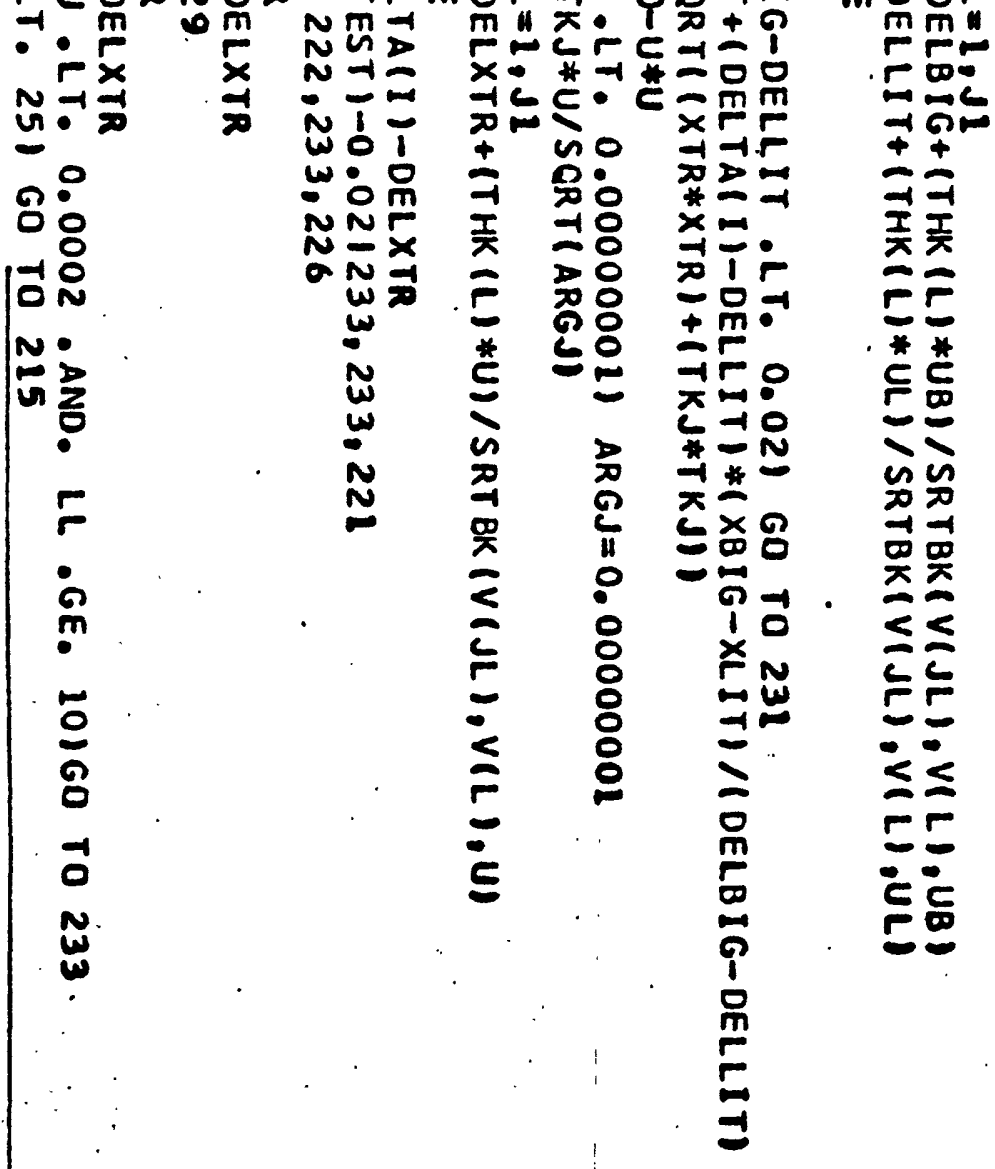

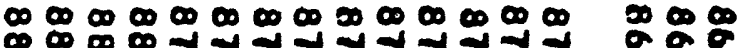 แN}

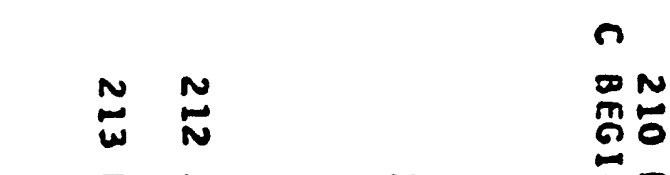

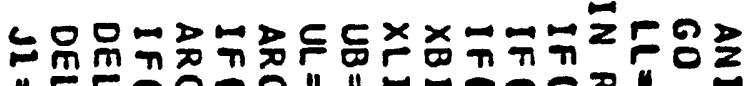

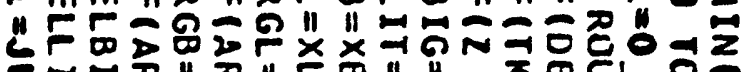

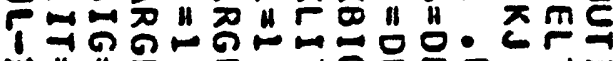

11

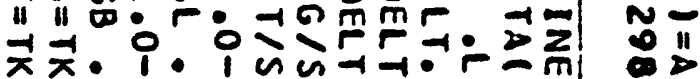

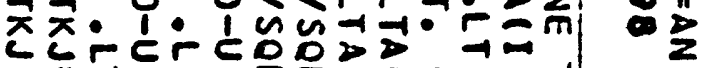
* -1 西-1 $000=0 \cdot-1$

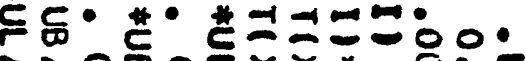
oc of

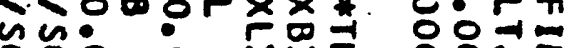
ป็० 0 m 꿍요

ㅇㅇㅇ

ด्र

2.

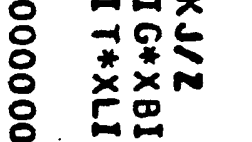

등ㅇㅇㅇㅛ

0800 는

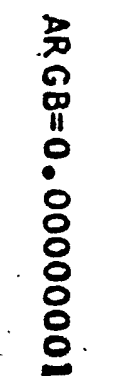

$\begin{array}{ll}\text {. } & 0 \\ 0 & 0 \\ 0 & 0 \\ 11 & 11 \\ 0 & 0 \\ 0 & 8 \\ 0 & 8 \\ 0 & 0 \\ 0 & 8 \\ 0 & 8 \\ 0 & 8 \\ 0 & 0\end{array}$

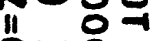

궃ㅇㅇㅇㅇ

준육에

준

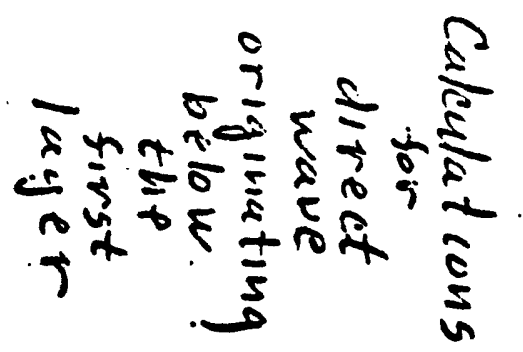


$n$

mํำดี

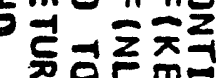

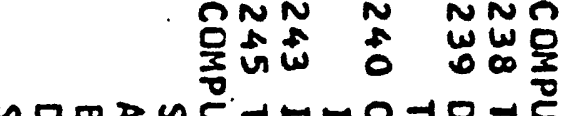

$n$

jun

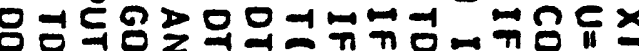

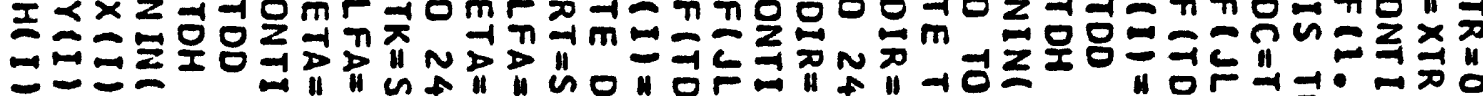

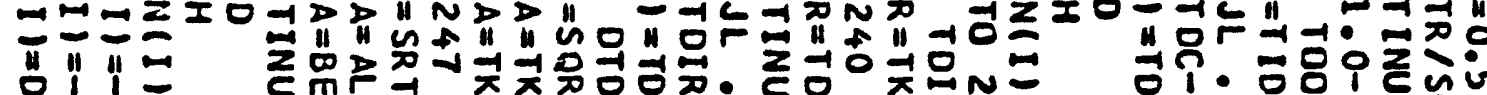
留

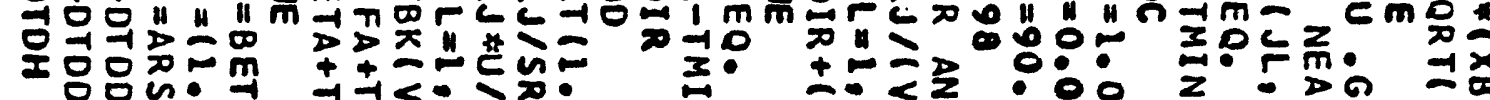

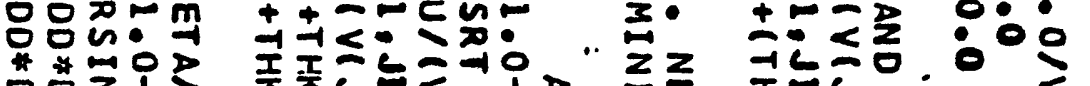

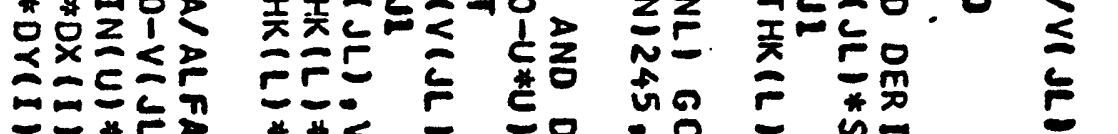

ระ

$\Xi \equiv=\frac{5}{2}$

ㅁํㅁำ

$\omega \frac{\omega}{0}$

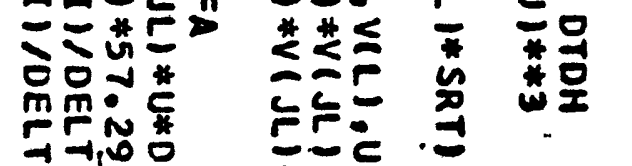

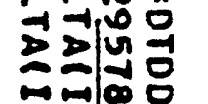

焉要

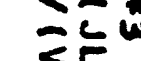

ज़:

No-

每尔

$\sum \frac{\pi}{3}$

$\sum \sum_{0}$

$-$

$\sum$

政

究

E

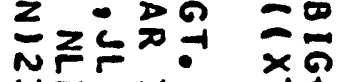

= 50:

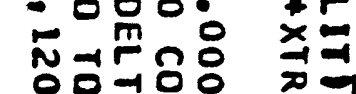
Nㅡ둥

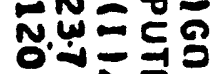

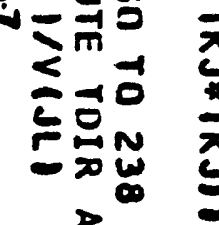

要全

竞

E 品

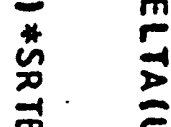

叧 芶

$=\quad x$

i

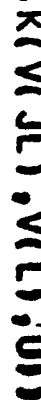

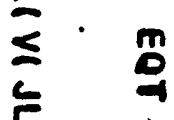

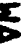

2

을

옹

유

m

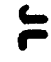

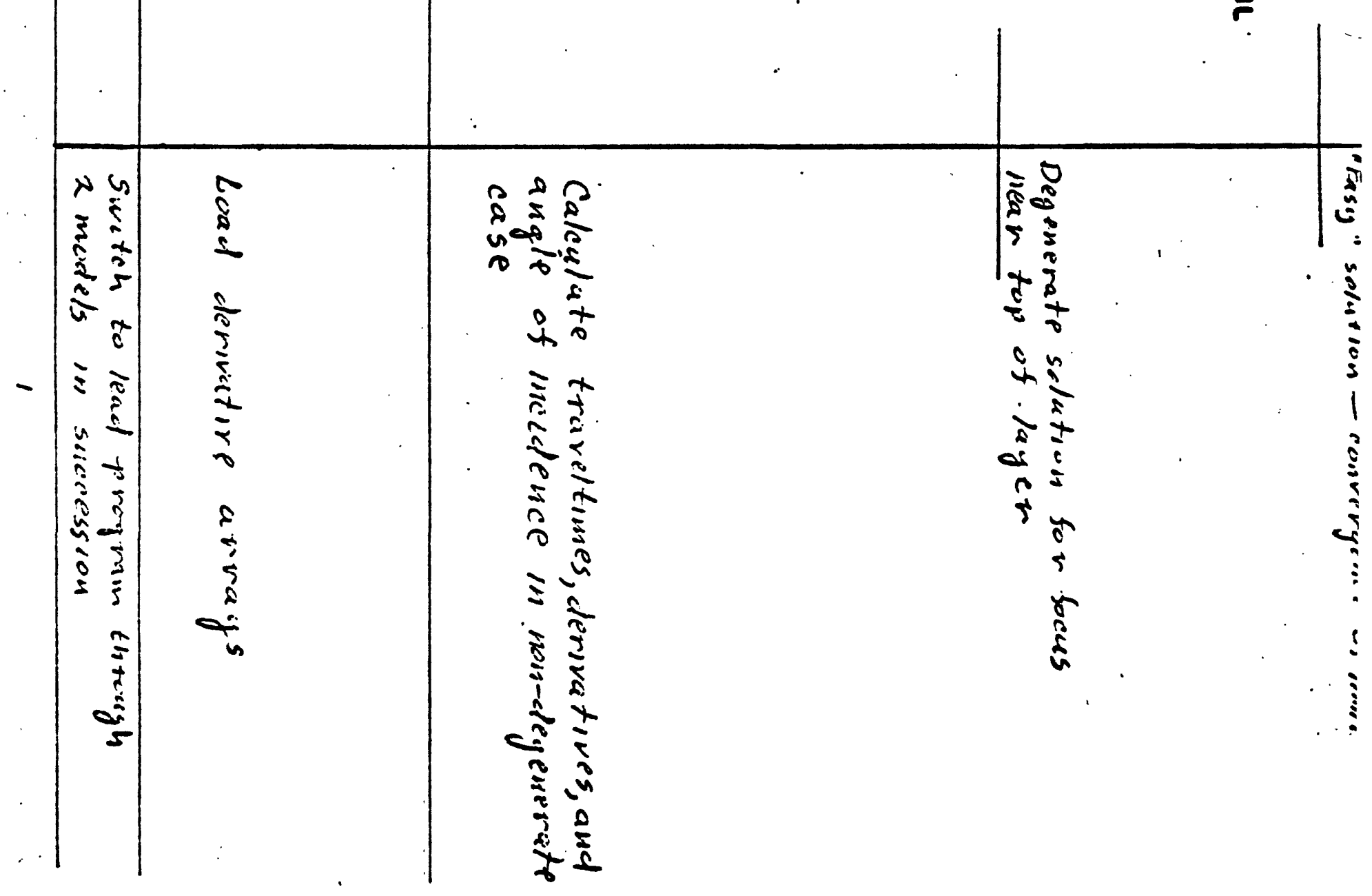


0

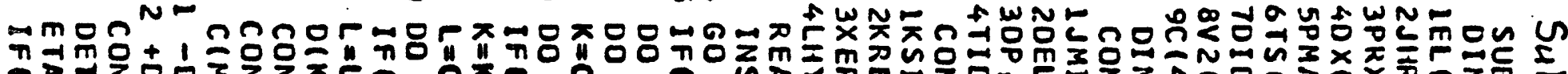

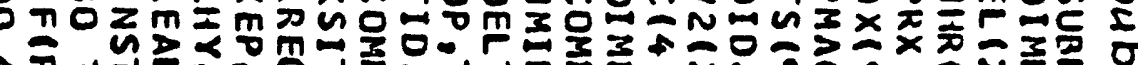

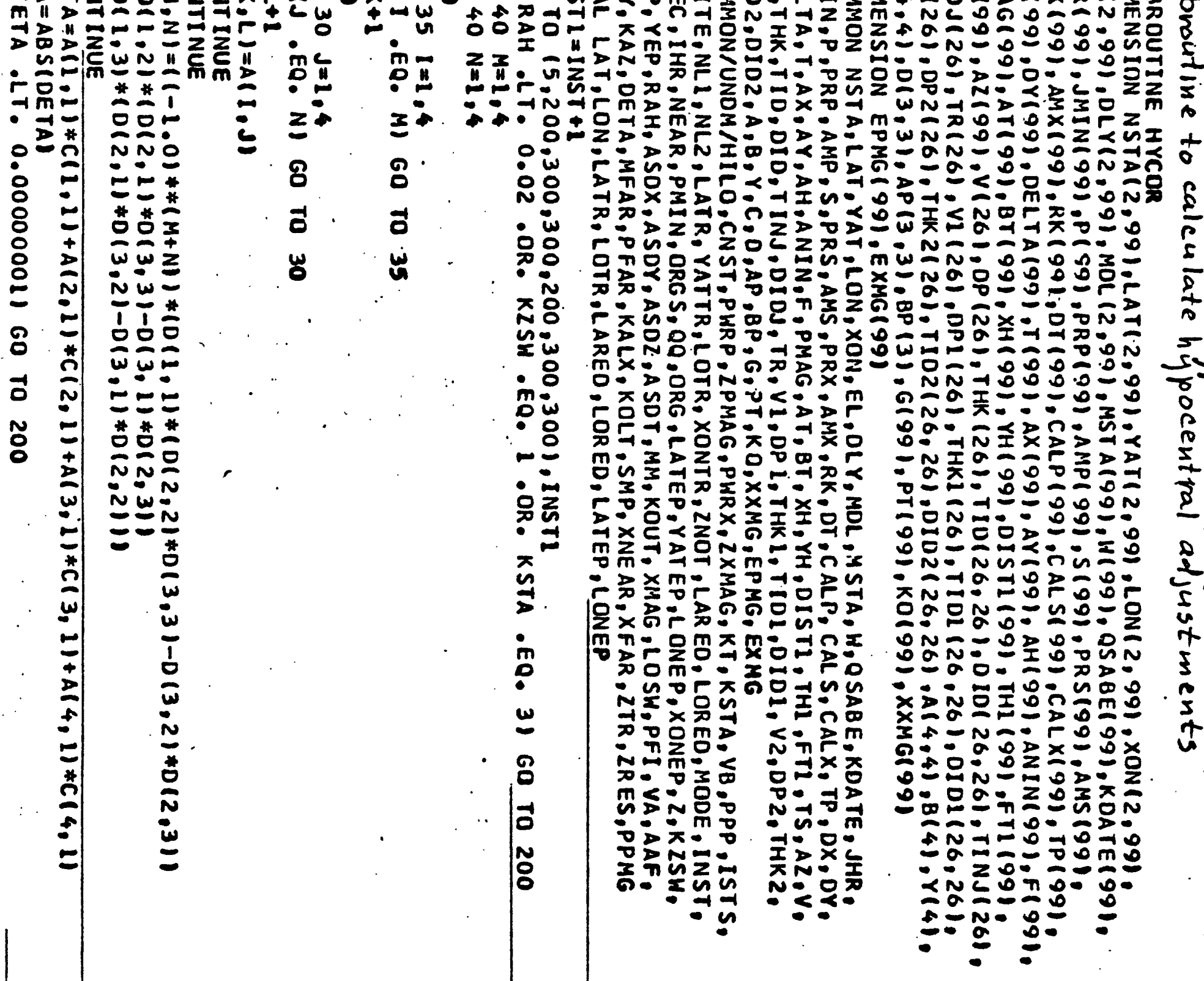




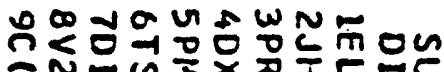

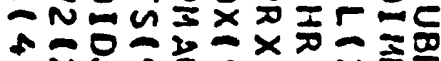
I0กำ $00->=0-10$

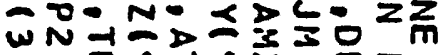
-

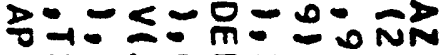

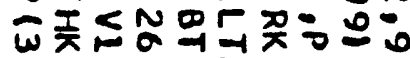
- nN-

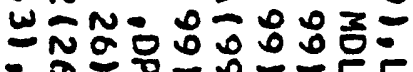

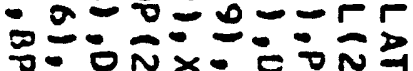

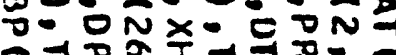

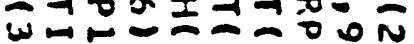

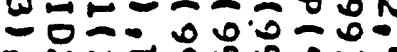

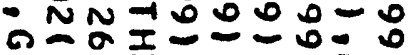

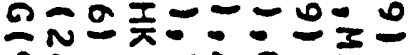

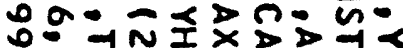

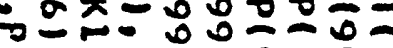
$\rightarrow-1=-000 \mathrm{~N}$

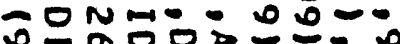

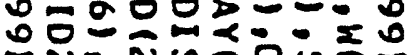

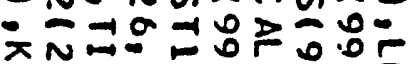

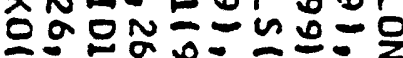
$\because N \tilde{N}=0 \geq$ $-200-200$

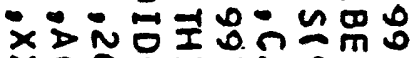

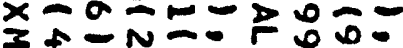
品: $00 x=0 x$

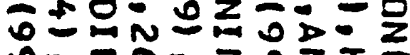

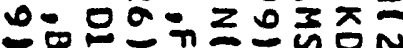

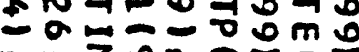

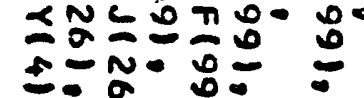
- a- 0- -

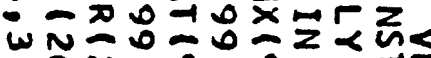

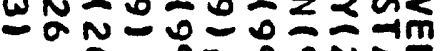

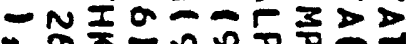

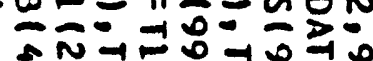

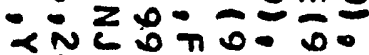

$\div$ -

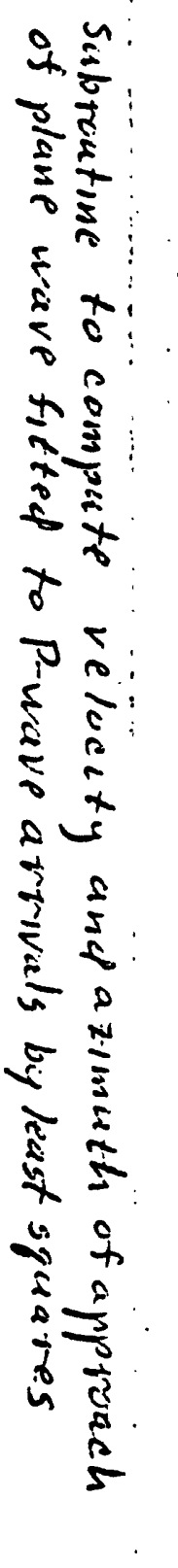

ถัดे 㟧 ๗

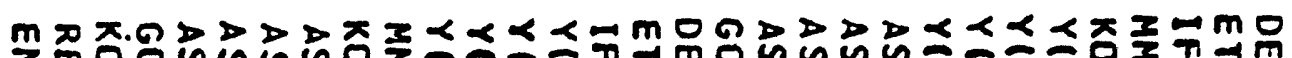

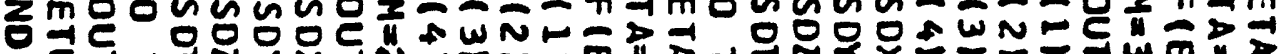

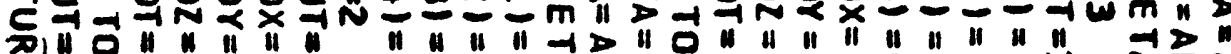

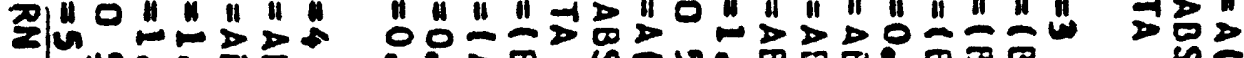
䜣: - O

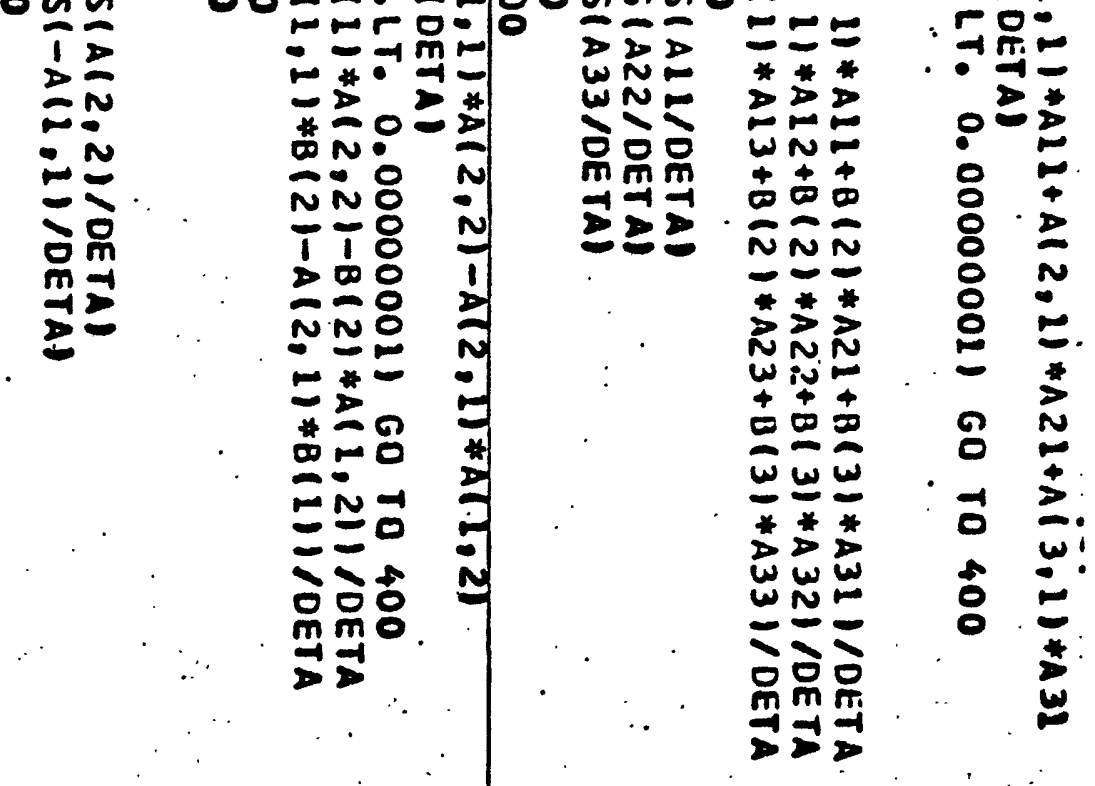

$\therefore \geq$

j. is

है

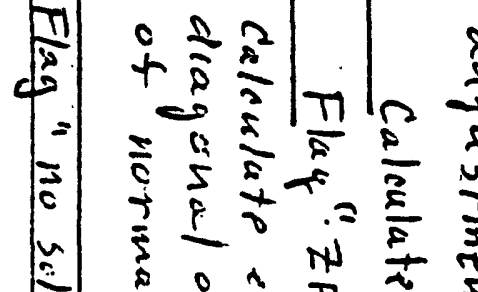

舟市

$5=\frac{1}{5}$

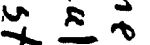

$\frac{1}{2}$

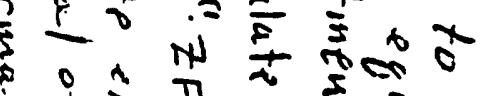

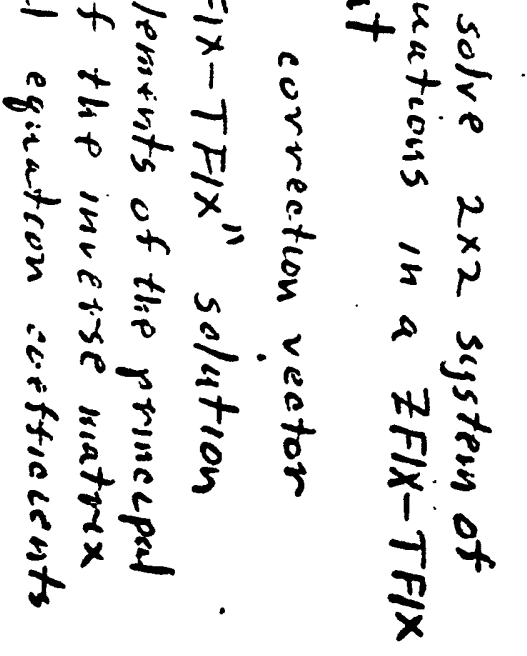

ระะ

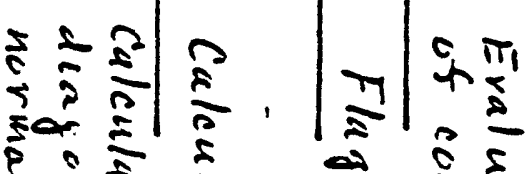
0 हो हो का 12 $+x$ is इ है

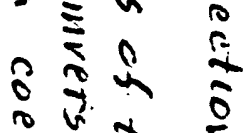

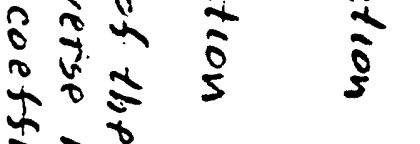

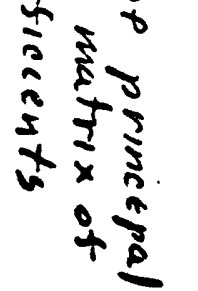

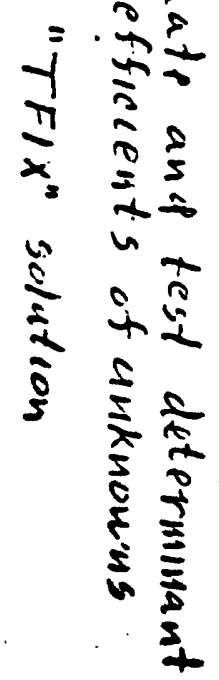




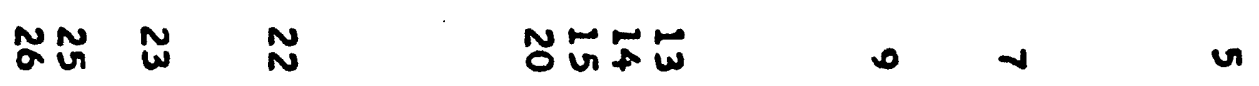

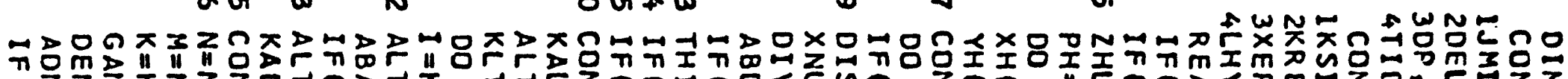

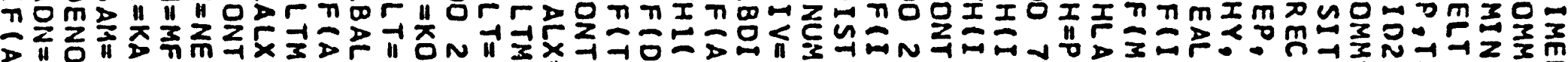

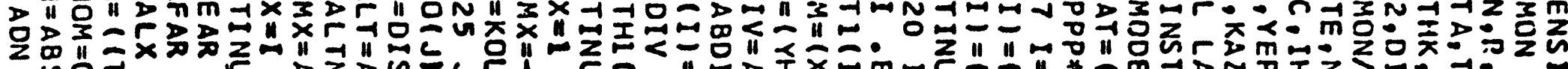

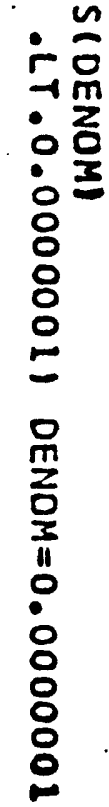

$\Delta \vec{z} ⿻ \bar{\omega}=$

$4 \rightarrow 0$

C一"

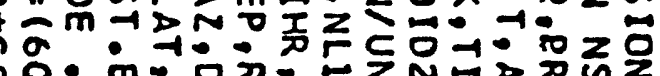

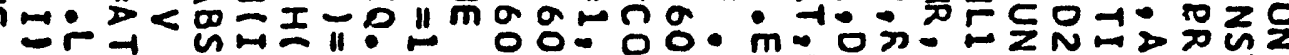

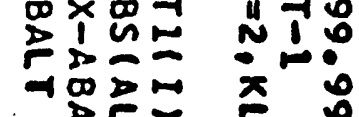

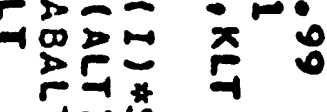

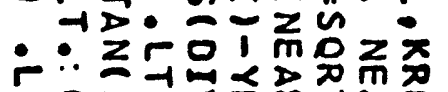

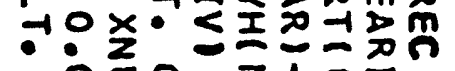

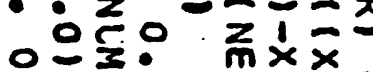

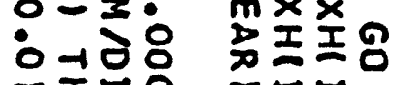

-

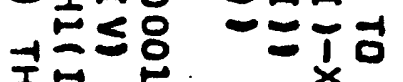

至=

든

폰

至要

$\pm=$

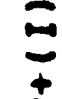

$+$

is

象

$\underset{\omega}{\omega}$

.

을

$\sum_{\substack{i \\ j}}$

$\underset{2}{2}$

$=$

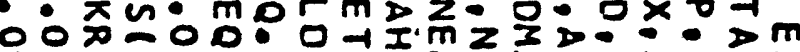

*

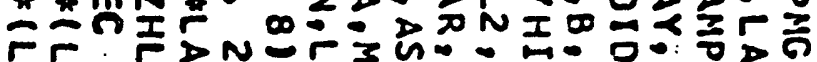

$\rightarrow 0$ 2

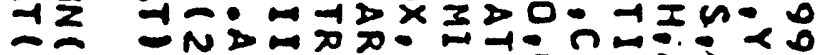

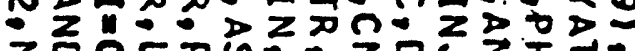

in zoor

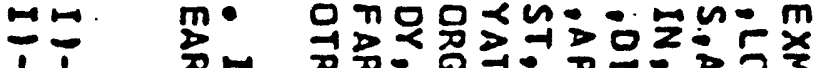

11 ग

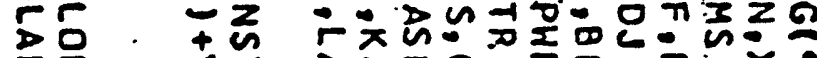

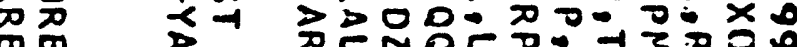

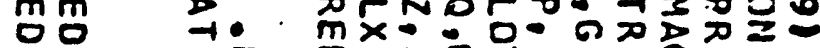

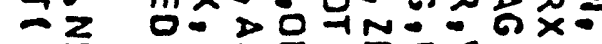

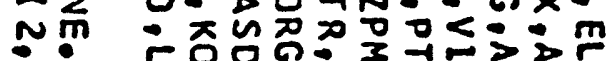

文齐

$\geq \frac{1}{2}$

กิก

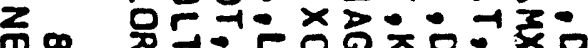

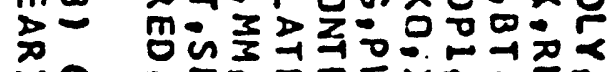

次

$M$

$=$

若苦

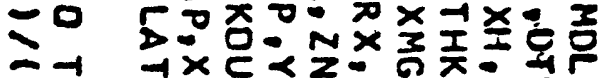

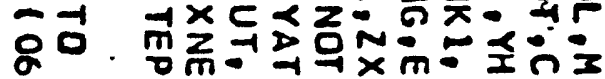

3

西

3

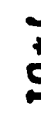

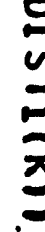

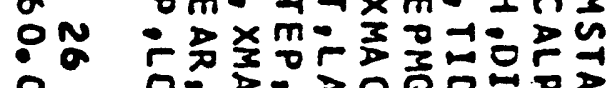

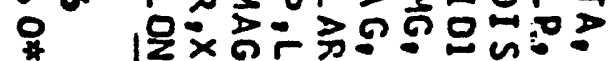

u m no m m >*

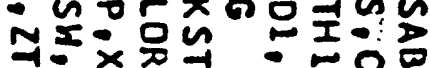

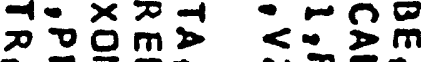
구요 N而通 苋处造

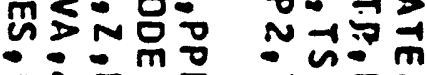

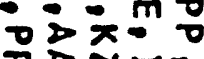

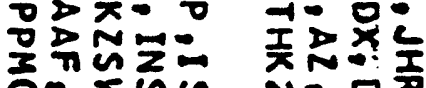

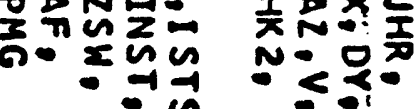

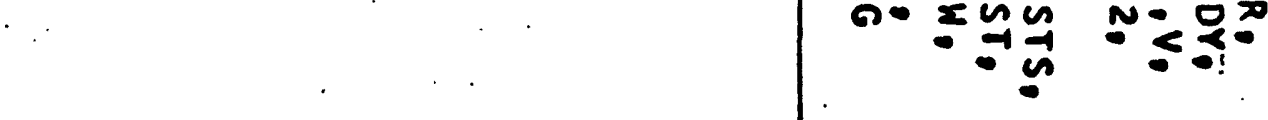

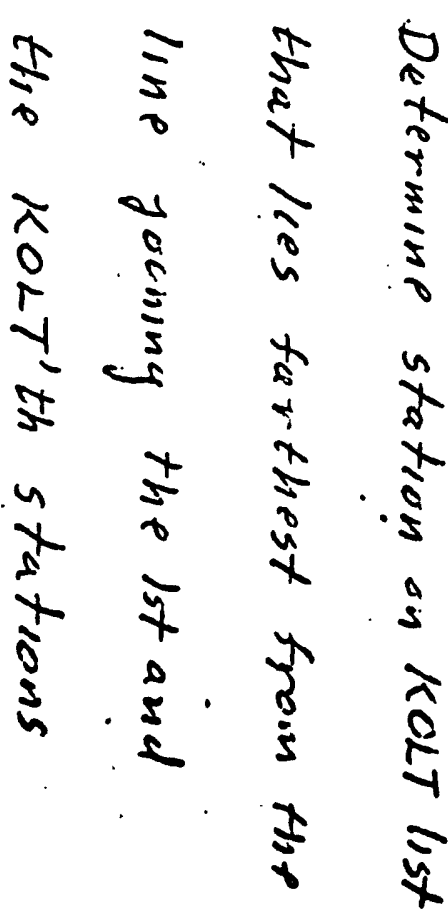

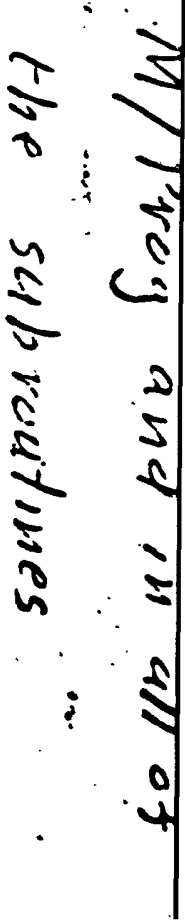


Adjust incolt loop

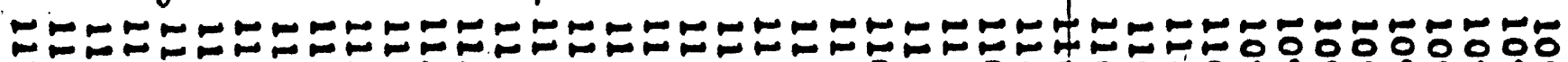

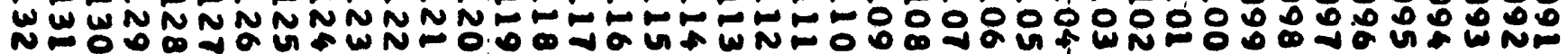

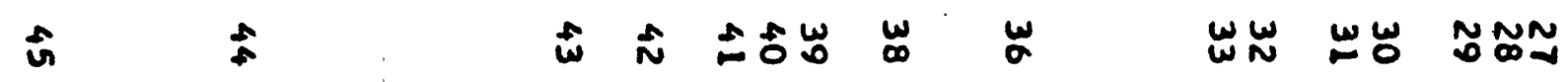

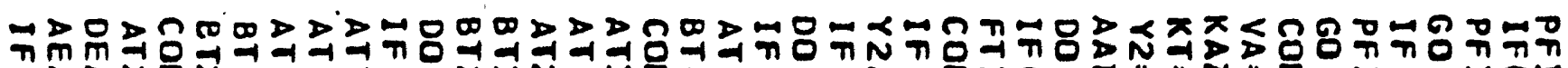

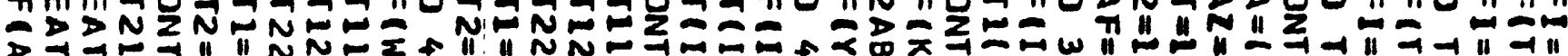

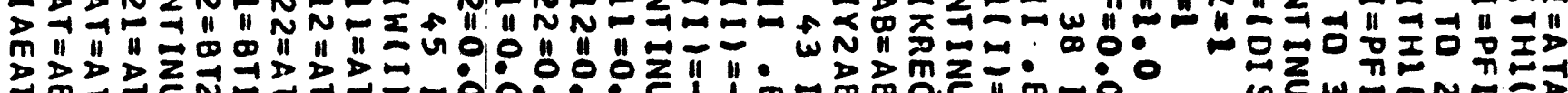

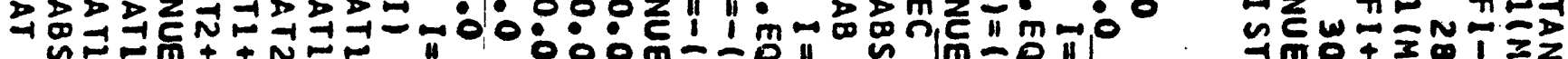

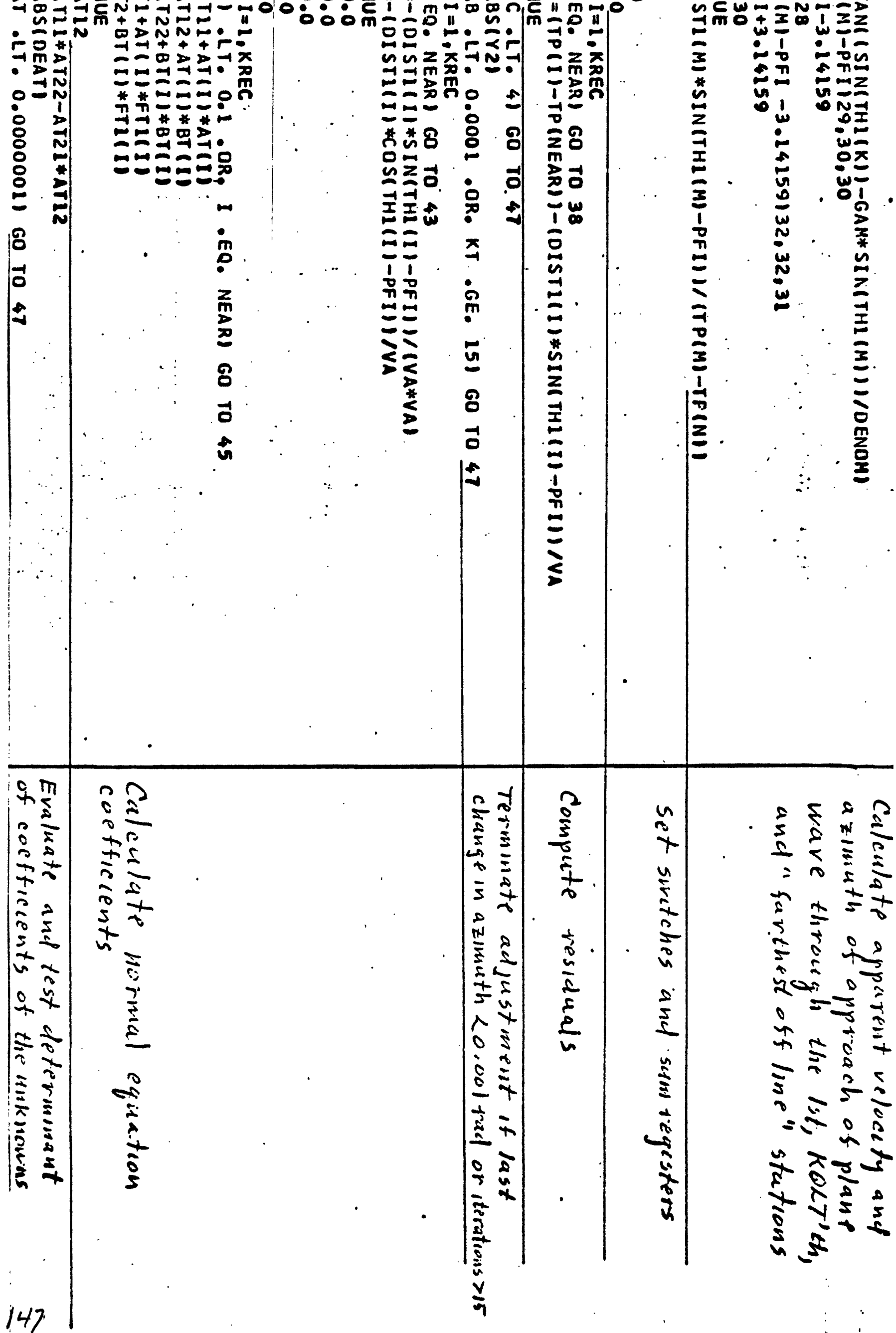




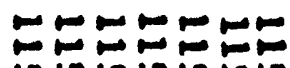

yूungungu

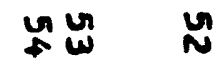

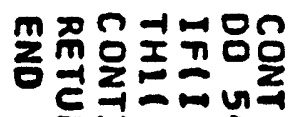

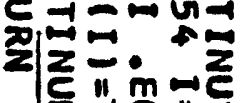

耑

Iㄴ:

三交交

$=\prod_{\substack{\mathrm{m} \\ \mathrm{m}}}$

층

तु

is

î.

:

प

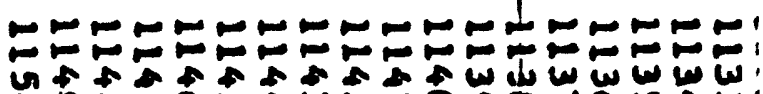

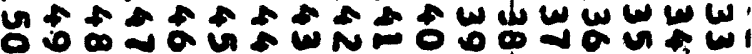

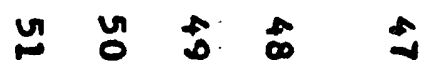

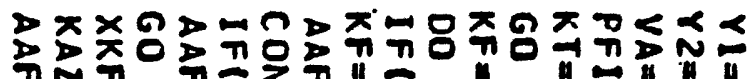

万र

"

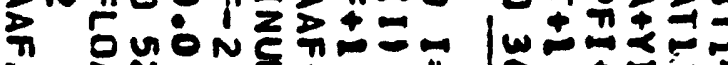

茂

齐 齐 过

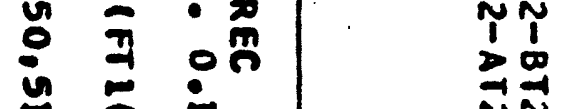

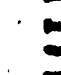

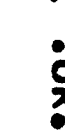

:

a

6

ᄅ্

8

$\stackrel{N}{=}$

$\pm$

$\frac{x}{5}$

of

है

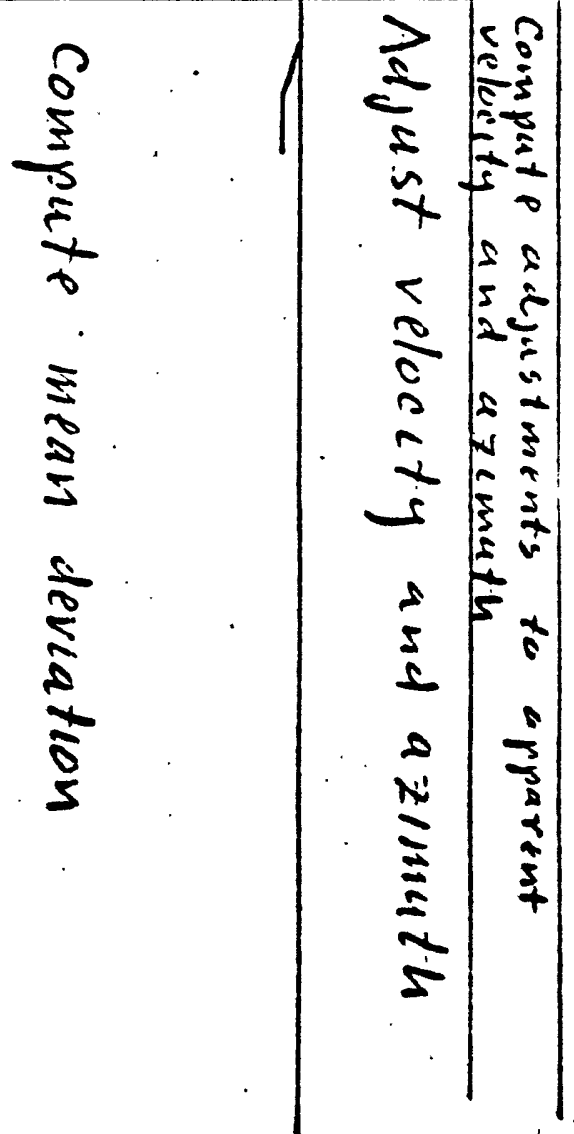


กํำ

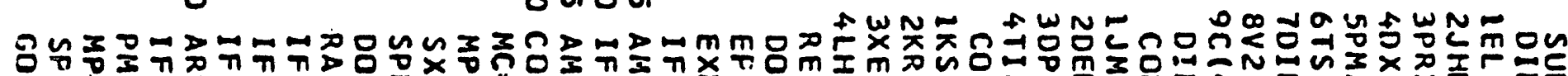
о

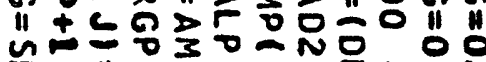

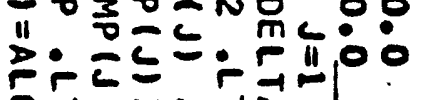

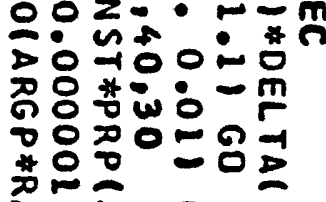$$
\text { 更 }
$$$$
\text { 㶽 }
$$$$
\text { * }
$$

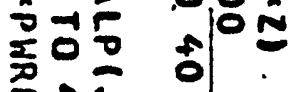$$
\text { 은 }
$$$$
1
$$$$
\text { 弪 }
$$

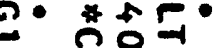

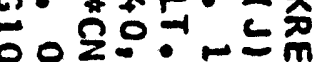$$
\therefore \frac{3}{8}
$$

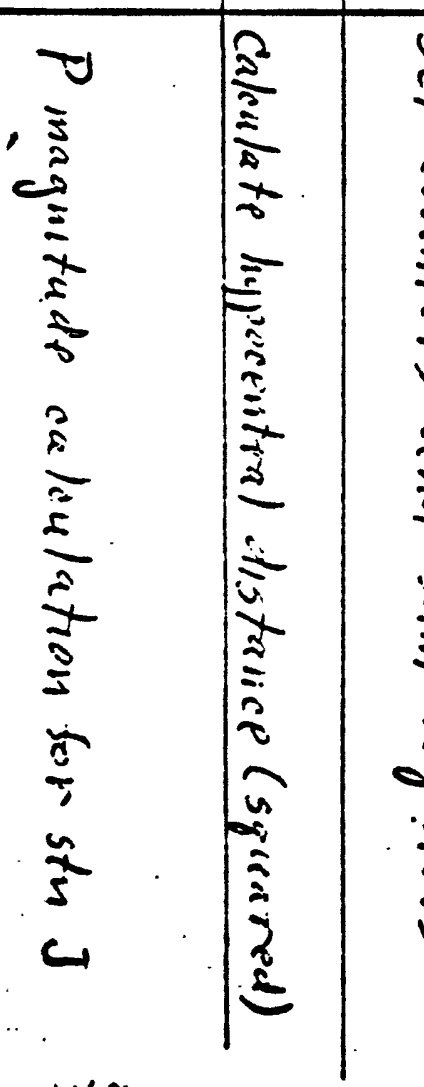

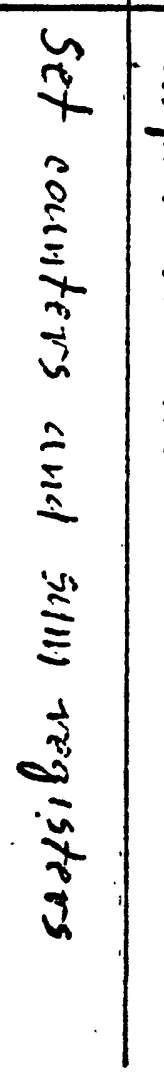
两

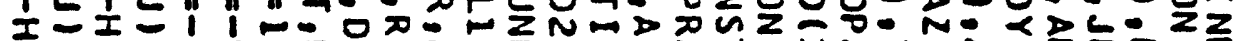

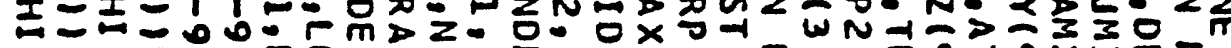
rFr $r$ :

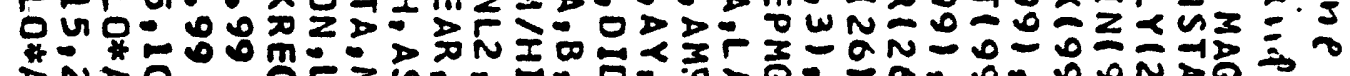

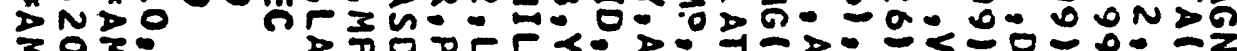

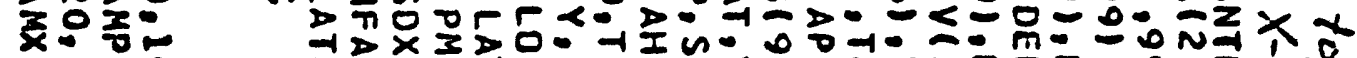
С́二厶

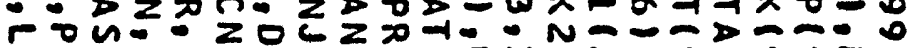

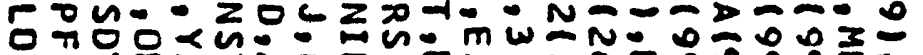

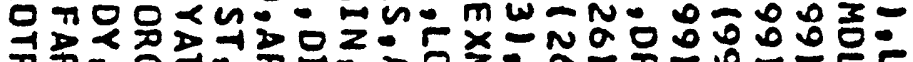

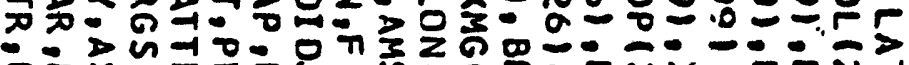

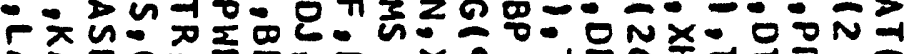

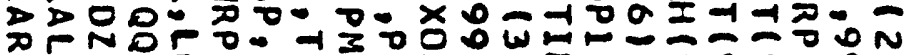

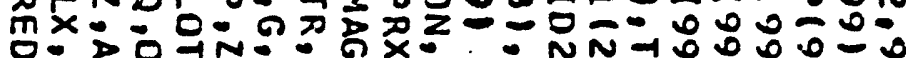

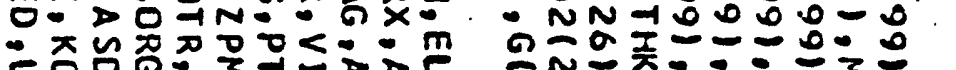

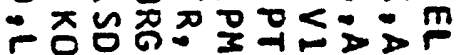

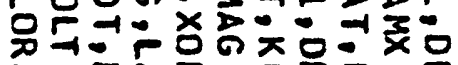
mis min

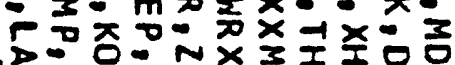

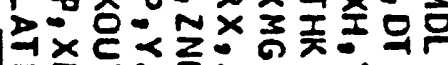

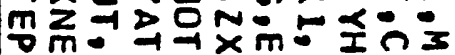

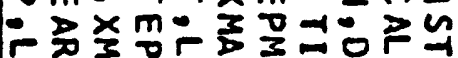

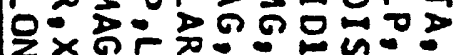

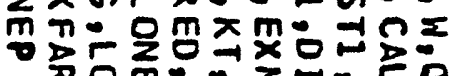

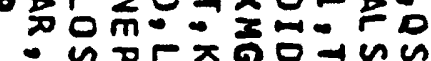
늘등

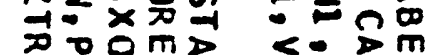

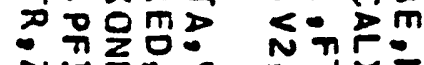

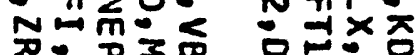
(

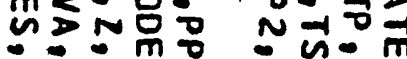

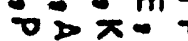

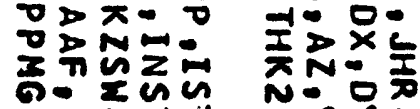

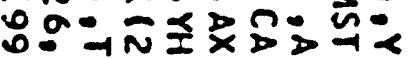

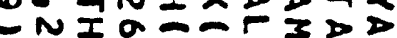

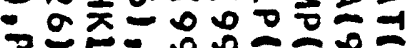
บ

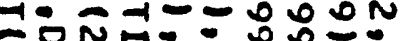
음으은

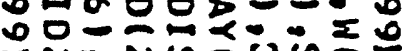

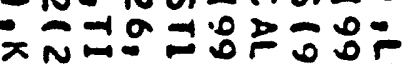

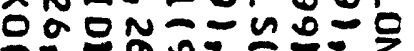

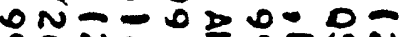

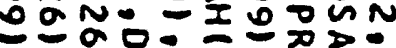

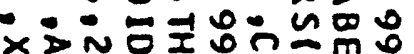

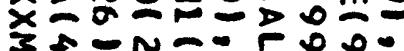
万ิ

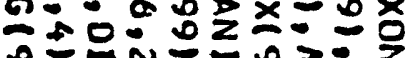

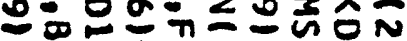

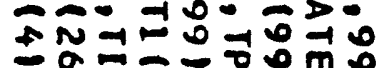
-

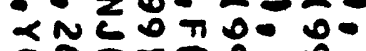
$\leq \alpha \leq \frac{\pi}{2} \div$ $\pm 0 \frac{0}{0} 0 \pm$ 


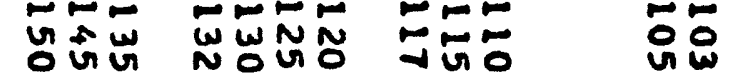

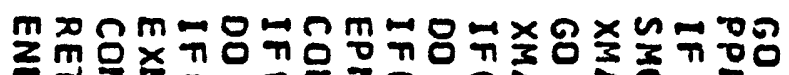
을

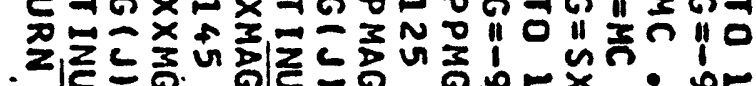

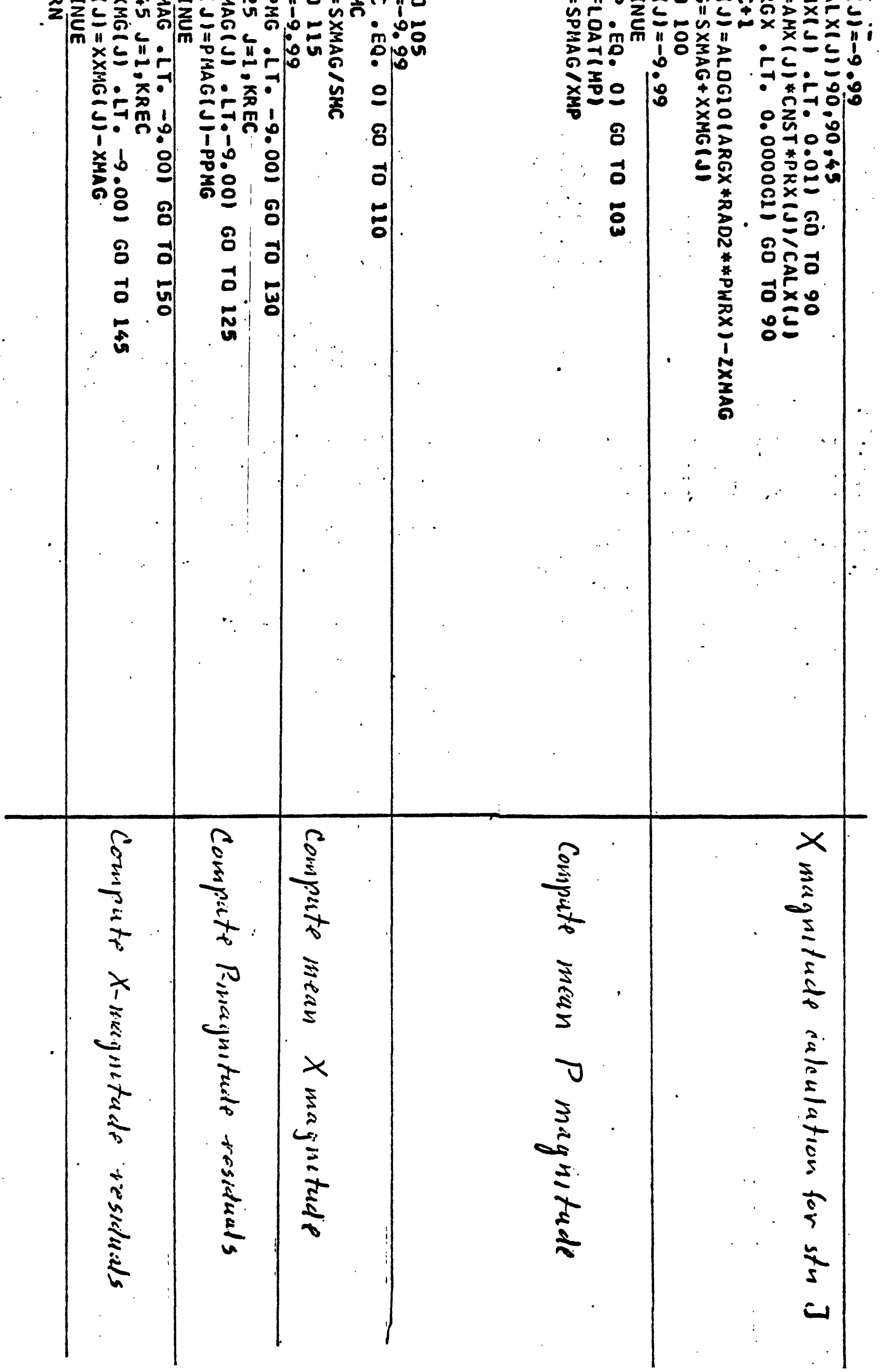

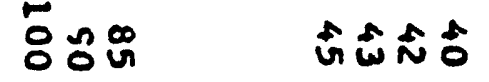

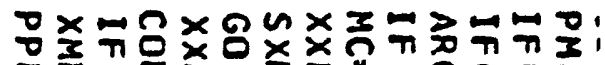
ว काI

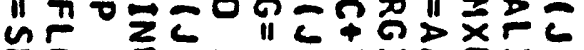

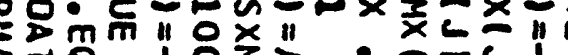
ב。잉 (1) 现

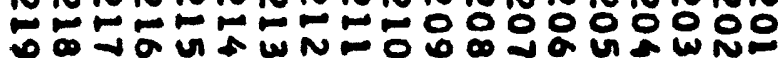



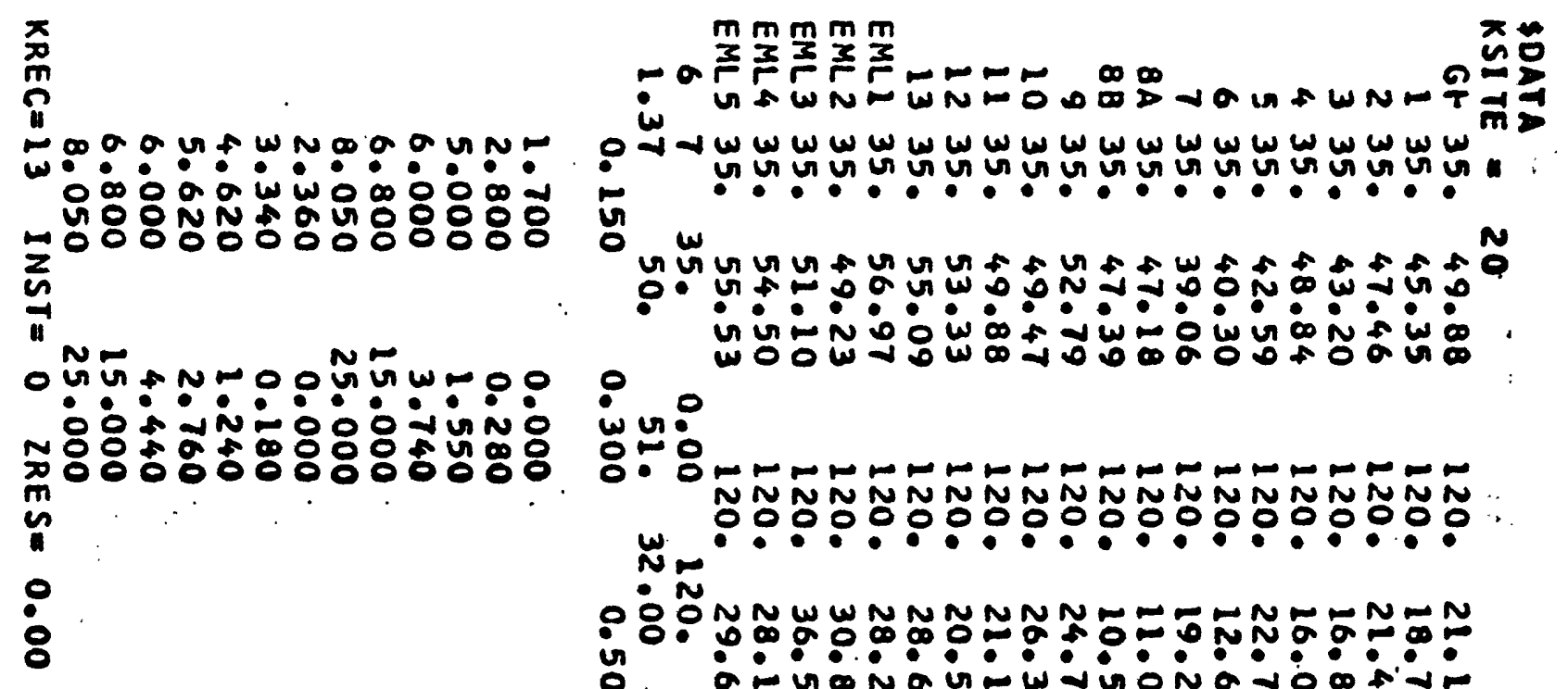

:

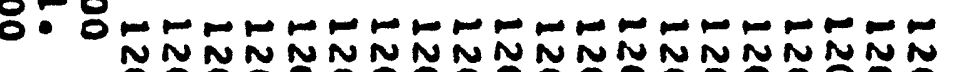

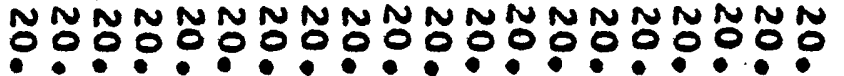

N.

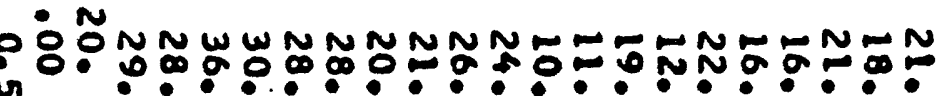

: i:

00000000000000000000

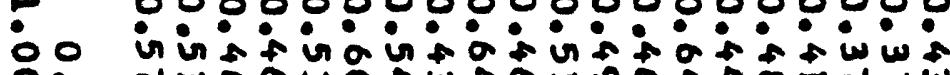

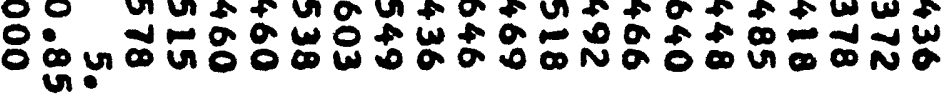
:

N

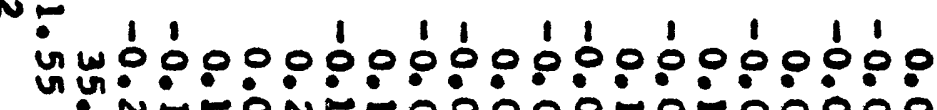

U Nลั

8 界莒

$:$

âu

0

$:^{0}$

0

$: \omega$

ธ.

:

w.

$\stackrel{\infty}{\infty}$

웡

5

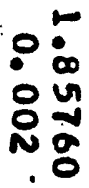




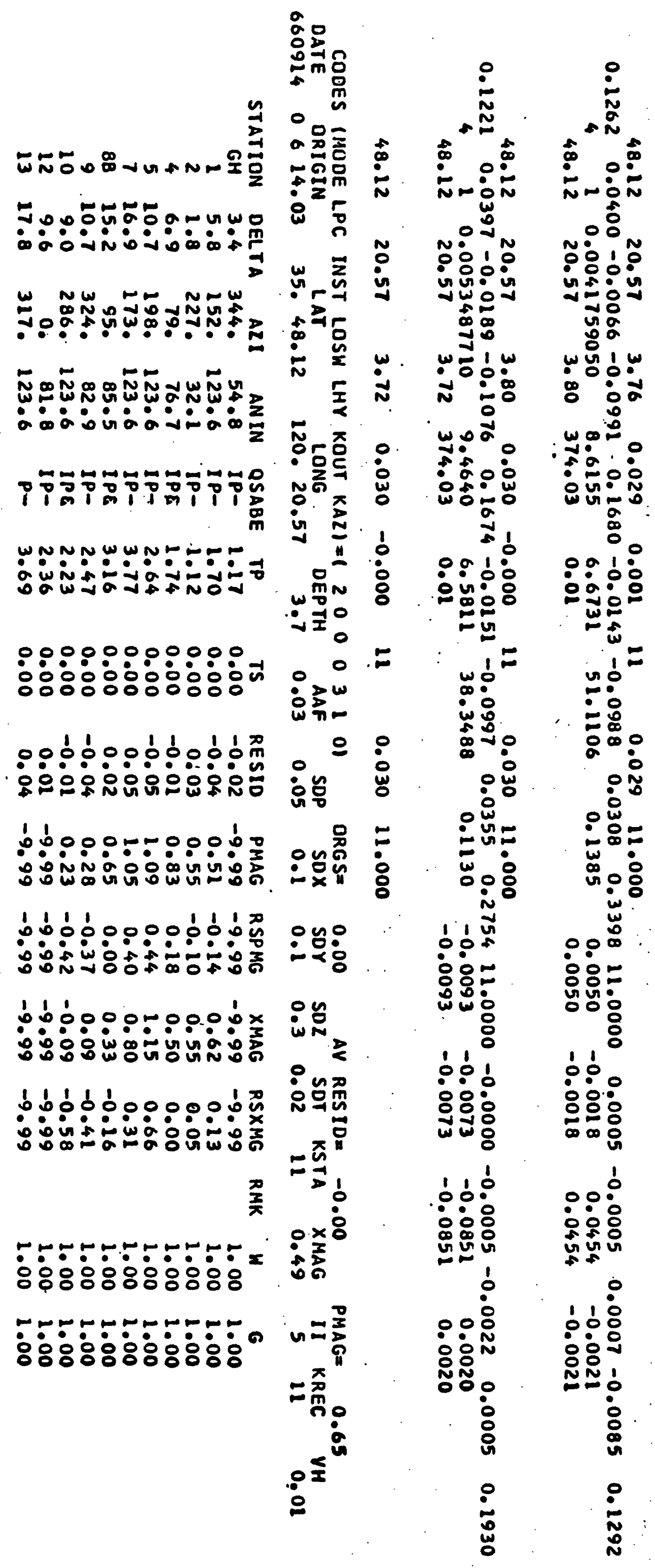

